Final Technical Report

\title{
Novel Refractory Materials for High Alkali, High Temperature Environments
}

June 2012

\section{Principal Investigators:}

Dr. James G. Hemrick

Oak Ridge National Laboratory

Dr. Jeffrey D. Smith

Kelley O'Hara

Missouri University of Science and Technology

Angela Rodrigues-Schroer

Dominick Colavito

MINTEQ International 


\title{
DOCUMENT AVAILABILITY
}

Reports produced after January 1, 1996, are generally available free via the U.S. Department of Energy (DOE) Information Bridge.

\section{Web site http://www.osti.gov/bridge}

Reports produced before January 1, 1996, may be purchased by members of the public from the following source.

\author{
National Technical Information Service \\ 5285 Port Royal Road \\ Springfield, VA 22161 \\ Telephone 703-605-6000 (1-800-553-6847) \\ TDD 703-487-4639 \\ Fax 703-605-6900 \\ E-mail info@ntis.gov \\ Web site http://www.ntis.gov/support/ordernowabout.htm
}

Reports are available to DOE employees, DOE contractors, Energy Technology Data Exchange (ETDE) representatives, and International Nuclear Information System (INIS) representatives from the following source.

Office of Scientific and Technical Information

P.O. Box 62

Oak Ridge, TN 37831

Telephone 865-576-8401

Fax 865-576-5728

E-mail reports@osti.gov

Web site http://www.osti.gov/contact.html

This report was prepared as an account of work sponsored by an agency of the United States Government. Neither the United States Government nor any agency thereof, nor any of their employees, makes any warranty, express or implied, or assumes any legal liability or responsibility for the accuracy, completeness, or usefulness of any information, apparatus, product, or process disclosed, or represents that its use would not infringe privately owned rights. Reference herein to any specific commercial product, process, or service by trade name, trademark, manufacturer, or otherwise, does not necessarily constitute or imply its endorsement, recommendation, or favoring by the United States Government or any agency thereof. The views and opinions of authors expressed herein do not necessarily state or reflect those of the United States Government or any agency thereof. 
NOVEL REFRACTORY MATERIALS FOR HIGH ALKALI, HIGH TEMPERATURE ENVIRONMENTS

Dr. J. G. Hemrick, Dr. J.D. Smith, K. O’Hara, A. Rodrigues-Schroer, D. Colavito

June 2012

Prepared by OAK RIDGE NATIONAL LABORATORY

Oak Ridge, Tennessee 37831-6079 managed by UT-BATTELLE, LLC

for the

U.S. DEPARTMENT OF ENERGY under contract DE-AC05-00OR22725 



\section{Acknowledgments, Disclaimer, and Proprietary Data Notice}

\section{Acknowledgments}

This report is based upon work supported by the U.S. Department of Energy under Award CPS Agreement \# 14954. The work in this document would not have been possible without the contributions of Dr. Fritz Henry from MinTeq who passed away during in 2009. Fritz was a leading developer of the refractory materials developed under this project for lime and gasification applications and of the light-weight shotcrete materials. His contributions to this project were many and his presence during the last years of the project was greatly missed.

The authors are indebted to the industrial partners who participated in this project for supplying samples for post mortem analysis. Special thanks go to the companies who provided industrial trial sites for validation of materials developed under this project. Also the contributions of PhD student Kelley O'Hara at MS\&T and the summer work of former MS\&T undergraduate Kyle Anderson are acknowledged. Additionally the authors recognize the contributions of the past and present technical staff at ORNL including Erick Loveland, Andre Prigmore, Zach Burns, Gorti Sarma, Randy Parten, Robbie Peascoe-Meisner, and Shirley Waters. The contributions and oversight of the ORNL Energy Materials Program Office headed by Dr. Craig Blue are also acknowledged, as well as the guidance provided by former ORNL program manager Peter Angelini and Dr. Mahesh Jha of DOE Golden.

\section{Disclaimer}

This report was prepared as an account of work sponsored by an agency of the United States Government. Neither the United States Government nor any agency thereof, nor any of their employees, makes any warranty, express or implied, or assumes any legal liability or responsibility for the accuracy, completeness, or usefulness of any information, apparatus, product, or process disclosed, or represents that its use would not infringe privately owned rights. Reference herein to any specific commercial product, process, or service by trade name, trademark, manufacturer, or otherwise, does not necessarily constitute or imply its endorsement, recommendation, or favoring by the United States Government or any agency thereof. The views and opinions of authors expressed herein do not necessarily state or reflect those of the United States Government or any agency thereof.

\section{Proprietary Data Notice}

If there is any patentable material or protected data in the report, the recipient, consistent with the data protection provisions of the award, must mark the appropriate block in Section K of DOE F 241.3, clearly specify it here, and identify them on appropriate pages of the report. Other than patentable material or protected data, reports must not contain any proprietary data (limited rights data), classified information, information 
subject to export control classification, or other information not subject to release. Protected data are specific technical data, first produced in the performance of the award, which is protected from public release for a period of time by the terms of the award agreement. Reports delivered without such notice may be deemed to have been furnished with unlimited rights, and the Government assumes no liability for the disclosure, reproduction, or use of such reports. 


\section{CONTENTS}

Page

LIST OF FIGURES ................................................................... iii

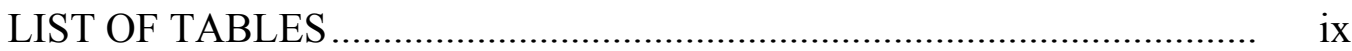

ABBREVIATIONS AND ACRONYMS ............................................ xi

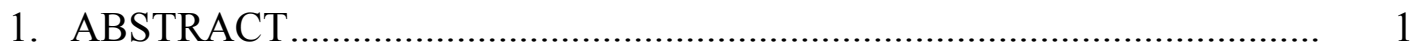

2. PROJECT OBJECTIVE .................................................................... 3

3. BACKGROUND .......................................................................... 3

4. PROPOSED PROJECT TASKS AND MILESTONES ............................ 5

5. TECHNICAL DISCUSSION OF ACTUAL WORK PERFORMED........... 8

Task 1 Development of refractory materials ................................. 12

Task 2 Identification of new materials and fundamental

understanding of materials ............................................ 22

Task 3 Production of refractory materials .................................... 44

Task 4 Measurement of key refractory properties .......................... 44

Refractories for the Glass Industry .................................. 45

Refractories for the Aluminum Industry .......................... 46

Refractories for Lime Kilns ........................................... 54

Refractory for Coal and Black Liquor Gasifiers................. 61

Thermal Analysis of Refractories ................................... 77

Mechanical Analysis of Refractories ................................ 85

Rotary Furnace Testing ................................................. 89

Energy Savings Estimates Based on Measured Refractory

Properties .................................................................. 92

Task 5 Development of new refractory application techniques........ 93

Task 6 Development of on-line inspection and hot repair

techniques ............................................................... 94

Task 7 Formation of database ..................................................... 95

Task 8 In-plant trials and commercialization................................. 97

6. PUBLICATIONS AND PRESENTATIONS RESULTING FROM

THIS PROJECT ...................................................................... 107

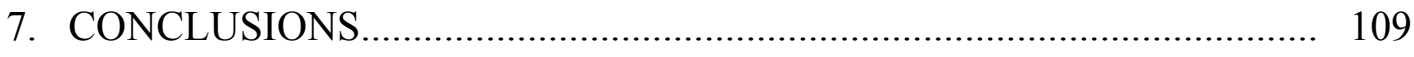

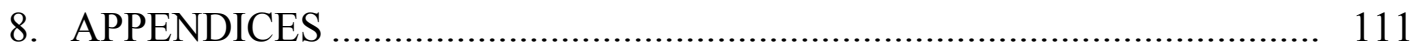


Appendix 1: Results from FEA modeling of refractory lining (taken from summary report document) ............................................................. 113

Appendix 2: Property Testing Standardization............................................ 119

Appendix 3: Characterization Matrix for Refractory Materials ................... 123

Appendix 4: Materials Included in Comprehensive Refractory Property

Database Created Under This Project ................................................ 125

Appendix 5: INSULSHOT ${ }^{\mathrm{TM}}$ FH Technical Data Sheet .............................. 127

Appendix 6: ROTOSHOT ${ }^{\mathrm{TM}}$ AL Technical Data Sheet.............................. 129

Appendix 7: FASTFIRE ${ }^{\circledR}$ MG-SP SHOT Technical Data Sheet .................. 131

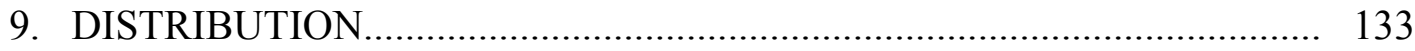




\section{LIST OF FIGURES}

Figure Page

1. Original Project Team Organization ...................................................... 4

2. Example of Estimated Energy Savings Possible for New Lining Materials and Techniques Developed for Lime Kiln Applications

3. Results of ABAQUS FEA Modeling of MINTEQ Insulation Design Concept

4. Distribution of Hoop Stress [MPa] for the Case of Single Layer of Standard Insulation ....

5. Distribution of Hoop Stress $[\mathrm{MPa}]$ for the Case of Multi-Layer of Standard Insulation

6. Distribution of Hoop Stress [MPa] for the Case of Square Configuration Lining

7. Distribution of Hoop Stress $[\mathrm{MPa}]$ for the Case of Round Configuration Lining

8. Distribution of Hoop Stress [MPa] for the Case of Arch Configuration Lining

9. Schematic and Mesh for Standard Design .....

10. Distribution of Temperature $\left({ }^{\circ} \mathrm{C}\right)$ Under Operating Conditions for Standard Design

11. Distribution of Hoop Stress (MPa) Under Operating Conditions for Standard Design

12. Distribution of Hoop Stress $(\mathrm{MPa})$ in the Refractory Material Only Under Operating Conditions for Standard Design....

13. Thermal Conductivity in the MgO-NiO Solid Solution System

14. Pre- and Post-Sintering Pictures MgO Samples with Various Additions of $\mathrm{FeO}$ and $\mathrm{ZnO}$ and $\mathrm{Al}_{2} \mathrm{O}_{3}$ Samples with Various Additions of $\mathrm{Ga}_{2} \mathrm{O}_{3}$, $\mathrm{Cr}_{2} \mathrm{O}_{3}$, and $\mathrm{Mn}_{2} \mathrm{O}_{3}$.

15. Representative XRD Patterns at $800^{\circ} \mathrm{C}$ (a) and $1300^{\circ} \mathrm{C}$ (b) Indicating No Solid Solution Formation....

16. XRD Pattern for $\mathrm{MgMn}_{2} \mathrm{O}_{4}$ Sample Showing Presence of Residual MgO ... 26

17. SEM Image of $\mathrm{Al}_{2} \mathrm{O}_{3}$ Pellet .................................................................... 27

18. SEM/EDS Image of $\mathrm{Al}_{2} \mathrm{O}_{3}$ Pellet Showing Location of Aluminum............. 27

19. SEM/EDS Image of $\mathrm{Al}_{2} \mathrm{O}_{3}$ Pellet Showing Location of Magnesium ........... 28

20. Pattern Resulting from SEM/EDS Performed on Top Layer of Formed Spinel Layer

21. Pattern Resulting from SEM/EDS Performed on Bottom Layer of Formed Spinel Layer....

22. Secondary Electron Image of $\mathrm{Al}_{2} \mathrm{O}_{3}$ Pellet after Diffusion Study ............... 30

23. Backscattered Electron Image of $\mathrm{Al}_{2} \mathrm{O}_{3}$ Pellet after Diffusion Study........... $\quad 30$

24. Phase Maps from EDS Analysis of $\mathrm{Al}_{2} \mathrm{O}_{3}$ Pellets Showing Diffusion Layers

25. Phase Maps from EDS Analysis of $\mathrm{Al}_{2} \mathrm{O}_{3}$ Pellets Showing Diffusion Layers 
26. XRD Analysis of $\mathrm{MgAl}_{2} \mathrm{O}_{4}$ Formed from (a) Oxides and (b) Chlorides...... 33

27. XRD Analysis of (a) $\mathrm{ZnAl}_{2} \mathrm{O}_{4}$ and (b) $\mathrm{MgGa}_{2} \mathrm{O}_{4}$ Formed from Oxides........ 34

28. XRD Analysis Showing Solid Solution Formation Between $\mathrm{MgAl}_{2} \mathrm{O}_{4}$ and $\mathrm{MgGa}_{2} \mathrm{O}_{4}$

29. Laser Flash Results for MgAl-MgGa System Plotted vs. Temperature ........ 37

30. Laser Flash Results for MgAl-MgGa System Plotted vs. Composition ........ 37

31. $\mathrm{MgO}-\mathrm{Al}_{2} \mathrm{O}_{3}$ Phase Diagram Showing the Initial Composition Studied........ 39

32. Samples Processed at $1900^{\circ} \mathrm{C}$ - a) $78 \mathrm{wt} \%$ Alumina, b) $86 \mathrm{wt} \%$ Alumina, c) $88 \mathrm{wt} \%$ Alumina, d) $91 \mathrm{wt} \%$ Alumina, and e) $92 \mathrm{wt} \%$ Alumina

33. Thermal Diffusivity vs. Temperature for $\mathrm{MgAl}_{2} \mathrm{O}_{4}-\mathrm{MgGa}_{2} \mathrm{O}_{4}$ Solid Solutions

34. Thermal Conductivity Versus Temperature for $\mathrm{MgAl}_{2} \mathrm{O}_{4}-\mathrm{MgGa}_{2} \mathrm{O}_{4}$ System

35. Schematic for Steady-State Heat Flow Calculations Showing Initial Conditions

36. Examples of Salvaged Samples Showing Lime Kiln Refractory Degradation.

37. Salvaged Lime Kiln Brick Samples....

38. Analysis of Salvaged Fusion Cast AZS Refractory Material

39. Examples of Optical Microscopy Results from Salvaged Aleris Aluminum Samples.

40. Example of XRD Results from Salvaged Aleris Aluminum Samples

41. Examples of SEM/EDS Results from Salvaged Aleris Aluminum Samples

42. Test Sample of Current Aluminum Refractory Tested In ORNL Immersion Test

43. Immersion Test Samples of MINTEQ Developed Refractories for Aluminum

44. MINTEQ Refractory Samples Following Alcoa Standardized Cup Testing at MS\&T

45 Materials After Steam Aluminum Cup Testing.....

46. Aluminum Cup Penetration Test Samples in from "Alcoa Al Cup Test" Performed in 7075 Aluminum Alloy...

47. MS\&T Lime Corrosion Cup Test Results ....

48. Lime Mud Cup Test Samples of MINTEQ Developed Refractories for Lime Kilns

49. Analysis of Salvaged Refractory Brick Provided by Weyerhaeuser ............ 56

50. Analyses of Samples from Lime Cup Testing Performed by MinTeq Using Field Emission Scanning Electron Microscopy (FESEM)...

51. $\mathrm{CaO}-\mathrm{Al}_{2} \mathrm{O}_{3}-\mathrm{SiO}_{2}$ Phase Diagram

52. Lime Mud Testing of Experimental Refractory Spinel Former (B) for Lime Kiln Application

53. ORNL Lime Corrosion Cup Testing of Spinel Former (B) Material ........... 59

54. Examples of Lime Cup Testing Results for Spinel Forming and Magnesia-Rich Shotcrete Formulations.

55. Example of Lime Smelt Cup Exposure Tests Performed at MINTEQ 
56. Lime Smelt Cup Exposure Tests Performed on Final Version of Spinel

Forming Composition for Use in Lime Kilns

57. Coal Smelt Cup Test Samples of MINTEQ Developed Refractories for Coal Gasification

58. Post Mortem Analysis of MINTEQ Spinel Based Formulation .....

59. Alkali Testing of Experimental Refractory Spinel Former for Black Liquor Gasifier Application

60. Smelt Testing of Experimental Refractory Spinel Former for Black Liquor Gasifier Application

61. Smelt Testing of Experimental Refractory Spinel Former for Black Liquor Gasifier Application with Alternative Raw Materials

62. Examples of Black Liquor Smelt Immersion Testing Results - Lab Samples

63. Examples of Black Liquor Smelt Immersion Testing Results for Industrial Samples.

64. Example of Black Liquor Smelt Cup Exposure Tests Performed at ORNL on Improved Industrial Refractory Formulation

65. Black Liquor Smelt Immersion Testing Results for Magnesia-Rich Shotcrete Material

66. Magnesia-Rich Spinel Samples for Coal Smelt Exposure Testing.....

67. Magnesia-Rich Spinel Sample Fired at $1371^{\circ} \mathrm{C}\left(2500^{\circ} \mathrm{F}\right)$ Before (a) and After (b) Coal Smelt Exposure Testing .

68. Coal Smelt Interaction with Magnesia-Rich Spinel Sample Fired at $1371^{\circ} \mathrm{C} \quad 68$

69. Magnesia-Rich Spinel Sample Fired at $1510^{\circ} \mathrm{C}\left(2750^{\circ} \mathrm{F}\right)$ Before (a) and After (b) Coal Smelt Exposure Testing ....

70. Coal Smelt Interaction with Magnesia-Rich Spinel Sample Fired at $1510^{\circ} \mathrm{C} \quad 69$

71. DTA/TGA Analysis of Shotcreted Refractory Sample Cured at $110^{\circ} \mathrm{C}$ $\left(230^{\circ} \mathrm{F}\right)$

72. Magnesia-Rich Spinel Sample for Coal Smelt Exposure Testing.

73. Magnesia-Rich Spinel Sample Fired at $1510^{\circ} \mathrm{C}\left(2750^{\circ} \mathrm{F}\right)$ after Coal Smelt Exposure Testing Showing Lack of Smelt Penetration and Corrosion.

74. Examples from Cup Testing of Latest Spinel Formulations in Contact with (a) Black Liquor Smelt and (b) Coal Smelt

75. Schematic Representation of Slurry Based Coating Process ....................... 73

76. Coated Spinel Refractory Cube

77. SEM Micrograph of Continuous Spinel Coating on Spinel Composition Refractory Cube Sample

78. EDS Scan of Coating Applied on Spinel Composition Refractory Cube Sample As Shown in Figure 77

79. Evaluation of Coating Quality at Various Heat Treat Temperatures.

80. Refractory Cup Samples Before and After Exposure to Molten Coal Slag. Coated Modified Alumina-Rich Spinel Material Before (a) and After (b and c) Testing 
81. Coated Refractory Cup Testing Samples Following Exposure to Molten Coal Slag Representing (a) Sample From Previous First Round of Testing, (b) Sample From Previous Second Round of Testing, and (c) Sample From Current Round of Testing

82. Coated Refractory Cup Testing Samples From Current Round of Testing Following Exposure to Molten Coal Slag Showing (1) Pre-wet Cavity and Coating with Original Solids Loading, (2) Pre-wet Cavity and Coating with Reduced Solids Loading (a), (3) Pre-wet Cavity and Coating with Solids Loading $(b<a)$, and (4) Non Pre-wet Cavity and Coating with Original Solids Loading

83. Calculated Thermal Conductivity vs. Temperature for $\mathrm{MgAl}_{2} \mathrm{O}_{4}$ with $0,1,2$, 4 , and $8 \mathrm{wt} \% \mathrm{BaAl}_{2} \mathrm{O}_{4}$ Based on Laser Flash thermal Diffusivity Measurements

84. Hot Wire Thermal Conductivity Results for Back-up Lining Material........ 78

85. ORNL HDIR Thermal Conductivity Results for Back-up Lining Material .. 79

86. HDIR Thermal Conductivity Measurements for Spinel Forming Refractories

87. HDIR Thermal Conductivity Measurements for Magnesia Rich Refractory

88. Room Temperature Thermal Diffusivity Results Obtained by Laser Flash Technique.

89. Thermal Conductivity of Experimental Aluminum Industry Shotcrete Material Developed Under This Project

90. Examples of Dilatometer Thermal Expansion Results

91. Thermal Expansion of Insulating Back-up Shotcrete Material.

92. Thermal Expansion of Aluminum Industry Shotcrete Material

93. Thermal Expansion Curve for Cast Magnesia-Rich Spinel Material

94. Thermal Expansion Curve for Shot Magnesia-Rich Spinel Material

95. Examples of Mechanical Test Results (a - Compressive Strength Testing, $\mathrm{b}-$ Creep Testing)

96. Creep Behavior of Insulating Back-up Shotcrete Material ......................... 88

97. Creep Behavior of Aluminum Industry Shotcrete Material........................ 88

98. Abrasion Testing Results for Aluminum Industry Shotcrete Material ......... 89

99. MinTeq Rotary Furnace Simulation Test Schematic and Actual Picture of Completed System

100. Rotary Furnace Simulation Test System During Testing and Pictures of Lining Before and After Aluminum Refractory Test ....

101. Spent Refractory Crucible Repair Material/Technique Adhesion Study Results for Aluminum Industry Applications

102. Examples of Pages from Comprehensive Refractory Property Database Constructed and Hosted at ORNL

103. Pictures of Insulating Shotcrete Demonstration Showing Form Before Shooting (a) and Form During Shooting (b)....

104. Aluminum Rotary Dross Furnace at Newco Metals (Bedford, IN) Before and During Installation of Developed Aluminum Furnace Refractory

105. Aluminum Rotary Dross Furnace at Newco Metals (Bedford, IN) in Operation. 
106. Super Sack of Commercially Released Light Weight Refractory Material Developed Under This Project

107. Picture of Dryer Vessel (a) and Combustion Zone (b) Where Light Weight Refractory Was Installed......................................................................... 101

108. Installation of Light Weight Refractory in Combustion Zone of Dryer....... 102

109. Installed Insulshot Lightweight Back-up Refractory at Tate \& Lyle (Lafayette, IN) ........................................................................................

103 


\section{LIST OF TABLES}

Table

Page

1. Revised Task Structure and Schedule.................................................. 8

2. Milestone Schedule ............................................................................. 12

3. Summary of Materials Developed Under Project ..................................... 22

4. List of Spinels with Mg or Al in the Designated Cation Site Cross-Referenced from Burdett, Price and Price and a Compilation of Known Spinels .................................................................................. 24

5. Relative Amounts of $\mathrm{MgO}$ and $\mathrm{Al}_{2} \mathrm{O}_{3}$ as Calculated with EDS ................. 32

6. Spinel Compositions of Interest............................................................ 36

7. Calculated Densities of Prepared Laser Flash Specimens .......................... 36

8. Co-precipitated powder compositions in Weight Percent ......................... 38

9. $\mathrm{MgAl}_{2} \mathrm{O}_{4}-\mathrm{MgGa}_{2} \mathrm{O}_{4}$ Mixtures Studied ................................................ 38

10. Compositions Studied Based on $\mathrm{Wt} \%$ Alumina with Processing Temperatures Indicated........................................................................ $\quad 40$

11. $\mathrm{MgAl}_{2} \mathrm{O}_{4}-\mathrm{MgGa}_{2} \mathrm{O}_{4}$ Mixtures Being Studied ....................................... 41

12. Aluminum Cup Test Results for Shot Sample Pre-fired at $871^{\circ} \mathrm{C}$............... 53

13. Aluminum Cup Test Results for Shot Sample Pre-fired at $1260^{\circ} \mathrm{C}$............. 53

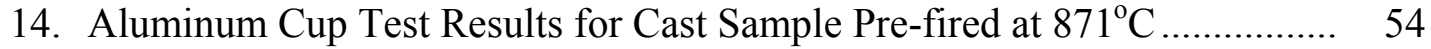

15. Aluminum Cup Test Results for Cast Sample Pre-fired at $1260^{\circ} \mathrm{C}$.............. 54

16. XRD Analysis of Crystalline Phases (by \%) with Temperature .................. 69

17. DTA/TGA Analysis of Shotcreted Refractory Sample Cured at $110^{\circ} \mathrm{C}$ $\left(230^{\circ} \mathrm{F}\right)$

18. Laser Flash Diffusivity Values for $\mathrm{MgAl}_{2} \mathrm{O}_{4}-\mathrm{MgGa} 2 \mathrm{O} 4$ Samples from MS\&T

19. Summary of Refractory Thermal Expansion Results .............................. 82

20. Lime Kiln Energy Analysis ............................................................... 92 


\section{ABBREVIATIONS AND ACRONYMS}

$\begin{array}{ll}\text { AZS } & \text { Alumina-Zirconia-Silicate } \\ \text { CL } & \text { Cathodoluminescence } \\ \text { CTE } & \text { Coefficient of Thermal Expansion } \\ \text { DOE } & \text { Department of Energy } \\ \text { DTA } & \text { Differential Thermal Analysis } \\ \text { EDS } & \text { Energy Dispersive Spectroscopy } \\ \text { FESEM } & \text { Filed Emission Scanning Electron Microscopy } \\ \text { HDIR } & \text { High Density Infra-Red } \\ \text { ITP } & \text { Industrial Technologies Program } \\ \text { MINTEQ } & \text { MINTEQ International, Inc. } \\ \text { MOR } & \text { Modulus of Rupture } \\ \text { MS\&T } & \text { Missouri University of Science and Technology } \\ \text { ORNL } & \text { Oak Ridge National Laboratory } \\ \text { QFD } & \text { Quality Function Deployment } \\ \text { SEM } & \text { Scanning Electron Microscopy } \\ \text { TGA } & \text { Thermal Gravimetric Analysis } \\ \text { XRD } & \text { X-ray Diffraction } \\ \text { XRF } & \text { X-ray Fluorescence }\end{array}$


NOVEL REFRACTORY MATERIALS FOR HIGH ALKALI, HIGH TEMPERATURE ENVIRONMENTS

Dr. J. G. Hemrick, Dr. J.D. Smith, K. O'Hara, A. Rodrigues-Schroer, and D. Colavito 



\begin{abstract}
A project was led by Oak Ridge National Laboratory (ORNL) in collaboration with a research team comprised of the academic institution Missouri University of Science and Technology (MS\&T), and the industrial company MINTEQ International, Inc. (MINTEQ), along with representatives from the aluminum, chemical, glass, and forest products industries. The project was to address the need for new innovative refractory compositions by developing a family of novel $\mathrm{MgO}-\mathrm{Al}_{2} \mathrm{O}_{3}, \mathrm{MgAl}_{2} \mathrm{O}_{4}$, or other similar spinel structured or alumina-based unshaped refractory compositions (castables, gunnables, shotcretes, etc.) utilizing new aggregate materials, bond systems, protective coatings, and phase formation techniques (in-situ phase formation, altered conversion temperatures, accelerated reactions, etc). This family of refractory compositions would then be tailored for use in hightemperature, high-alkaline industrial environments like those found in the aluminum, chemical, forest products, glass, and steel industries.
\end{abstract}

Both practical refractory development experience and computer modeling techniques were used to aid in the design of this new family of materials. The newly developed materials were expected to offer alternative material choices for high-temperature, high-alkali environments that were capable of operating at higher temperatures (goal of increasing operating temperature by $100-200^{\circ} \mathrm{C}$ depending on process) or for longer periods of time (goal of twice the life span of current materials or next process determined service increment). This would lead to less process down time, greater energy efficiency for associated manufacturing processes (more heat kept in process), and materials that could be installed/repaired in a more efficient manner. The overall project goal was a 5\% improvement in energy efficiency (brought about through a 20\% improvement in thermal efficiency) resulting in a savings of 3.7 TBtu/yr (7.2 billion $\mathrm{ft}^{3}$ natural gas) by the year 2030 . Additionally, new application techniques and systems were developed as part of this project to optimize the installation of this new family of refractory materials to maximize the properties of installed linings and to facilitate nuances such as hot installation and repair.

Under this project, seven new shotcrete materials were developed for both primary and repair applications in aluminum, black liquor, coal gasification, and lime kiln environments. Developed materials were based on alumino-silicate, magnesia, and spinel forming systems. One of the developed materials was an insulating shotcrete to be used behind the high conductivity spinel linings developed under this project.

Fundamental research work was carried out at MS\&T throughout the life of the project to provide support for the development and production of the experimental refractory materials being developed. Work was also ongoing at ORNL and MS\&T through the duration of the project on the measurement and characterization of key refractory properties as identified during year one of the project. Both materials currently being used in the industrial processes as identified and supplied by the industrial partners of this project and new materials being provided and developed by MINTEQ were evaluated as necessary. Additionally, energy savings estimates based on measured properties of the experimentally developed refractory systems from this project were made at MINTEQ to validate the energy savings estimates originally proposed for the project. 
As another part of the project, on-line inspection and hot repair techniques were considered. It was determined that although repair materials were successfully developed under this project for aluminum, black liquor, and coal gasification systems which enable hot repair, there was only minor interest from industry in implementing these materials. On-line inspection techniques were also identified under this project which are currently used in the steel industry, but implementation of these techniques in applications such as black liquor and coal gasification where higher temperatures and tighter access clearances exist proved difficult due to cost considerations. Therefore, on-line inspection was not further pursued under this project.

Information from data collected during this and previous DOE projects was inputted into a refractory database housed at a public site (http://extwebapps.ornl.gov/crpd/Default.aspx). This database was initially populated with over twenty five refractory systems.

Industrial trials of the insulating shotcrete (INSULSHOT ${ }^{\mathrm{TM}} \mathrm{FH}$ ) and the material for use in aluminum rotary furnaces (ROTOSHOT ${ }^{\mathrm{TM}} \mathrm{AL}$ ) developed under this project were performed validating the commercial potential of these materials. Additionally, the magnesia-rich spinel formulation (FAST FIRE ${ }^{\circledR}$ MG-SP SHOT) for use in black liquor and lime kiln/cement applications was commercially released by MINTEQ. Industrial trials were monitored through the end of the project, and will be continued by the respective industrial trial sites as long as materials remain viable or until the associated processes where the materials are being tested are brought down for normal maintenance outages. In total, over one hundred and sixty tons of refractory for use in aluminum furnaces and sixty tons of the lightweight back-up refractory material were installed in commercial furnaces to validate the materials developed under this project and in all cases the materials exceeded the customer's expectations.

Fourteen presentations were given, twelve papers were published, and two posters and one R\&D 100 Award application were composed regarding this project. 


\section{PROJECT OBJECTIVE}

The objective of the project was to address the need for new innovative refractory compositions by developing a family of novel $\mathrm{MgO}-\mathrm{Al}_{2} \mathrm{O}_{3}, \mathrm{MgAl}_{2} \mathrm{O}_{4}$, or other similar spinel structured or alumina-based unshaped refractory compositions (castables, gunnables, shotcretes, etc.) utilizing new aggregate materials, bond systems, protective coatings, and phase formation techniques (in-situ phase formation, altered conversion temperatures, accelerated reactions, etc). This family of refractory compositions would then be tailored for use in high-temperature, high-alkaline industrial environments like those found in the aluminum, chemical, forest products, glass, and steel industries.

Both practical refractory development experience and computer modeling techniques were used to aid in the design of this new family of materials. The newly developed materials were expected to offer alternative material choices for high-temperature, high-alkali environments that were capable of operating at higher temperatures (goal of increasing operating temperature by $100-200^{\circ} \mathrm{C}$ depending on process) or for longer periods of time (goal of twice the life span of current materials or next process determined service increment). This would lead to less process down time, greater energy efficiency for associated manufacturing processes (more heat kept in process), and materials that could be installed/repaired in a more efficient manner. The overall project goal was a $5 \%$ improvement in energy efficiency (brought about through a $20 \%$ improvement in thermal efficiency) resulting in a savings of $3.7 \mathrm{TBtu} / \mathrm{yr}$ (7.2 billion $\mathrm{ft}^{3}$ natural gas) by the year 2030 . Additionally, new application techniques and systems were developed as part of this project to optimize the installation of this new family of refractory materials to maximize the properties of installed linings and to facilitate nuances such as hot installation and repair.

\section{BACKGROUND}

Currently available refractory materials (bricks, castables, gunnables, etc.) are limited in their application by many factors including chemical reactions between the service environment and the refractory material, mechanical degradation of the refractory material by the service environment, temperature limitations on the use of a particular refractory material, and the inability to install or repair the refractory material in a cost effective manner or while the vessel is in service. All of these limitations reduce the energy efficiency of the process as degraded refractory materials lead to loss of process heat (reduced insulation by refractories) and the need for maintenance through repair or replacement of refractory linings. Such maintenance often requires cooling of the furnace or refractory lined vessel which entails loss of energy due to cooling and consumption of energy due to reheating. Additionally, a loss in production time and capability is sacrificed.

Therefore, there is a need to develop refractory systems based on utilizing novel aggregates, binder systems (bonds), methods of phase formation, and refractory application systems for two applications. These are refractories for new (original) lining installations and refractories specifically tailored for on-line (hot) maintenance installations. Additionally, acceptable installation designs, systems and processes are needed to optimize material application and maximize the installed material's properties. This will lead to improved speed of installation, thereby reducing the process down time, and improved installed materials. Energy and process efficiency can be further improved through the development 
of new methods for the inspecting and repair of refractory linings at temperature. This will allow for on-line evaluation of uneven refractory wear and targeted refractory repair leading to decreased process down-time, reduced repair costs and elimination of need to cool and reheat process vessels.

The project was also to address the applicability and limitations of currently available materials and the improvements possible through the use of the newly developed family of materials, by measuring and comparing key properties of refractory materials. This was to include the determination of properties such as thermal conductivity, corrosion, abrasion and wear, creep, modulus of rupture, thermal expansion, thermal shock, toughness, elastic modulus, strength, and density. These property measurements were also to be used to initiate the formation of an un-biased, comprehensive database concerning currently used and newly developed refractory materials, a needed but unavailable resource highly desired by the refractory user community.

The overall goal of this project was two-fold. The first goal was to produce novel refractory compositions which will allow for improved energy efficiency through better insulation, decreased deterioration (corrosion and wear), and reduced process down-time for repair or replacement of refractory linings. Additionally, improved refractories could lead to increased process operating temperatures which will lead to more energy and cost efficient operations. The second goal was to develop new refractory application techniques which would improve the speed of an installation, thereby reducing the down time of the process. Also methods of hot installation were sought which would allow for hot repairs and on-line maintenance leading to reduced process downtimes and eliminating the need to cool and reheat process vessels.

A research team was formed to carry out the proposed work led by Oak Ridge National Laboratory (ORNL) and was comprised of the academic institution Missouri University of Science and Technology (MS\&T), and the industrial company MINTEQ International, Inc. (MINTEQ), along with representatives from the aluminum, chemical, glass, and forest products industries. The original members and organization of this team is shown in Figure 1.

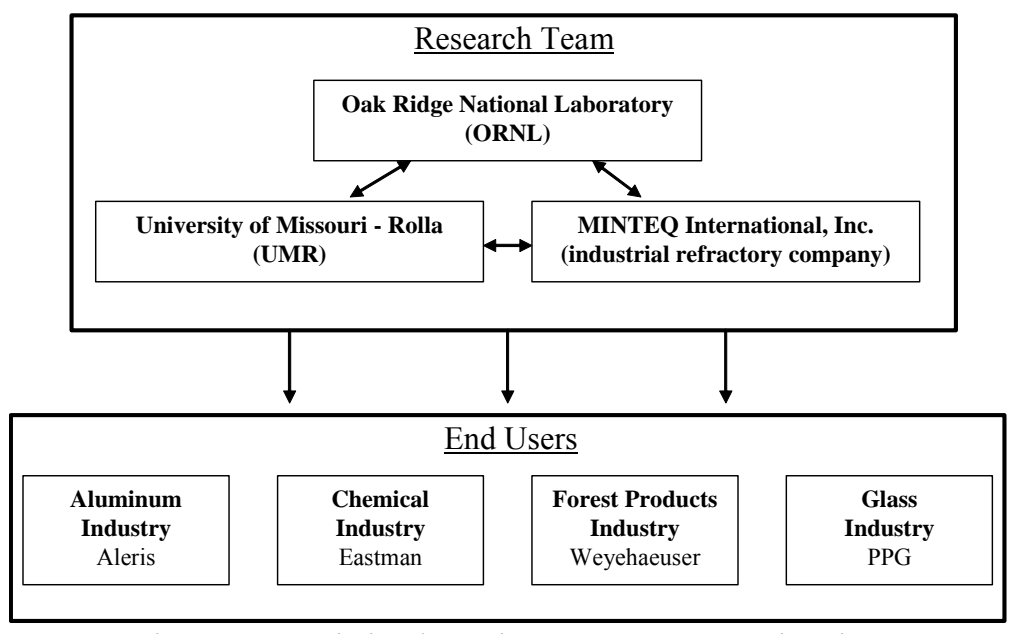

Figure 1. Original Project Team Organization

(note: University of Missouri - Rolla changed its name to Missouri University of Science and Technology during the performance period of the project) 


\section{PROPOSED PROJECT TASKS AND MILESTONES}

The tasks in the originally proposed work scope included the following:

Task 1: Development and production of a family of novel magnesia and/or alumina containing unshaped refractory materials.

(Task duration - first year, with production of refractories extending through life of project)

New aggregate materials, bond systems and protective coatings will be identified and investigated for use in our target applications. These refractory components will consist of both naturally occurring materials and new synthetic materials that may or may not currently be used in refractory production. ORNL will lead this effort with significant support from MS\&T and MINTEQ drawing on their extensive refractory research history and current refractory production technology. MINTEQ will then use the findings from this task to identify and evaluate application (installation) and processing (production) techniques (such as in-situ phase formation, altered conversion temperatures, accelerated reactions, etc.). These efforts will also be supported at ORNL and MS\&T through more fundamental work to provide insight into these new refractory systems through thermodynamic, microstructural, or mechanical modeling.

Once candidate refractory systems have been identified and validated for application and production, MINTEQ will produce small batches of these new refractories. New refractories will be screened for corrosion resistance and strength as they are produced to insure their applicability to the end uses defined by the industrial partners. Refractory systems meeting these qualifications will meet the first milestone of the project and will be investigated for use in the remainder of the project. Such materials will be tailored in the remainder of the project to meet the energy goals through extended lifetimes ( $2 \mathrm{X}$ goal) and improved thermal efficiency (20\% improvement) over currently used materials.

Task 2: Measurement of key properties of current and newly developed refractory materials.

(Task duration - second year)

The project will address the applicability and limitations of currently used materials from the aluminum, chemical, forest products, and glass industries and newly developed materials from this project by measuring and comparing key properties of the materials. The best currently performing refractory materials from each industry will be supplied by the four industrial participants for characterization as in-kind cost share. MINTEQ will also supply samples of the new refractory systems from Task 1 for analysis. All materials will be evaluated for properties such as thermal conductivity, creep, thermal expansion/shock, abrasion/wear, corrosion, and strength/modulus. Samples will also be characterized by various physical and microstructural means both before and after testing. These properties will be the basis for evaluating the improved performance of the new materials as compared to existing materials and for predicting the meeting of the energy goals of the project.

Task 3: Development of new refractory application techniques.

(Task duration - second year)

For success in this project, it will be necessary to develop entirely new application techniques and systems to optimize material installation and maximize the installed 
material's properties of the newly developed refractory materials. For this task, MINTEQ will draw on its extensive prior art and experience in this area to identify and develop suitable application techniques and equipment for installation of the refractory materials developed in Task 1. MINTEQ will then perform testing of these techniques and equipment, along with the effect on physical and mechanical properties of the installed refractory at their facilities. Such measured quantities will include application rate, \% rebound, density, porosity, and strength. In addition, samples of the installed material will be supplied to ORNL and MS\&T for more extensive testing and evaluation through corrosion and wear testing, strength testing, and microstructural evaluation. These properties will directly impact the performance of the newly developed refractories in their end use and therefore are crucial to meeting the energy goals of the project. Successful development and validation of suitable application techniques and equipment will meet the second milestone of the project.

\section{Task 4: Development of on-line inspection methods and hot-repair techniques. (Task duration - third year)}

To further reduce the energy used by industrial refractory consumers, as part of the project, improved methods of performing hot refractory maintenance will be sought and methods of on-line inspection will be developed or modified from existing technologies. This effort will be led by MINTEQ, drawing on its extensive prior experience in this area. ORNL and MS\&T will support this effort by providing efforts into the reviewing of current on-line maintenance methods and modeling support to predict how methods could be improved or modified to lead to better heat retention or lower energy demands for installing repair materials. MINTEQ will develop applicable on-line inspection methods, hot-repair techniques, and equipment along with adapting the newly developed refractory systems and application methods from Task 1 and 3 for on-line repair. This task should lead to additional energy savings through reducing the need to shut down or fully cool refractory lined vessels in order to repair failed or deteriorating refractory. On-line monitoring and maintenance will also allow for identification of refractory deterioration in real time allowing for immediate repair of areas where heat is being lost and will allow for repair of only needed areas instead of having to replace entire linings resulting in not only energy savings for the process but energy savings through not having to produce the extra refractory materials. Hard numbers for these energy savings are not known at this time and would vary by process, but effects could be large considering the gross amount of energy lost in cooling and then reheating a typical glass melter, aluminum furnace, or industrial gasifier. The completion of the development of hot-repair techniques will meet the third milestone of this project.

\section{Task 5: Formation of a comprehensive database concerning currently used and newly developed refractory materials.}

(Task duration - middle of third year to middle of fourth year)

The property measurements made on currently used materials and newly developed materials in Task 2 will be used to initiate the formation of an un-biased, comprehensive database concerning refractory materials. This has been identified as a needed but unavailable resource, highly desired by the refractory user community which will lead to better refractory selection for industrial processes resulting in more energy efficient furnaces throughout American industry. A server location for such a database will be 
created at ORNL and arrangements for its upkeep will be put in place. ORNL and MS\&T will organize the data collected from this project and other previous refractory projects for input into the database. Additional data for the database will be provided by industrial partners and MINTEQ as in-kind support.

\section{Task 6: Performance of in-plant trials and commercialization. (Task duration - fourth year)}

Based on the results obtained in Tasks 2-4, the project research team will work with the industrial partners to select processes in which to test the newly developed materials. Industrial facilities from the aluminum, chemical, forest products, and glass industries will be candidate locations for use as in-plant trials with access and testing done in these facilities being potentially counted toward each company's in-kind contribution to the project. The research team will closely work with the industrial partners in setting up the testing facilities and testing conditions. Commercialization efforts will be led by MINTEQ following their standard methods. Successful in-plant trials may be used to validate the energy savings goals set forth and predicted by the various tasks of the project and will meet the final milestone of the project.

\section{Task 7: Reporting and Administration.}

(Task duration - entire project)

This task will be led by ORNL, with participation from MS\&T and MINTEQ. Quarterly review meetings will be held and required reports will be sent to Deparmnet of Energy (DOE) quarterly and annually. Reports will be composed and submitted to the industrial partners upon completion of industrial trials. Costs will cover personnel time for report writing and some travel costs for meetings. A final report will be prepared upon completion of the project.

Original Project Milestones:

Year One: (1) Demonstrate capability of producing a family of new materials with twice the life span of current materials and which have $20 \%$ better thermal efficiency than current materials. (09/30/07)

Year Two: (2) Validate that new materials possess twice the life span of current materials and $20 \%$ better thermal efficiency than current materials. (9/30/08).

(3) Demonstrate ability to install the family of new materials produced in year one. New applications techniques and systems will be tailored for the newly developed materials to optimize installed material properties. Installed materials will preserve the $2 \mathrm{X}$ improvement in life span and $20 \%$ improvement in thermal efficiency over current materials. (09/30/08)

Year Three: (4) Demonstrate ability to perform on-line inspection and feasibility of hotrepair techniques. These methods are expected to increase lining lifetimes by at least $2 \mathrm{X}$ and to decrease the number of needed maintenance shutdowns by half. (09/30/09)

Year Four: (5) Obtain six months of in-plant operating experience at industrial partner locations. This will provide a validation of refractory performance on an industrial scale, as compared to lab scale results previously obtained during the project. By comparing performance of new materials to that of currently 
used materials under identical service conditions, the goals of $2 \mathrm{X}$ improvement in life span and 20\% improvement in thermal efficiency will be validated. $(09 / 30 / 10)$

\section{TECHNICAL DISCUSSION OF ACTUAL WORK PERFORMED}

In the final execution of this project, Task 1 defined above was further differentiated by dividing it into three separate tasks. "Task 1. Development of Refractory Materials" dealt specifically with the originally proposed development of candidate materials during year one of the project. "Task 2. Identification of new materials and fundamental understanding of materials" was created to be a more fundamental task largely carried out at MS\&T throughout the duration of the project in support of the material development and deployment efforts. "Task 3. Production of Refractory Materials" encompassed the original production of experimentally developed materials and the subsequent continued production of materials during the duration of the project for both laboratory and industrial testing as needed. Table 1 shows the new task structure, subtasks, and the planned and actual completion dates of each task.

Table 1. Revised Task Structure and Schedule

\begin{tabular}{|c|c|c|c|c|c|c|}
\hline \multirow{2}{*}{$\begin{array}{c}\text { Task/ } \\
\text { Subtask } \\
\text { Number }\end{array}$} & \multirow[b]{2}{*}{$\begin{array}{l}\text { Title or Brief } \\
\text { Description }\end{array}$} & \multicolumn{4}{|c|}{ Task Completion Date } & \multirow[b]{2}{*}{ Comments } \\
\hline & & $\left|\begin{array}{c}\text { Original } \\
\text { Planned }\end{array}\right|$ & $\begin{array}{l}\text { Revised } \\
\text { Planned }\end{array}$ & Actual & $\begin{array}{c}\% \\
\text { Complete }\end{array}$ & \\
\hline 1 & $\begin{array}{c}\text { Development of } \\
\text { refractory materials }\end{array}$ & 9/28/07 & & 9/28/07 & 100 & \\
\hline 1.1 & $\begin{array}{c}\text { Identification of refractory } \\
\text { components }\end{array}$ & $1 / 31 / 07$ & $2 / 28 / 07$ & $2 / 28 / 07$ & 100 & \begin{tabular}{|c} 
Refractory families and \\
candidate materials defined.
\end{tabular} \\
\hline 1.2 & $\begin{array}{c}\text { Evaluation of application } \\
\text { techniques }\end{array}$ & $2 / 28 / 07$ & $3 / 30 / 07$ & $3 / 30 / 07$ & 100 & $\begin{array}{l}\text { Candidate application } \\
\text { techniques defined. }\end{array}$ \\
\hline 1.3 & $\begin{array}{c}\text { Identification of } \\
\text { processing techniques }\end{array}$ & $3 / 30 / 07$ & & $3 / 30 / 07$ & 100 & $\begin{array}{l}\text { Candidate processing } \\
\text { techniques defined. }\end{array}$ \\
\hline 1.4 & $\begin{array}{c}\text { Microstructural, } \\
\text { mechanical, and } \\
\text { thermodynamic modeling }\end{array}$ & $6 / 29 / 07$ & 9/28/07 & $9 / 28 / 07$ & 100 & $\begin{array}{l}\text { Modeling of initial materials } \\
\text { completed. }\end{array}$ \\
\hline 1.5 & $\begin{array}{c}\text { Wear and strength testing } \\
\text { standardization }\end{array}$ & 9/28/07 & & 9/28/07 & 100 & $\begin{array}{l}\text { Methods selected, but will } \\
\text { be revisited throughout the } \\
\text { project. }\end{array}$ \\
\hline 1.6 & $\begin{array}{l}\text { Initial production of } \\
\text { refractory materials }\end{array}$ & $9 / 28 / 07$ & & $9 / 28 / 07$ & 100 & $\begin{array}{l}\text { Initial materials produced } \\
\text { and validated. }\end{array}$ \\
\hline
\end{tabular}




\begin{tabular}{|c|c|c|c|c|c|c|}
\hline \multirow{2}{*}{$\begin{array}{l}\text { Task/ } \\
\text { Subtask } \\
\text { Number }\end{array}$} & \multirow{2}{*}{$\begin{array}{l}\text { Title or Brief } \\
\text { Description }\end{array}$} & \multicolumn{4}{|c|}{ Task Completion Date } & \multirow[b]{2}{*}{ Comments } \\
\hline & & $\begin{array}{l}\text { Original } \\
\text { Planned }\end{array}$ & $\begin{array}{l}\text { Revised } \\
\text { Planned }\end{array}$ & Actual & $\begin{array}{c}\% \\
\text { Complete }\end{array}$ & \\
\hline 2 & $\begin{array}{c}\text { Identification of new } \\
\text { materials and } \\
\text { fundamental } \\
\text { understanding of } \\
\text { materials } \\
\end{array}$ & $3 / 31 / 10$ & & $3 / 31 / 10$ & 100 & $\begin{array}{l}\text { Refractory development } \\
\text { continued through the entire } \\
\text { life of the project. }\end{array}$ \\
\hline 2.1 & $\begin{array}{l}\text { Study of spinel solid } \\
\text { solutions and thermal } \\
\text { conductivity effects }\end{array}$ & $9 / 28 / 07$ & $3 / 31 / 08$ & $3 / 31 / 08$ & 100 & \\
\hline 2.2 & $\begin{array}{c}\text { Fundamental } \\
\text { understanding of spinel } \\
\text { (microstructure/formation) }\end{array}$ & $12 / 31 / 09$ & $3 / 31 / 10$ & $3 / 31 / 10$ & 100 & \\
\hline 2.3 & $\begin{array}{c}\text { Study of polycrystalline } \\
\text { diffusion couples }\end{array}$ & $6 / 30 / 09$ & $3 / 31 / 10$ & $3 / 31 / 10$ & 100 & \\
\hline 2.4 & $\begin{array}{l}\text { Study of refractory mix } \\
\text { components and roles }\end{array}$ & $6 / 30 / 09$ & $9 / 30 / 09$ & $9 / 30 / 09$ & 100 & \\
\hline
\end{tabular}

\begin{tabular}{|c|c|c|c|c|c|c|}
\hline \multirow{2}{*}{$\begin{array}{c}\text { Task/ } \\
\text { Subtask } \\
\text { Number }\end{array}$} & $\begin{array}{c}\text { Title or Brief } \\
\text { Description }\end{array}$ & \multicolumn{2}{|c|}{ Task Completion Date } & \multirow{2}{*}{ Comments } \\
\cline { 3 - 6 } & Priginal & $\begin{array}{c}\text { Revised } \\
\text { Planned }\end{array}$ & Actual & $\begin{array}{c}\% \\
\text { Complete }\end{array}$ & \\
\hline 3.1 & $\begin{array}{c}\text { Production of refractory } \\
\text { materials }\end{array}$ & $3 / 31 / 10$ & $9 / 30 / 11$ & $9 / 30 / 11$ & 100 & \\
\hline 3.2 & $\begin{array}{c}\text { Production of } \\
\text { refractories }\end{array}$ & $3 / 31 / 10$ & $9 / 30 / 11$ & $9 / 30 / 11$ & 100 & $\begin{array}{c}\text { Refractory production } \\
\text { continued through the entire } \\
\text { life of the project. }\end{array}$ \\
\hline $\begin{array}{c}\text { Microstructural, } \\
\text { mechanical, and } \\
\text { thermodynamic modeling }\end{array}$ & $9 / 30 / 09$ & $6 / 30 / 09$ & 100 & \\
\hline
\end{tabular}




\begin{tabular}{|c|c|c|c|c|c|c|}
\hline \multirow{2}{*}{$\begin{array}{c}\text { Task/ } \\
\text { Subtask } \\
\text { Number }\end{array}$} & \multirow{2}{*}{$\begin{array}{l}\text { Title or Brief } \\
\text { Description }\end{array}$} & \multicolumn{4}{|c|}{ Task Completion Date } & \multirow{2}{*}{ Comments } \\
\hline & & $\begin{array}{l}\text { Original } \\
\text { Planned }\end{array}$ & $\begin{array}{l}\text { Revised } \\
\text { Planned }\end{array}$ & Actual & $\begin{array}{c}\% \\
\text { Complete }\end{array}$ & \\
\hline 4 & $\begin{array}{l}\text { Measurement of key } \\
\text { refractory properties }\end{array}$ & $9 / 30 / 08$ & $12 / 31 / 08$ & $12 / 31 / 08$ & 100 & \\
\hline 4.1 & $\begin{array}{l}\text { Thermal conductivity and } \\
\text { creep }\end{array}$ & $3 / 31 / 08$ & 9/30/08 & $9 / 30 / 08$ & 100 & \\
\hline 4.2 & $\begin{array}{l}\text { Abrasion, wear, and } \\
\text { thermal expansion }\end{array}$ & $3 / 31 / 08$ & 9/30/08 & $11 / 30 / 08$ & 100 & \\
\hline 4.3 & $\begin{array}{c}\text { Corrosion, strength, and } \\
\text { thermal shock }\end{array}$ & $6 / 30 / 08$ & 9/30/08 & $9 / 30 / 08$ & 100 & $\begin{array}{l}\text { Thermal shock testing not } \\
\text { needed. }\end{array}$ \\
\hline 4.4 & $\begin{array}{c}\text { Physical } \\
\text { characterization }\end{array}$ & $9 / 30 / 08$ & & 9/30/08 & 100 & \\
\hline 4.5 & $\begin{array}{l}\text { Microstructural } \\
\text { evaluation }\end{array}$ & $9 / 30 / 08$ & & 9/30/08 & 100 & \\
\hline
\end{tabular}

\begin{tabular}{|r|c|c|c|c|c|c|}
\hline \multirow{2}{*}{$\begin{array}{c}\text { Task/ } \\
\text { Subtask } \\
\text { Number }\end{array}$} & Title or Brief & \multicolumn{3}{|c|}{ Task Completion Date } & \multirow{2}{*}{ Comments } \\
\cline { 3 - 6 } & Description & $\begin{array}{c}\text { Original } \\
\text { Planned }\end{array}$ & $\begin{array}{c}\text { Revised } \\
\text { Planned }\end{array}$ & Actual & $\begin{array}{c}\text { \% } \\
\text { Complete }\end{array}$ & \\
\hline 5 & $\begin{array}{c}\text { Development of new } \\
\text { refractory application } \\
\text { techniques }\end{array}$ & $9 / 30 / 08$ & $12 / 31 / 08$ & $12 / 31 / 08$ & 100 & \\
\hline 5.1 & $\begin{array}{c}\text { Development of } \\
\text { techniques }\end{array}$ & $7 / 31 / 08$ & & $7 / 31 / 08$ & 100 & \\
\hline 5.3 & $\begin{array}{c}\text { Development of } \\
\text { equipment }\end{array}$ & $8 / 29 / 08$ & & $8 / 29 / 08$ & 100 & \\
\hline 5.4 & Initial application and \\
& Wroperty evaluation & $9 / 30 / 08$ & & $9 / 30 / 08$ & 100 & \\
\hline 5.5 & Strength testing & $9 / 30 / 08$ & & $9 / 30 / 08$ & 100 & \\
\hline 5.6 & $\begin{array}{c}\text { Microstructural } \\
\text { evaluation }\end{array}$ & $9 / 30 / 08$ & $12 / 31 / 08$ & $12 / 31 / 08$ & 100 & \\
\hline
\end{tabular}




\begin{tabular}{|c|c|c|c|c|c|c|}
\hline \multirow{2}{*}{$\begin{array}{c}\text { Task/ } \\
\text { Subtask } \\
\text { Number }\end{array}$} & \multirow{2}{*}{$\begin{array}{l}\text { Title or Brief } \\
\text { Description }\end{array}$} & \multicolumn{4}{|c|}{ Task Completion Date } & \multirow{2}{*}{ Comments } \\
\hline & & $\begin{array}{l}\text { Original } \\
\text { Planned }\end{array}$ & $\begin{array}{l}\text { Revised } \\
\text { Planned }\end{array}$ & Actual & $\begin{array}{c}\% \\
\text { Complete }\end{array}$ & \\
\hline 6 & $\begin{array}{l}\text { Development of on-line } \\
\text { inspection and hot- } \\
\text { repair techniques }\end{array}$ & 9/30/09 & & $9 / 30 / 09$ & 100 & $\begin{array}{c}\text { Hot repair materials } \\
\text { developed, on-line } \\
\text { inspection not feasible }\end{array}$ \\
\hline 6.1 & $\begin{array}{l}\text { Review of current } \\
\text { methods }\end{array}$ & $3 / 31 / 09$ & & $3 / 31 / 09$ & 100 & \\
\hline 6.2 & $\begin{array}{l}\text { Microstructural, } \\
\text { mechanical, and } \\
\text { thermodynamic modeling }\end{array}$ & $6 / 30 / 09$ & & $6 / 30 / 09$ & 100 & \\
\hline 6.3 & $\begin{array}{c}\text { Development of new } \\
\text { methods and techniques } \\
\text { for new materials }\end{array}$ & $3 / 31 / 09$ & $6 / 30 / 09$ & $6 / 30 / 09$ & 100 & \\
\hline 6.4 & $\begin{array}{l}\text { Adaptation of newly } \\
\text { developed technology } \\
\text { to developed materials }\end{array}$ & 9/30/09 & & 9/30/09 & 100 & $\begin{array}{l}\text { On-line inspection found to } \\
\text { be cost prohibitive }\end{array}$ \\
\hline
\end{tabular}

\begin{tabular}{|c|c|c|c|c|c|c|}
\hline \multirow{2}{*}{$\begin{array}{c}\text { Task/ } \\
\text { Subtask } \\
\text { Number }\end{array}$} & \multirow{2}{*}{$\begin{array}{l}\text { Title or Brief } \\
\text { Description }\end{array}$} & \multicolumn{4}{|c|}{ Task Completion Date } & \multirow{2}{*}{ Comments } \\
\hline & & $\begin{array}{l}\text { Original } \\
\text { Planned }\end{array}$ & $\begin{array}{l}\text { Revised } \\
\text { Planned }\end{array}$ & Actual & $\begin{array}{c}\% \\
\text { Complete }\end{array}$ & \\
\hline 7 & Formation of database & $3 / 31 / 10$ & $6 / 30 / 11$ & $6 / 30 / 11$ & 100 & \\
\hline 7.1 & Creation of server & $7 / 31 / 09$ & $7 / 31 / 10$ & $9 / 30 / 10$ & 100 & \\
\hline 7.2 & $\begin{array}{c}\text { Organization and input of } \\
\text { data }\end{array}$ & $3 / 31 / 10$ & $6 / 30 / 11$ & $6 / 30 / 11$ & 100 & \\
\hline 7.3 & $\begin{array}{l}\text { Distribution of } \\
\text { information }\end{array}$ & $3 / 31 / 10$ & $6 / 30 / 11$ & $6 / 30 / 11$ & 100 & \\
\hline
\end{tabular}

\begin{tabular}{|r|c|c|c|c|c|c|}
\hline \multirow{2}{*}{$\begin{array}{c}\text { Task/ } \\
\text { Subtask } \\
\text { Number }\end{array}$} & $\begin{array}{c}\text { Title or Brief } \\
\text { Description }\end{array}$ & \multicolumn{3}{|c|}{ Task Completion Date } & \multirow{2}{*}{ Comments } \\
\cline { 3 - 6 } & $\begin{array}{c}\text { Original } \\
\text { Planned }\end{array}$ & $\begin{array}{c}\text { Revised } \\
\text { Planned }\end{array}$ & Actual & $\begin{array}{c}\% \\
\text { Complete }\end{array}$ & \\
\hline 8 & $\begin{array}{c}\text { In-plant trials and } \\
\text { commercialization }\end{array}$ & $9 / 30 / 10$ & $3 / 31 / 12$ & $3 / 31 / 12$ & 100 & \\
\hline 8.1 & $\begin{array}{c}\text { Performance of in-plant } \\
\text { trials }\end{array}$ & $9 / 30 / 10$ & $3 / 31 / 12$ & $3 / 31 / 12$ & 100 & $\begin{array}{c}\text { Trials continued after } \\
\text { completion of project }\end{array}$ \\
\hline 8.3 & $\begin{array}{c}\text { Commercialization } \\
\text { efforts }\end{array}$ & $9 / 30 / 10$ & $12 / 31 / 10$ & $12 / 31 / 10$ & 100 & $\begin{array}{c}\text { Plan put together and } \\
\text { implemented by MINTEQ }\end{array}$ \\
\hline
\end{tabular}




\begin{tabular}{|c|c|c|c|c|c|c|}
\hline \multirow{2}{*}{$\begin{array}{c}\text { Task/ } \\
\text { Subtask } \\
\text { Number }\end{array}$} & \multirow{2}{*}{$\begin{array}{l}\text { Title or Brief } \\
\text { Description }\end{array}$} & \multicolumn{4}{|c|}{ Task Completion Date } & \multirow{2}{*}{ Comments } \\
\hline & & $\begin{array}{l}\text { Original } \\
\text { Planned }\end{array}$ & $\begin{array}{l}\text { Revised } \\
\text { Planned }\end{array}$ & Actual & $\begin{array}{c}\% \\
\text { Complete }\end{array}$ & \\
\hline 9 & $\begin{array}{l}\text { Reporting and } \\
\text { administration }\end{array}$ & $9 / 30 / 10$ & $3 / 31 / 12$ & $3 / 31 / 12$ & 100 & $\begin{array}{l}\text { Reporting continued through } \\
\text { the entire life of the project. }\end{array}$ \\
\hline
\end{tabular}

The original project milestones and their completion dates are shown in Table 2. More in depth discussion of key results from each task are also given below.

Table 2. Milestone Schedule

\begin{tabular}{|c|c|c|c|c|c|c|}
\hline \multirow{2}{*}{$\begin{array}{c}\text { Milestones } \\
\text { Go-No } \\
\text { Go's }\end{array}$} & \multirow{2}{*}{$\begin{array}{l}\text { Title or Brief } \\
\text { Description }\end{array}$} & \multicolumn{4}{|c|}{ Milestone Completion Date } & \multirow[b]{2}{*}{ Comments } \\
\hline & & $\begin{array}{l}\text { Original } \\
\text { Planned }\end{array}$ & $\begin{array}{l}\text { Revised } \\
\text { Planned }\end{array}$ & Actual & $\begin{array}{c}\% \\
\text { Complete }\end{array}$ & \\
\hline 1 & $\begin{array}{l}\text { Get CRADA with } \\
\text { MINTEQ in place }\end{array}$ & $12 / 29 / 06$ & $1 / 31 / 07$ & $1 / 23 / 07$ & 100 & \\
\hline 2 & $\begin{array}{c}\text { Demonstrate production of } \\
\text { new family of refractory } \\
\text { materials }\end{array}$ & 9/28/07 & & $9 / 28 / 07$ & 100 & \\
\hline 3 & $\begin{array}{c}\text { Validate properties of new } \\
\text { materials will lead to } \\
\text { improved life span and } \\
\text { thermal efficiency }\end{array}$ & 9/30/08 & $12 / 31 / 08$ & $12 / 31 / 08$ & 100 & \\
\hline 4 & $\begin{array}{c}\text { Demonstrate ability to } \\
\text { install new family of } \\
\text { materials }\end{array}$ & $9 / 30 / 08$ & & 9/30/08 & 100 & \\
\hline 5 & $\begin{array}{c}\text { Demonstrate ability to } \\
\text { perform on-line inspection } \\
\text { and feasibility of hot- } \\
\text { repair }\end{array}$ & 9/30/09 & & 9/30/09 & 100 & $\begin{array}{c}\begin{array}{c}\text { Hot repair materials } \\
\text { developed, on-line } \\
\text { inspection found to be cost } \\
\text { prohibitive }\end{array}\end{array}$ \\
\hline 6 & \begin{tabular}{|c|}
$\begin{array}{c}\text { Obtain six months of in- } \\
\text { plant operating experience } \\
\text { at industrial locations }\end{array}$ \\
\end{tabular} & $9 / 30 / 10$ & $3 / 31 / 12$ & $3 / 31 / 12$ & 100 & $\begin{array}{l}\text { Trials continued after } \\
\text { completion of project }\end{array}$ \\
\hline
\end{tabular}

\section{Task 1 Development of refractory materials}

This task was completed at the end of the first year of the project (9/07).

Refractory development efforts were based on characterization of failed materials from industrial partners and analysis utilizing a tool known as "Quality Function Deployment" (QFD). This tool, brought to the project by MINTEQ, was used for capturing, prioritizing and translating the needs of our four originally targeted markets into a single development program and to guide the initial research direction and efforts of the project. This tool was used to aid in project direction and maximizing the chance of project success by targeting areas where there was 1) commonality between processes/furnaces from various industries, 2) significant chance of meaningful energy savings, and 3) likelihood of achieving success using the approaches proposed for this project. Spreadsheets were developed for Aleris 
rotary and reverberatory furnaces, a PPG melting furnace and regenerator, the Eastman coal gasifier, and the Weyerhaeuser gasfier and lime kiln based on visits to industrial partner sites.

Based on the QFD analysis, seven process vessels were identified across the four industries as exhibiting refractory related issues that may be addressed by this project. These consisted of two rotary furnaces, two gasifiers, two reverberatory furnaces, and a regenerator. There appeared to also be commonality between the materials used in the Weyerhaeuser lime kiln and the Aleris rotary furnace and between the requirements for the Eastman and Weyerhaeuser gasifers. Thus, by targeting two units (the Weyerhaeuser lime kiln and the Eastman gasifier) issues for four of the seven units and three of the four industries were addressed. Additionally, reverberatory furnaces were being used at both Aleris and PPG where it appeared that a benefit could be realized in both applications from refractory with better insulating and erosion resistance properties. Several opportunities for repair materials/techniques and on-line evaluation were also exhibited across these furnaces. After further consideration related to the type of materials being developed under this project, the regenerator application at PPG was deemed outside of the scope of this project. Work therefore focused on the six tasks shown below:

Topics Proposed for Research Conducted During Project

1. Development of new refractory materials to replace those currently used by Weyerhaeuser in the first section of their lime kiln (the burning zone).

2. Use of materials developed for lime kiln (in developed or slightly altered form) in the Aleris rotary furnace application.

3. Development of new refractory materials to replace those currently used by Eastman in their coal gasifier.

4. Use of materials developed for coal gasifier (in developed or slightly altered form) in the Weyerhaeuser black liquor gasifier application.

5. Development of new refractory materials to replace those currently used by Aleris in their aluminum reverberatory furnaces.

6. Use of materials developed for aluminum reverberatory furnaces (in developed or slightly altered form) in the PPG glass reverberatory furnace application.

In addition, an effort was made to characterize materials currently used in the above applications as a standard of evaluating the projected performance of newly developed materials as defined in the QFD tool spreadsheets.

Modeling was used to perform microstructural, mechanical, and thermodynamic simulation of current materials for performance prediction of newly developed materials subjected to the currently defined industrial applications and environments. Additionally, thermal modeling software was acquired by MINTEQ for use in their refractory development efforts. Work was simultaneously performed at ORNL and MINTEQ with initial modeling efforts used to estimate energy savings possible with new lining materials and techniques developed under the project. An example of this is shown in Figure 2 for a lime kiln application where estimated cold face temperatures were calculated based on candidate lining systems. 
Cases Considered:

Base Case - 6" Ufala brick degraded to 3", 1.5" Skamol brick

(based on brick performance data from Weyerhaeuser)

Maintain Thickness - 6" Ufala brick undegraded, 1.5" Skamol brick

(hypothetical best case where no wear occurs)

Improved Hotface - 6" of improved hotface material degraded to 4.5", 1.5" Skamol brick

(lower wear hotface material backed with currently used Skamol brick)

Improved Hotface and Backup - 6" of improved hotface degraded to 4.5", 1.5"

experimental backup

(lower wear hotface material backed with lower conductivity material)

Cold Face Temperature Plot

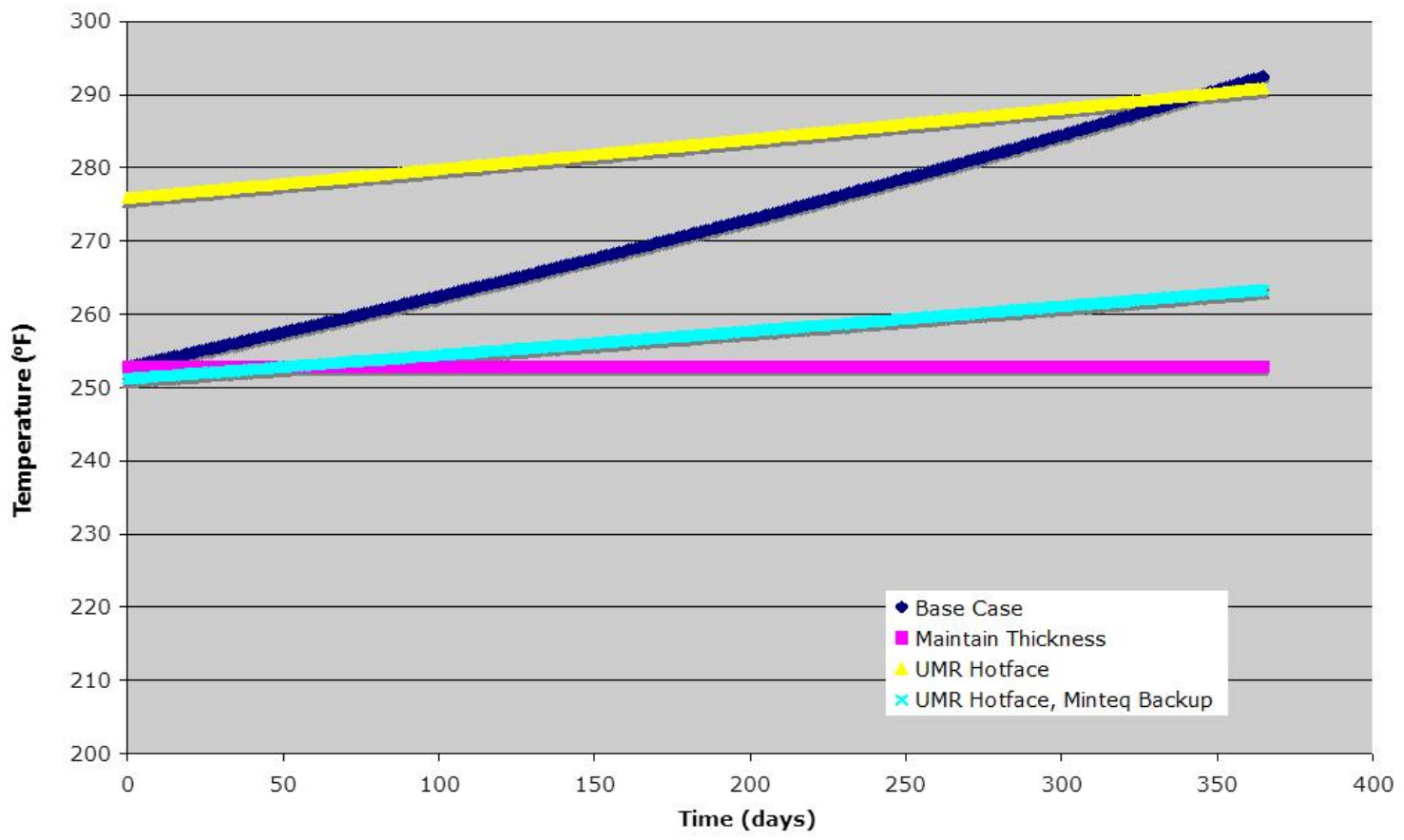

Figure 2. Example of Estimated Energy Savings Possible with New Lining Materials and Techniques Developed for Lime Kiln Applications (best case indicated by constant cold face temperature)

FEA modeling was also performed at ORNL on the new insulation design concept developed by MINTEQ during this project to verify its stress handling ability. The objective of the modeling was to study the temperature and stress distributions of refractory linings used in cylindrical vessels such as boilers, kilns, or other process vessels. The commercial software package ABAQUS was used for this thermal/mechanical analysis. Due to the axisymmetric nature of the geometry, the analysis was carried out using a two-dimensional section normal to the axial direction of the cylinder and only considering one-quarter of the cross-section. Results from the analysis (shown in Figure 3) were used to show the ability of various lining materials to: 1) provide sufficient insulation for the process and 2) withstand loading due to thermal expansion and weight of the lining. Cases with and without plastic 
deformation were considered along with assumptions of plane strain or plane stress conditions.

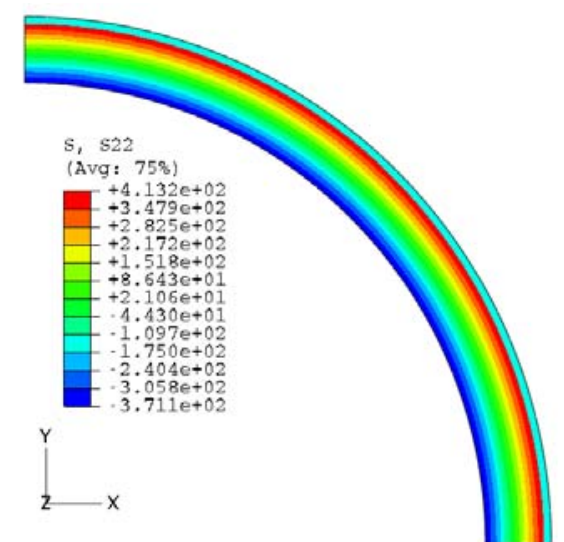

Plane Strain, No Plastic Deformation

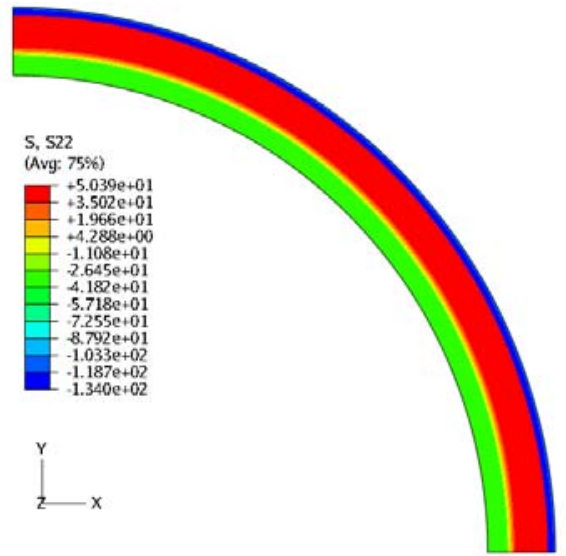

Plane Strain, with Plastic Deformation

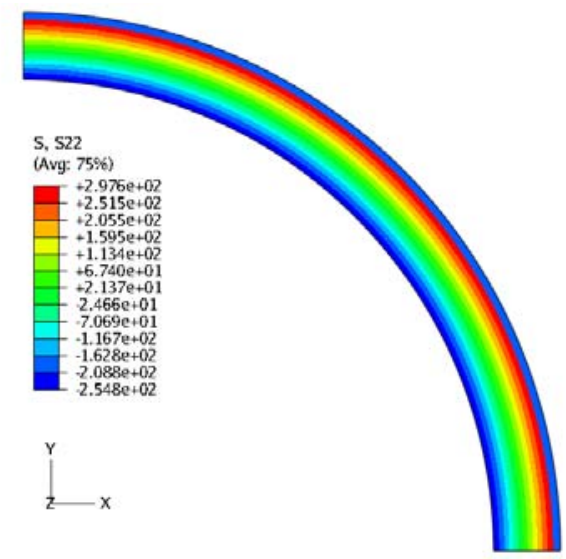

Plane Stress, No Plastic Deformation

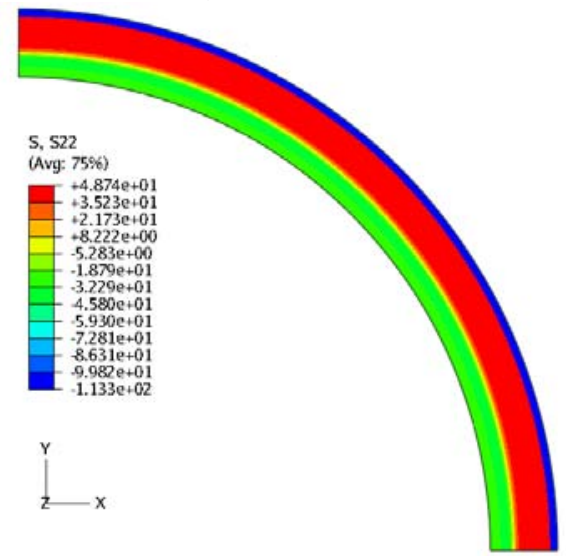

Plane Stress, with Plastic Deformation

Figure 3. Results from ABAQUS FEA Modeling of MINTEQ Insulation Design Concept

The basic approach for this analysis involved developing a finite element mesh for the geometry under consideration, and performing thermal and mechanical analysis in a sequential fashion, where the temperature field from the thermal analysis is used as input for the mechanical analysis. The existing design for the cylindrical vessel consisted of an outer shell made of A36 carbon steel, with two layers of refractory materials lining the inside surface. The innermost lining had a wall thickness of 6 in. $(152.4 \mathrm{~mm})$, with a $2 \mathrm{in} .(50.8$ $\mathrm{mm}$ ) thick layer of insulation material between the inner lining and the steel shell. The steel shell was 1 in. $(25.4 \mathrm{~mm})$ thick, with an outer diameter of $12 \mathrm{ft}$. $(3657.6 \mathrm{~mm})$. The material for the inner hot face lining was taken to be Ufala, and the intermediate layer was Skamol M-Extra "E". Due to the axi-symmetric nature of the geometry, the analysis was carried out using a two-dimensional section normal to the axial direction of the cylinder by considering the smallest angular portion of the cross-section that formed a repeatable unit. The nodes along the radial direction at the top and bottom edges were tied using multi-point constraints to make the boundary conditions periodic in the circumferential direction.

Thermal and mechanical analyses were carried out in two steps, by first heating the vessel to operating conditions, followed by cooling back to room temperature. For the thermal 
analysis, under operating conditions, the inside surface was assumed to be in contact with a gaseous environment at $2500^{\circ} \mathrm{F}\left(1371^{\circ} \mathrm{C}\right)$, and the outside surface was assumed to be in contact with ambient air at $80^{\circ} \mathrm{F}\left(26.7^{\circ} \mathrm{C}\right)$. The heat transfer coefficient at both inside and outside surfaces was taken to be $10 \mathrm{~W} / \mathrm{m}^{2} \mathrm{~K}$, and an emissivity factor of 0.5 was used for radiant heating. The temperature distribution in the cross-section under operating conditions shows a decrease in temperature in the radial direction from the inside to the outside surface.

Figure 4 - Figure 8 show the hoop stress distributions for different cases considered, with the stress contours plotted in the refractory lining only for better contrast. Figure 4 shows the case with only Ufala material for the entire lining, and shows the maximum tensile stress developing at the outer diameter of the refractory layer (next to the steel shell), and maximum compressive stress at the inner diameter. Figure 5 shows the case with the standard design, with a continuous layer of the intermediate Skamol layer between the inner Ufala layer and the steel shell. Presence of the intermediate layer reduces the tensile stress at the outer diameter of the Ufala layer, but leads to an increase in the compressive stress at the inner diameter.

Instead of a continuous layer of the backup refractory material, three alternate designs with alternate geometries for the backup layer were considered. Hoop stress distributions for these three cases are shown in Figure 6 - Figure 8, respectively. All three cases showed stress distributions that are in between the two extremes of no backup layer (Figure 4) and continuous backup layer (Figure 5). The compressive hoop stress at the inner diameter is lower for all three alternate designs compared to the standard design. The tensile stress distribution at the outer diameter is very similar for all three alternate designs.

S, S22

(Avg: 75\%)

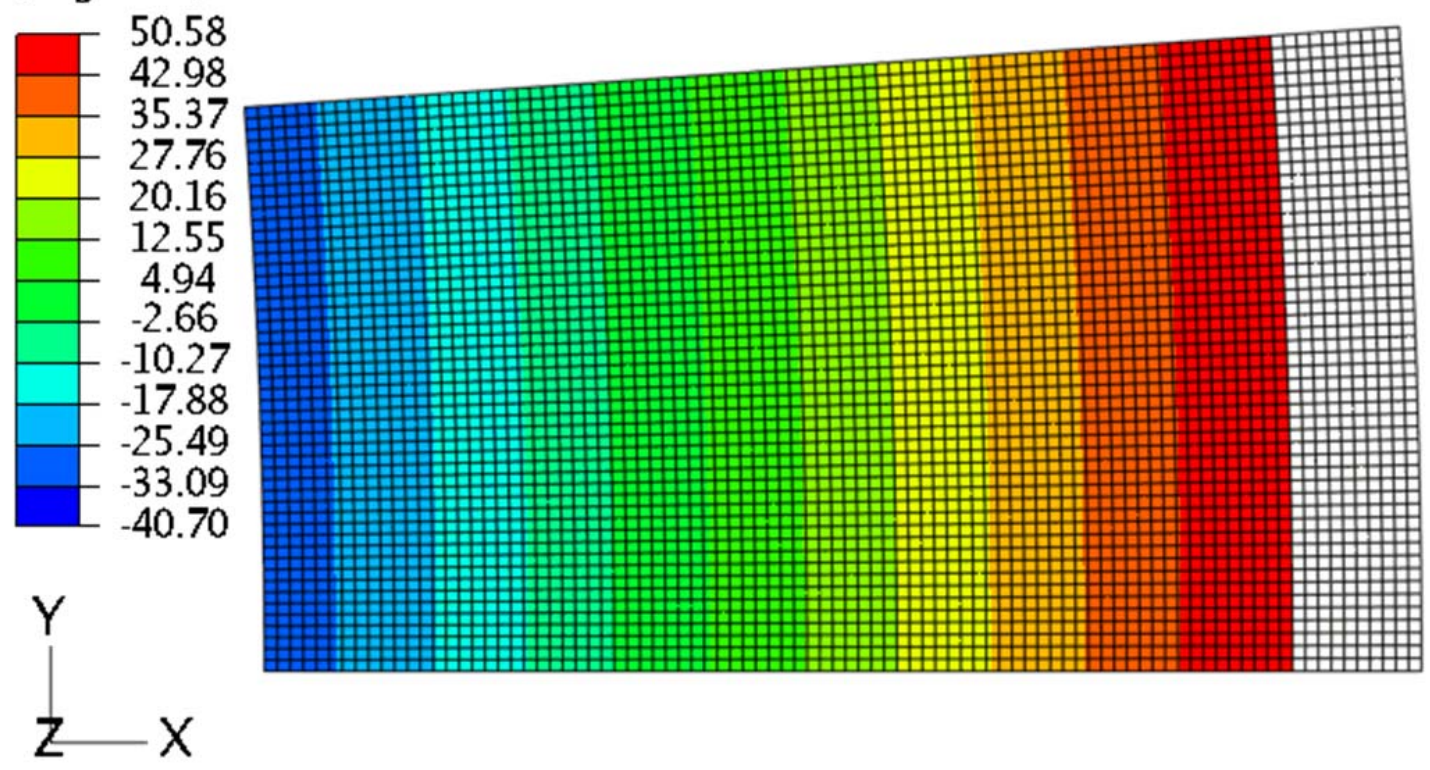

Figure 4. Distribution of Hoop Stress [MPa] for the Case of Single Layer of Standard Insulation 
S, S22

(Avg: $75 \%$ )
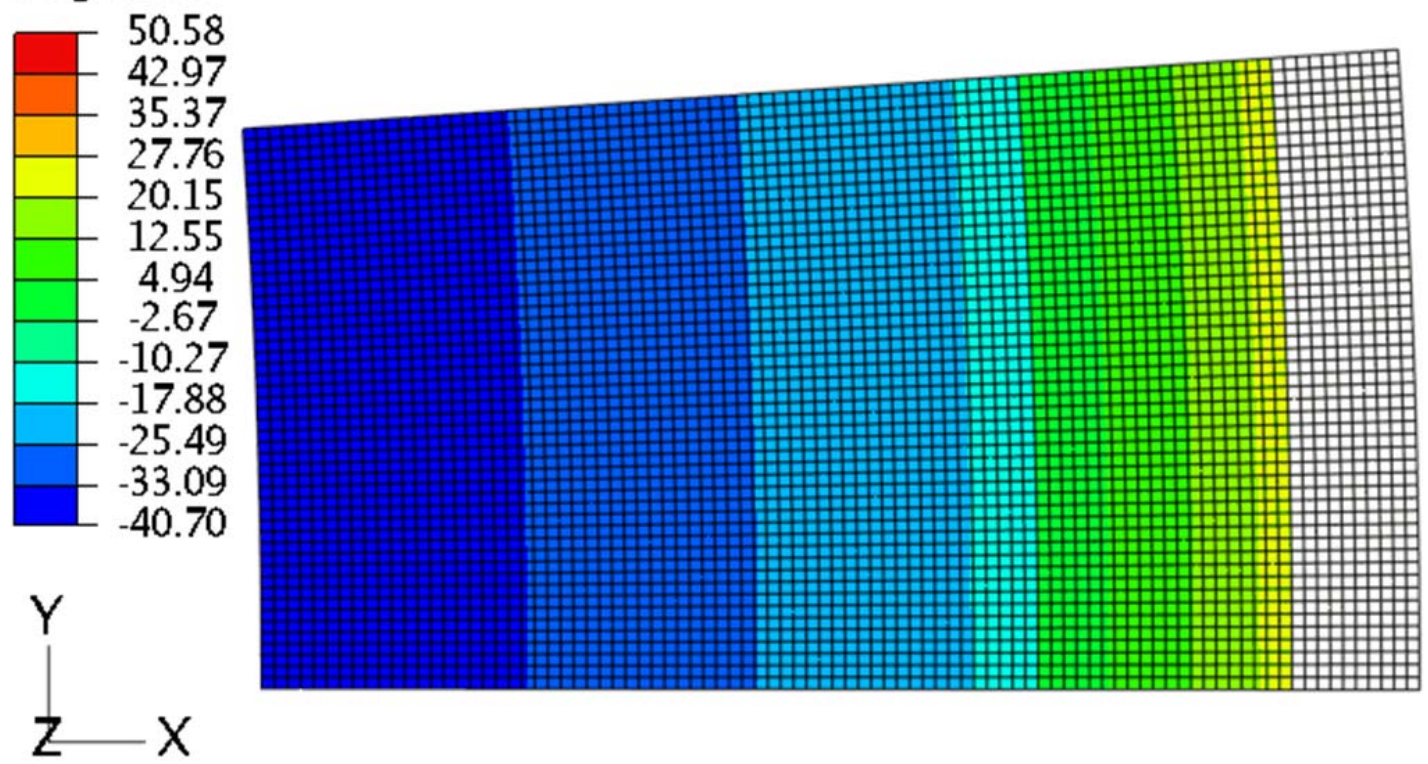

Figure 5. Distribution of Hoop Stress [MPa] for the Case of Multi-Layer of Standard Insulation

S, S22

(Avg: 75\%)
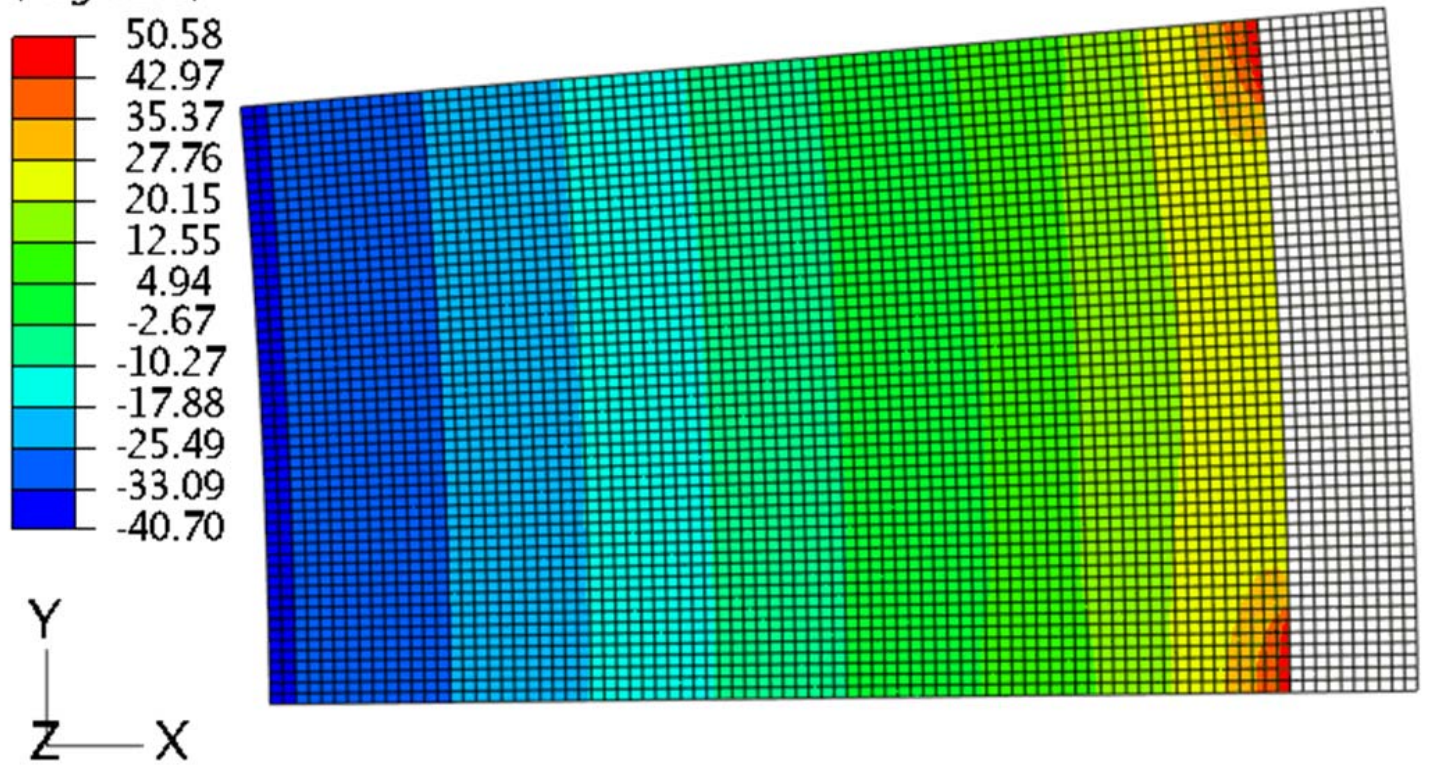

Figure 6. Distribution of Hoop Stress [MPa] for the Case of Square Configuration Lining 
S, S22

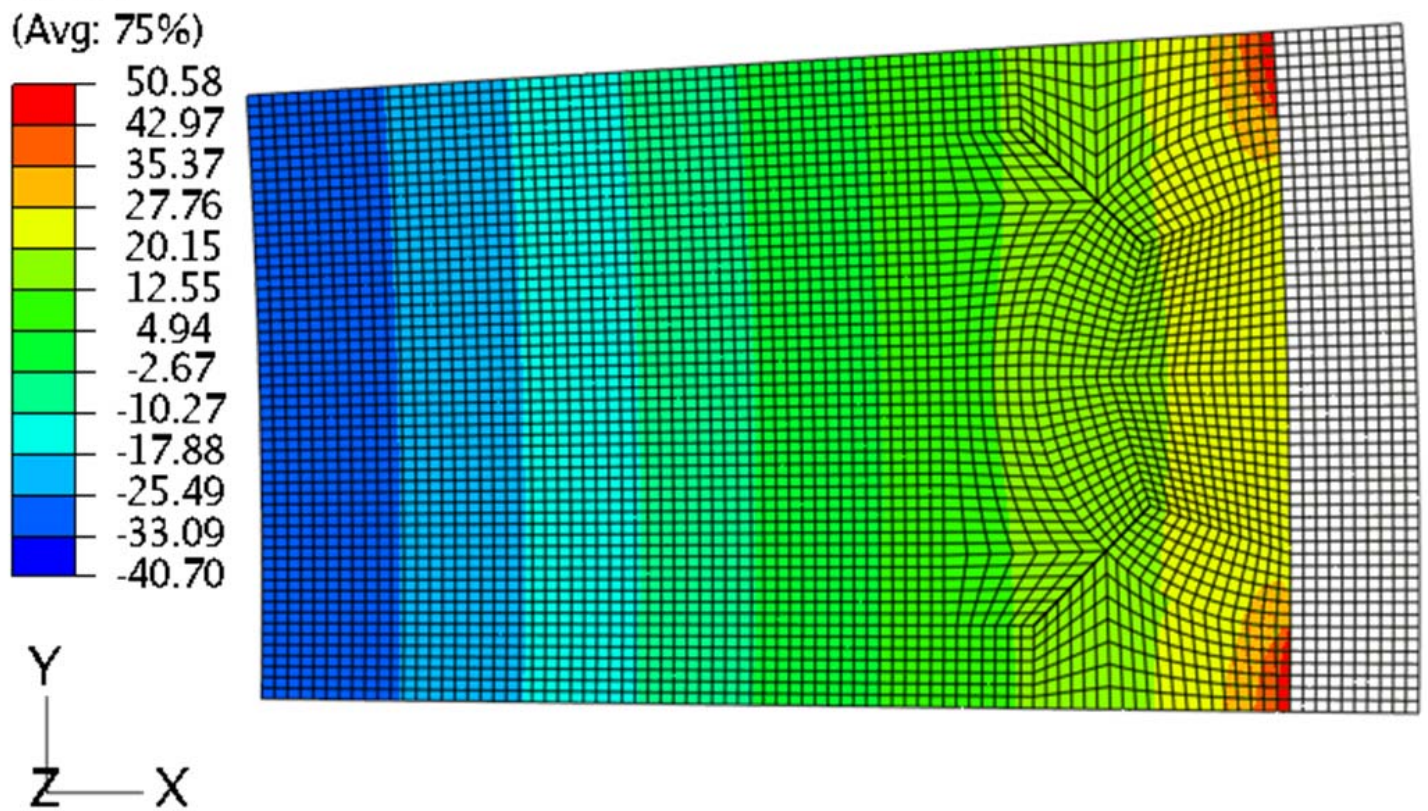

Figure 7. Distribution of Hoop Stress [MPa] for the Case of Round Configuration Lining

S, S22

(Avg: 75\%)

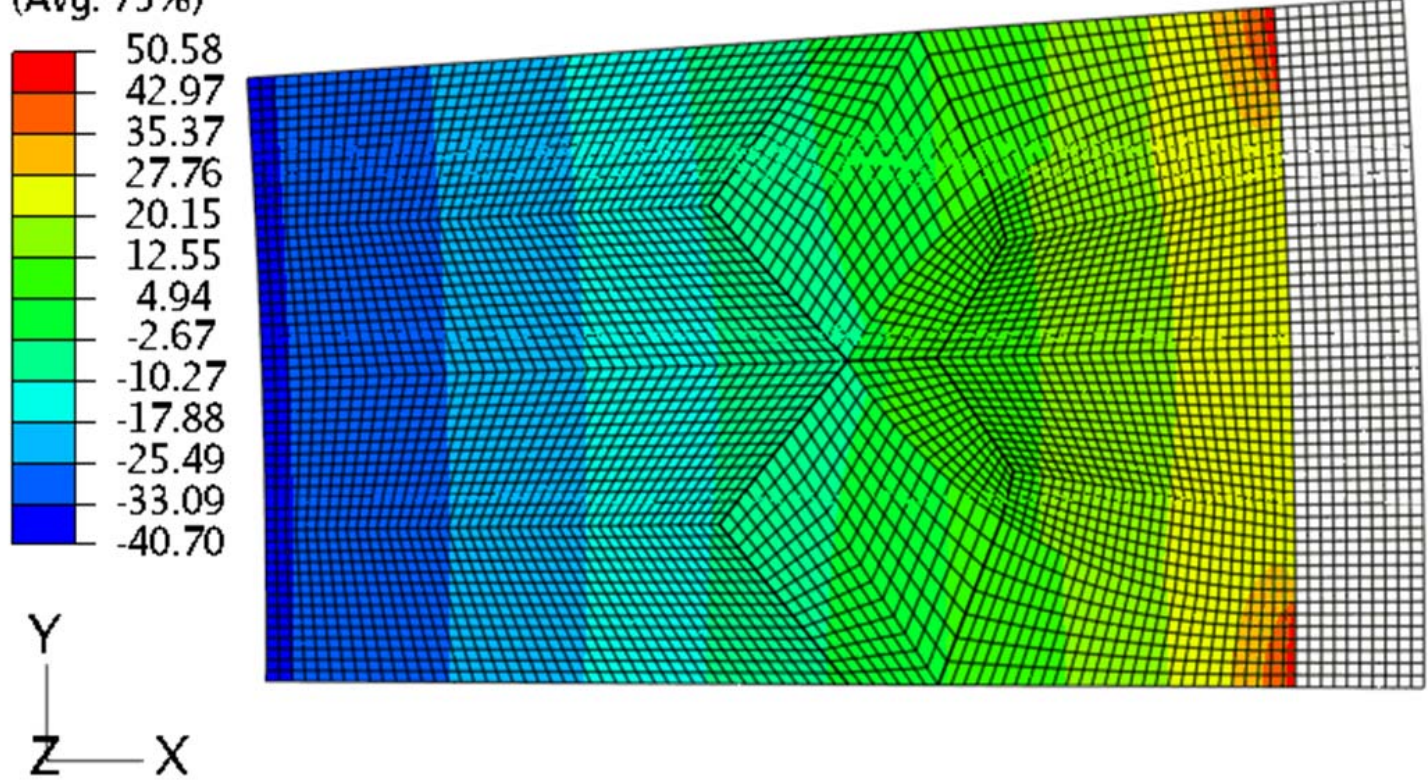

Figure 8. Distribution of Hoop Stress [MPa] for the Case of Arch Configuration Lining

The above models assumed a perfect bond at the interface between the different layers (hot face and backup lining, refractory and steel shell). Additional modeling was next performed in which the current model was changed to account for frictional sliding at these interfaces 
during the mechanical analyses, with a value of 0.1 for the coefficient of friction. However, these interfaces were considered to be in perfect contact for the thermal analyses. Simulations were performed for the standard design, and the designs with 84 squares, round arches and gothic arches for the backup lining.

Figure 9 shows the schematic and mesh used for the standard design. The corresponding temperature distribution is shown in Figure 10. The hoop stress distribution for the entire thickness under this case is shown in Figure 11 and for only in the refractory lining in Figure 12. Similar results are shown in Appendix 1 for the case with 84 squares, for the case with 84 round arches, and for the case with 84 gothic arches.

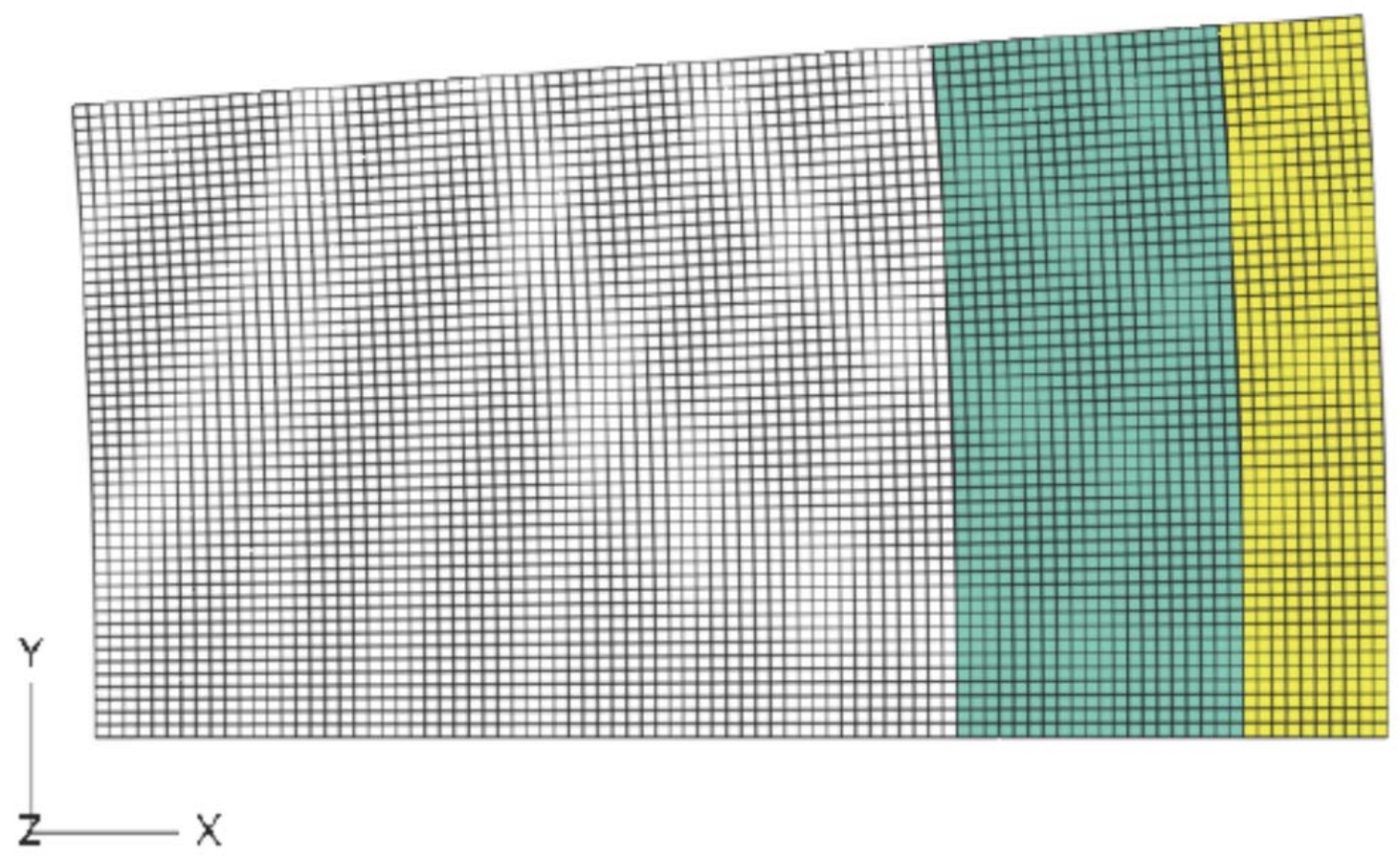

Figure 9. Schematic and Mesh for Standard Design 


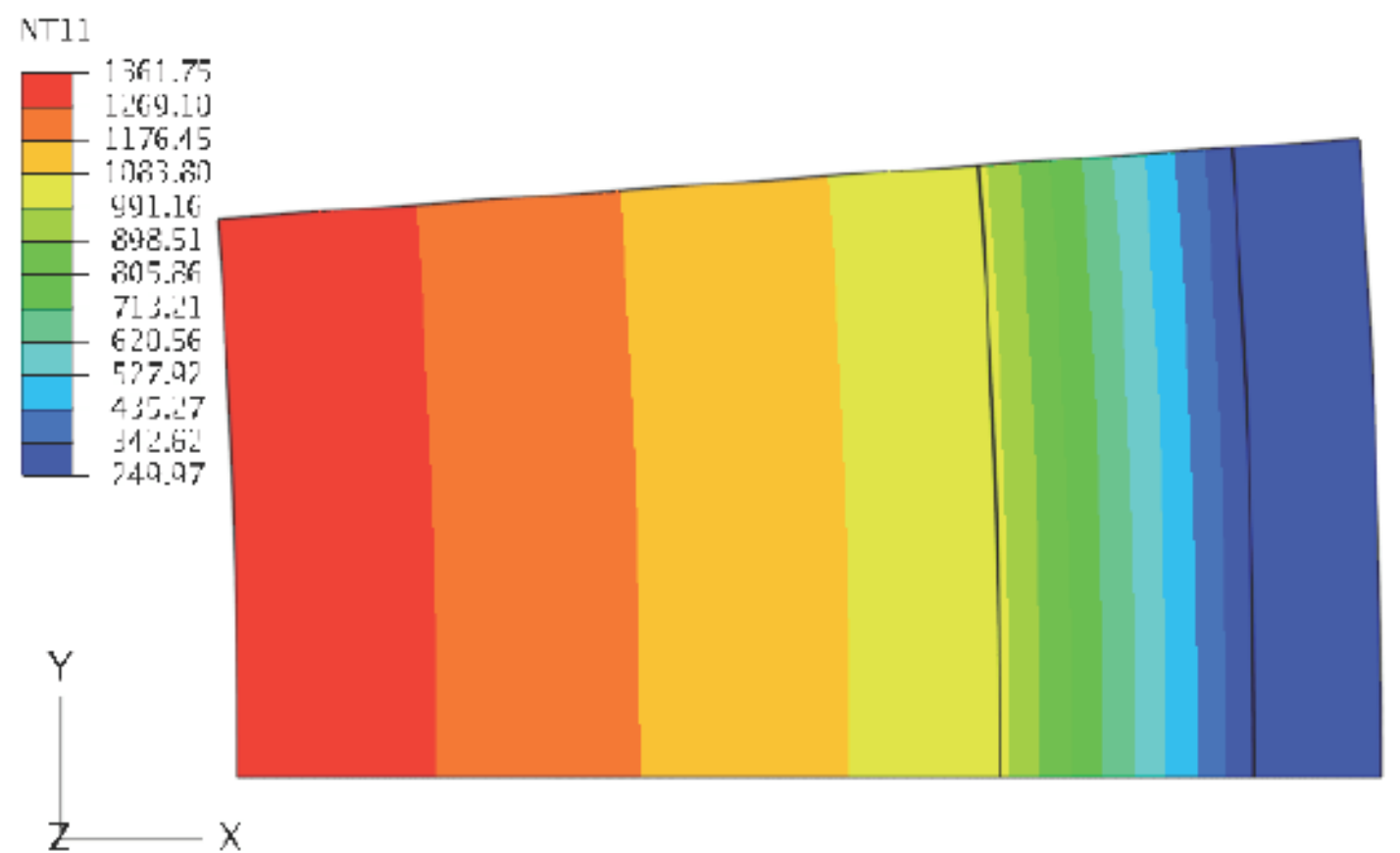

Figure 10. Distribution of Temperature $\left({ }^{\circ} \mathrm{C}\right)$ Under Operating Conditions for Standard Design

5,672

(Avg 75\%)
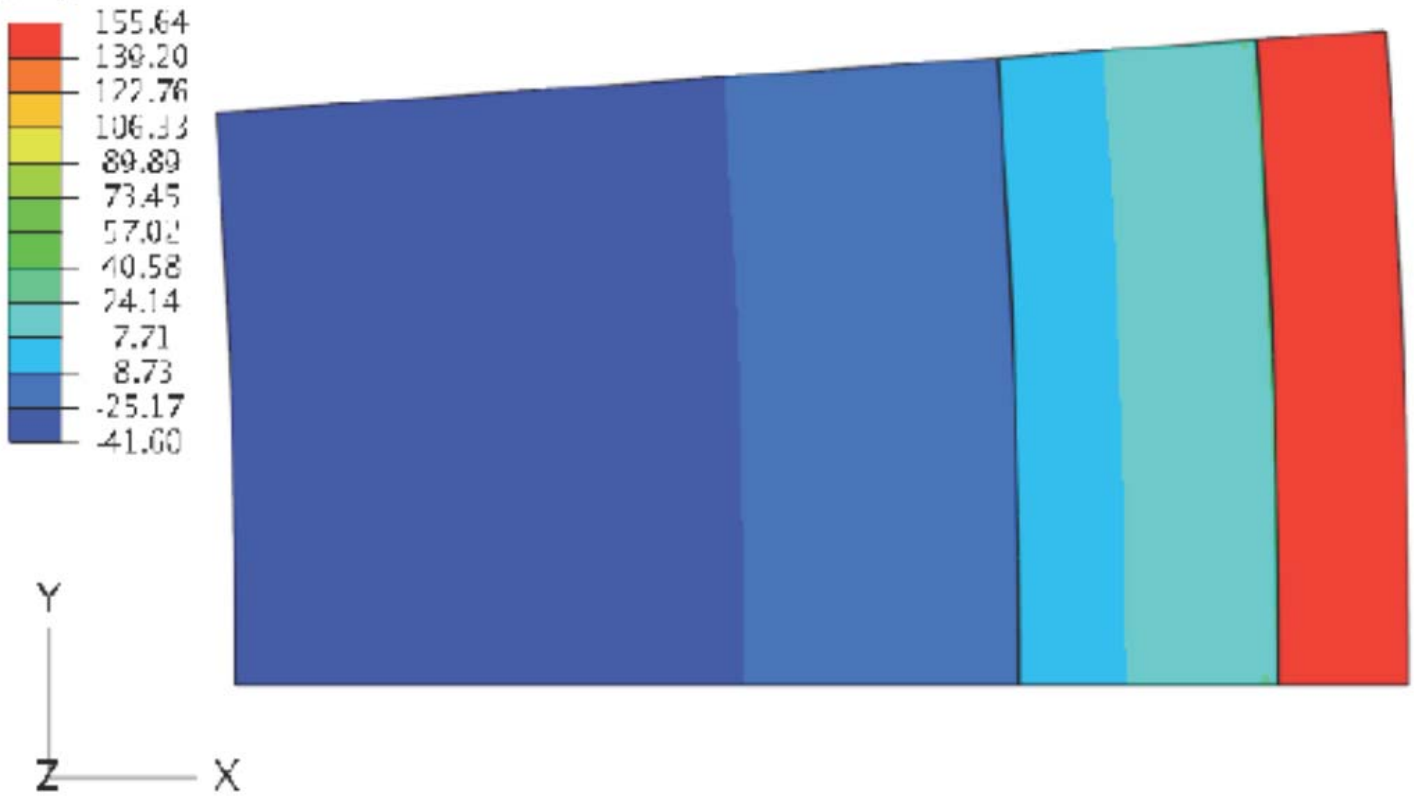

Figure 11. Distribution of Hoop Stress (MPa) Under Operating Conditions for Standard Design 


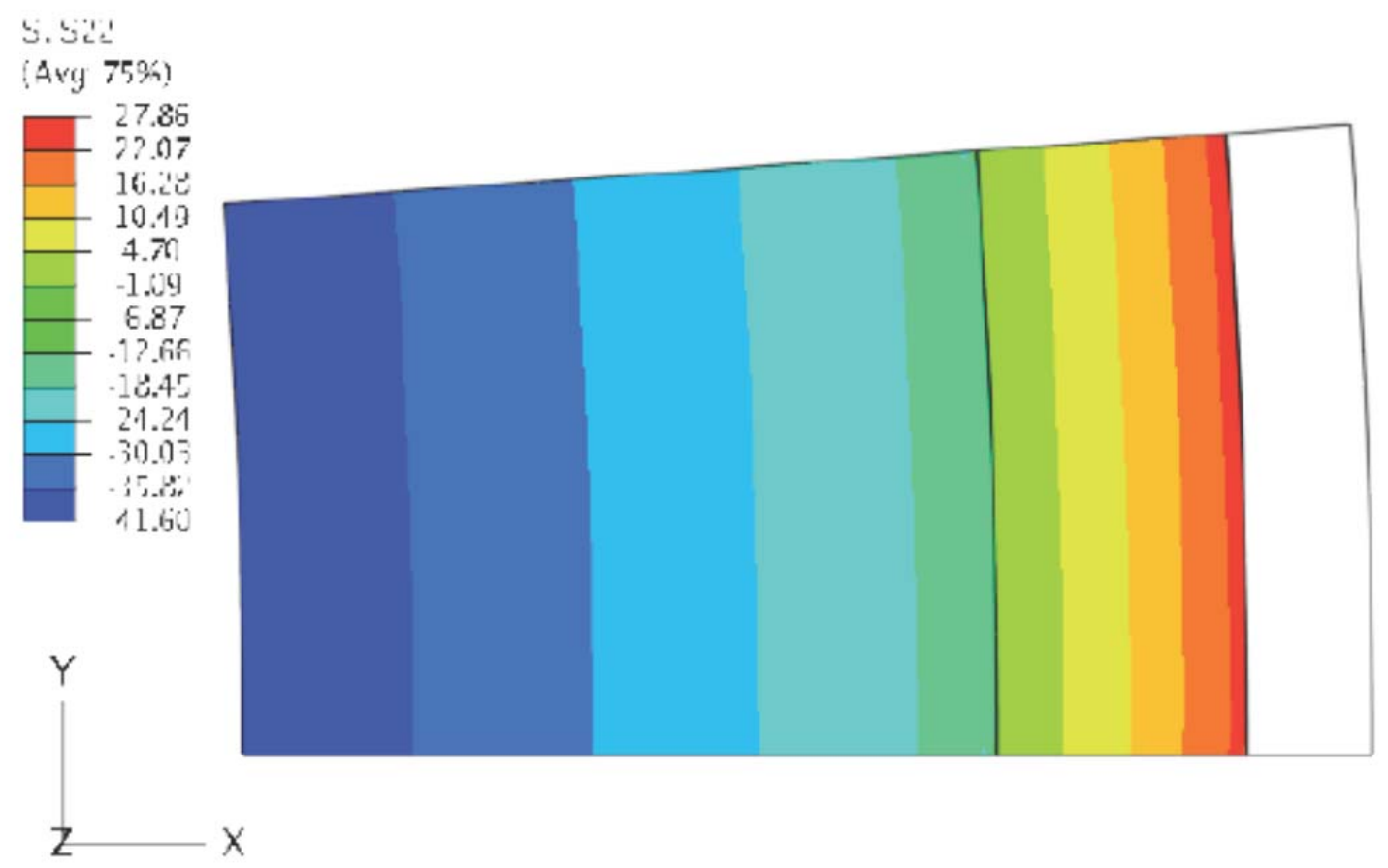

Figure 12. Distribution of Hoop Stress (MPa) in the Refractory Material Only Under Operating Conditions for Standard Design

For the standard design, the hoop stress is highest in tension at the OD of the steel shell $(155.64 \mathrm{MPa})$, and highest in compression at the ID of the hot face $(-41.6 \mathrm{MPa})$. Considering the stress distribution only in the refractory material, the highest tensile stress is at the OD of the backup lining (27.86 MPa). All of the alternate designs lead to a lower magnitude for the tensile hoop stress at the shell OD and compressive hoop stress at the hot face ID, compared to the standard design. The stress in the backup lining is also much lower for all of the alternate designs compared to the standard design. While the stress distributions for the cases with 84 squares and 84 gothic arches are quite comparable, the case with 84 round arches has the lowest tensile stress $(51.16 \mathrm{MPa})$ at the shell OD, but also a higher tensile stress $(30.73 \mathrm{MPa})$ at the crown of the arch in the hot face lining. Therefore, if one considers the lowest stress in the refractory lining to be of maximum importance, the design with the 84 gothic arches appears to be the most suitable.

Based on the operating issues and proposed research topics, as defined by the QFD analysis, and the information gained through the modeling discussed above, several refractory families and candidate materials were defined. These consisted of alumino-silicate, magnesia, and spinel forming systems, along with a family of light weight refractory backup materials. The actual materials developed are shown in Table 3. Further development and validation of these materials was carried out in the other tasks of the project, as described below. 
Table 3. Summary of Materials Developed Under Project

\begin{tabular}{|c|c|c|}
\hline Industry & Material & Application \\
\hline Aluminum & $\begin{array}{l}\text { Alumino-Silicate (A) } \\
\text { Alumino-Silicate (B) } \\
\text { Spinel Former (A) }\end{array}$ & $\begin{array}{l}\text { Primary lining } \\
\text { Repair material } \\
\text { Repair material } \\
\text { (alumina rich) }\end{array}$ \\
\hline Black Liquor & $\begin{array}{l}\text { Spinel Former (B) } \\
\text { Phosphate Bonded } \\
\text { Castable (A) }\end{array}$ & $\begin{array}{l}\text { Repair material } \\
\text { (magnesia rich) } \\
\text { Repair material } \\
\text { (magnesia rich) }\end{array}$ \\
\hline Coal Gasification & Spinel Former (C) & $\begin{array}{l}\text { Repair material } \\
\text { (alumina rich) }\end{array}$ \\
\hline Insulating Back-up & $\begin{array}{l}\text { Light Weight } \\
\text { Castable (A) }\end{array}$ & $\begin{array}{l}\text { Secondary lining } \\
\text { for spinel } \\
\text { material } \\
\text { applications } \\
\end{array}$ \\
\hline Lime Kiln & Spinel Former (B) & $\begin{array}{l}\text { Primary lining } \\
\text { (magnesia rich) }\end{array}$ \\
\hline
\end{tabular}

(note: letters A, B, C designate materials of same family, but different compositions)

The candidate application and processing techniques for these materials was defined as shotcreting. Experimental materials were produced and validated meeting Milestone/GoNo Go Decision Point 2.

Task 2 Identification of new materials and fundamental understanding of materials Work on this task continued at MS\&T throughout the life of the project to provide support for the development and production of the experimental refractory materials being developed. Work was focused on extending the fundamental understanding of the spinel microstructure and of spinel formation, along with the effects of microstructure and degree of formation on properties such as thermal expansion and refractoriness, density/porosity, thermal conductivity, and penetration/corrosion resistance. This work directly fed into the spinel forming refractory development which was on-going though out the duration of the project at MINTEQ.

A doctorate student at MS\&T, Kelley O'Hara, focused her efforts on this project and the understanding of the structural-property relationships in solid solutions with an emphasis on refractory oxide spinels. These included both regular spinels such as traditional aluminum spinel and similar structured materials and inverse spinels such as indium based-spinels and similar materials. Initial work focused on the preparation of spinel pellets as well as the identification of candidate oxide solutes for thermal conductivity evaluations. As another aspect of the project, she also explored the potential to produce a spinel-type refractory raw material with reduced thermal conductivity. Ideally, beneficial conductivity reductions would be realized without sacrificing the inherently attractive properties of the refractory oxide spinels. Thermal conductivity reductions were reported in the literature for magnesia with additions of nickel oxide incorporated via solid solution as is shown in Figure 13 where a 10 volume percent addition of nickel oxide reduced the thermal conductivity of the magnesia by nearly $80 \%$ at $200^{\circ} \mathrm{C}$ and by roughly $50 \%$ at $1000^{\circ} \mathrm{C}$. It was hypothesized that 
similar behavior may be possible for spinel systems with high mutual-solid-solubility. In that regard, magnesium aluminate spinel powder (Almatis, AR78 $0-0.2 \mathrm{~mm}$ ) was obtained to serve as the baseline for early investigations. Pellets were produced with varying additions of a secondary spinel (barium aluminate, e.g.) and evaluated for thermal conductivity using the laser flash technique.

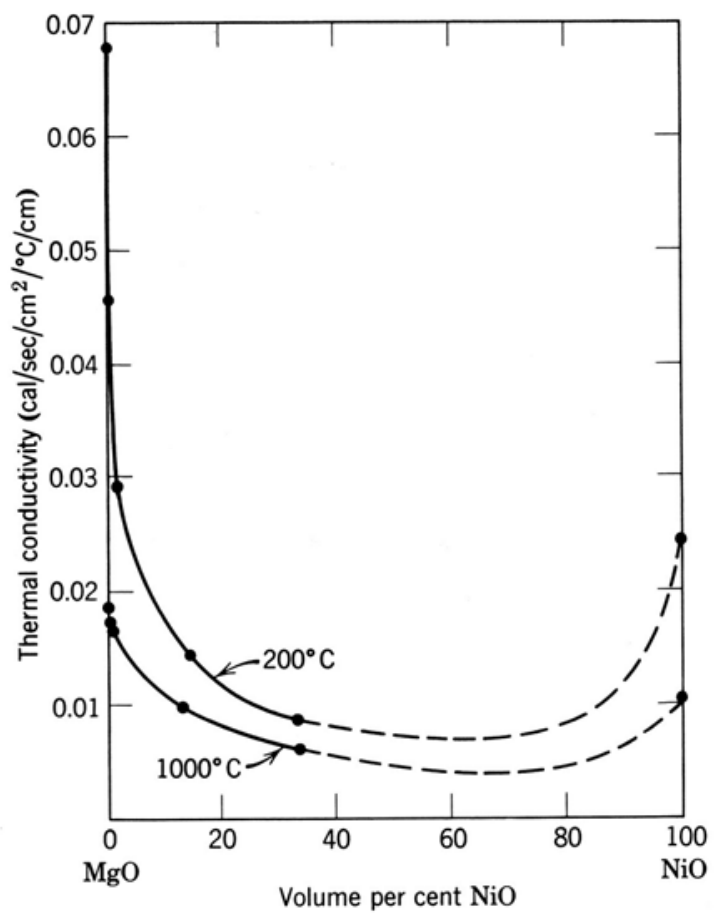

Figure 13. Thermal Conductivity in the MgO-NiO Solid Solution System. [After Kingery']

Work at MS\&T to identify materials having the spinel structure resulted in the compilation of a list of the known spinels, as well as a list of spinels based on a model by Burdett, Price, and Price ${ }^{\text {ii }}$. Further crystallographic analysis of the spinel structure was carried out to help determine different possible candidates to be mixed with $\mathrm{MgAl}_{2} \mathrm{O}_{4}$. The radius of the octahedral void was calculated based on the oxygen close packed structure and was found to be $0.547 \AA$. This is the smallest that the structure can be, which therefore represents the smallest cation that will fit in the octahedral site in the spinel structure. The radius of the tetrahedral void was also calculated based on the oxygen close packed structure and was found to be $0.297 \AA$. Similarly, this represents the smallest cation that will fit in the tetrahedral site in the spinel structure.

Based on the above analysis, $\mathrm{NiCr}_{2} \mathrm{O}_{4}$ was chosen for testing based on its high melting temperature, its easy accessibility, and its anticipated compatibility with $\mathrm{MgAl}_{2} \mathrm{O}_{4}$. Both $\mathrm{MgAl}_{2} \mathrm{O}_{4}$ and $\mathrm{NiCr}_{2} \mathrm{O}_{4}$ are normal spinels at room temperature. Samples were made at 0,1 , 2, 4, 8 , and $16 \mathrm{~mol} \% \mathrm{NiCr}_{2} \mathrm{O}_{4}$ and sintered at $1200^{\circ} \mathrm{C}, 1400^{\circ} \mathrm{C}$, and $1600^{\circ} \mathrm{C}$. Three samples for each composition/sintering temperature combination were tested. Also for preliminary

\footnotetext{
${ }^{i}$ W.D. Kingery, H.K. Bowen, and D.R. Uhlmann, Introduction to Ceramics. John Wiley \& Sons, Inc., (1976).

ii J.K. Burdett, G.D. Price, and S.L. Price, "Role of the Crystal-Field Theory in Determining the Structures of Spinels," Journal of the American Chemical Society, Vol. 104, Iss. 1, pp. 92-95, (1982).
} 
testing it was decided to use $\mathrm{MgAl}_{2} \mathrm{O}_{4}$ as a base material. Other aspects considered included the melting temperature of the spinel, the degree of inversion, environmental issues, and the compatibility with $\mathrm{MgAl}_{2} \mathrm{O}_{4}$. The original list was compiled by eliminating all spinels that did not have $\mathrm{Mg}$ or $\mathrm{Al}$ in the designated cation site. The final list of possible spinels is shown in Table 4. It can be seen in the table that one of the recommended materials was $\mathrm{MgCr}_{2} \mathrm{O}_{4}$. This material, although there are environmental concerns, was initially considered for testing because of its predicted ability to form solid solution with $\mathrm{MgAl}_{2} \mathrm{O}_{4}$ due to crystal structure and atom size. X-ray Diffraction (XRD) cards for these samples were also obtained to further compare microstructures in order to help predict solid solution formation. Each of the spinels in Table 4 were compared to $\mathrm{MgAl}_{2} \mathrm{O}_{4}$ by laying the XRD results over top of each other and it was noted that the XRD patterns are similar with varying peak intensities.

Table 4. List of Spinels with Mg or Al in the Designated Cation Site Cross-Referenced from Burdett, Price and Price and a Compilation of Known Spinels

\begin{tabular}{|l|l|}
\hline Normal Spinels & Inverse Spinels \\
\hline $\mathrm{MgCr}_{2} \mathrm{O}_{4}$ & $\mathrm{MgFe}_{2} \mathrm{O}_{4}$ \\
\hline $\mathrm{MgMn}_{2} \mathrm{O}_{4}$ & $\mathrm{Mgl} \mathrm{n}_{2} \mathrm{O}_{4}$ \\
\hline $\mathrm{CuAl}_{2} \mathrm{O}_{4}$ & $\mathrm{MgGa}_{2} \mathrm{O}_{4}$ \\
\hline $\mathrm{ZnAl}_{2} \mathrm{O}_{4}$ & \\
\hline $\mathrm{FeAl}_{2} \mathrm{O}_{4}$ & \\
\hline
\end{tabular}

Based on the above analysis, solid solutions of magnesia and alumina were studied at MS\&T. $\mathrm{MgO}$ samples were prepared with 1, 2, 4, and 8 mol. \% additions of $\mathrm{FeO}$ and $\mathrm{ZnO}$. $\mathrm{Al}_{2} \mathrm{O}_{3}$ samples were also prepared with $1,2,4$, and 8 mol. \% additions of $\mathrm{Ga}_{2} \mathrm{O}_{3}, \mathrm{Cr}_{2} \mathrm{O}_{3}$, and $\mathrm{Mn}_{2} \mathrm{O}_{3}$. These samples were sintered at $800,900,1000,1100,1200$, and $1300^{\circ} \mathrm{C}$ for one hour. A pre- and post-sintering picture of the samples is shown in Figure 14. It can be noted particularly in the $\mathrm{MgO}+\mathrm{FeO}, \mathrm{Al}_{2} \mathrm{O}_{3}+\mathrm{Cr}_{2} \mathrm{O}_{3}$, and $\mathrm{Al}_{2} \mathrm{O}_{3}+\mathrm{Mn}_{2} \mathrm{O}_{3}$ samples that the color changes upon sintering. Obvious change in color occurred at $1100^{\circ} \mathrm{C}$. XRD was performed on all of the samples made. Solid solution formation was expected to be seen, particularly at higher temperatures. Representative XRD patterns at $800^{\circ} \mathrm{C}$ and $1300^{\circ} \mathrm{C}$ are shown in Figure 15. It can be seen that there is no apparent shift in the peaks at either temperature, indicating no solid solutions were actually formed.

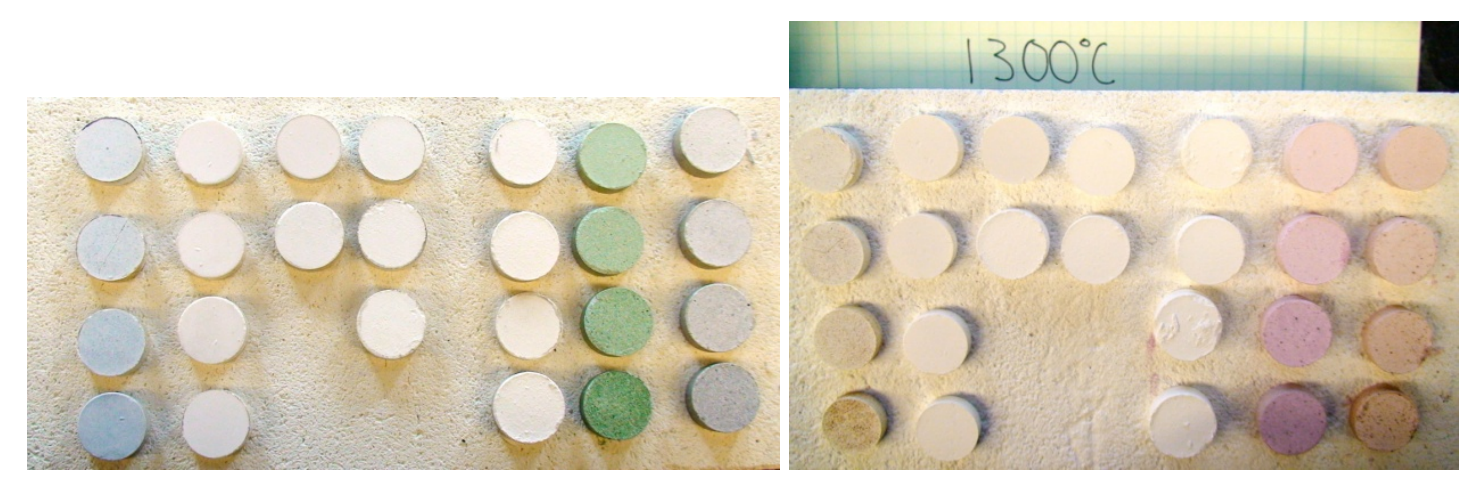

Figure 14. Pre- and Post-Sintering Pictures $\mathrm{MgO}$ Samples with Various Additions of $\mathrm{FeO}$ and $\mathrm{ZnO}$ and $\mathrm{Al}_{2} \mathrm{O}_{3}$ Samples with Various Additions of $\mathrm{Ga}_{2} \mathrm{O}_{3}, \mathrm{Cr}_{2} \mathrm{O}_{3}$, and $\mathrm{Mn}_{2} \mathrm{O}_{3}$ 

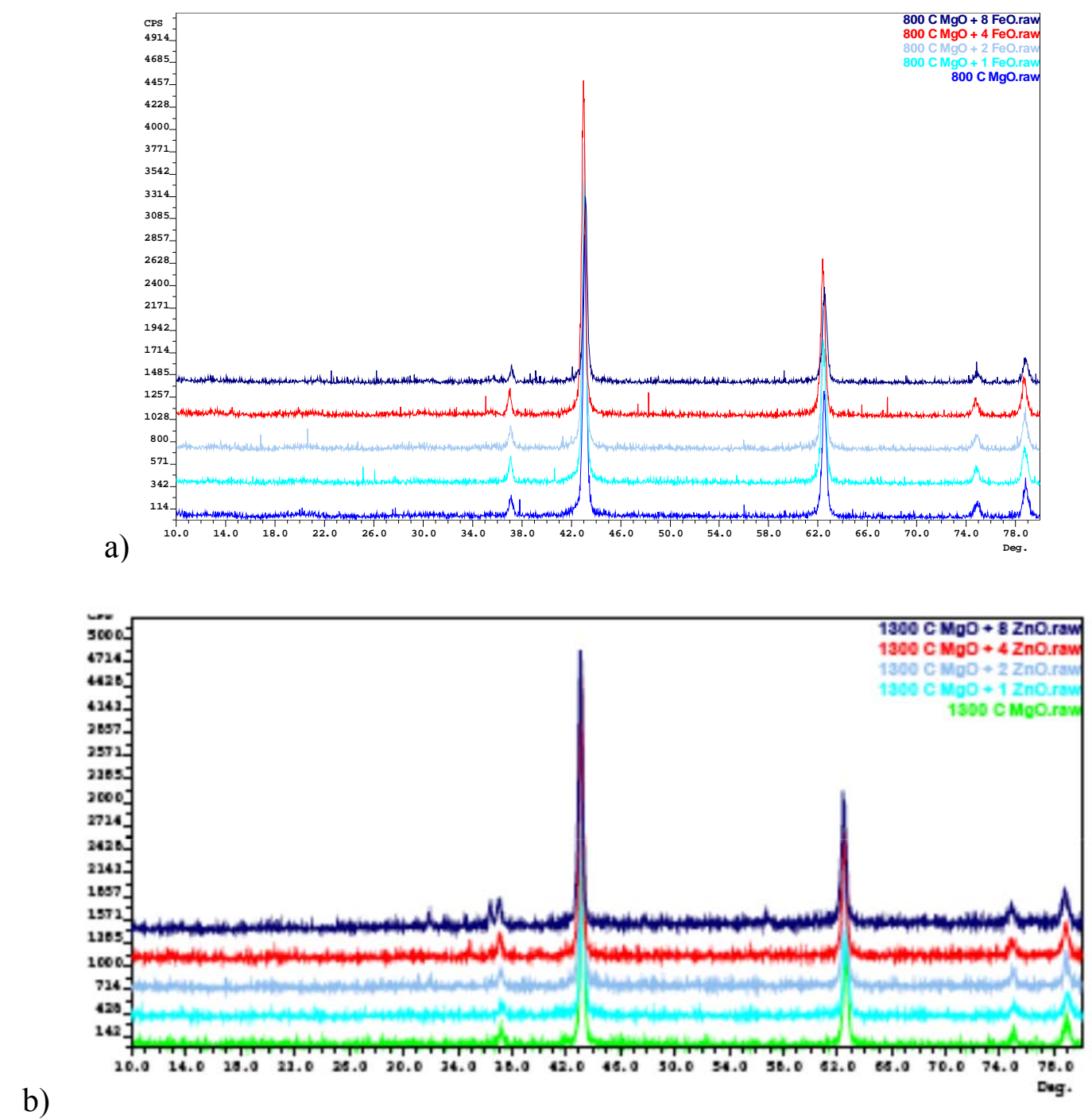

Figure 15. Representative XRD Patterns at $800^{\circ} \mathrm{C}$ (a) and $1300^{\circ} \mathrm{C}(\mathrm{b})$ Indicating No Solid Solution Formation

Attempts were also made to produce $\mathrm{MgCr}_{2} \mathrm{O}_{4}$ from $\mathrm{MgO}$ and $\mathrm{Cr}_{2} \mathrm{O}_{3}, \mathrm{MgGa}_{2} \mathrm{O}_{4}$ from $\mathrm{MgO}$ and $\mathrm{Ga}_{2} \mathrm{O}_{3}, \mathrm{MgMn}_{2} \mathrm{O}_{4}$ from $\mathrm{MgO}$ and $\mathrm{Mn}_{2} \mathrm{O}_{3}, \mathrm{FeAl}_{2} \mathrm{O}_{4}$ from $\mathrm{FeO}$ and $\mathrm{Al}_{2} \mathrm{O}_{3}, \mathrm{ZnAl}_{2} \mathrm{O}_{4}$ from $\mathrm{ZnO}$ and $\mathrm{Al}_{2} \mathrm{O}_{3}$, and $\mathrm{MgAl}_{2} \mathrm{O}_{4}$ from $\mathrm{MgO}$ and $\mathrm{Al}_{2} \mathrm{O}_{3}$. These samples were produced at $1600^{\circ} \mathrm{C}$ with a 13 hour hold, and then cooled at $300^{\circ} \mathrm{C} / \mathrm{hr} . \mathrm{MgCr}_{2} \mathrm{O}_{4}, \mathrm{MgGa}_{2} \mathrm{O}_{4}$, and $\mathrm{ZnAl}_{2} \mathrm{O}_{4}$ were successfully produced through these tests. The $\mathrm{MgO}-\mathrm{Mn}_{2} \mathrm{O}_{3}$ sample produced $\mathrm{MgMn}_{2} \mathrm{O}_{4}$, however, it was observed that there was still $\mathrm{MgO}$ left over, which can be seen in the XRD pattern shown in Figure 16. The $\mathrm{MgO}-\mathrm{Al}_{2} \mathrm{O}_{3}$ sample also produced $\mathrm{MgAl}_{2} \mathrm{O}_{4}$, but not to completion, as both $\mathrm{MgO}$ and $\mathrm{Al}_{2} \mathrm{O}_{3}$ was present in the final sample. The $\mathrm{FeO}-$ $\mathrm{Al}_{2} \mathrm{O}_{3}$ sample oxidized to form $\mathrm{AlFeO}_{3}$ and $\mathrm{Al}_{2} \mathrm{O}_{3}$, which could be expected without using a controlled atmosphere. 


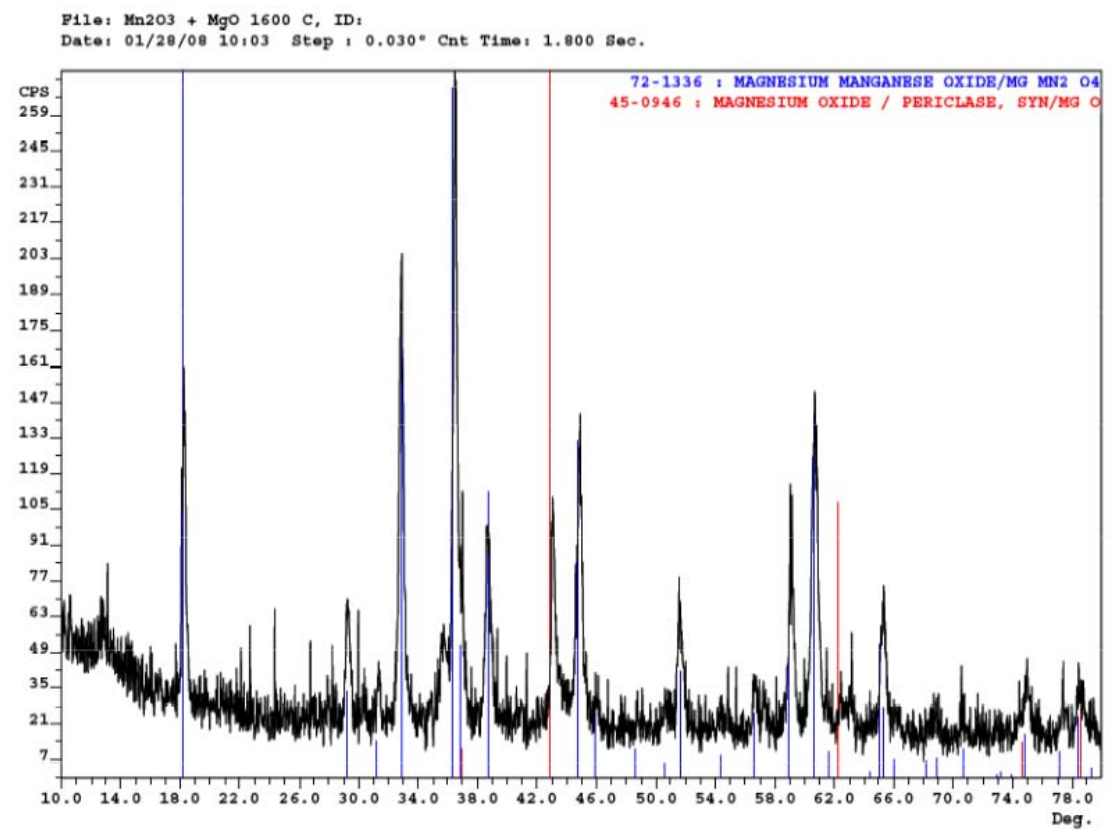

Figure 16. XRD Pattern for $\mathrm{MgMn}_{2} \mathrm{O}_{4}$ Sample Showing Presence of Residual MgO

Based on the results presented above, polycrystalline diffusion couple studies were performed. Couples between high purity $\mathrm{MgO}$ and $\mathrm{Al}_{2} \mathrm{O}_{3}, \mathrm{MgO}$ provided by MINTEQ and varying $\mathrm{Al}_{2} \mathrm{O}_{3}$, as well as $\mathrm{MgO}$ and $\mathrm{Al}_{2} \mathrm{O}_{3}$ with different dopants were studied. The first test was run with high purity $\mathrm{MgO}$ and $\mathrm{Al}_{2} \mathrm{O}_{3}$ at $1700^{\circ} \mathrm{C}$ for 120 hours, followed by cooling to room temperature as an extreme case in hopes of seeing the formation of a solid solution. This test was then used as a base to determine the rest of the times and temperatures for the study.

The powders used for the initial couples were a $10 \mu \mathrm{m} \mathrm{MgO}$ and $0.4 \mu \mathrm{m} \mathrm{Al}_{2} \mathrm{O}_{3}$. The first test run was performed with no added pressure to the couple. After processing, it was seen that spinel formation only occurred at the center of the couple. This was likely caused by the volume expansion that accompanies spinel formation. Additionally, it was apparent that inter-diffusion occurs between $\mathrm{Al}_{2} \mathrm{O}_{3}$ and $\mathrm{MgO}$, but the two pellets do not stay together. There was also the presence of what appears to be a fracture surface between the spinel layer that forms and the $\mathrm{MgO}$.

The following three images are from one of the original couples made. Figure 17 is a basic Scanning Electron Microscopy (SEM) image of the $\mathrm{Al}_{2} \mathrm{O}_{3}$ pellet. It can be seen at the top of the image that there is a layer formed on top of the polished $\mathrm{Al}_{2} \mathrm{O}_{3}$ pellet. Figure 18 and Figure 19 are SEM images incorporating Energy Dispersive Spectroscopy (EDS) image maps showing the location of the aluminum and magnesium, respectively. This is positive evidence that inter-diffusion was occurring. 


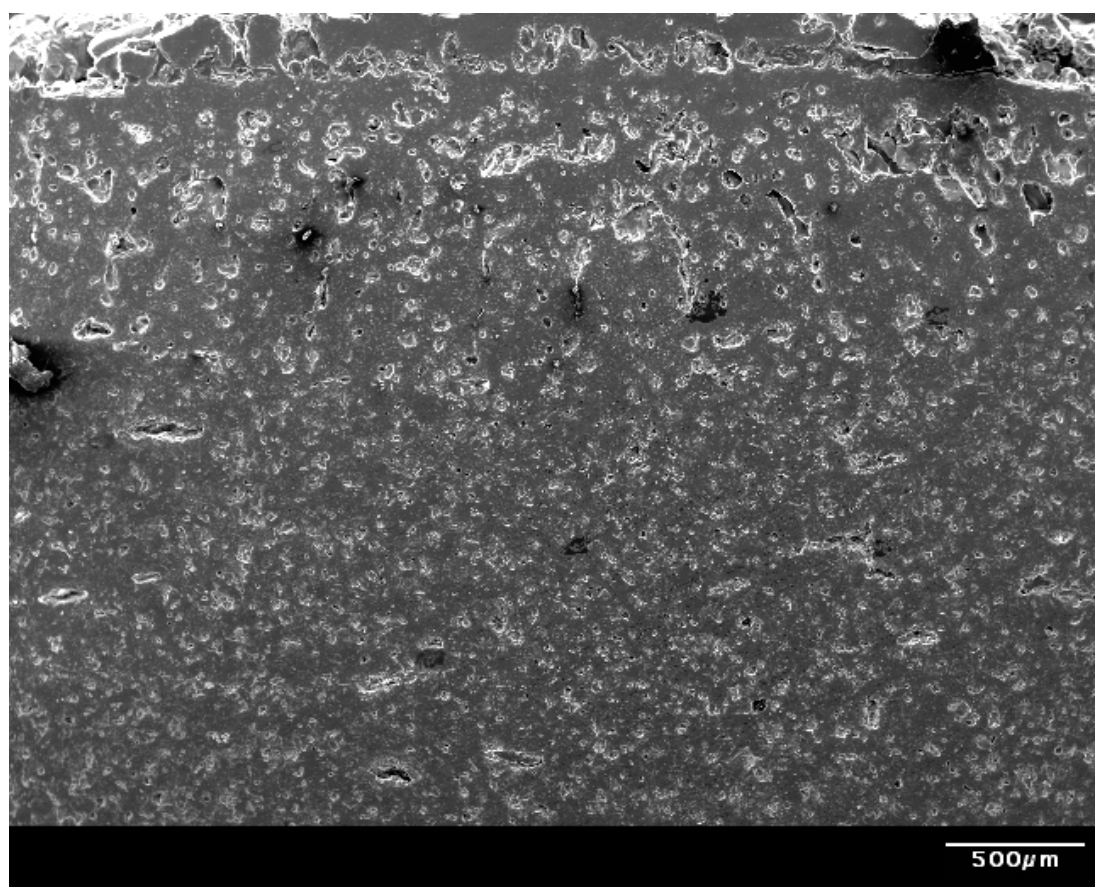

Figure 17. SEM Image of $\mathrm{Al}_{2} \mathrm{O}_{3}$ Pellet

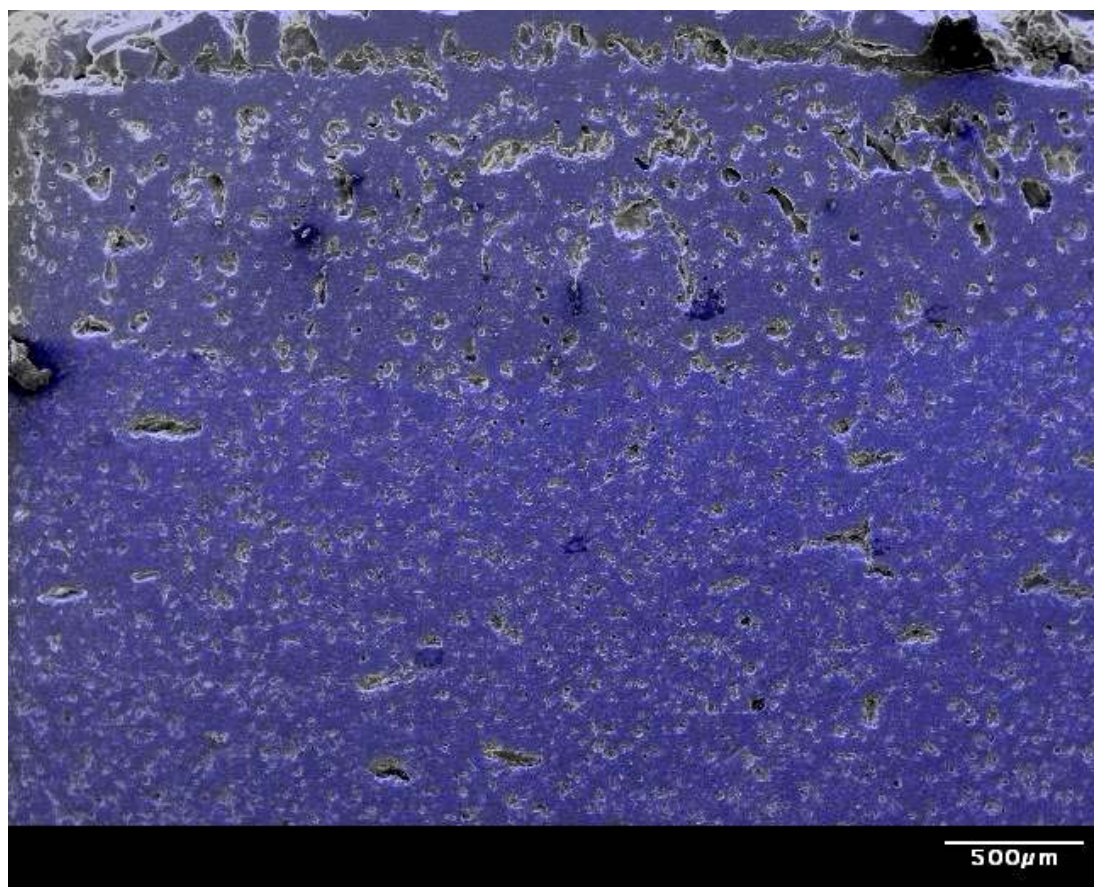

Figure 18. SEM/EDS Image of $\mathrm{Al}_{2} \mathrm{O}_{3}$ Pellet Showing Location of Aluminum 


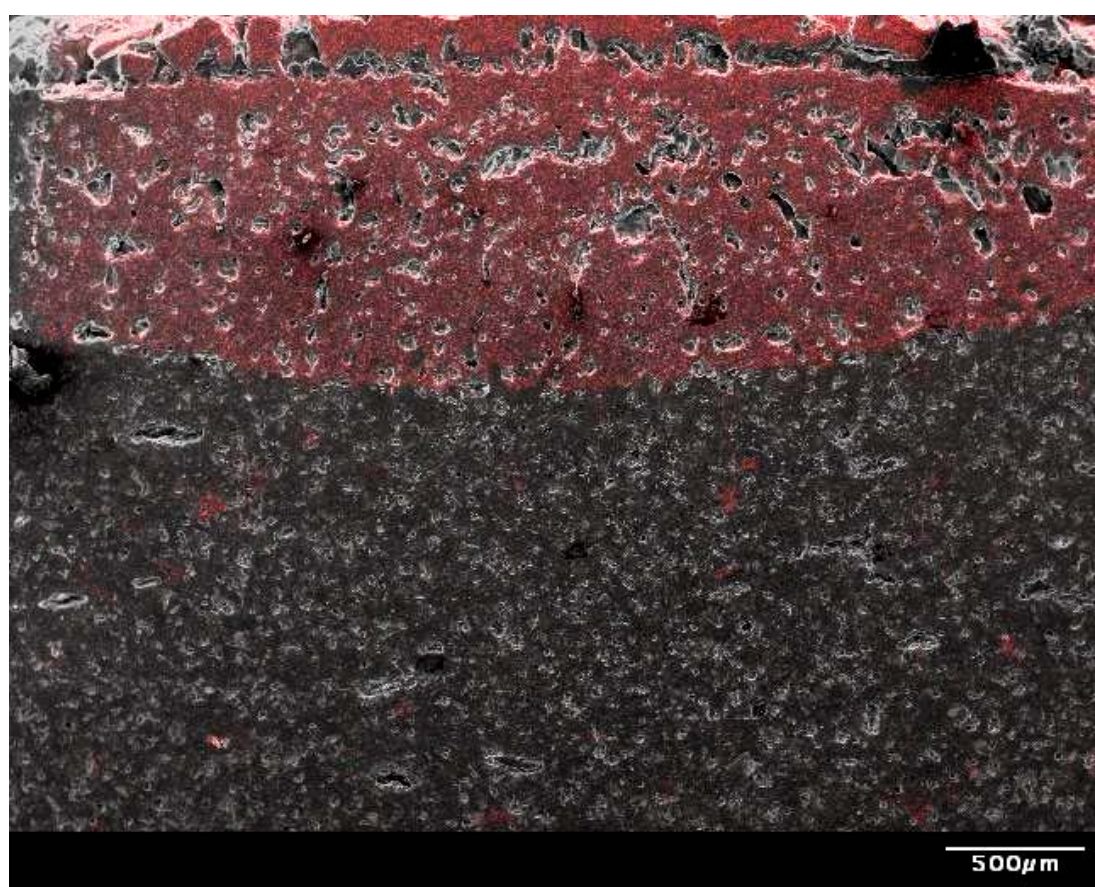

Figure 19. SEM/EDS Image of $\mathrm{Al}_{2} \mathrm{O}_{3}$ Pellet Showing Location of Magnesium

Further SEM/EDS was performed on this sample in two different locations to generate elemental plot patterns. Figure 20 and Figure 21 show the locations of the additional SEM/EDS (red cross hairs on SEM image inset) and the present oxides for each location. The $\mathrm{MgO}$ and $\mathrm{Al}_{2} \mathrm{O}_{3}$ content found in Figure 20 were calculated to be $30 \mathrm{wt} \%$ and $70 \mathrm{wt} \%$, respectively. The $\mathrm{MgO}$ and $\mathrm{Al}_{2} \mathrm{O}_{3}$ content found in Figure 21 were calculated to be $20 \mathrm{wt} \%$ and $80 \mathrm{wt} \%$, respectively.

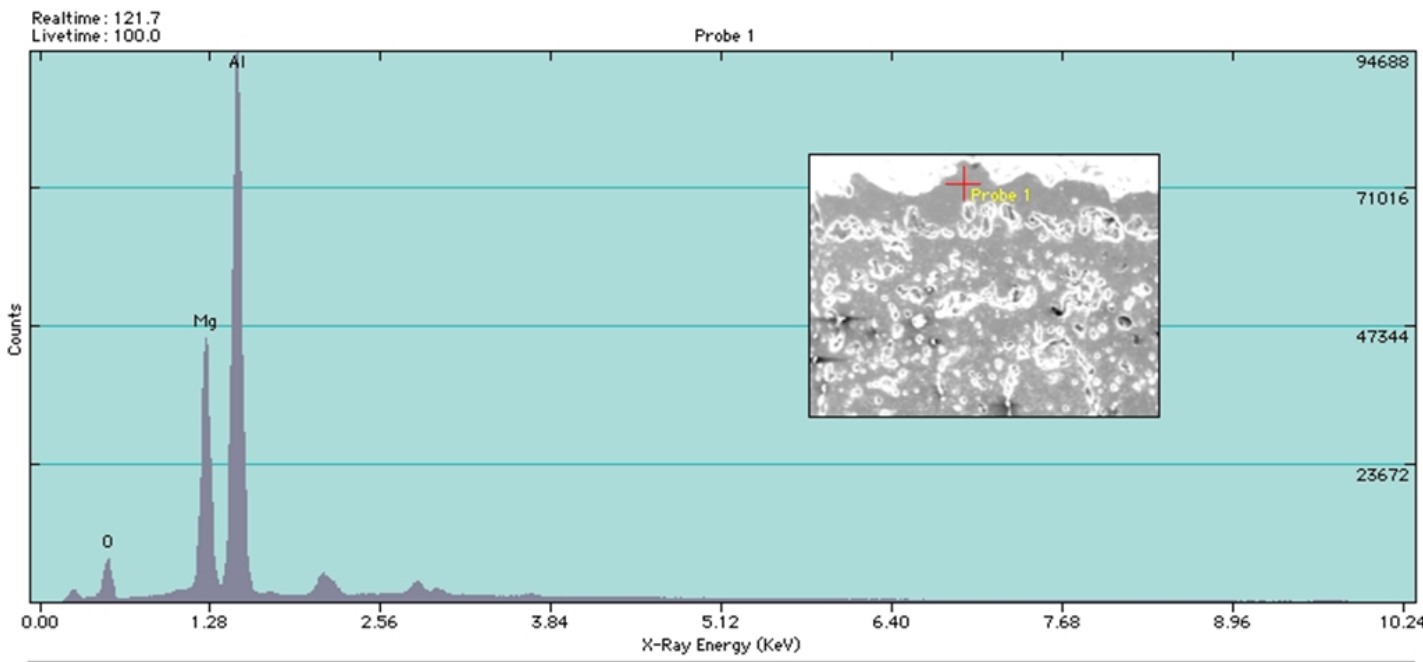

Quantitative Results for Probe

Analysis: Thin Film Method: Standardless

Acquired 02-0ct-2008, $15.0 \mathrm{KeV} @ 10 \mathrm{eV} /$ channel

Figure 20. Pattern Resulting from SEM/EDS Performed on Top Layer of Formed Spinel Layer 


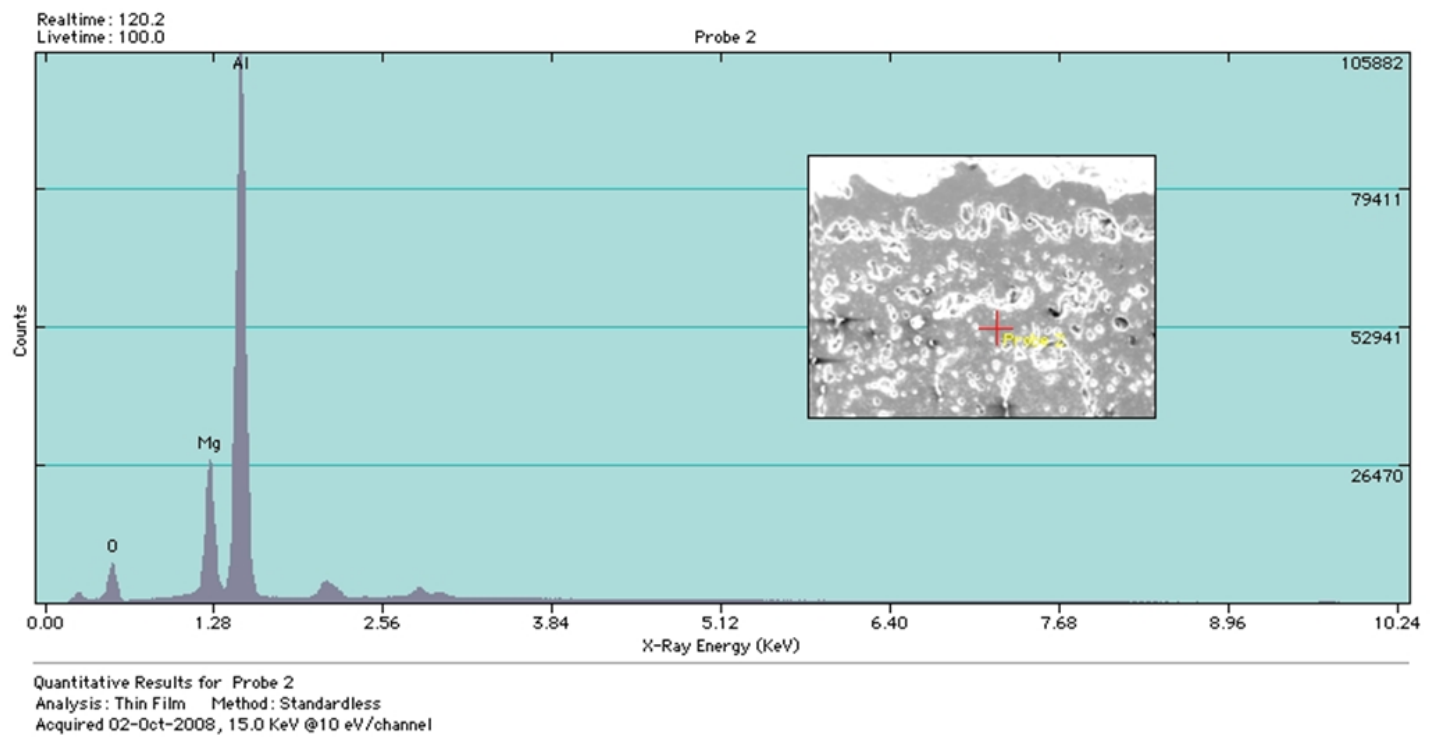

Figure 21. Pattern Resulting from SEM/EDS Performed on Bottom Layer of Formed Spinel Layer

In the next test, pure $\mathrm{MgO}$ powder and pure $\mathrm{Al}_{2} \mathrm{O}_{3}$ powder (both supplied by MINTEQ) was dry pressed with small binder additions at $12,000 \mathrm{psi}$, and then isostatically pressed at $30,000 \mathrm{lbs}$. The samples were then sintered at $1650^{\circ} \mathrm{C}$ for 4 hours and polished to a $0.25 \mu \mathrm{m}$ diamond finish. The pellets were then coupled together beneath dense $\mathrm{Al}_{2} \mathrm{O}_{3}$ for added pressure and sintered at $1700^{\circ} \mathrm{C}$ for 120 hours. There was no adherence found between the couple, so each sample was individually mounted in epoxy. The samples were then cut in half and polished to $0.25 \mu \mathrm{m}$ diamond finish for analysis.

The $\mathrm{Al}_{2} \mathrm{O}_{3}$ pellet was polished and imaged using the SEM and secondary electron imaging to obtain a focused quality image, which can be seen in Figure 22. A backscattered electron image was also obtained in hopes of being able to further distinguish between different phases. However, since Mg and Al have very similar bonding energies it was not possible to distinguish between the two as can be seen in Figure 23. 


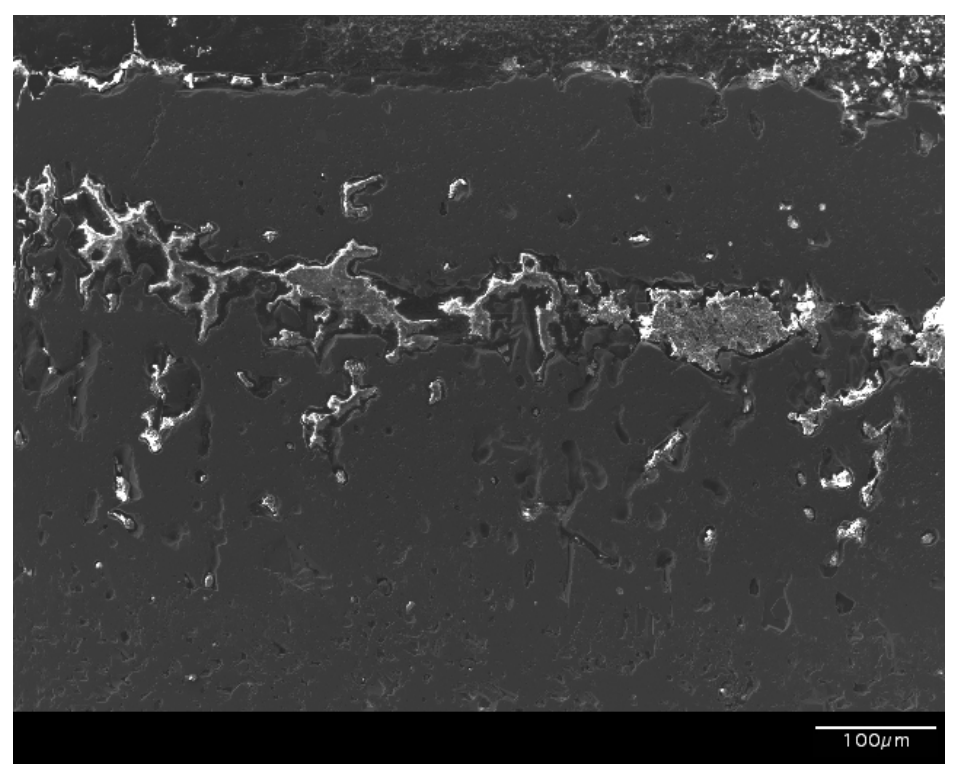

Figure 22. Secondary Electron Image of $\mathrm{Al}_{2} \mathrm{O}_{3}$ Pellet after Diffusion Study

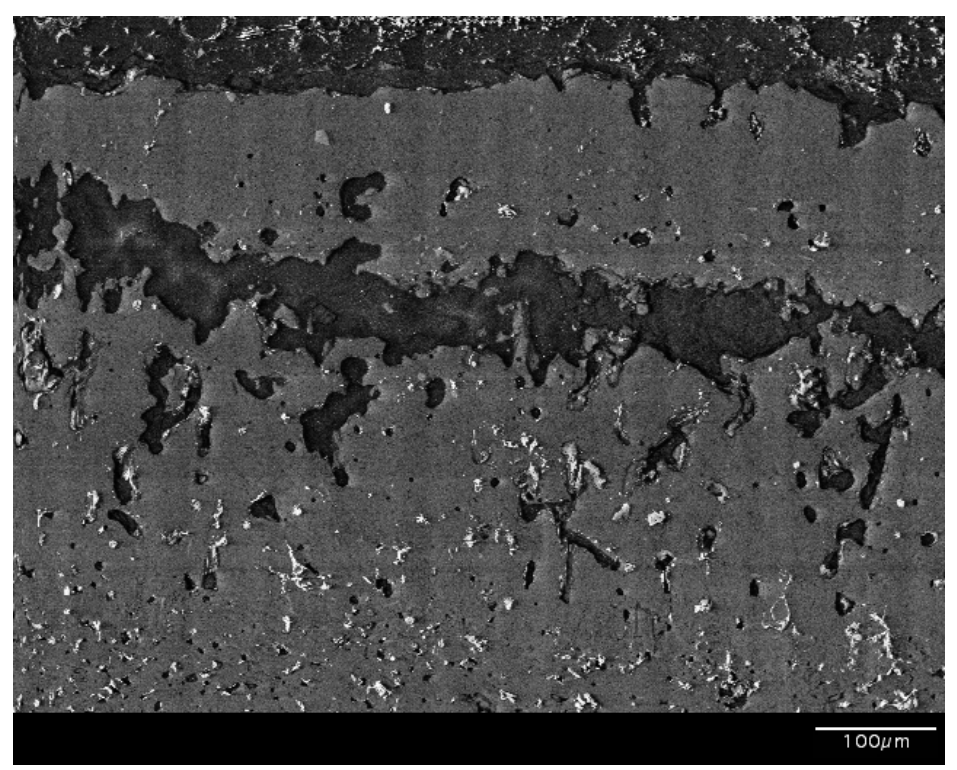

Figure 23. Backscattered Electron Image of $\mathrm{Al}_{2} \mathrm{O}_{3}$ Pellet after Diffusion Study

Pure $\mathrm{MgO}$ and $\mathrm{Al}_{2} \mathrm{O}_{3}$ were used for standards for EDS analysis, and were processed under the same conditions described above. After processing, the $\mathrm{MgO}$ and $\mathrm{Al}_{2} \mathrm{O}_{3}$ pellets were not joined together; however there was a porous layer present in the $\mathrm{Al}_{2} \mathrm{O}_{3}$ sample between the two distinct diffusion layers, which can be seen in Figure 24. It was observed that there was an indention in the $\mathrm{MgO}$ pellet, indicating a sort of fracture surface between the spinel forming layer and $\mathrm{MgO}$. Additionally, upon observation of the $\mathrm{MgO}$ pellet in the SEM there was no $\mathrm{Al}_{2} \mathrm{O}_{3}$ present. It is known that the molar volume of spinel is $39.76 \mathrm{~cm}^{3} / \mathrm{mol}, \mathrm{MgO}$ is $11.24 \mathrm{~cm}^{3} / \mathrm{mol}$, and $\mathrm{Al}_{2} \mathrm{O}_{3}$ is $25.58 \mathrm{~cm}^{3} / \mathrm{mol}$. With such a large volume difference between $\mathrm{MgO}$ and spinel the fracture surface is not surprising. 


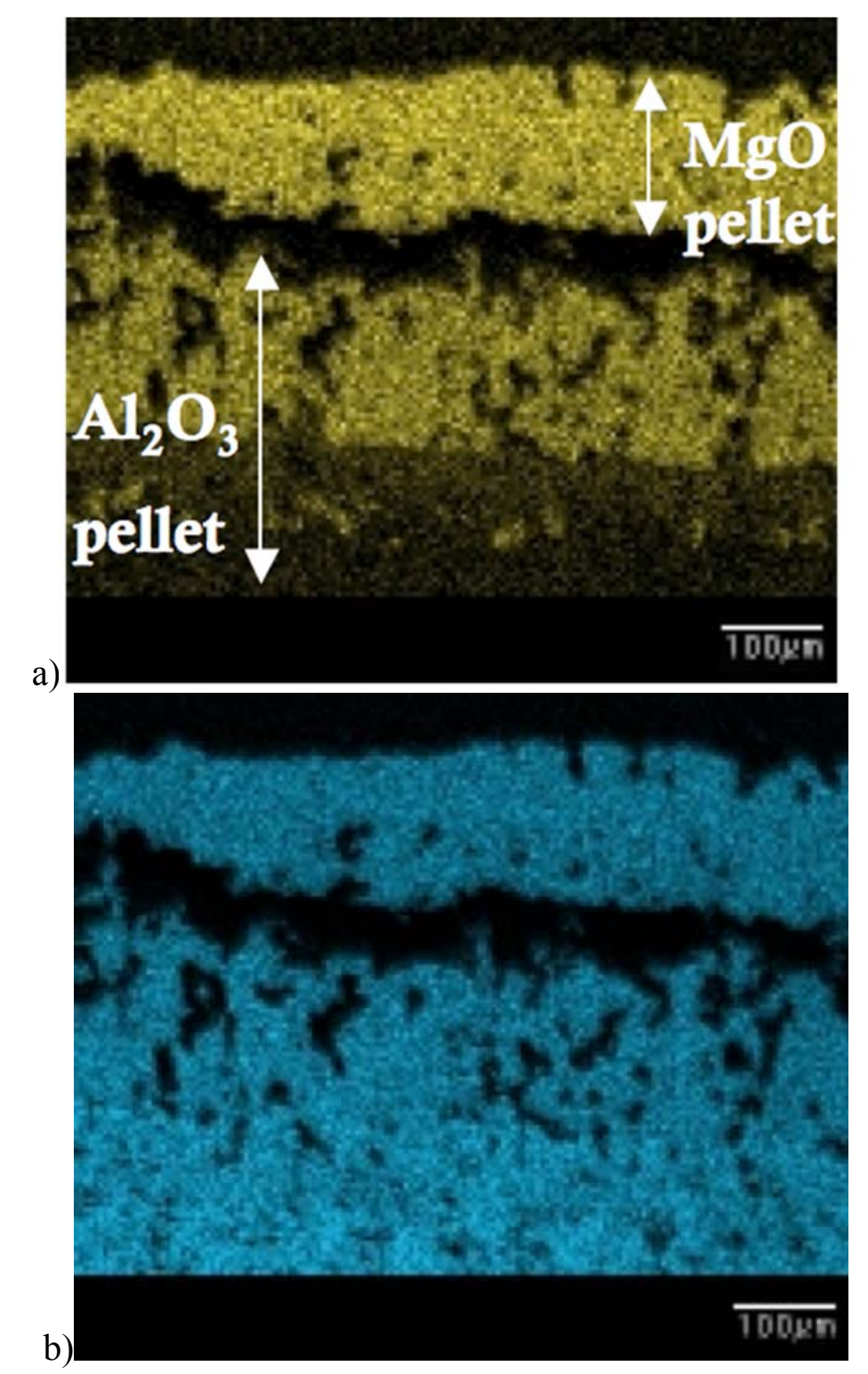

Figure 24. Phase Maps from EDS Analysis of $\mathrm{Al}_{2} \mathrm{O}_{3}$ Pellets Showing Diffusion Layers (a - Mg, b - Al)

After processing, it can be seen that there was inter-diffusion that occurred between the $\mathrm{Al}_{2} \mathrm{O}_{3}$ and $\mathrm{MgO}$. Analysis of the SEM image showed $\mathrm{MgO}$ diffused into the $\mathrm{Al}_{2} \mathrm{O}_{3}$ approximately $170 \pm 20 \mu \mathrm{m}$ and $\mathrm{Al}_{2} \mathrm{O}_{3}$ diffused into the $\mathrm{MgO}$ approximately $150 \pm 10 \mu \mathrm{m}$. Additionally, EDS analysis was performed throughout the sample layer to see the variation in concentration, as seen in Figure 25. The analysis was performed both with and without standards, and is reported in Table 5. 


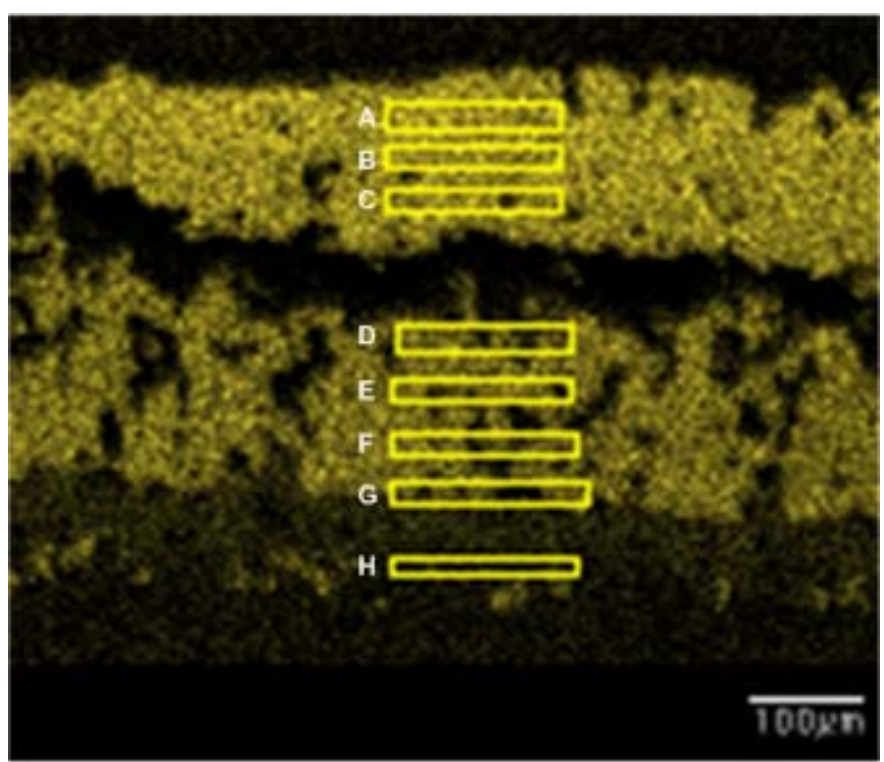

Figure 25. Phase Maps from EDS Analysis of $\mathrm{Al}_{2} \mathrm{O}_{3}$ Pellets Showing Diffusion Layers

Table 5. Relative Amounts of $\mathrm{MgO}$ and $\mathrm{Al}_{2} \mathrm{O}_{3}$ as Calculated with EDS

\begin{tabular}{|cc|c|c|c|}
\hline & \multicolumn{3}{c}{ MgO (wt\%) } & \multicolumn{2}{c|}{ Al2O3 (wt\%) } \\
Standard & Standardless & \multicolumn{1}{c|}{ Standard } & Standardless \\
A & 31 & 27 & 69 & 73 \\
B & 30 & 25 & 71 & 75 \\
C & 29 & 25 & 71 & 75 \\
D & 22 & 19 & 78 & 81 \\
E & 23 & 20 & 77 & 80 \\
F & 22 & 19 & 78 & 82 \\
G & 15 & 13 & 85 & 87 \\
H & 3 & 2 & 97 & 98 \\
\hline
\end{tabular}

Following the diffusion couple study, $\mathrm{MgAl}_{2} \mathrm{O}_{4}$ (spinel) was prepared using a co-precipitate method from $\mathrm{MgCl}_{2}-6 \mathrm{H}_{2} \mathrm{O}$ and $\mathrm{AlCl}_{3}-6 \mathrm{H}_{2} \mathrm{O}$ (FisherScientic). The chlorides were dissolved in distilled water and mixed stoichiometrically. The mixture was heated to $60^{\circ} \mathrm{C}$ and stirred at a controlled rate. Ammonium hydroxide was added to the solution until a $\mathrm{pH}$ between 9 and 10 was reached. The precipitate was maintained at a $\mathrm{pH}$ between 9 and 10 and a temperature of $60^{\circ} \mathrm{C}$ for 30 minutes. The solution was then cooled to room temperature and dried slowly at $120^{\circ} \mathrm{C}$ for approximately 48 hours. The gel was then calcined at $1200^{\circ} \mathrm{C}$ for 24 hours and the powder was then crushed to -325 mesh. Experimentation confirmed that even at elevated temperatures exceeding $1600^{\circ} \mathrm{C} \mathrm{MgAl}_{2} \mathrm{O}_{4}$ formation from solid oxides resulted in some $\mathrm{MgO}$ and $\mathrm{Al}_{2} \mathrm{O}_{4}$ still in the system. All samples were processed in air in a Deltech front loading furnace. $\mathrm{ZnAl}_{2} \mathrm{O}_{4}$ and $\mathrm{MgGa}_{2} \mathrm{O}_{4}$ were also formed from solid oxides. Stoichiometric mixtures were uniaxially pressed and sintered at $1600^{\circ} \mathrm{C}$ for 8 hours and pellets were then crushed to -325 mesh.

As discussed above, after attempting to form stoichiometric $\mathrm{MgAl}_{2} \mathrm{O}_{4}$ spinel from solid oxides it was found that even at $1600^{\circ} \mathrm{C}$ there was still $\mathrm{MgO}$ and $\mathrm{Al}_{2} \mathrm{O}_{3}$ remaining. The precipitate method was then used to produce stoichiometric $\mathrm{MgAl}_{2} \mathrm{O}_{4}$ at a processing 
temperature of $1200^{\circ} \mathrm{C}$. As can be seen in Figure 26 there is no longer any $\mathrm{MgO}$ or $\mathrm{Al}_{2} \mathrm{O}_{3}$ remaining in the sample made from chlorides. $\mathrm{ZnAl}_{2} \mathrm{O}_{4}$ and $\mathrm{MgGa}_{2} \mathrm{O}_{4}$ were also both formed $\left(1600^{\circ} \mathrm{C}\right.$ processing temperature for 8 hours) from the solid oxides of each of the components. Figure 27 shows that both $\mathrm{ZnAl}_{2} \mathrm{O}_{4}$ and $\mathrm{MgGa}_{2} \mathrm{O}_{4}$ were also stoichiometric.

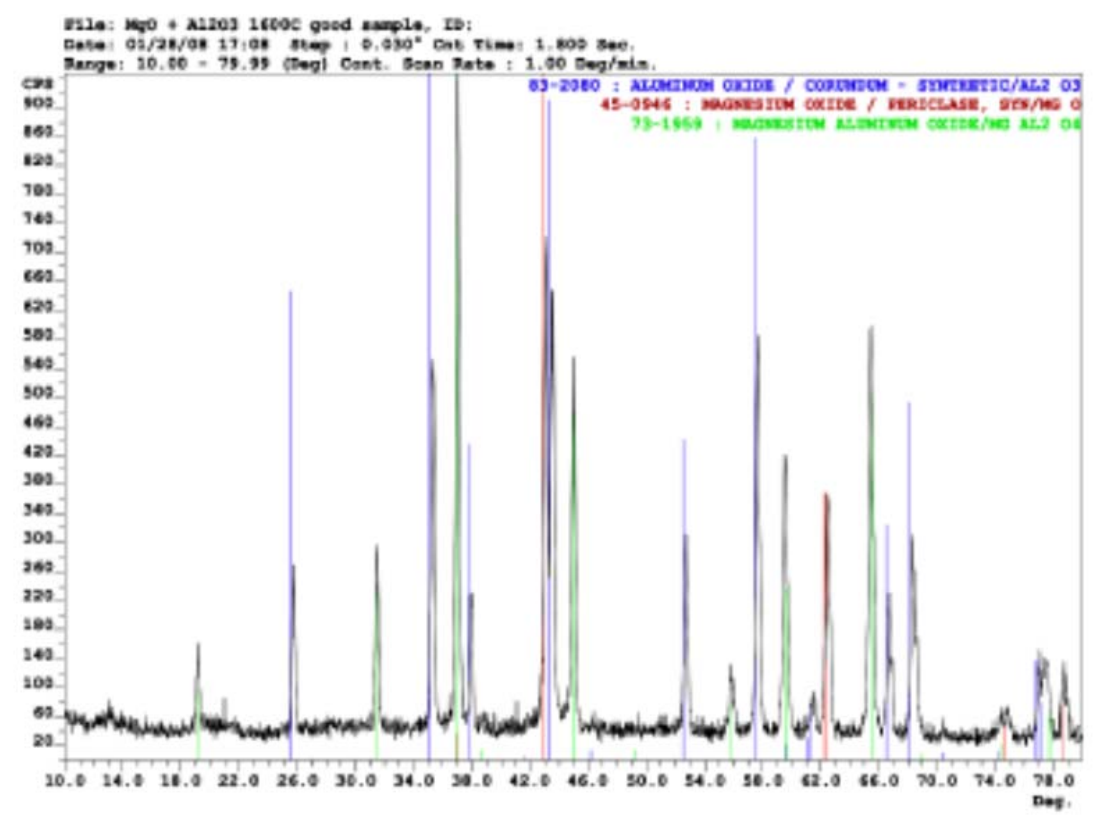

(a) solid oxides

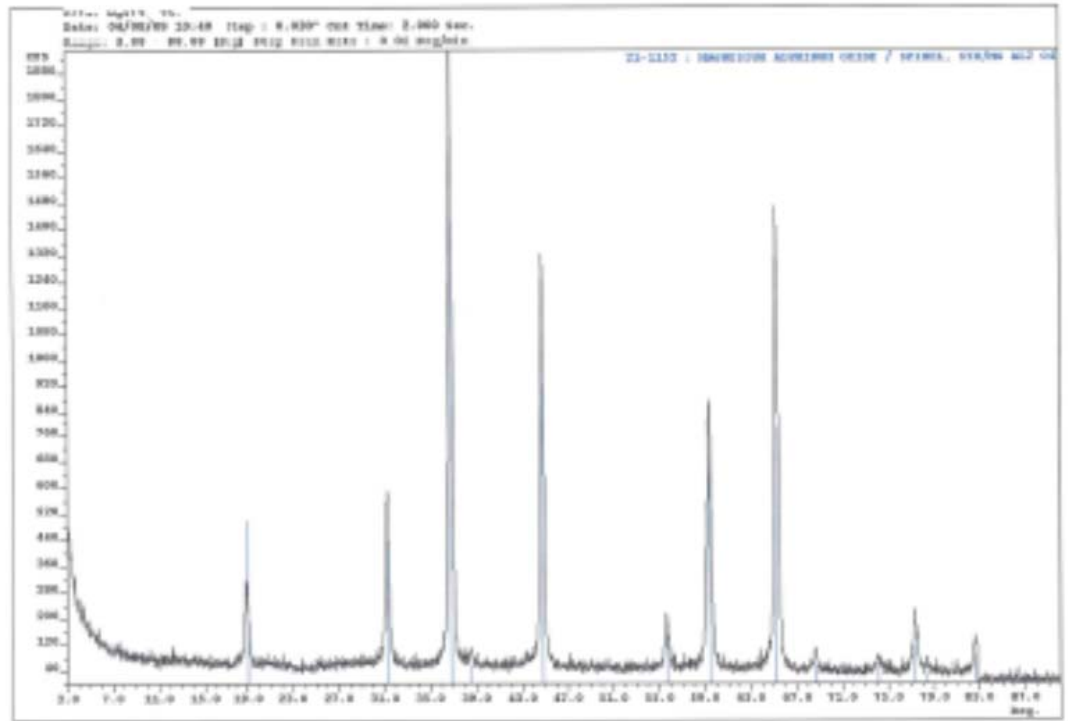

(b) chbrides

Figure 26. XRD Analysis of $\mathrm{MgAl}_{2} \mathrm{O}_{4}$ Formed from (a) Oxides and (b) Chlorides 


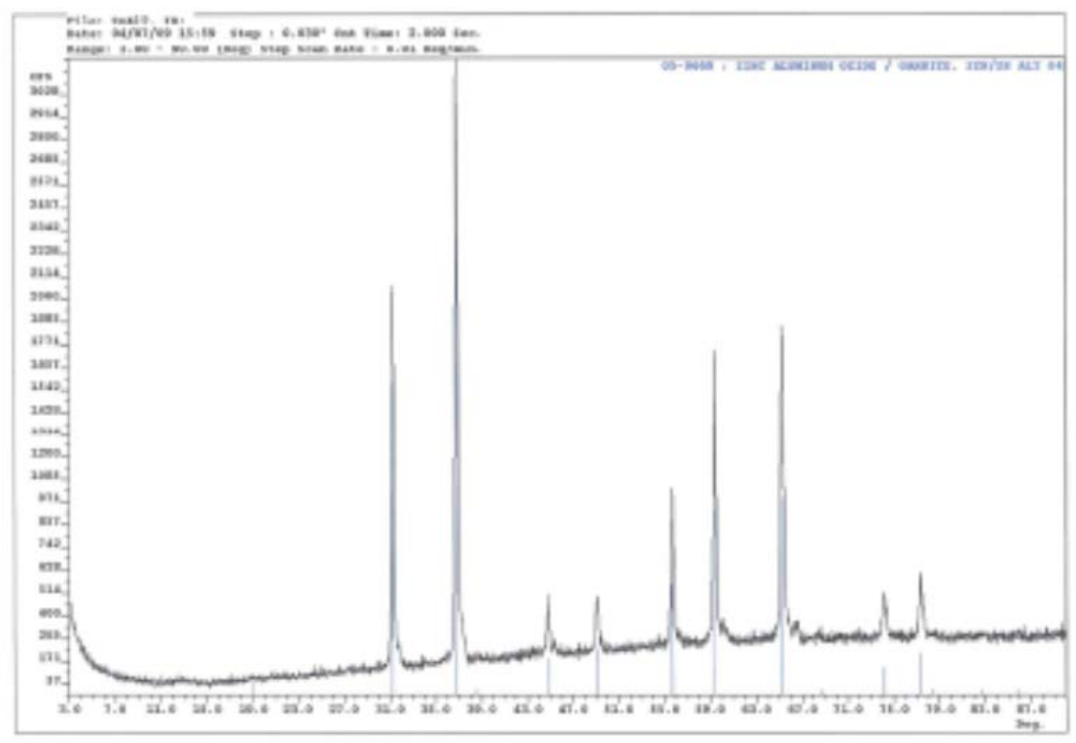

(a) $\mathrm{ZnAl}_{2} \mathrm{O}_{4}$

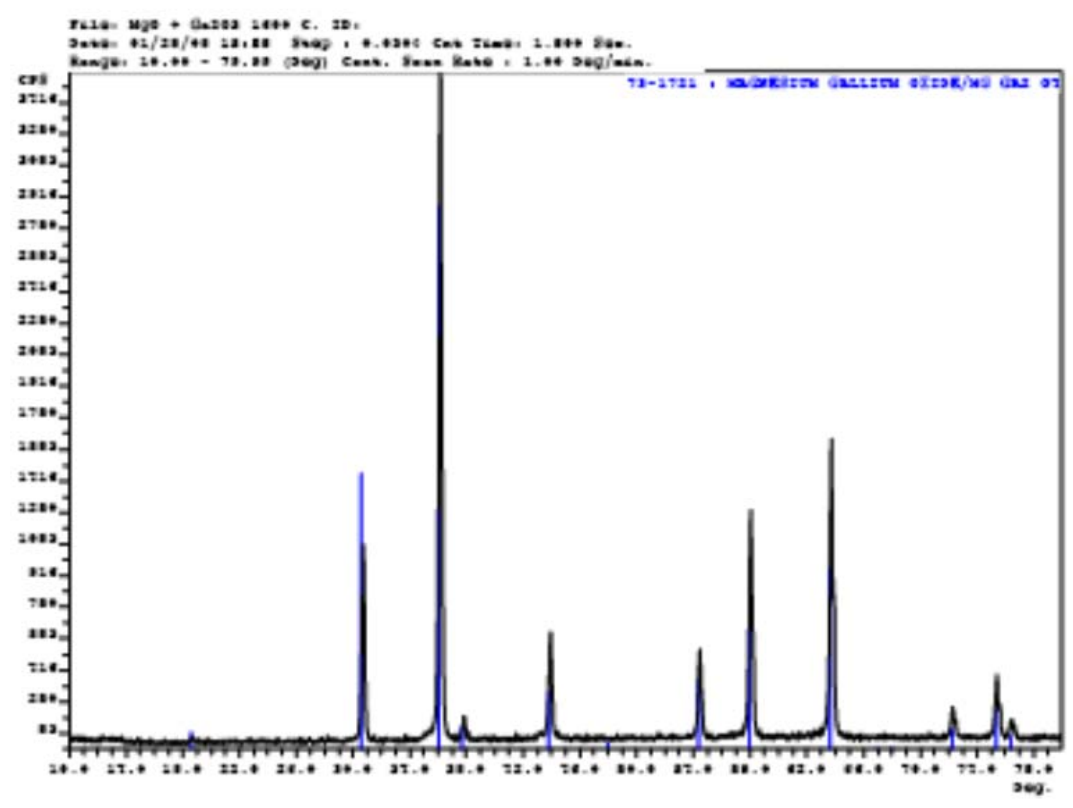

(b) $\mathrm{MgGaO}_{8}$

Figure 27. XRD Analysis of (a) $\mathrm{ZnAl}_{2} \mathrm{O}_{4}$ and (b) $\mathrm{MgGa}_{2} \mathrm{O}_{4}$ Formed from Oxides

To further investigate solid solution formation, mixtures of $0.25 \mathrm{~mol} \% \mathrm{MgAl}_{2} \mathrm{O}_{4}-0.75 \mathrm{~mol} \%$ $\mathrm{ZnAl}_{2} \mathrm{O}_{4}, 0.50 \mathrm{~mol} \% \mathrm{MgAl}_{2} \mathrm{O}_{4}-0.50 \mathrm{~mol} \% \mathrm{ZnAl}_{2} \mathrm{O}_{4}$, and $0.75 \mathrm{~mol} \% \mathrm{MgAl}_{2} \mathrm{O}_{4}-0.25 \mathrm{~mol} \%$ $\mathrm{ZnAl}_{2} \mathrm{O}_{4}$ were uniaxially pressed at $5000 \mathrm{psi}$ and sintered at $1300^{\circ} \mathrm{C}$ for 5 hours. The samples were then ground back to powder to perform XRD analysis. The reported lattice parameter for $\mathrm{MgAl}_{2} \mathrm{O}_{4}$ is $8.083 \AA$ and for $\mathrm{ZnAl} 2 \mathrm{O} 4$ is $8.084 \AA$ making it difficult to determine that solid solution formed from XRD analysis. Therefore, lattice parameter data was obtained from PCPDFWIN version 2.1 PDF number 211152 and 050669, respectively. 
Mixtures of $0.25 \mathrm{~mol} \% \mathrm{MgAl}_{2} \mathrm{O}_{4}-0.75 \mathrm{~mol} \% \mathrm{MgGa}_{2} \mathrm{O}_{4}, 0.50 \mathrm{~mol} \% \mathrm{MgAl}_{2} \mathrm{O}_{4}-0.50 \mathrm{~mol} \%$ $\mathrm{MgGa}_{2} \mathrm{O}_{4}$, and $0.75 \mathrm{~mol}_{0} \mathrm{MgAl}_{2} \mathrm{O}_{4}-0.25 \mathrm{~mol} \% \mathrm{MgGa}_{2} \mathrm{O}_{4}$ were also uniaxially pressed at $5000 \mathrm{psi}$ and sintered at $1300^{\circ} \mathrm{C}$ for 5 hours. With a lattice parameter of $8.280 \AA$ the shift in the peaks from the XRD patterns is more distinctive in this case, and it can be seen in Figure 28 that solid solutions formed for all mixtures. Lattice parameter data was also obtained from PCPDFWIN version 2.1 PDF number 100113.

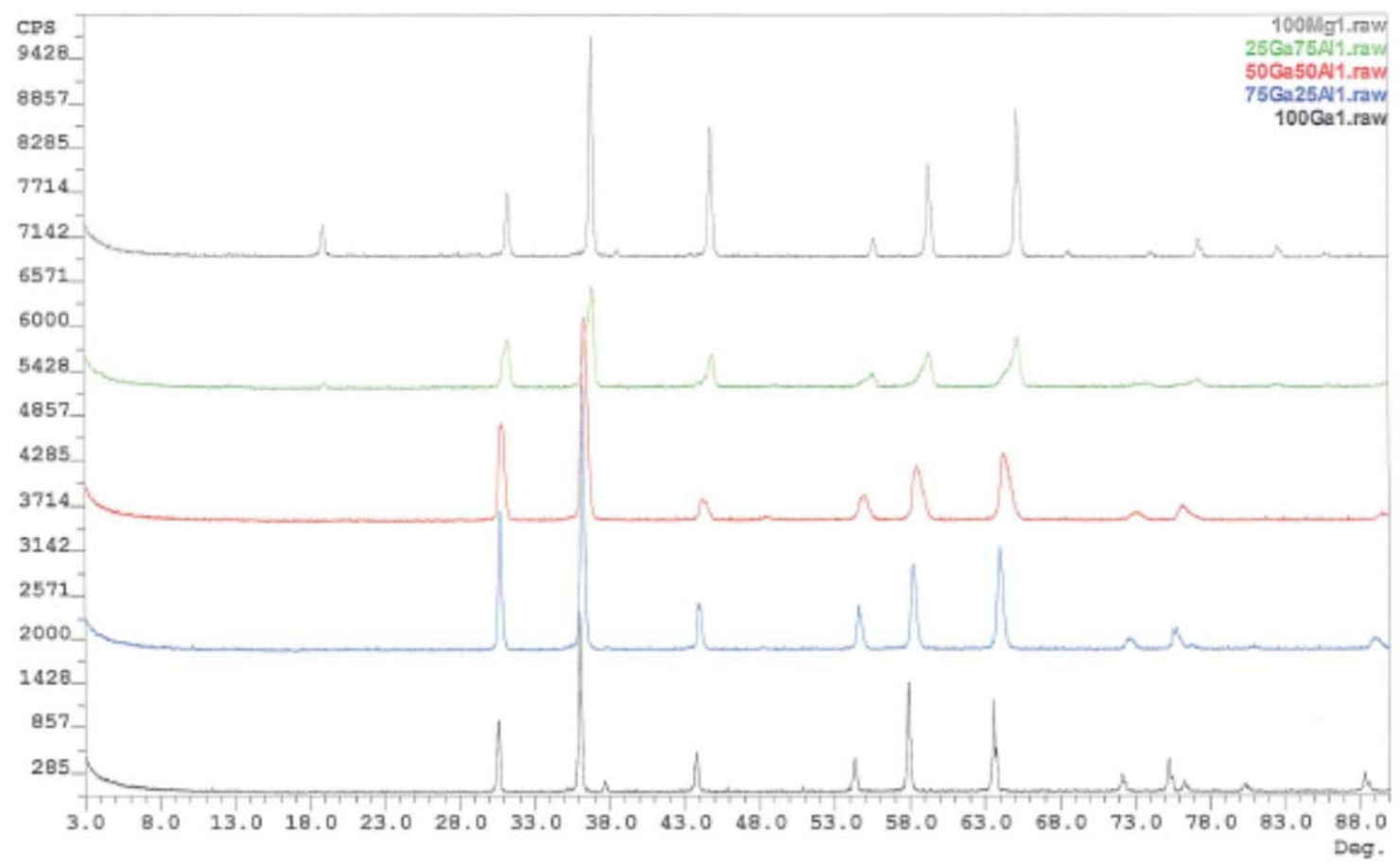

Figure 28. XRD Analysis Showing Solid Solution Formation Between $\mathrm{MgAl}_{2} \mathrm{O}_{4}$ and $\mathrm{MgGa}_{2} \mathrm{O}_{4}$

Three pellets from each of the mixtures above, as well as each of the end members, $\mathrm{MgAl}_{2} \mathrm{O}_{4}, \mathrm{ZnAl}_{2} \mathrm{O}_{4}$, and $\mathrm{MgGa}_{2} \mathrm{O}_{4}$, were used for Archimedes density analysis. Additionally, XRD was performed on representative powder samples of each mixture to determine solid solution formation. Finally, $1 / 2$ " diameter pellets, between 2 and $3 \mathrm{~mm}$ thick were prepared for thermal conductivity testing by the Laser Flash technique at ORNL.

Next, samples of $\mathrm{MgAl}_{2} \mathrm{O}_{4}$ were ground to a -325 mesh powder and then ball milled with zirconia milling media for 24 hours. This resulted in a powder with a particle size of $\mathrm{d}=0.5 \mu \mathrm{m}$. After isostatically pressing at $30,000 \mathrm{lbs}$, the samples were sintered at $1725^{\circ} \mathrm{C}$ for 8 hours obtaining a density of $94.34 \pm 1.26 \mathrm{~g} / \mathrm{cm}^{3}$. It was decided that in order to decrease contamination of the powder during the grinding process, jet milling of the powder would be attempted to obtain a desired particle size of $\mathrm{d}=0.5 \mu \mathrm{m}$. Between $500 \mathrm{~g}$ and $1000 \mathrm{~g}$ of each of the three spinels $\left(\mathrm{MgAl}_{2} \mathrm{O}_{4}, \mathrm{MgGa}_{2} \mathrm{O}_{4}\right.$, and $\left.\mathrm{ZnAl}_{3} \mathrm{O}_{4}\right)$ were processed jet milled.

After all powder has been jet milled, samples were prepared for laser flash measurements. Table 6 shows the different anticipated compositions of interest. Similar samples were also made from each of the oxide constituents, $\mathrm{MgO}-\mathrm{ZnO}$ and $\mathrm{Al}_{2} \mathrm{O}_{3}-\mathrm{Ga}_{2} \mathrm{O}_{3}$, for laser flash 
analysis. Additionally, samples were studied using Raman spectroscopy to identify structure of the spinel formation.

Table 6. Spinel Compositions of Interest

\begin{tabular}{|c|c|c|c|}
\hline Sample & MgAl204 & $\mathrm{Zn} A \mid 204$ & MgGa204 \\
\hline 1 & 100 & - & - \\
\hline 2 & 98 & 2 & - \\
\hline 3 & 96 & 4 & - \\
\hline 4 & 94 & 6 & - \\
\hline 5 & 92 & 8 & - \\
\hline 6 & 90 & 10 & - \\
\hline 7 & 75 & 25 & - \\
\hline 8 & 50 & 50 & - \\
\hline 9 & 25 & 75 & - \\
\hline 10 & - & 100 & - \\
\hline 11 & 98 & - & 2 \\
\hline 12 & 96 & - & 4 \\
\hline 13 & 94 & - & 6 \\
\hline 14 & 92 & - & 8 \\
\hline 15 & 90 & - & 10 \\
\hline 16 & 75 & - & 25 \\
\hline 17 & 50 & - & 50 \\
\hline 18 & 25 & - & 75 \\
\hline 19 & - & - & 100 \\
\hline
\end{tabular}

Densities were calculated for all prepared samples and were found to be between 90 and $95 \%$ of theoretical as shown in Table 7.

Table 7. Calculated Densities of Prepared Laser Flash Specimens

\begin{tabular}{|c|c|c|c|}
\hline & Density $\left(\mathbf{q} / \mathbf{c m}^{\mathbf{3}}\right)$ & Absolute Density $\left(\mathbf{q} / \mathbf{c m}^{\mathbf{3}}\right)$ & \% Theoretical Density \\
\hline $\mathrm{JM}-\mathrm{MgAl}-\mathrm{MgGa}-1$ & 3.3905 & 3.6091 & 93.94 \\
\hline $\mathrm{JM}-\mathrm{MgAl}-\mathrm{MgGa}-2$ & 3.4908 & 3.6725 & 95.05 \\
\hline $\mathrm{JM}-\mathrm{MgAl}-\mathrm{MgGa}-3$ & 3.6248 & 3.8816 & 93.38 \\
\hline $\mathrm{JM}-\mathrm{MgAl}-\mathrm{MgGa}-4$ & 4.3813 & 4.6258 & 94.72 \\
\hline $\mathrm{JM}-\mathrm{MgAl}-\mathrm{MgGa}-5$ & 5.1197 & 5.6202 & 91.09 \\
\hline
\end{tabular}

Laser flash results for these materials are shown in Figure 29. As hoped, a decrease in thermal conductivity was seen as the solid solution content was increased. Additionally, the conductivities of the solid solution systems were substantially lower than that of pure $\mathrm{MgO}$ $(2.85 \mathrm{~W} / \mathrm{mK})$ and $\mathrm{MgAl}_{2} \mathrm{O}_{4}$ spinel $(8.95 \mathrm{~W} / \mathrm{mK})$. A $10 \%$ solid solution addition was seen to reduce the conductivity of $\mathrm{MgO}$ by $75 \%$ and of $\mathrm{MgAl}_{2} \mathrm{O}_{4}$ by $25 \%$ at $200^{\circ} \mathrm{C}$. At higher temperatures, the reduction in the $\mathrm{MgO}$ system was only $50 \%$ with a $10 \%$ solid solution content and was negligible for the spinel system. This is demonstrated in Figure 30. 


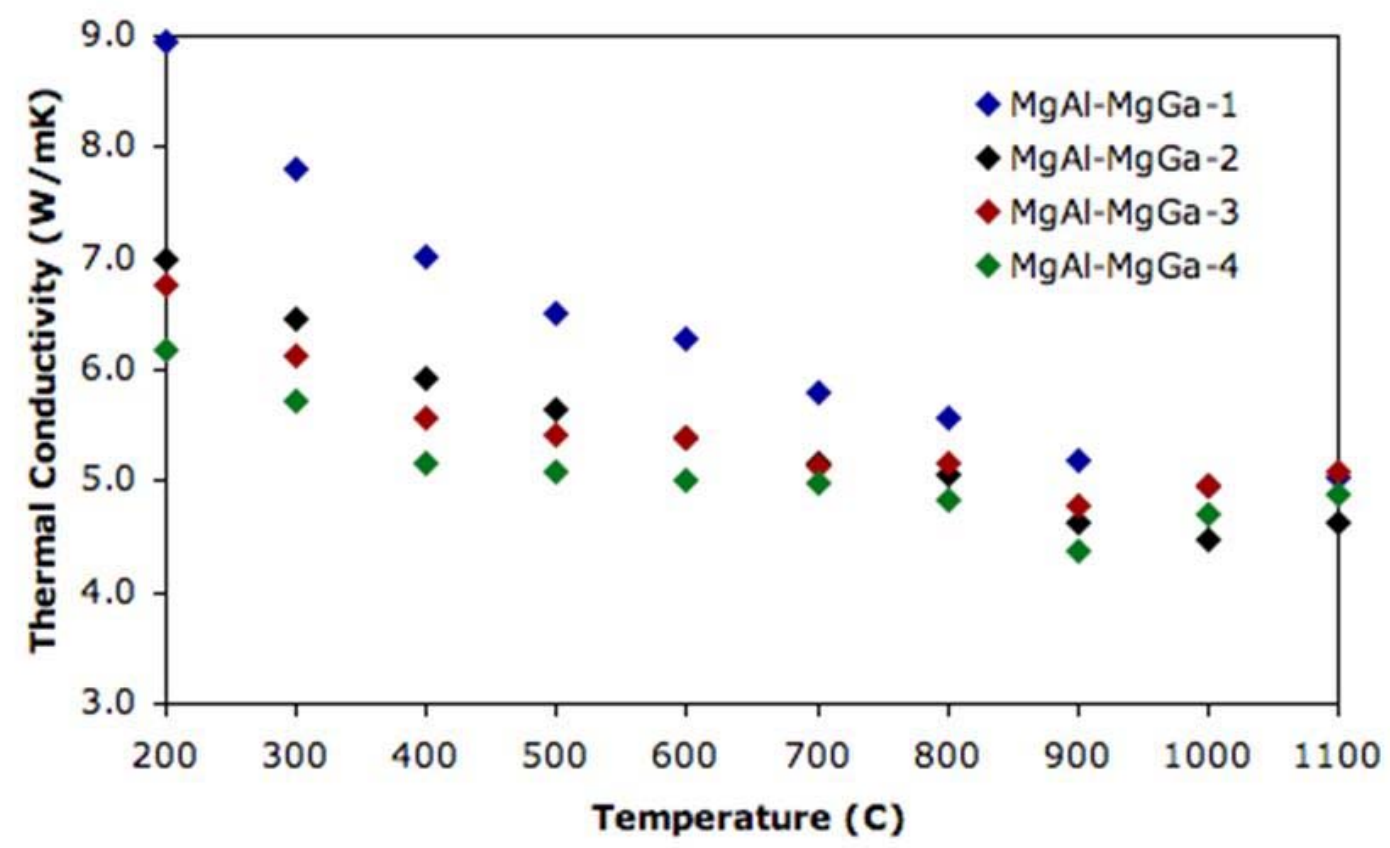

Figure 29. Laser Flash Results for MgAl-MgGa System Plotted vs. Temperature

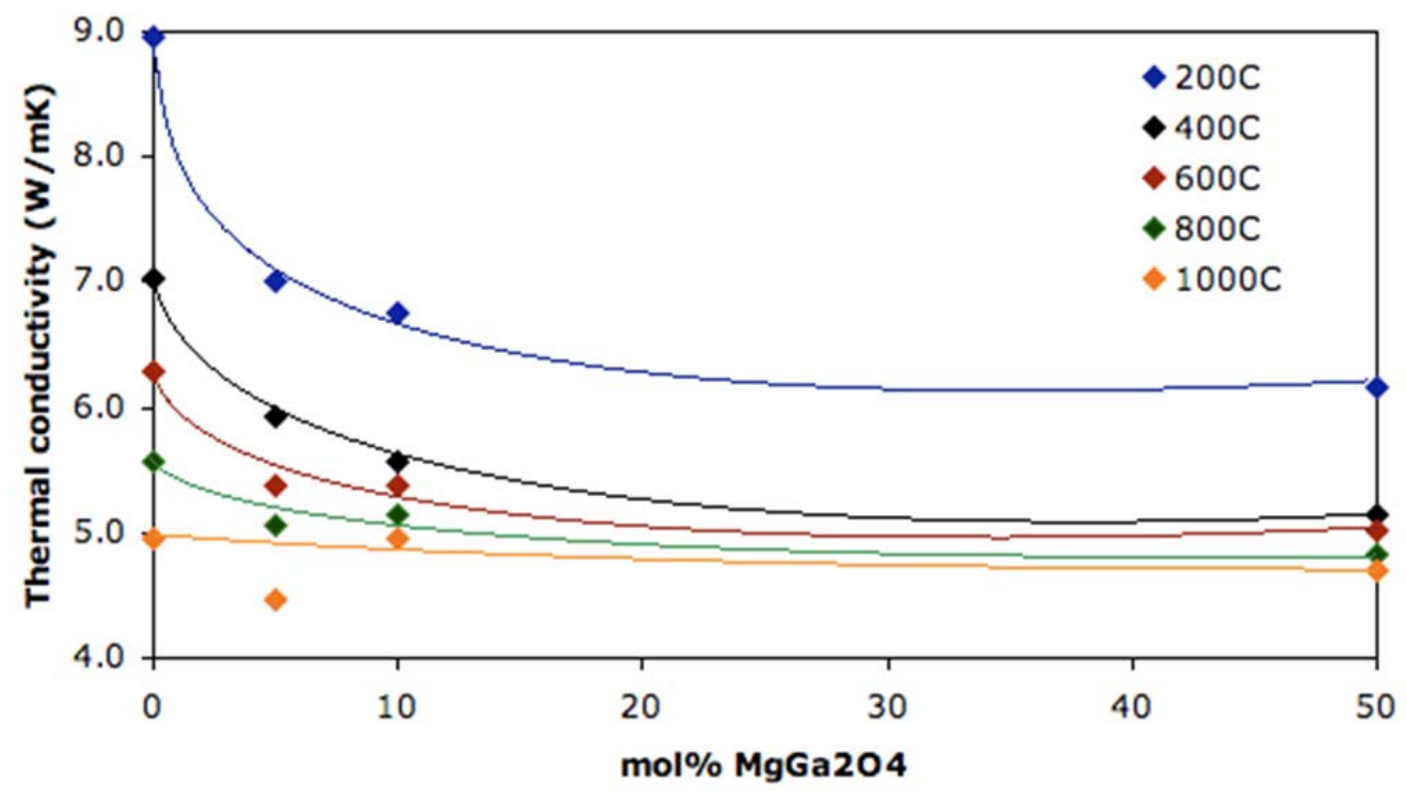

Figure 30. Laser Flash Results for MgAl-MgGa System Plotted vs. Composition

The effect of density was also examined for these specimens, but was determined not to affect the conductivity for the $90-95 \%$ dense samples studied.

As a follow on to these experiments, $\mathrm{MgAl}_{2} \mathrm{O}_{4}-\mathrm{MgGa}_{2} \mathrm{O}_{4}$ samples were prepared using jet milled powders in the same manner as the previous prepared jet milled MgAl-MgGa (1-5) samples. These samples were prepared in order to do further thermal diffusivity studies, for 
Raman Spectroscopy studies to identify structure of the spinel formation, and for high temperature X-ray Diffraction (XRD) analysis. The temperatures chosen for XRD analysis directly corresponded with the temperatures previously used for thermal diffusivity testing, allowing for a direct comparison of results.

Additionally, $\mathrm{MgO}-\mathrm{Al}_{2} \mathrm{O}_{3}$ co-precipitates were formed with the compositions outlined in Table 8 . These compositions form the currently accepted boundary between $\mathrm{MgAl}_{2} \mathrm{O}_{4}$ and $\mathrm{Al}_{2} \mathrm{O}_{3}$ in the two-component phase diagram. Samples were sintered at various temperatures between $1500^{\circ} \mathrm{C}$ and $1900^{\circ} \mathrm{C}$ and quenched in air. These samples were used to confirm the boundary curve between $\mathrm{MgAl}_{2} \mathrm{O}_{4}$ and $\mathrm{Al}_{2} \mathrm{O}_{3}$, as well as to evaluate the thermal diffusivity of these material compositions.

Table 8. Co-precipitated powder compositions in Weight Percent

\begin{tabular}{|c|c|c|}
\hline Sample & wt\% MgO & wt\% Al203 \\
\hline 1 & 22 & 78 \\
\hline 2 & 21 & 79 \\
\hline 3 & 20 & 80 \\
\hline 4 & 19 & 81 \\
\hline 5 & 17 & 83 \\
\hline 6 & 16 & 84 \\
\hline 7 & 14 & 86 \\
\hline 8 & 12 & 88 \\
\hline 9 & 9 & 91 \\
\hline 10 & 8 & 92 \\
\hline
\end{tabular}

Five $\mathrm{MgAl}_{2} \mathrm{O}_{4}-\mathrm{MgGa}_{2} \mathrm{O}_{4}$ mixtures were also prepared using jet milled powders (shown in Table 9) and were tested using laser flash diffusivity to determine thermal conductivity (based on measured density and heat capacity). Multiple samples were run of each composition to generate statistical data, provide more confidence in the experimental values, and to evaluate standard errors. Additionally, the samples were tested with the assumption that the density of the sample stays the same throughout the experiment. Samples were also prepared for thermal expansion measurement.

Table 9. $\mathrm{MgAl}_{2} \mathrm{O}_{4}-\mathrm{MgGa}_{2} \mathrm{O}_{4}$ Mixtures Studied

\begin{tabular}{|c|c|c|}
\hline & $\begin{array}{c}\text { MgA204 } \\
\text { (mol\%) }\end{array}$ & $\begin{array}{c}\text { Mgca2o4 } \\
\text { (mol\%) }\end{array}$ \\
\hline JM-MgAl-MgGa-1 & 100 & - \\
\hline$J M-M g A l-M g G a-2$ & 95 & 5 \\
\hline$J M-M g A l-M g G a-3$ & 90 & 10 \\
\hline$J M-M g A l-M g G a-4$ & 50 & 50 \\
\hline$J M-M g A l-M g G a-5$ & - & 100 \\
\hline
\end{tabular}

In addition, software provided by refractory manufacturer ThermalCeramics (Augusta, GA) was used to determine percent heat loss when refractories containing these and other 
compositions are used as part of a theoretical lining system. To accent this work, MS\&T developed a similar software package of its own that was also used for comparison.

MS\&T also performed a study of the $\mathrm{MgO}-\mathrm{Al}_{2} \mathrm{O}_{3}$ phase diagram (shown in Figure 31 ). High temperature XRD was used to determine the composition of mixtures at varying temperatures. Initial studies were performed on compositions from the $\mathrm{Al}_{2} \mathrm{O}_{3}$ rich side of the diagram starting with $91 \mathrm{wt} \% \mathrm{Al}_{2} \mathrm{O}_{3}-9 \mathrm{wt} \% \mathrm{MgO}$. Additionally, samples were prepared from other regions of the diagram for high temperature XRD as well as thermal conductivity evaluation.

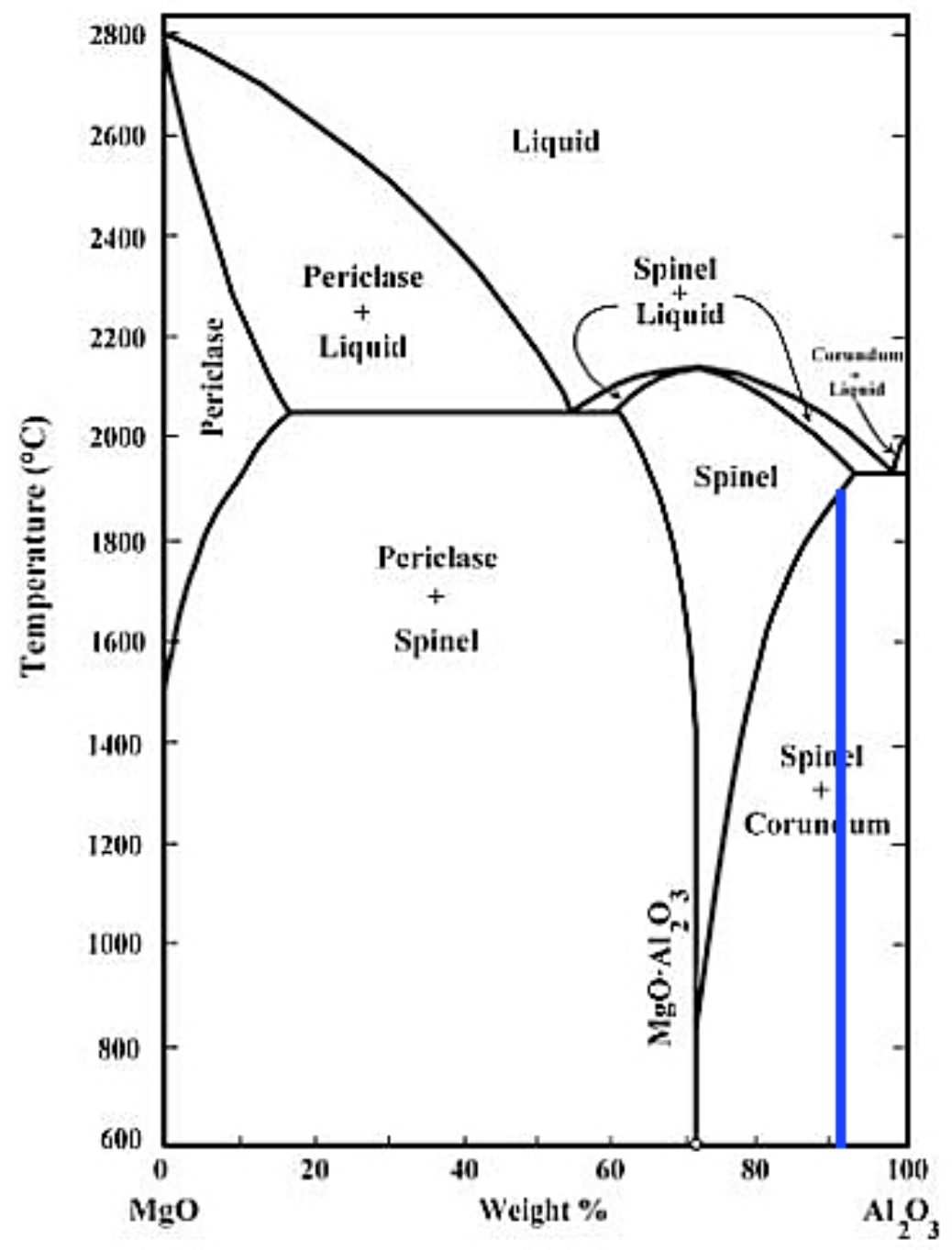

Figure 31. $\mathrm{MgO}-\mathrm{Al}_{2} \mathrm{O}_{3}$ Phase Diagram Showing the Initial Composition Studied (blue line)

Compositions on the alumina rich side of the diagram were produced using co-precipitation, as listed in Table 10. 
Table 10. Compositions Studied Based on $\mathrm{Wt} \%$ Alumina with Processing Temperatures Indicated

\begin{tabular}{|c|c|c|c|c|c|}
\hline $\begin{array}{c}\text { Alumina } \\
\text { wt\% }\end{array}$ & $\mathbf{1 5 0 0}$ & $\mathbf{1 6 0 0}$ & $\mathbf{1 7 0 0}$ & $\mathbf{1 8 0 0}$ & $\mathbf{1 9 0 0}$ \\
\hline 78 & $\mathrm{X}$ & & $\mathrm{X}$ & $\mathrm{X}$ & $\mathrm{X}$ \\
\hline 79 & $\mathrm{X}$ & $\mathrm{X}$ & & & \\
\hline 80 & $\mathrm{X}$ & $\mathrm{X}$ & & & \\
\hline 81 & & $\mathrm{X}$ & $\mathrm{X}$ & & \\
\hline 83 & & & $\mathrm{X}$ & & $\mathrm{X}$ \\
\hline 84 & & & $\mathrm{X}$ & $\mathrm{X}$ & \\
\hline 86 & & & & $\mathrm{X}$ & $\mathrm{X}$ \\
\hline 88 & & & & $\mathrm{X}$ & $\mathrm{X}$ \\
\hline 91 & & & & & $\mathrm{X}$ \\
\hline 92 & & & & & $\mathrm{X}$ \\
\hline
\end{tabular}

Each composition was processed at varying temperatures in order to verify the boundary curve between spinel and alumina, which can also be seen in Table 10. Samples were processed at $1500^{\circ} \mathrm{C}, 1600^{\circ} \mathrm{C}$, and $1700^{\circ} \mathrm{C}$ for 8 hours and then air quenched with all experiments done in air. XRD was performed to determine the compositions at each temperature. The compositions were originally selected in hopes to obtain final chemistries straddling the boundary curve. However, it was determined that all samples processed were still $100 \%$ spinel solid solution, indicating that the boundary curve will likely need to be adjusted. On the current phase diagram this composition lies in the spinel-alumina phase field, however, the XRD pattern has no indication of alumina.

Samples processed at $1900^{\circ} \mathrm{C}$ were held for 8 hours and then cooled at approximately $10^{\circ} \mathrm{C} / \mathrm{sec}$ to room temperature in nitrogen. All samples had $<5 \%$ porosity and were prepared for laser flash experiments. Figure 32 shows pictures of the samples after processing. All samples were white prior to heat treatment. It can be seen as the amount of alumina increases the color of the samples darkens. When the samples were cut for laser flash evaluation it was determined that the color change was consistent throughout the sample. Samples were prepared for XRD and SEM/EDS to determine if the discoloration is a cause of contamination. 
a)

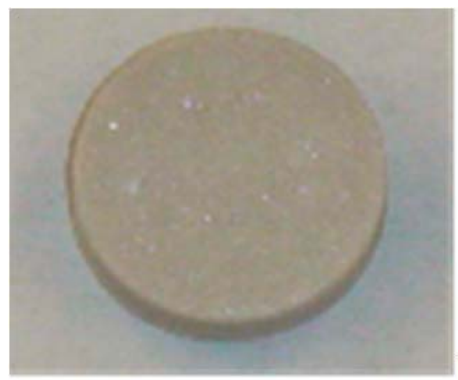

c)

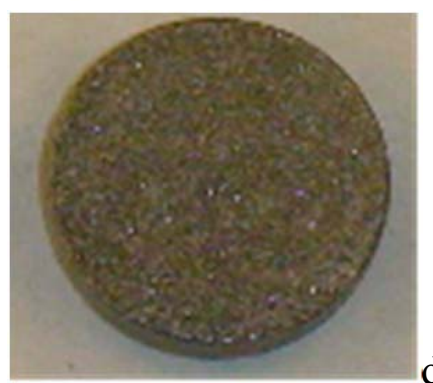

b)

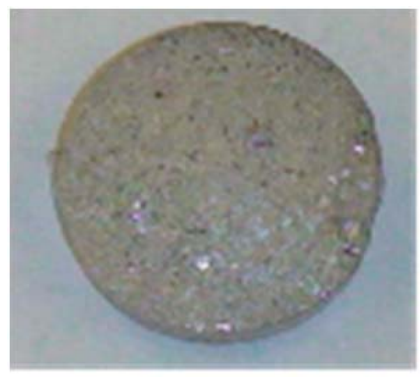

d)

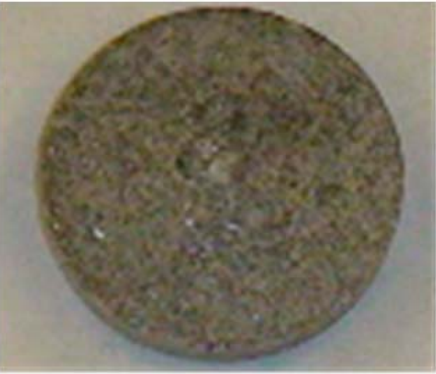

e)

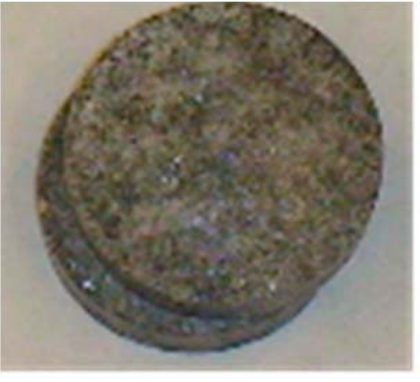

Figure 32. Samples Processed at $1900^{\circ} \mathrm{C}$ - a) $78 \mathrm{wt} \%$ Alumina, b) $86 \mathrm{wt} \%$ Alumina, c) $88 \mathrm{wt} \%$ Alumina, d) $91 \mathrm{wt} \%$ Alumina, and e) $92 \mathrm{wt} \%$ Alumina

Three samples from each of the compositions listed in Table 11 were prepared for evaluation by laser flash diffusivity. Measurements were conducted every $200^{\circ} \mathrm{C}$ from $100^{\circ} \mathrm{C}$ to $900^{\circ} \mathrm{C}$ as shown in Figure 33 where it can be seen that the solid solution is having a lowering effect on the thermal diffusivity. Additionally, the diffusivity is decreasing with temperature as expected.

Table 11. $\mathrm{MgAl}_{2} \mathrm{O}_{4}-\mathrm{MgGa}_{2} \mathrm{O}_{4}$ Mixtures Being Studied

\begin{tabular}{|c|c|c|}
\hline & $\begin{array}{c}\text { MgAl2O4 } \\
\text { (mol\%) }\end{array}$ & $\begin{array}{c}\mathrm{MgGa2O4} \\
(\mathrm{mol} \%)\end{array}$ \\
\hline JM-MgAl-MgGa-1 & 100 & - \\
\hline JM-MgAl-MgGa-2 & 95 & 5 \\
\hline JM-MgAl-MgGa-3 & 90 & 10 \\
\hline JM-MgAl-MgGa-4 & 50 & 50 \\
\hline JM-MgAl-MgGa-5 & 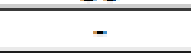 & 100 \\
\hline
\end{tabular}




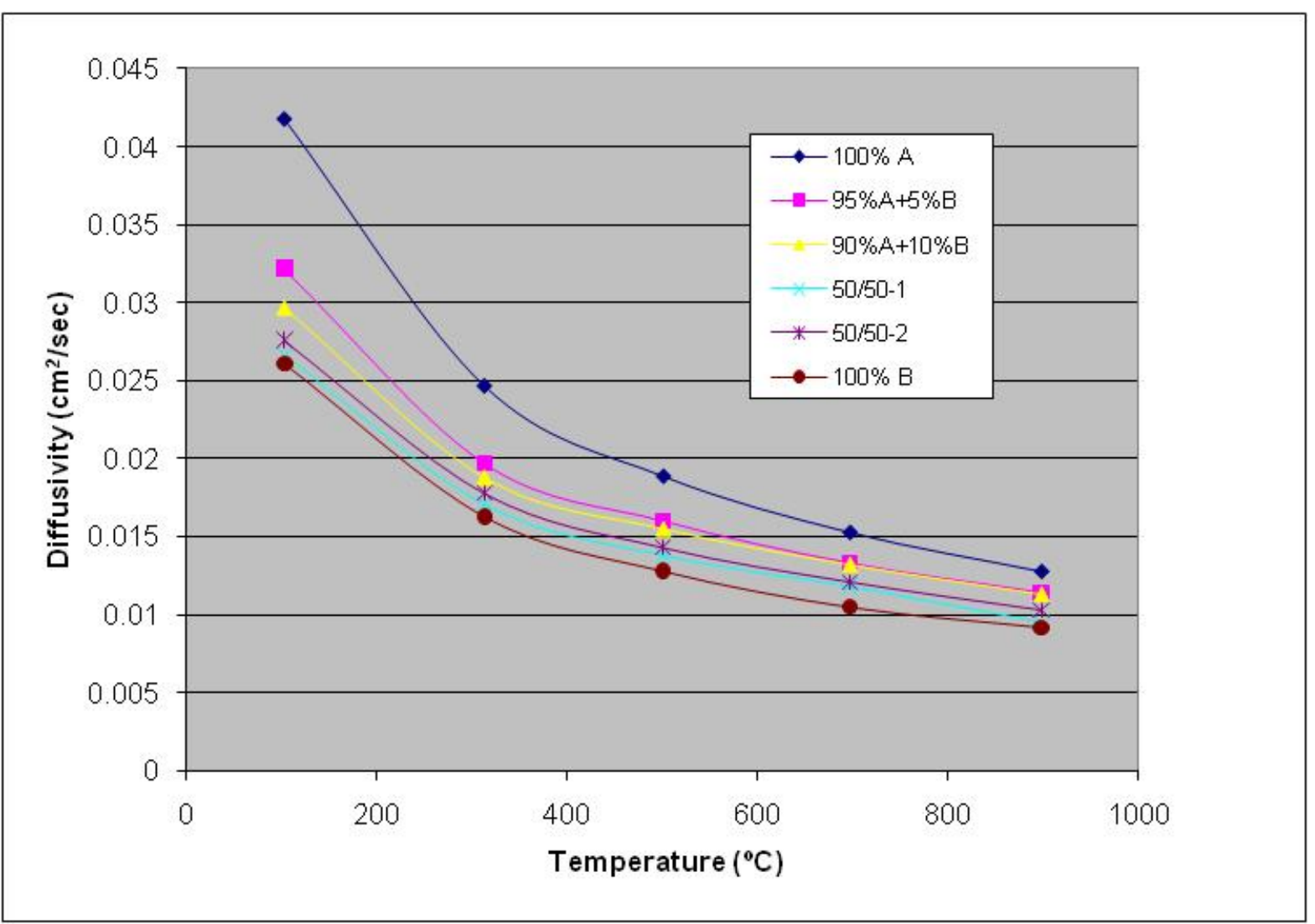

Figure 33. Thermal Diffusivity vs. Temperature for $\mathrm{MgAl}_{2} \mathrm{O}_{4}-\mathrm{MgGa}_{2} \mathrm{O}_{4}$ Solid Solutions $\left(\mathrm{A}=\mathrm{MgAl}_{2} \mathrm{O}_{4}, \mathrm{~B}=\mathrm{MgGa}_{2} \mathrm{O}_{4}\right)$

The Comprehensive Examination was passed by Kelley O'Hara at MS\&T in March 2011 regarding work performed related to this project. A written document related to this examination was also prepared based on the testing and results described above. Such topics as $\mathrm{MgO}-\mathrm{Al}_{2} \mathrm{O}_{3}$ and spinel-spinel solid solutions, spinel formation, phase equilibria of the $\mathrm{MgO}-\mathrm{Al}_{2} \mathrm{O}_{3}$ system, defect chemistry in $\mathrm{MgAl}_{2} \mathrm{O}_{4}$, and thermal diffusivity/conductivity of the $\mathrm{MgO}-\mathrm{Al}_{2} \mathrm{O}_{3}$ system were covered ${ }^{\mathrm{iii}}$. Kelley is planning to finish her Ph.D. degree in June 2012.

Following completion of her comprehensive examination, Kelley continued her work on investigating the solid solution effects of spinel formation and the effect on thermal diffusivity. Basic $\mathrm{MgAl}_{2} \mathrm{O}_{4}$ was investigated along with the $\mathrm{MgO}-\mathrm{Al}_{2} \mathrm{O}_{3}-\mathrm{Ga}_{2} \mathrm{O}_{3}$ system. Various additions of $\mathrm{MgGa}_{2} \mathrm{O}_{4}$ to $\mathrm{MgAl}_{2} \mathrm{O}_{4}$ were prepared and the laser flash technique was used to determine thermal diffusivity at temperatures between 200 and $1300^{\circ} \mathrm{C}$. It was determined that solid solution in the $\mathrm{MgAl}_{2} \mathrm{O}_{4}-\mathrm{MgGa}_{2} \mathrm{O}_{4}$ system significantly decreases thermal conductivity up to $1000^{\circ} \mathrm{C}$. At $200^{\circ} \mathrm{C}$ thermal conductivity decreased $25 \%$ with just $10 \mathrm{~mol} \%$ addition of $\mathrm{MgGa}_{2} \mathrm{O}_{4}$ to the system. At $800^{\circ} \mathrm{C}$ the thermal conductivity decreased $10 \%$ with 10 mol\% addition. Characteristic results are shown in Figure 34.

\footnotetext{
${ }^{\text {iii }}$ K.R. O'Hara, “A Dissertation Draft for the Comprehensive Examination,” Missouri University of Science and Technology, (2010).
} 


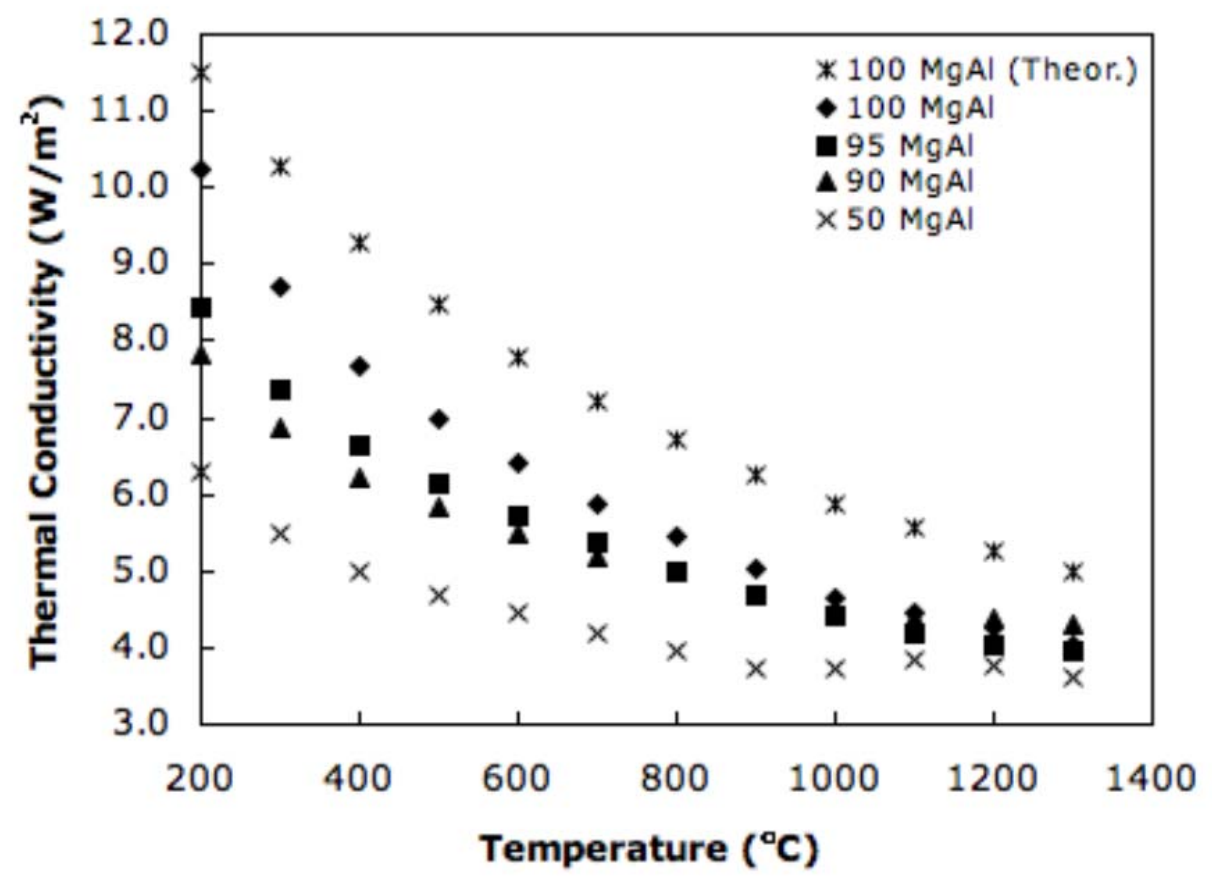

Figure 34. Thermal Conductivity Versus Temperature for $\mathrm{MgAl}_{2} \mathrm{O}_{4}-\mathrm{MgGa}_{2} \mathrm{O}_{4}$ System

Steady state calculations were conducted based on the thermal conductivity measurements made verses temperature. This analysis showed a hypothetical $11 \%$ decrease in heat flux for a $10 \mathrm{~mol} \% \mathrm{MgGa}_{2} \mathrm{O}_{4}$ system compared to a a pure $\mathrm{MgAl}_{2} \mathrm{O}_{4}$ system when considered across a 12 inch brick wall as shown in Figure 35.

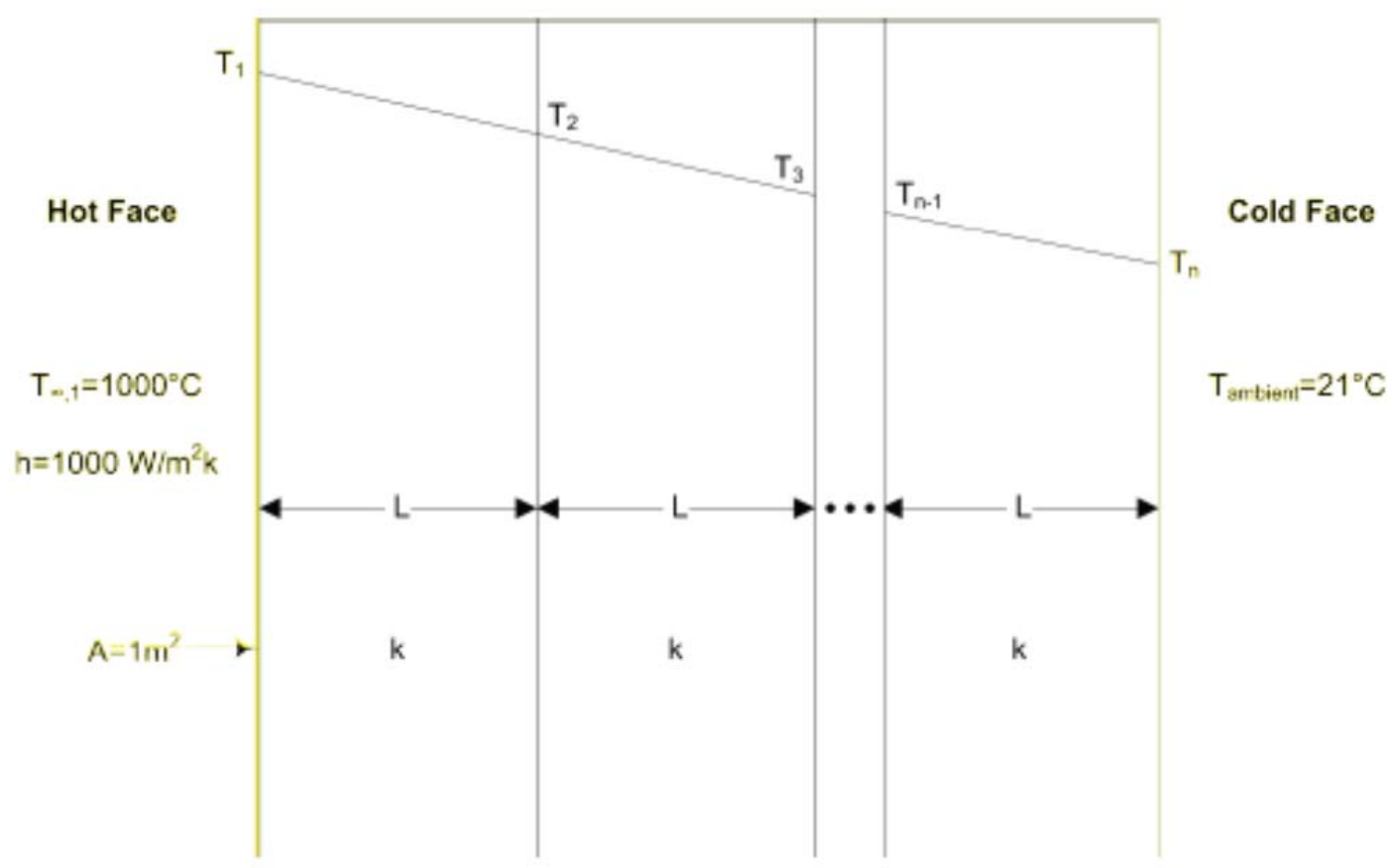

Figure 35. Schematic for Steady-State Heat Flow Calculations Showing Initial Conditions 
Other early work at MS\&T focused on identifying testing and property measurements needed for characterization of refractories currently being used in the industries of interest and the new refractories being developed by this project. Determination of needed testing was based on site visits and a literature search of standard and non-standard tests related to the critical engineering properties associated with the refractories used in the associated industrial processes. The identified test procedures by industry are shown in Appendix 2. This list of procedures served as a basis for the testing performed in the second year of the project, but was revised throughout the project as it was found that additional or different information was needed for refractory identification and analysis. Additionally, it was felt that an appropriate thermal shock and hot abrasion testing procedure did not currently exist for the industrial applications of interest, therefore new procedures were investigated.

\section{Task 3 Production of refractory materials}

Work on this task continued through the life of the project as materials were optimized for performance and individual applications. Materials were produced by MINTEQ for laboratory testing during development efforts, for laboratory validation trials, and for full industrial trials as needed.

\section{Task 4 Measurement of key refractory properties}

Original work on this task was completed in 12/08 to meet Milestone/Go-No Go Decision Point 3. Testing was continued though throughout the life of the project as information was required periodically when materials were modified or new materials were identified.

Work was ongoing at ORNL and MS\&T through the duration of the project on the measurement and characterization of key refractory properties as identified during year one of the project. Both materials currently being used in the industrial processes as identified and supplied by the industrial partners of this project and new materials being provided and developed by MINTEQ were evaluated as necessary. A summary of measured properties is shown in Appendix 3.

Early on in the project, materials currently used in the seven identified applications for study under this project were characterized at ORNL and MS\&T. Results from this analysis were used as a standard of evaluating the projected performance of newly developed materials as defined in the generated QFD tool spreadsheets. Salvaged materials were collected from the industrial partners as they had furnace shut-downs and relines. Examined materials included lime kiln and gasifier materials from Weyerhaeuser, coal slag samples from Eastman, and currently available materials from MINTEQ (examples shown in Figure 36 and Figure 37). Virgin refractory samples known to be used in the glass, aluminum, and chemical industries were also obtained from commercial vendors for testing and analysis. Testing included physical characterization, aluminum immersion testing, black liquor smelt immersion testing, lime exposure, and coal slag exposure. Analysis included optical microscopy, XRD, and electron microprobe. Initial results helped to identify mechanisms of refractory penetration and corrosion in each environment, along with needed refractory improvements for the new materials being developed. 


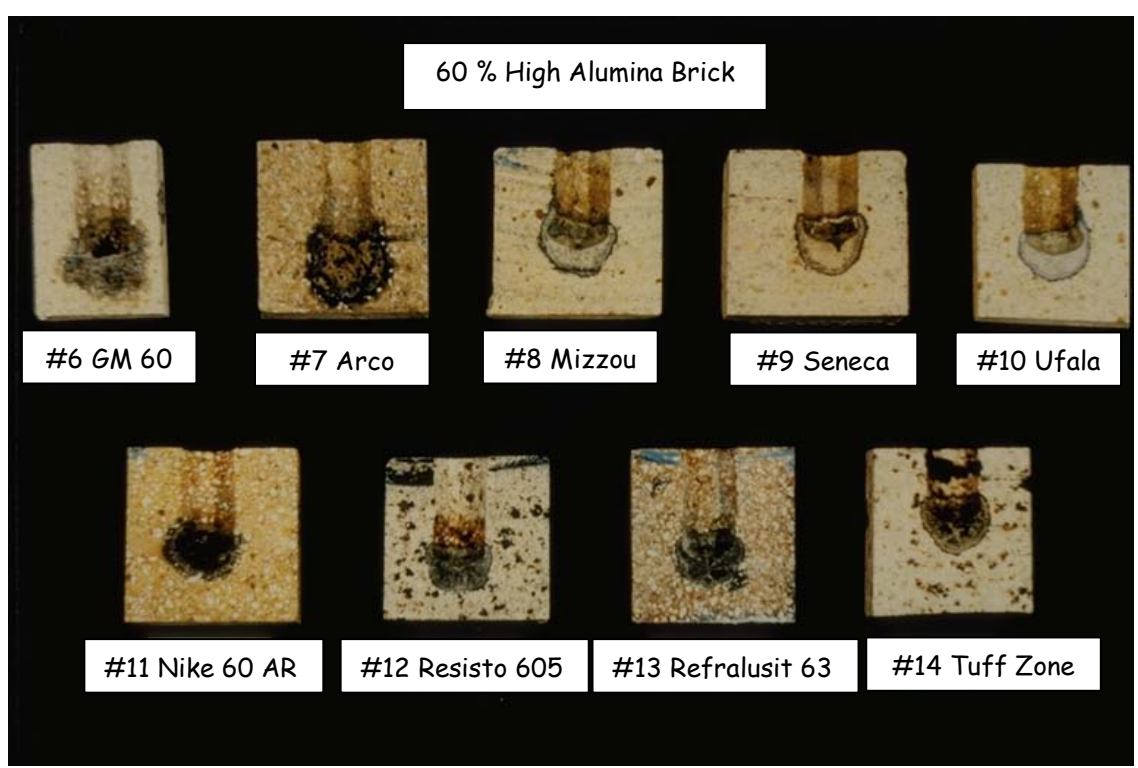

Figure 36. Examples of Salvaged Samples Showing Lime Kiln Refractory Degradation

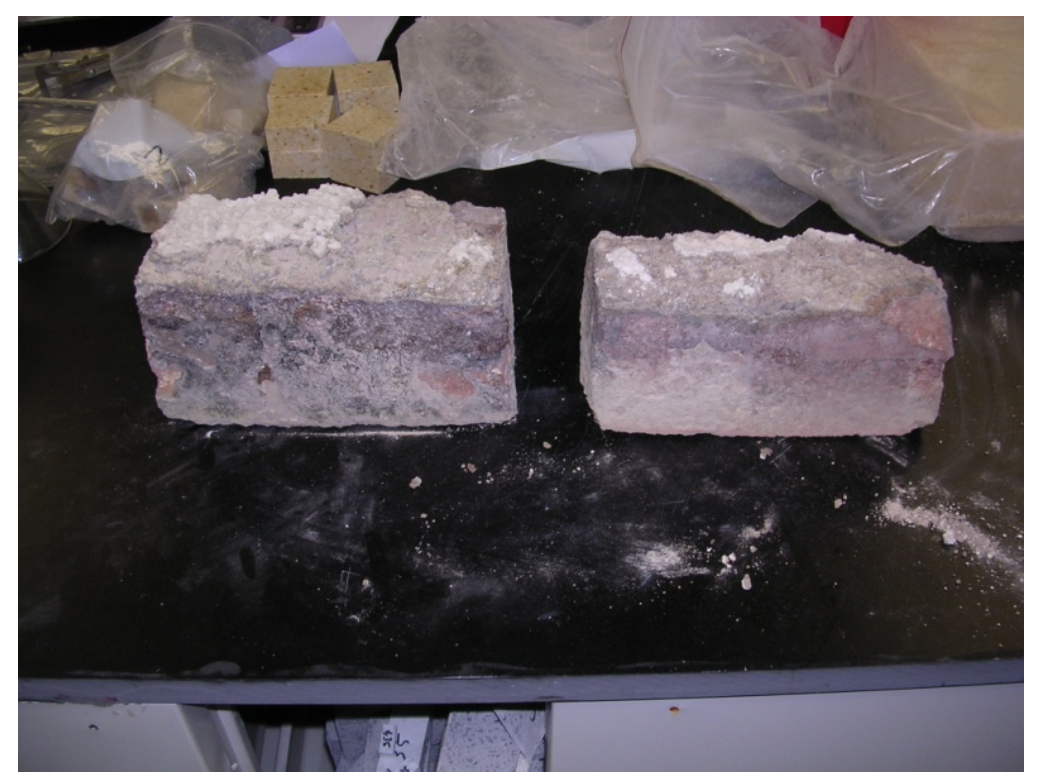

Figure 37. Salvaged Lime Kiln Brick Samples

Refractories for the Glass Industry

Fusion-cast alumina-zirconia-silicate (AZS) refractory materials received from a commercial glass manufacturer were analyzed for failure mechanisms and degradation products. Optical microscopy and SEM/EDS were performed on samples taken from supplied blocks representing both the glass/refractory interfaces and the "virgin" unreacted materials. Analysis of these samples showed soda infiltration from the glass into the microstructure of the refractory resulting in attack of the silica, alumina and zirconia. Microstructure of the zirconia particles (small round geometry vs. large blocky geometry) was found to be a leading indicator of resistance to soda. Also, increasing levels of attack (indicated by reaction zone size) were seen with decreased zirconia content of the original refractory. Micrographs and photographs of the analyzed samples are shown below in Figure 38. 

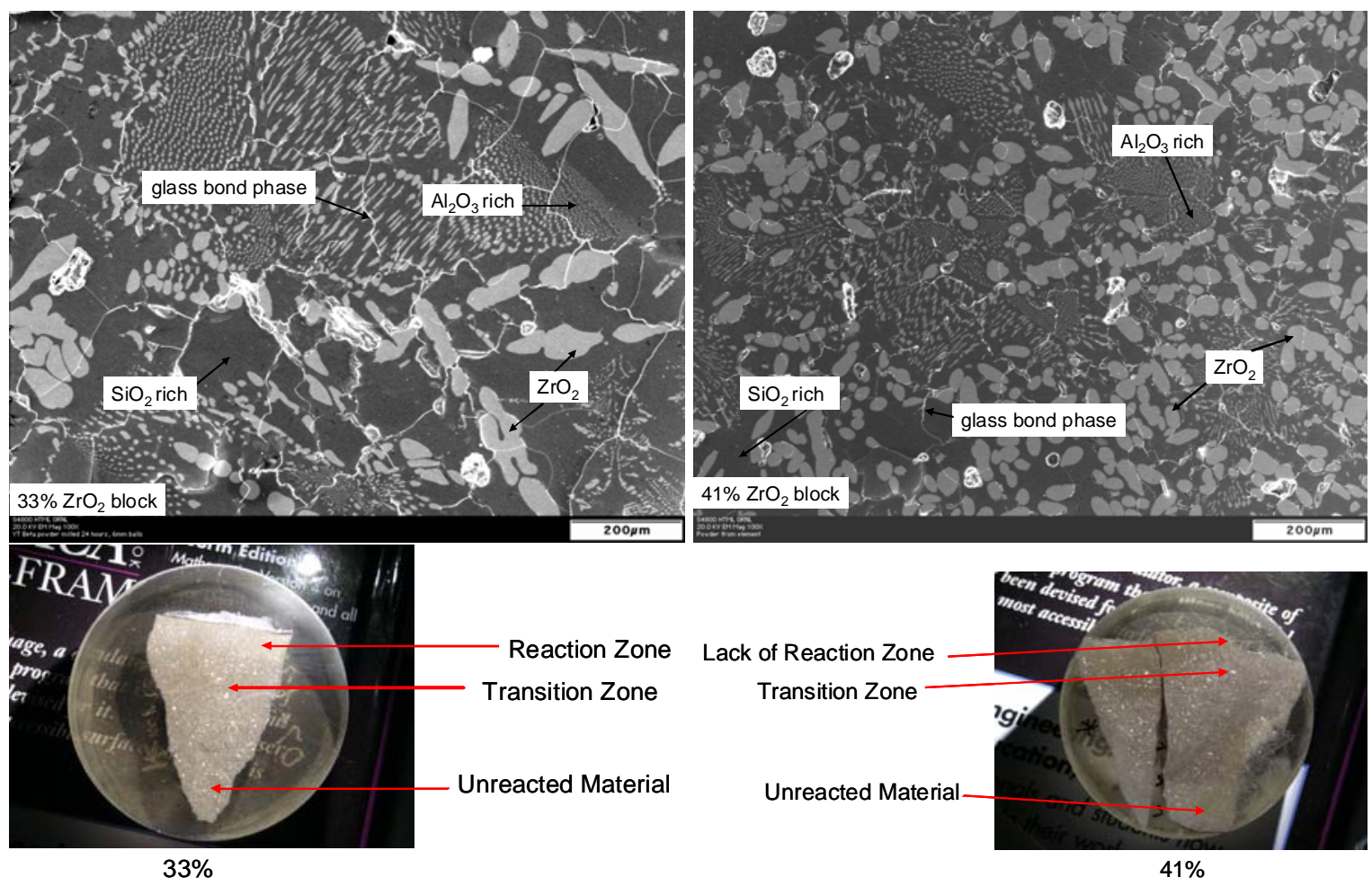

Figure 38. Analysis of Salvaged Fusion Cast AZS Refractory Material

Refractories for Aluminum Industry

Salvaged refractory brick was received from industrial partner Aleris Aluminum. One group of samples consisted of high alumina brick taken from rotary furnaces with service lives of one to one and a half years (production life times of 50-60 MM lbs.). A second group of samples consisted of round melter bricks taken from a reverberatory furnace after approximately four years of service (450 MM lbs. throughput). Cores were taken from these bricks for analysis at ORNL, MS\&T, and MINTEQ.

Samples were analyzed at ORNL by a summer intern student from MS\&T. Various characterization techniques were used to identify chemical and mechanical failure mechanisms degrading these refractories. Macroscopic anomalies were characterized by optical microscopy and phase analysis of samples was conducted with XRD. Chemical analysis was completed through SEM/EDS.

Core samples from varying brick depths and locations were studied to determine the impact of the metal/refractory interaction with respect to possible failure mechanisms. XRD analysis was performed on metal contact samples and compared to scans of core samples from deeper in the brick to verify phase changes as a result of elevated temperature and molten metal exposure. Examples of optical microscopy and XRD results are shown in Figure 39 and Figure 40, respectively. 


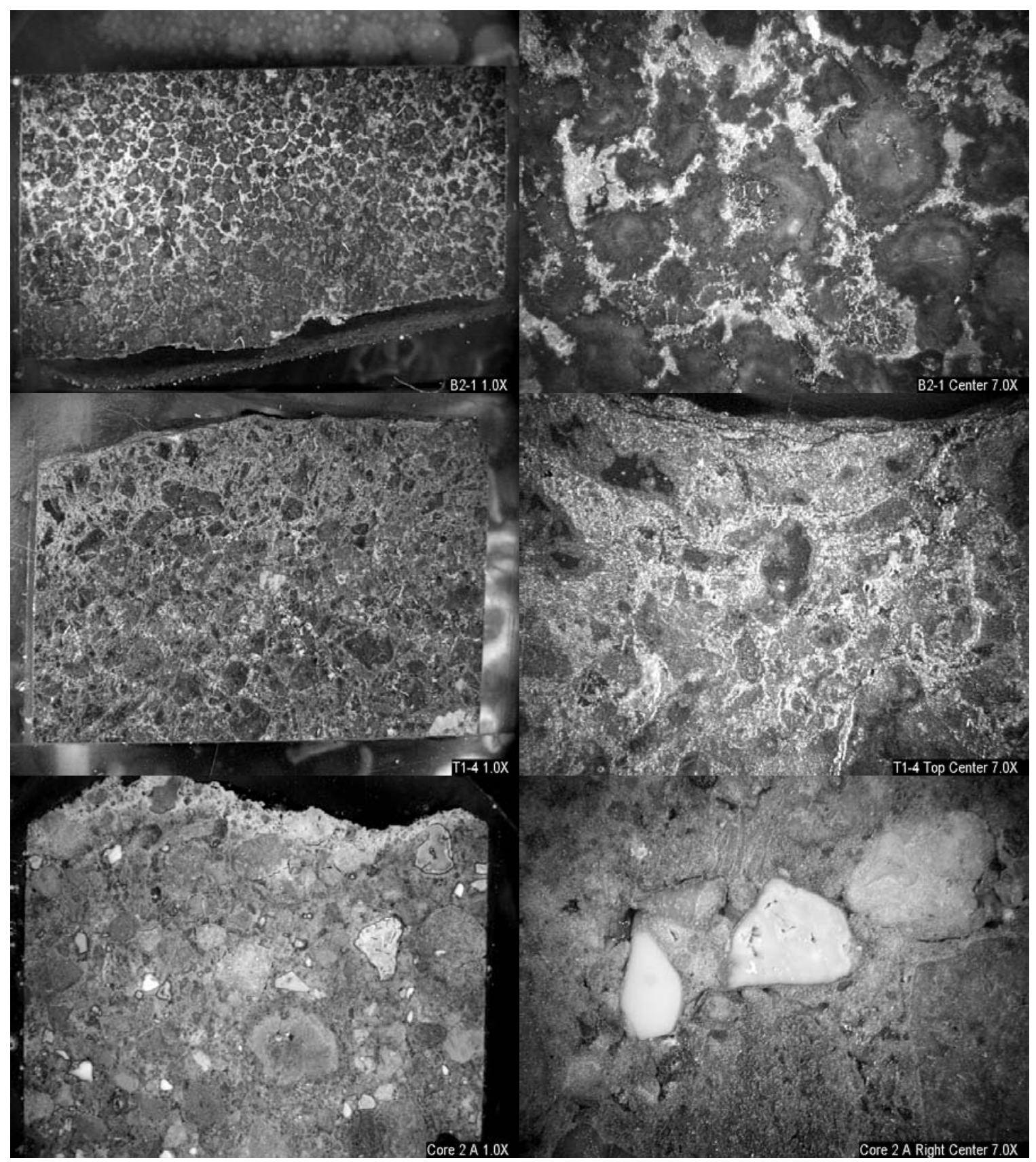

Figure 39. Examples of Optical Microscopy Results from Salvaged Aleris Aluminum Samples 

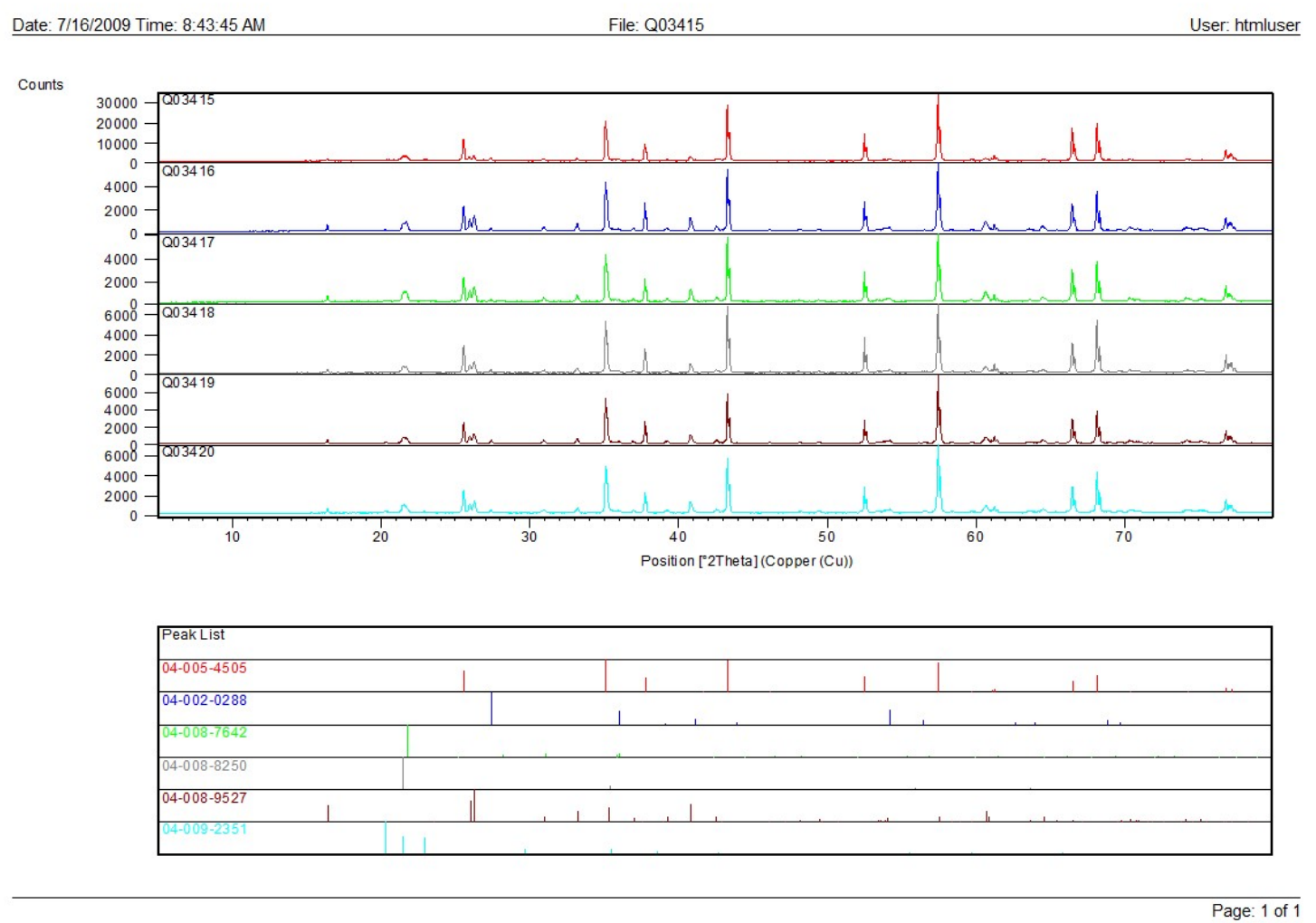

Figure 40. Example of XRD Results from Salvaged Aleris Aluminum Samples

Extensive mechanical and corrosive damage were found for samples in contact with molten metal, resulting in grain structure and phase changes within these regions. In metal line regions, some aluminum entering the bricks through porosity was oxidized to form metallic silicon. The metal formations then led to thermal shock from differing thermal expansions. Weakened aggregate in the material also appears to have caused fractures throughout the samples which led to reduced mechanical properties. Finally, it was found that the chemistry and phase composition of the samples remain constant beyond the limited surface reaction zones above the metal line. As contact with the melt increased, microstructural and macroscopic changes occurred to deeper core depths, increasing material failure from cracking.

SEM/EDS analysis was conducted on regions of interest based on the optical microscopy findings. Examples of SEM/EDS results are shown in Figure 41. It was found through the overall analysis of these samples that significant mechanical and corrosive damage occurs for samples in direct contact with molten metal, resulting in grain structure and phase changes within these regions. In metal line regions, formation of metallic silicon from the oxidation of aluminum metal was present and molten aluminum enters the system through porosity. Metal formations then lead to thermal shock from differing thermal expansions. Additionally, chlorine vapor from degassing reacts with alkali-based fluxes, forming salts within metal reaction zones. Weakened aggregate in the material appears to cause fractures throughout the samples and reduces mechanical properties. Previous research and 
thermodynamics show the formation of silicon through the oxidation of aluminum is favorable under operating conditions. Additionally, the wetting properties of the aluminum melt with respect to the mullite $\left(3 \mathrm{Al}_{2} \mathrm{O}_{3} * 2 \mathrm{SiO}_{2}\right)$ surface and the high porosity of the refractory material enhances the material corrosion through deeper penetration of the molten metal. Finally, it was found that the chemistry and phase composition of the samples remain constant beyond the limited surface reaction zones above the metal line, but at or below the metal line considerable microstructural and macroscopic changes are evident through the core depth.

a)
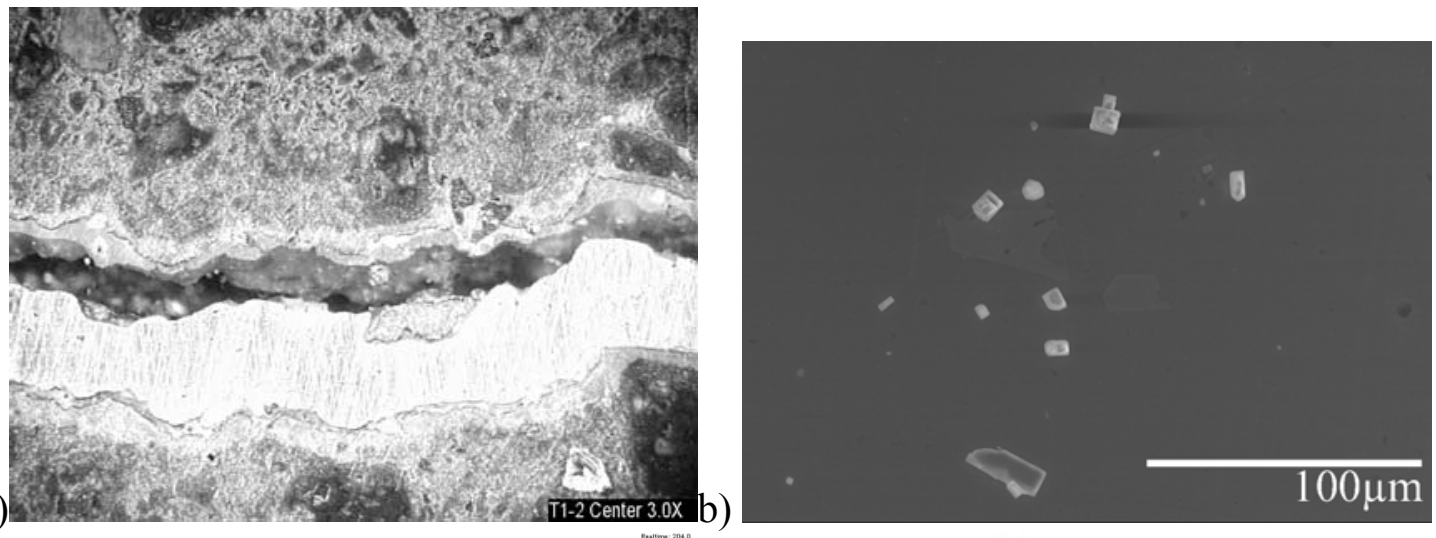

c)
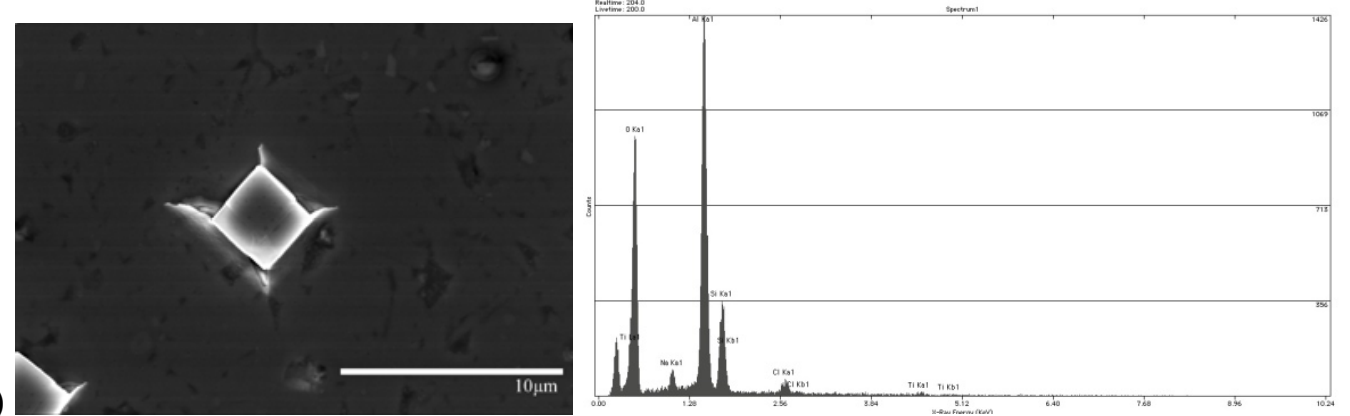

d)
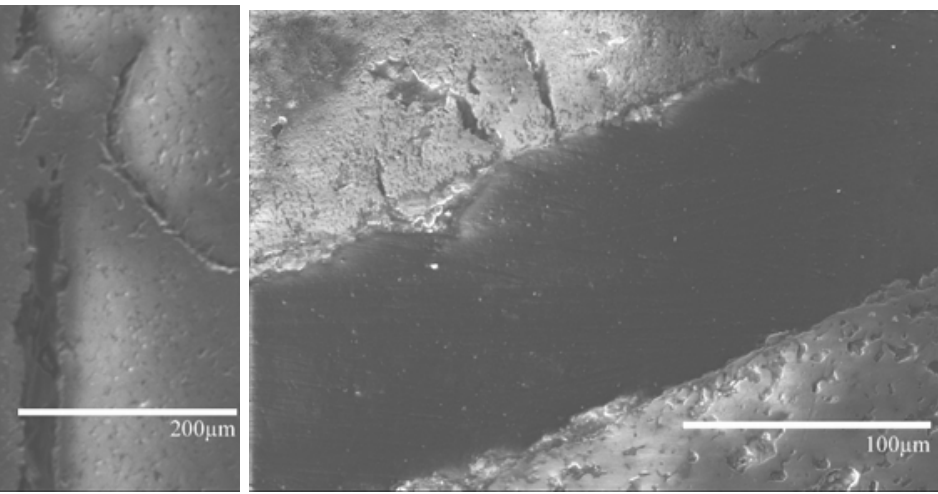

Figure 41. Examples of SEM/EDS Results from Salvaged Aleris Aluminum Samples

a-Metal formations resulting in fracture of samples due to differences in coefficient of thermal expansion between the metal and the ceramic matrix

$\mathrm{b}$ - Formations of cubic chloride salts and metals as determined by EDS

$\mathrm{c}-$ Cubic salt formation from below the metal line and accompanying EDS scan identifying it as a sodium chloride salt

$\mathrm{d}$ - Examples of cracking found in samples both within grains (left) due to weakened alumina aggregate and within matrix (right) due to mechanical damage 
The above analysis along with prior knowledge of aluminum contact refractories gained through a previous DOE Industrial Technologies Program (ITP) project was used in the consideration of materials for the Aleris reverberatory and rotary furnaces. Additionally, materials developed by MINTEQ were evaluated through aluminum immersion testing at ORNL and MS\&T as shown in Figure 42. Materials developed for use in aluminum reverberatory furnaces were also considered for use in the PPG glass reverberatory furnace application in the developed or a slightly altered form. Results from the MINTEQ developed refractories (high alumina materials) for aluminum contact were found to be favorable as shown in Figure 43.

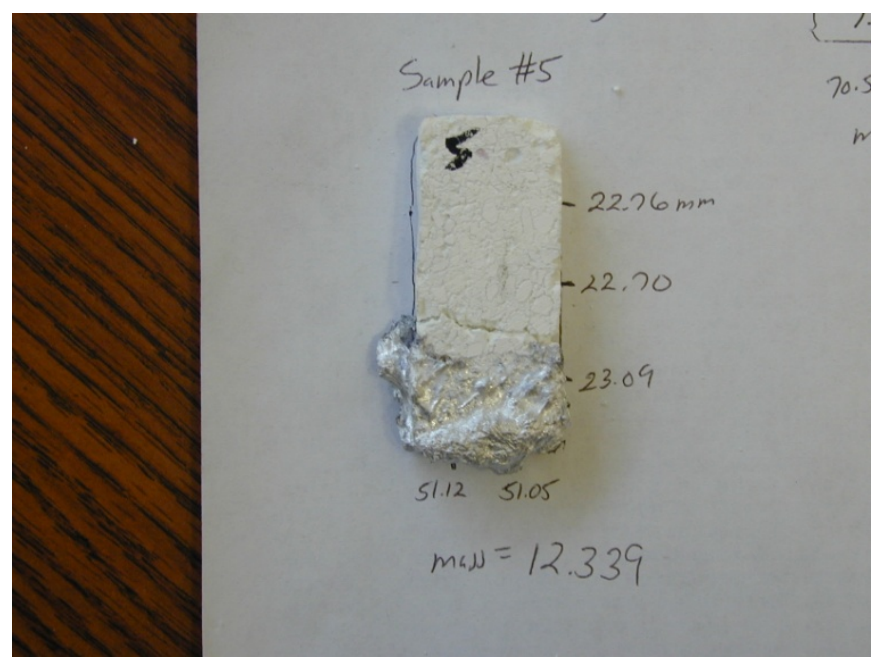

Figure 42. Test Sample of Current Aluminum Refractory Tested In ORNL Immersion Test

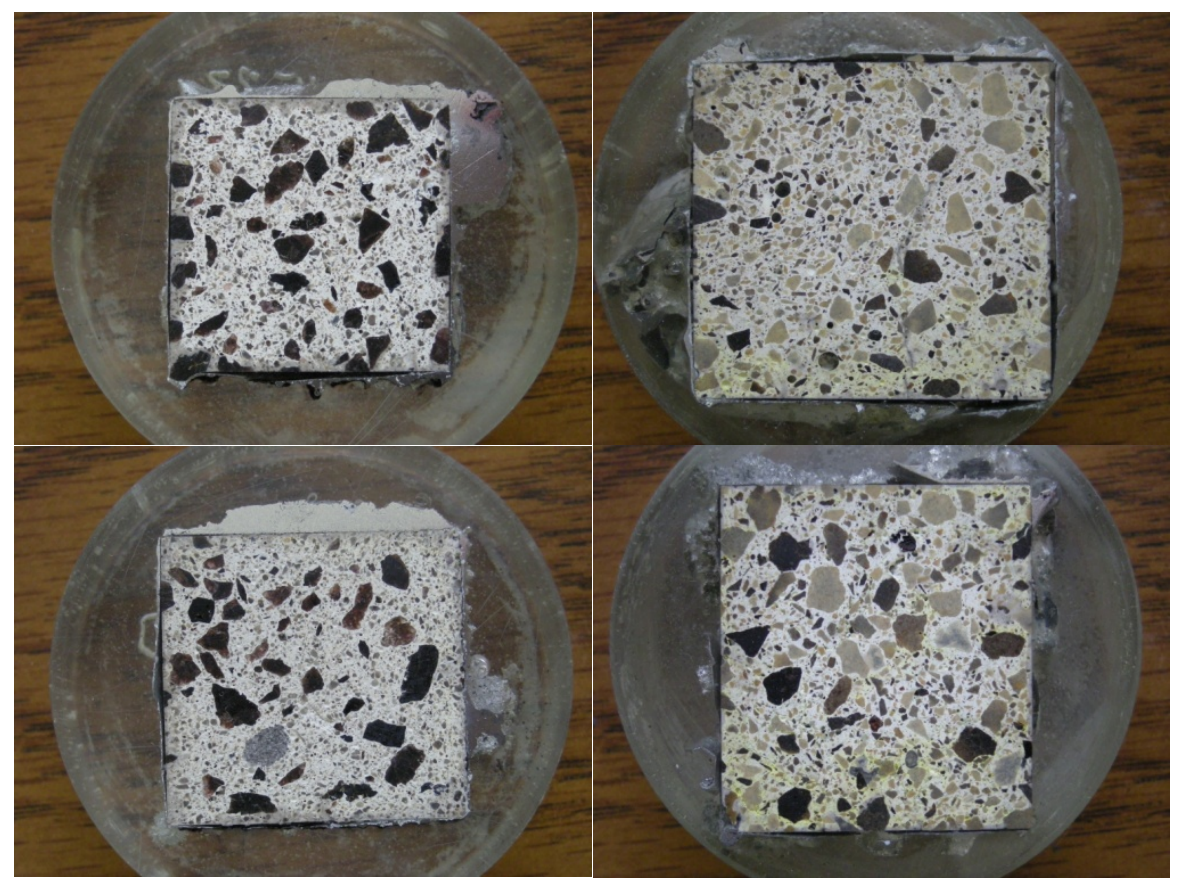

Figure 43. Immersion Test Samples of MINTEQ Developed Refractories for Aluminum

Additional corrosion testing of refractory materials produced by MINTEQ was conducted at MS\&T using a modified version of the Alcoa standardized cup test method which 
incorporates saturated steam and is believed to be a more extreme test. This test exposed deficiencies in these materials not previously seen in traditional cup or immersion testing and led to down selection of candidate refractory compositions by MINTEQ for aluminum applications. Pictures of exposed samples after sectioning are shown in Figure 44.

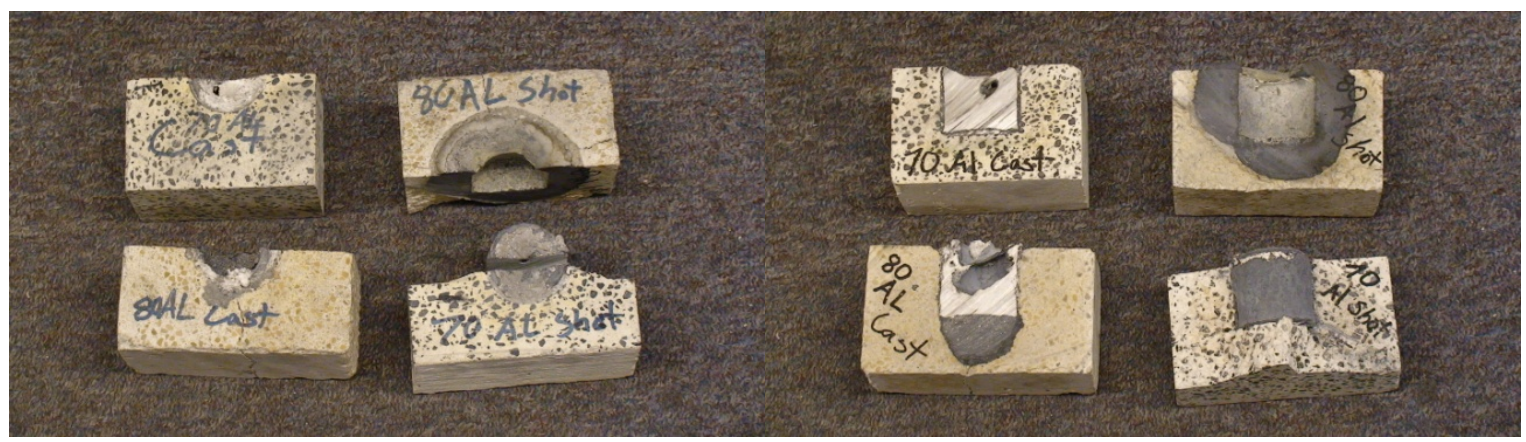

Figure 44. MINTEQ Refractory Samples Following Alcoa Standardized Cup Testing at MS\&T

XRD and X-ray Fluorescence (XRF) analysis were performed at MINTEQ on these samples, 70 and $80 \%$ alumina mateials. Magnesium penetration was seen in the $80 \%$ alumina material. Additionally, magnesium and calcium enrichment zones were seen at the hot side interface of the $70 \%$ alumina material that may inhibit slag penetration. The binder region of the $80 \%$ alumina material was also found to be more porous than that of the $70 \%$ alumina material.

Based on work performed by MINTEQ in collaboration with Corus Research Center (Netherlands), materials for aluminum applications were modified to improve their hot Modulus of Rupture (MOR) performance. Following modification, samples were tested for pumpability, hot MOR and other physical properties. Following this, the most promising material was shotcreted for evaluation through reheat testing and steam aluminum cup testing (performed at MS\&T). Materials were found to perform well as shown in Figure 45.

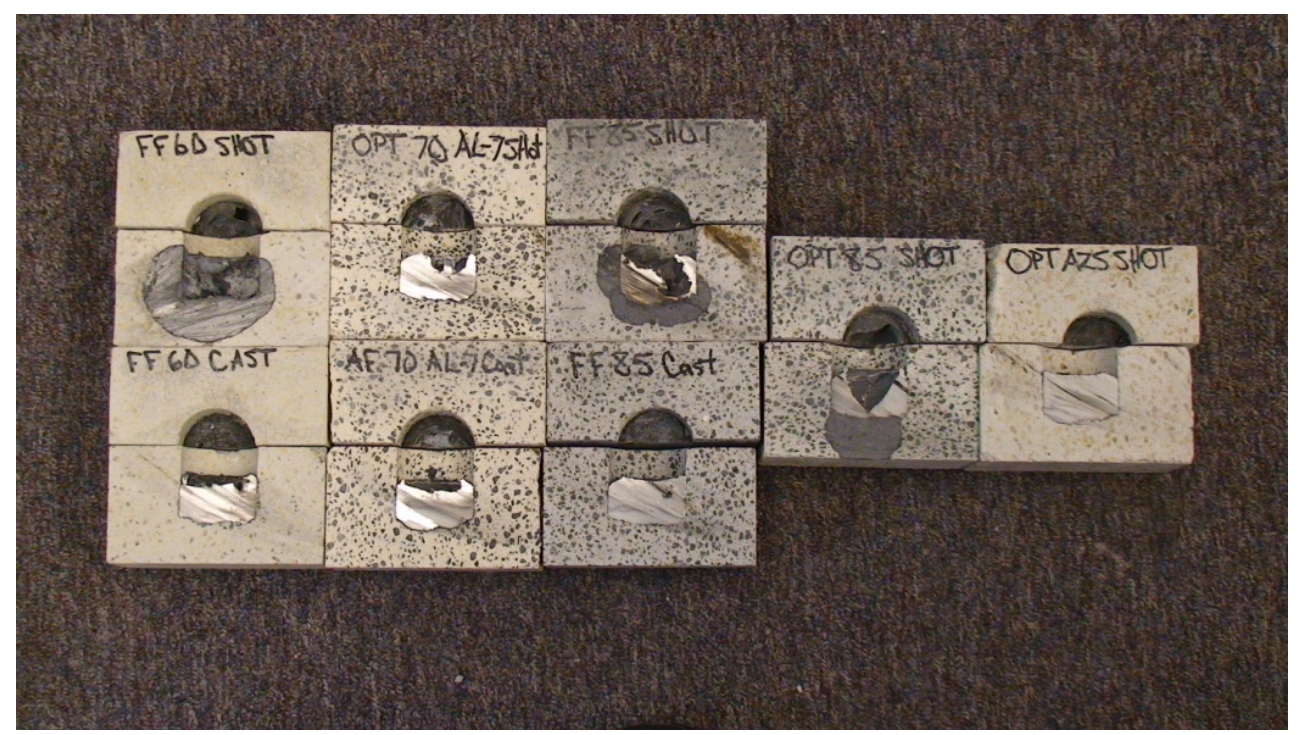

Figure 45. Materials After Steam Aluminum Cup Testing 
As a final validation of materials developed for aluminum applications, samples were evaluated by the "Alcoa Al Cup Test" performed by independent test laboratory Orton Ceramic. This test an even more extreme version of the steam cup testing performed at MS\&T. Both cast and shot versions of the material were evaluated. Samples were pre-fired at 871 and $1260^{\circ} \mathrm{C}\left(1600\right.$ and $\left.2300^{\circ} \mathrm{F}\right)$ before being tested at $815^{\circ} \mathrm{C}\left(1500^{\circ} \mathrm{F}\right)$ for 72 hours in alloy 7075 aluminum, according to Alcoa specifications. Tested samples are shown below in Figure 46.
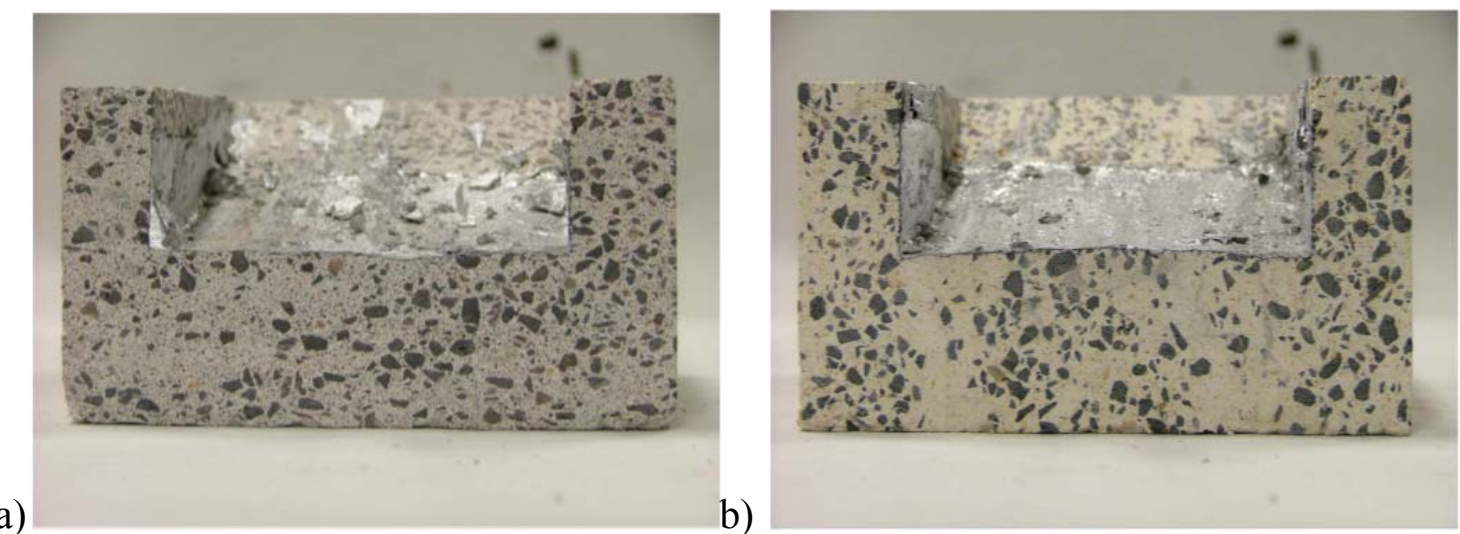

a)
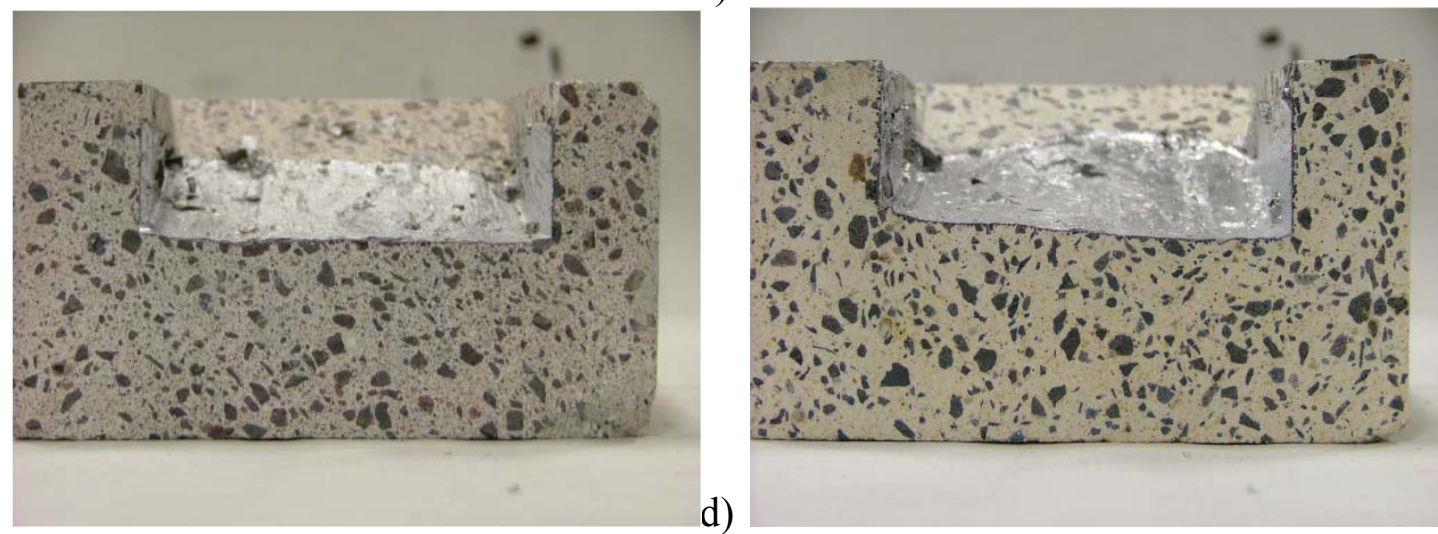

Figure 46. Aluminum Cup Penetration Test Samples in from "Alcoa Al Cup Test"

Performed in 7075 Aluminum Alloy

(a - shot sample pre-fired at $871^{\circ} \mathrm{C}, \mathrm{b}$ - shot sample pre-fired at $1260^{\circ} \mathrm{C}$, $\mathrm{c}$ - cast sample pre-fired at $871^{\circ} \mathrm{C}, \mathrm{d}$ - cast sample pre-fired at $1260^{\circ} \mathrm{C}$ )

All samples were rated as "excellent". Before and after test chemical analyses showing specific elemental penetrations are shown in Table 12 through Table 15. 
Table 12. Aluminum Cup Test Results for Shot Sample Pre-fired at $871^{\circ} \mathrm{C}$

\begin{tabular}{|c|c|c|c|c|}
\hline \multirow[b]{2}{*}{$\begin{array}{l}\text { Element } \\
\text { Analysis }\end{array}$} & \multirow[b]{2}{*}{$\begin{array}{l}\text { ASM } \\
\text { Spec. }\end{array}$} & \multirow[b]{2}{*}{$\begin{array}{l}\text { Before } \\
\text { Test } \\
\text { Sample }\end{array}$} & \multicolumn{2}{|c|}{ After Test Analyses ${ }^{a-c}$} \\
\hline & & & $\begin{array}{l}\text { Material } \\
\text { Preparation } \\
\text { Prefire Temp. } \\
\text { Test Temp. }\end{array}$ & $\begin{array}{l}\text { ROTASHOT AL (Sample \#1) } \\
\text { As Received } \\
1600^{\circ} \mathrm{F} \\
1500^{\circ} \mathrm{F}(72 \text { HOURS })\end{array}$ \\
\hline $\mathrm{Si}$ & $0.5 \max$ & 0.064 & & 0.27 \\
\hline $\mathrm{Fe}$ & $0.7 \max$ & 0.21 & & 0.24 \\
\hline $\mathrm{Mg}$ & $2.1-2.9$ & 2.21 & & 1.27 \\
\hline $\mathrm{Ti}$ & $0.2 \max$ & 0.026 & & 0.031 \\
\hline $\mathrm{Cu}$ & $1.2-2.0$ & 1.57 & & 1.68 \\
\hline $\mathrm{Mn}$ & $0.3 \max$ & 0.034 & & 0.036 \\
\hline $\mathrm{Zn}$ & 5.1-6.1 & 5.60 & & 5.88 \\
\hline $\mathrm{Cr}$ & $.18-.40$ & 0.18 & & 0.20 \\
\hline $\mathrm{Zr}$ & & 0.002 & & 0.002 \\
\hline
\end{tabular}

a Tested at $1500^{\circ} \mathrm{F}$ for $72 \mathrm{hrs}$ per Alcoa specification dated 4/17/91.

${ }^{b}$ The sample exhibited no visual reaction, discoloration, or metal penetration and was rated excellent per Milauskas (Ceram. Eng. Sci. Proc., 8 [1-2] 50-62 (1987)) photographic examples.

Table 13. Aluminum Cup Test Results for Shot Sample Pre-fired at $1260^{\circ} \mathrm{C}$

\begin{tabular}{|c|c|c|c|c|}
\hline \multirow[b]{2}{*}{$\begin{array}{l}\text { Element } \\
\text { Analysis }\end{array}$} & \multirow[b]{2}{*}{$\begin{array}{l}\text { ASM } \\
\text { Spec. }\end{array}$} & \multirow[b]{2}{*}{$\begin{array}{l}\text { Before } \\
\text { Test } \\
\text { Sample }\end{array}$} & \multicolumn{2}{|c|}{ After Test Analyses ${ }^{a-c}$} \\
\hline & & & $\begin{array}{l}\text { Material } \\
\text { Preparation } \\
\text { Prefire Temp. } \\
\text { Test Temp. }\end{array}$ & $\begin{array}{l}\text { ROTASHOT AL (Sample \#2) } \\
\text { As Received } \\
2300^{\circ} \mathrm{F} \\
1500^{\circ} \mathrm{F} \text { (72 HOURS) }\end{array}$ \\
\hline $\mathrm{Si}$ & $0.5 \max$ & 0.064 & & 0.30 \\
\hline $\mathrm{Fe}$ & $0.7 \max$ & 0.21 & & 0.24 \\
\hline $\mathrm{Mg}$ & $2.1-2.9$ & 2.21 & & 1.07 \\
\hline $\mathrm{Ti}$ & $0.2 \max$ & 0.026 & & 0.041 \\
\hline $\mathrm{Cu}$ & $1.2-2.0$ & 1.57 & & 1.68 \\
\hline $\mathrm{Mn}$ & $0.3 \max$ & 0.034 & & 0.037 \\
\hline $\mathrm{Zn}$ & $5.1-6.1$ & 5.60 & & 5.87 \\
\hline $\mathrm{Cr}$ & $.18-.40$ & 0.18 & & 0.21 \\
\hline $\mathrm{Zr}$ & & 0.002 & & 0.004 \\
\hline
\end{tabular}

a Tested at $1500^{\circ} \mathrm{F}$ for 72 hrs per Alcoa specification dated 4/17/91.

${ }^{b}$ The sample exhibited no visual reaction, discoloration, or metal penetration and was rated excellent per Milauskas (Ceram. Eng. Sci. Proc., 8 [1-2] 50-62 (1987)) photographic examples. 
Table 14. Aluminum Cup Test Results for Cast Sample Pre-fired at $871^{\circ} \mathrm{C}$

After Test Analyses ${ }^{a-c}$

\begin{tabular}{|c|c|c|c|c|}
\hline \multirow[b]{2}{*}{$\begin{array}{l}\text { Element } \\
\text { Analysis }\end{array}$} & \multirow[b]{2}{*}{$\begin{array}{l}\text { ASM } \\
\text { Spec. }\end{array}$} & \multirow[b]{2}{*}{$\begin{array}{l}\text { Before } \\
\text { Test } \\
\text { Sample }\end{array}$} & \\
\hline & & & $\begin{array}{l}\text { Material } \\
\text { Preparation } \\
\text { Prefire Temp. } \\
\text { Test Temp. }\end{array}$ & $\begin{array}{l}\text { ROTACAST AL (Sample \#3) } \\
\text { As Received } \\
1600^{\circ} \mathrm{F} \\
1500^{\circ} \mathrm{F} \text { ( } 72 \text { HOURS) }\end{array}$ \\
\hline $\mathrm{Si}$ & $0.5 \max$ & 0.064 & & 0.28 \\
\hline $\mathrm{Fe}$ & $0.7 \max$ & 0.21 & & 0.23 \\
\hline $\mathrm{Mg}$ & $2.1-2.9$ & 2.21 & & 1.16 \\
\hline $\mathrm{Ti}$ & $0.2 \max$ & 0.026 & & 0.035 \\
\hline $\mathrm{Cu}$ & $1.2-2.0$ & 1.57 & & 1.64 \\
\hline $\mathrm{Mn}$ & $0.3 \max$ & 0.034 & & 0.036 \\
\hline $\mathrm{Zn}$ & $5.1-6.1$ & 5.60 & & 5.82 \\
\hline $\mathrm{Cr}$ & $.18-.40$ & 0.18 & & 0.20 \\
\hline $\mathrm{Zr}$ & & 0.002 & & 0.002 \\
\hline
\end{tabular}

\footnotetext{
a Tested at $1500^{\circ} \mathrm{F}$ for $72 \mathrm{hrs}$ per Alcoa specification dated 4/17/91.

' The sample exhibited no visual reaction, discoloration, or metal penetration and was rated excellent per Milauskas (Ceram. Eng. Sci. Proc., 8 [1-2] 50-62 (1987)) photographic examples.
}

Table 15. Aluminum Cup Test Results for Cast Sample Pre-fired at $1260^{\circ} \mathrm{C}$

\begin{tabular}{|c|c|c|c|c|}
\hline \multirow[b]{2}{*}{$\begin{array}{l}\text { Element } \\
\text { Analysis }\end{array}$} & \multirow[b]{2}{*}{$\begin{array}{l}\text { ASM } \\
\text { Spec. }\end{array}$} & \multirow[b]{2}{*}{$\begin{array}{l}\text { Before } \\
\text { Test } \\
\text { Sample }\end{array}$} & \multicolumn{2}{|c|}{ After Test Analyses ${ }^{a-c}$} \\
\hline & & & $\begin{array}{l}\text { Material } \\
\text { Preparation } \\
\text { Prefire Temp. } \\
\text { Test Temp. }\end{array}$ & $\begin{array}{l}\text { ROTACAST AL (Sample \#4) } \\
\text { As Received } \\
2300^{\circ} \mathrm{F} \\
1500^{\circ} \mathrm{F} \text { ( } 72 \text { HOURS) }\end{array}$ \\
\hline $\mathrm{Si}$ & $0.5 \max$ & 0.064 & & 0.52 \\
\hline $\mathrm{Fe}$ & $0.7 \max$ & 0.21 & & 0.24 \\
\hline $\mathrm{Mg}$ & $2.1-2.9$ & 2.21 & & 1.00 \\
\hline $\mathrm{Ti}$ & $0.2 \max$ & 0.026 & & 0.040 \\
\hline $\mathrm{Cu}$ & $1.2-2.0$ & 1.57 & & 1.64 \\
\hline $\mathrm{Mn}$ & $0.3 \max$ & 0.034 & & 0.037 \\
\hline $\mathrm{Zn}$ & 5.1-6.1 & 5.60 & & 5.84 \\
\hline $\mathrm{Cr}$ & $.18-.40$ & 0.18 & & 0.21 \\
\hline $\mathrm{Zr}$ & & 0.002 & & 0.003 \\
\hline
\end{tabular}

\footnotetext{
a Tested at $1500^{\circ} \mathrm{F}$ for $72 \mathrm{hrs}$ per Alcoa specification dated 4/17/91.

b The sample exhibited no visual reaction, discoloration, or metal penetration and was rated excellent per Milauskas (Ceram. Eng. Sci. Proc., 8 [1-2] 50-62 (1987)) photographic examples.
}

Refractories for Lime Kilns

Corrosion evaluation of materials currently used for the lime kiln application was performed through cup testing at MS\&T and ORNL. Samples of Armor Flow 80AL, Optishot 80AL, and FastFire 60 were evaluated at MS\&T. Examples of the results are shown below in Figure 47. The 80AL materials (labeled "85 Shot" and "85 Cast" below) were originally designed for aluminum contact applications, but were tested here as a benchmark due to their high alumina content. As can be seen they performed poorly. The Fastfire 60 (shot and cast samples) were designed for lime contact and are seen to perform better, with the shot material outperforming the cast material. Initial testing of materials developed by MINTEQ for use in lime kiln applications (Figure 48) showed a need for further development. 


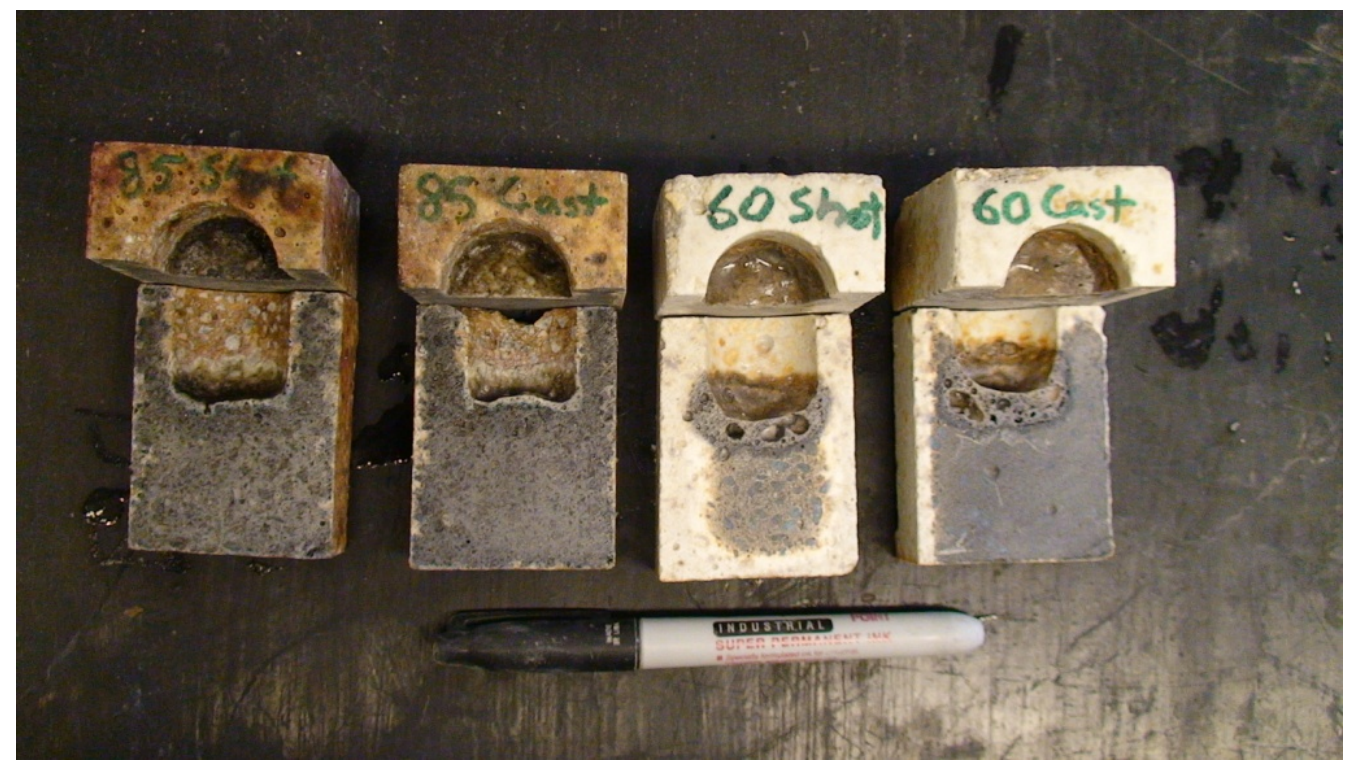

Figure 47. MS\&T Lime Corrosion Cup Test Results

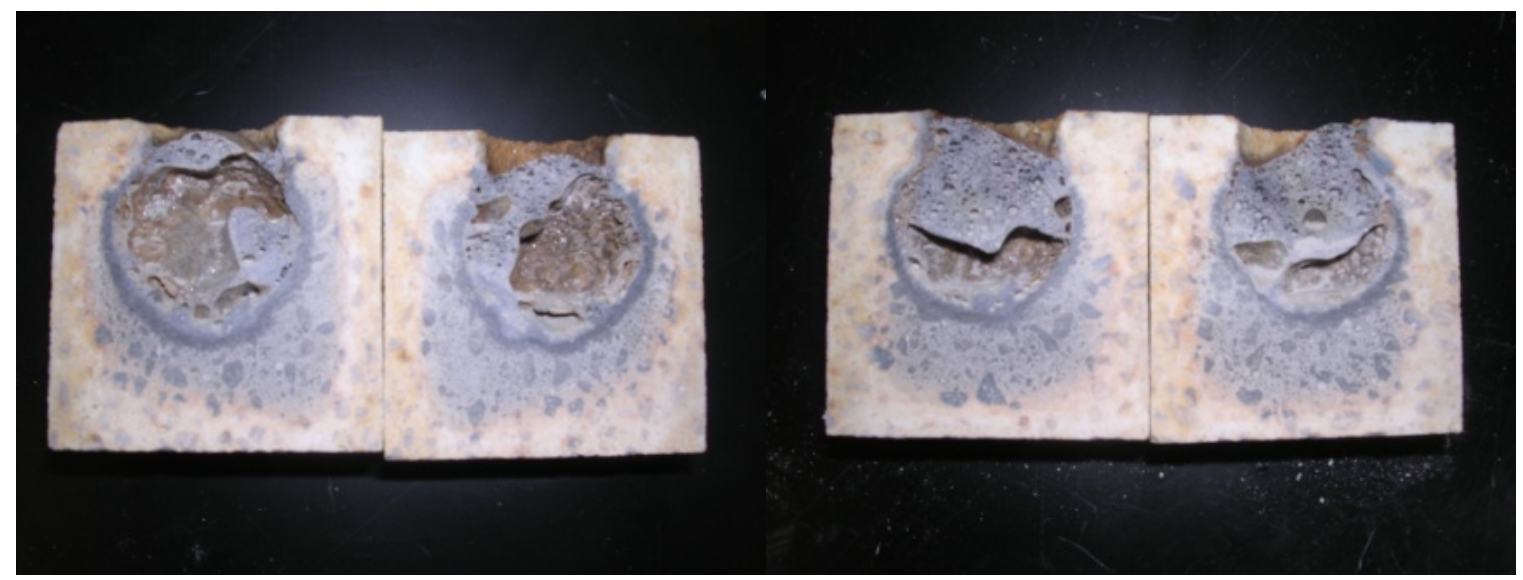

Figure 48. Lime Mud Cup Test Samples of MINTEQ Developed Refractories for Lime Kilns

Therefore, work was continued between Weyerhaeuser and MINTEQ on refractories for this application. Shotcretes coupled with an advanced design insulating safety lining were considered based on modeling efforts described elsewhere in this report. In support of this effort, analysis of salvaged refractory brick provided by Weyerhaeuser was performed at ORNL and MS\&T. Polished samples were prepared from cores taken from these bricks and analyzed by cathodoluminescence (CL), optical microscopy, and SEM/EDS. Slag penetration was found to occur only in the outer two to three areas (hot face) where penetration appears to have attacked the matrix and alumina grains. It should be noted though, that this brick had been reduced by to almost half its original thickness during the seven year furnace campaign. Pictures of the prepared core samples, examples of CL and optical results, and SEM micrographs are shown in Figure 49. 
a)

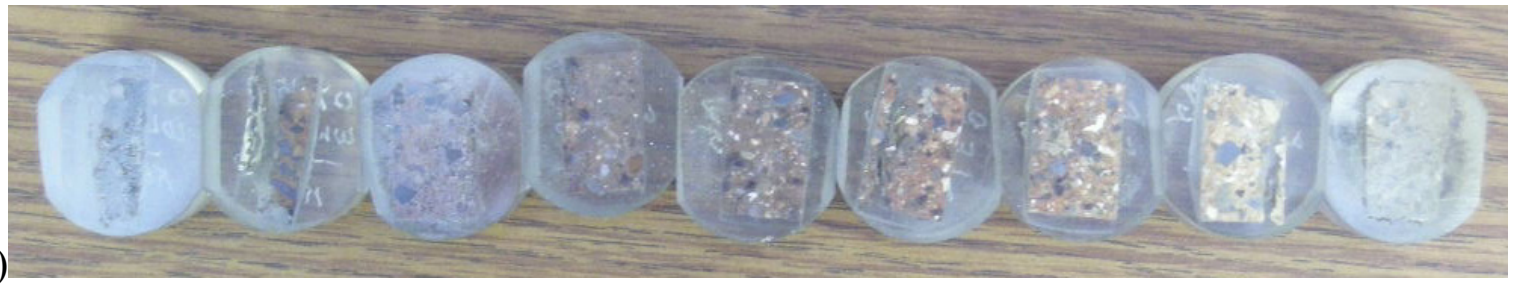

b)
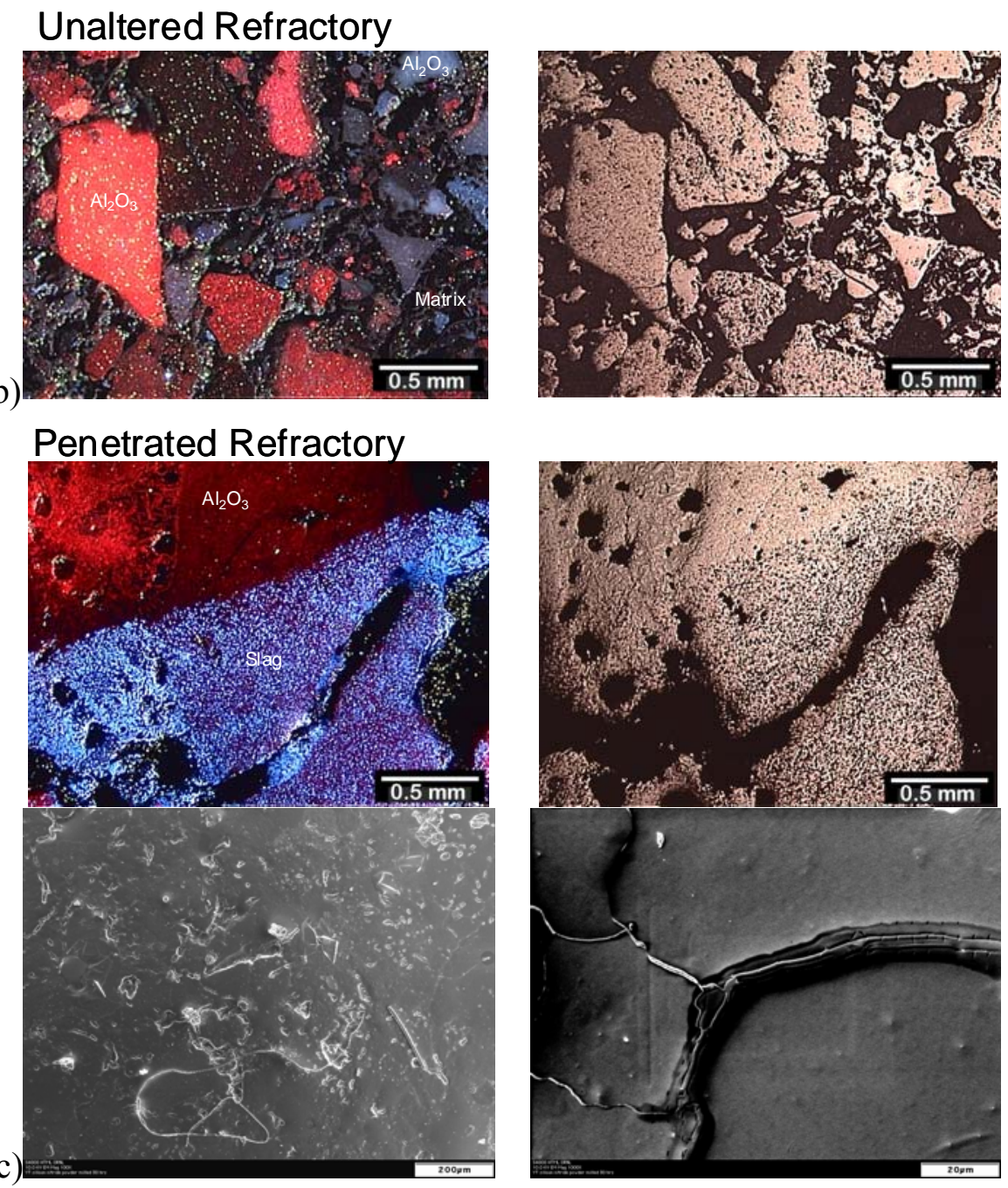

Figure 49. Analysis of Salvaged Refractory Brick Provided by Weyerhaeuser

Polished samples (a) were prepared from cores taken from provided bricks and analyzed by cathodoluminescence (CL) (b), and SEM/EDS (c).

Three additional samples were analyzed representing the hot face, middle interior region, and cold face of the brick. The hot face was found to show a dark reaction zone and layered structure with well defined, discrete phases or brick aggregates poorly resolved. Al and $\mathrm{Al} / \mathrm{Si}$ rich phases were found to be present throughout the brick, along with $\mathrm{P}, \mathrm{K}$ and $\mathrm{Mg}$. $\mathrm{Na}$ enrichment appears to occur on the hot face and $\mathrm{Ca}$ levels were found to be variable through the structure with higher levels found toward the cold face. CaSi and $\mathrm{CaAl}$ phases were found in the middle interior region. 
Analyses of MINTEQ developed refractory lime cup samples were also performed by MINTEQ (Figure 50).

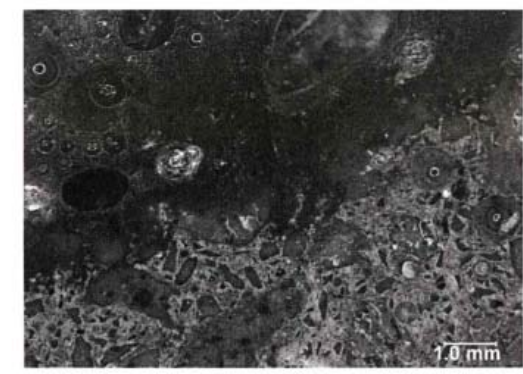

L19168_0_000c.jpg

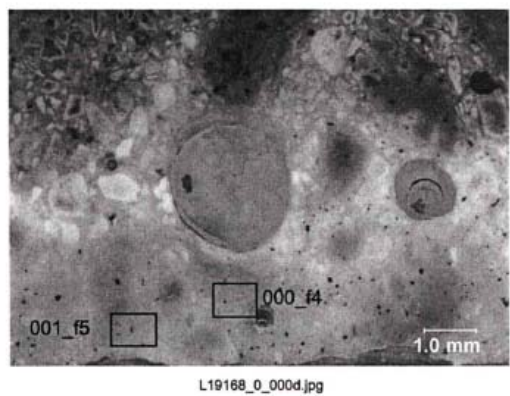

LOM Figure 1b. Fastire 60, 5192-57c:000c - center affected, 000d - center unaffected

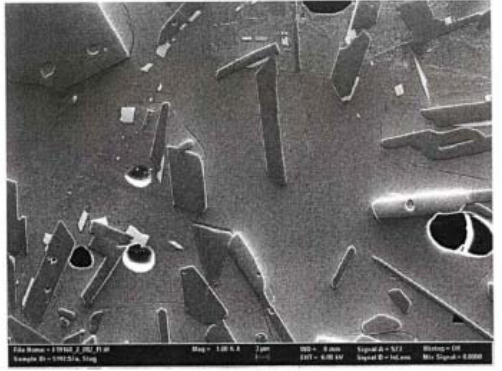

F19168_2_002_f1.tif

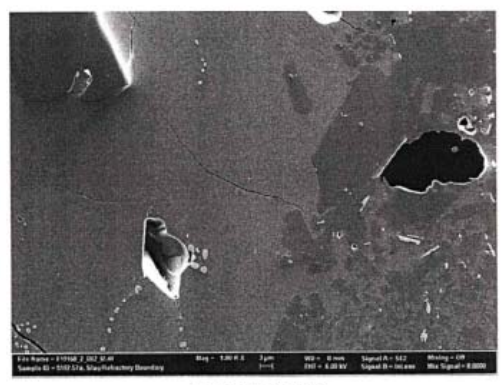

F19168_2_002_t2.tt

FESEM Figure 5a-5192-57a: slag region (111) and siagrefractory boundar (12)
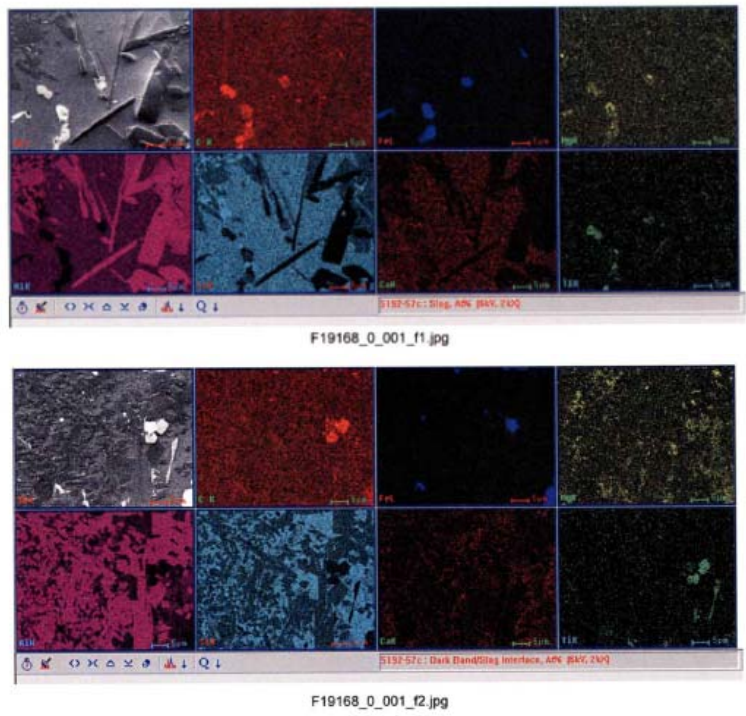

XEDS Figure 2a. Elemental map from slag (11) and slag/dark band boundary (12)

Figure 50. Analyses of Samples from Lime Cup Testing Performed by MINTEQ Using Field Emission Scanning Electron Microscopy (FESEM)

Post mortem studies using Field Emission Scanning Electron Microscopy (FESEM) showed the expected reactions between $\mathrm{CaO}$ and the tested shotcrete materials at temperatures above $1400^{\circ} \mathrm{C}$ with major reaction at $1500^{\circ} \mathrm{C}$. It was found that the reaction products were mainly the formation of corundum and anorthite, with minor discrete phases of iron, titanium carbide, and/calcium titanium oxide also seen. It was expected that the continuous feeding of lime (as would be present in an actual lime kiln) may lead to formation of gaonite as well. 
Based on the relative amounts of $\mathrm{CaO}$ and $\mathrm{Al}_{2} \mathrm{O}_{3} * \mathrm{SiO}_{2}$ found from the cup test, it appeared that the $\mathrm{CaO}-\mathrm{Al}_{2} \mathrm{O}_{3}-\mathrm{SiO}_{2}$ phase diagram could be used to describe these reactions. Analysis of newly developed basic brick showed no reaction at various test temperatures of 1100 $1500^{\circ} \mathrm{C}$.

$\mathrm{CaO}-\mathrm{Al}_{2} \mathrm{O}_{3}-\mathrm{SiO}_{2}$

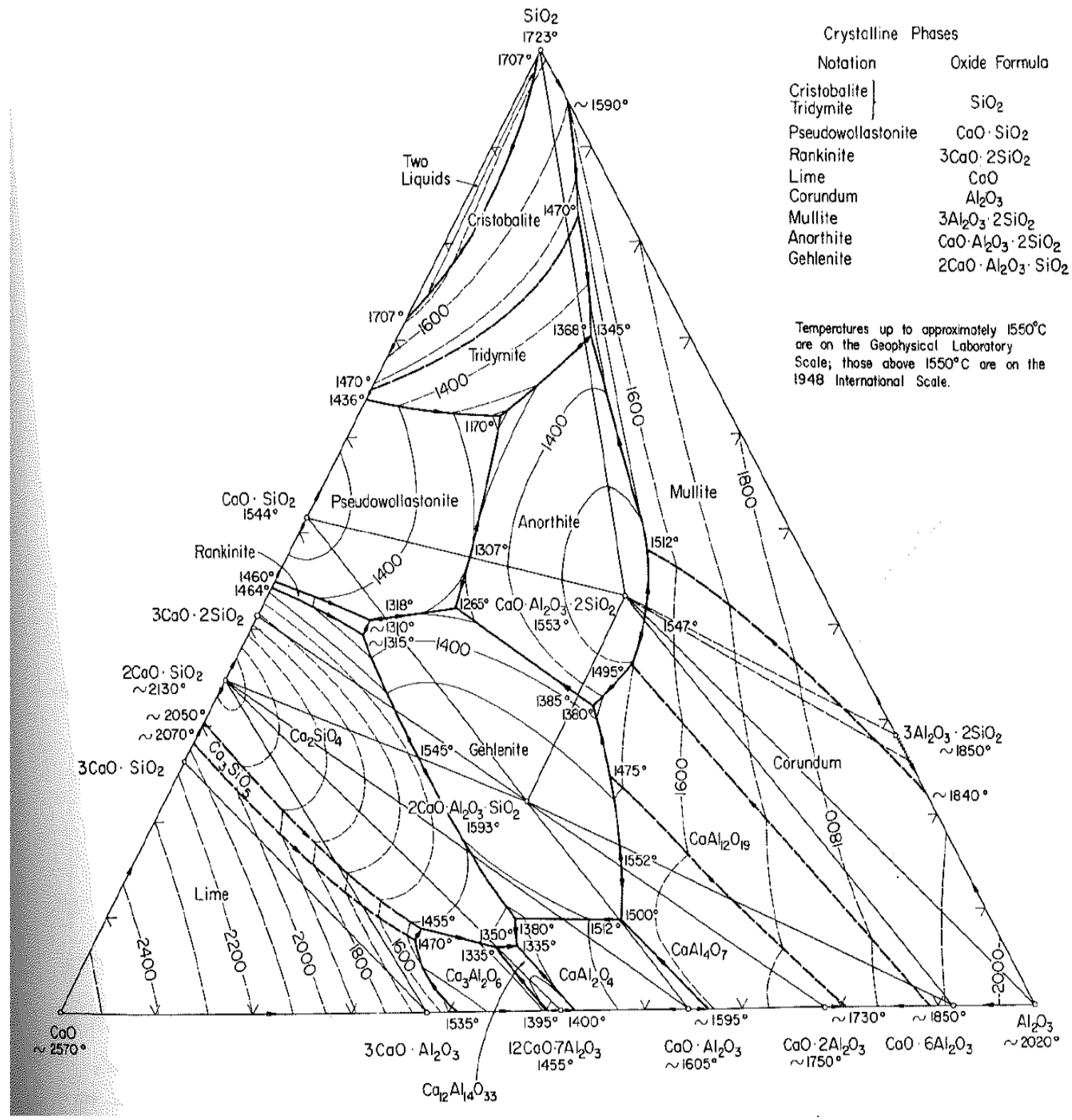

Figure 51. $\mathrm{CaO}-\mathrm{Al}_{2} \mathrm{O}_{3}-\mathrm{SiO}_{2}$ Phase Diagram ${ }^{\text {iv }}$

This magnesia rich spinel forming refractory composition was further modified to circumvent hydration issues related to cracking during drying. Cup testing of this product by MINTEQ at $1400^{\circ} \mathrm{C}$ showed no adherence to lime mud as shown in Figure 52.

\footnotetext{
${ }^{\text {iv }}$ Phase Diagrams for Ceramists Volume I, Edited by: E.M. Levin, C.R. Robbins, and H.F. McMurdie, Fig. 630, The American Ceramic Society, Inc. (1964).
} 


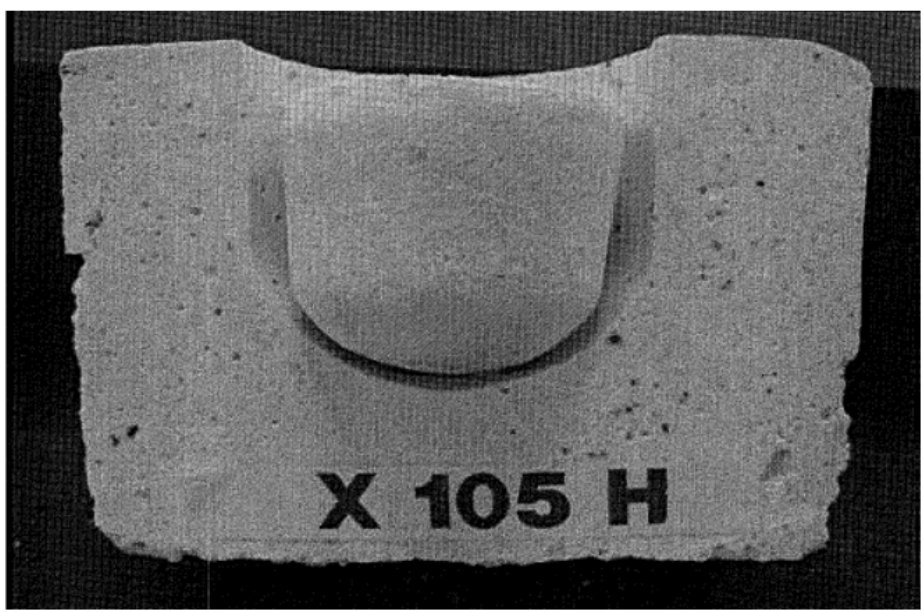

Figure 52. Lime Mud Testing of Experimental Refractory Spinel Former (B) for Lime Kiln Application

Initial results from cup tests run on this material at ORNL are shown in Figure 53. As can be seen, similar to the results at MINTEQ, there was no interaction of the lime mud with the refractory and the resulting plug of melted material freely falls from the cup leaving no sign of attack.
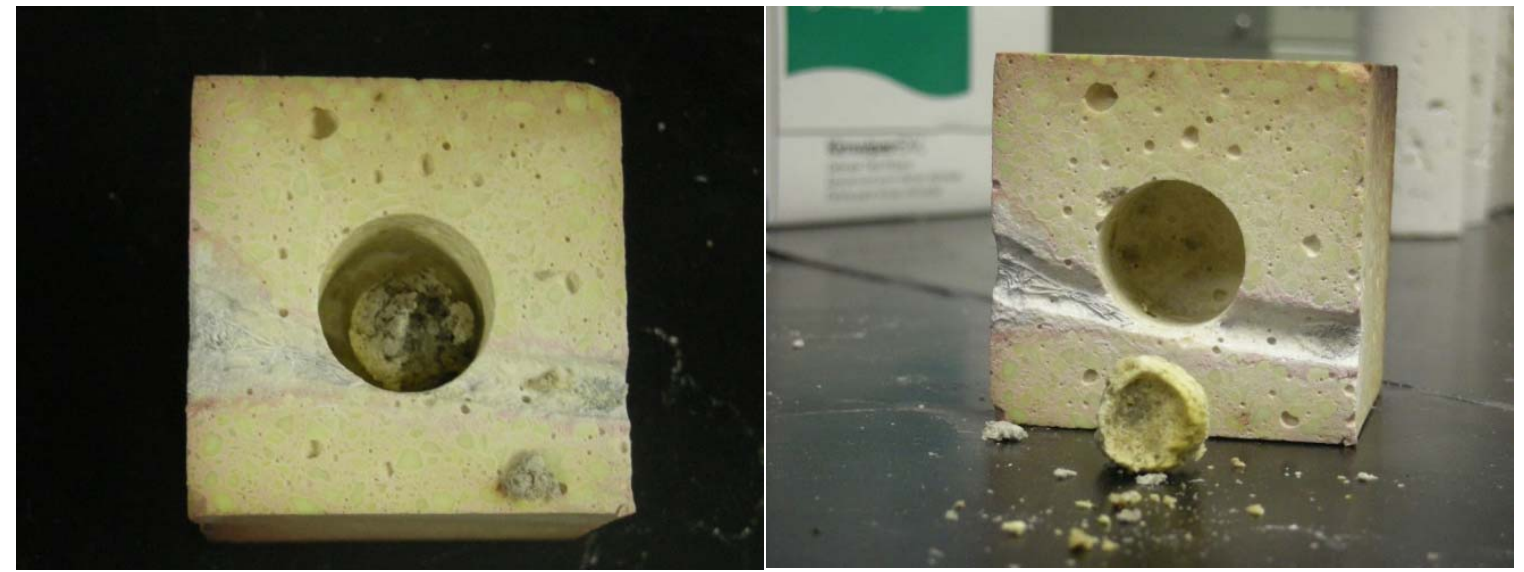

Figure 53. ORNL Lime Corrosion Cup Testing of Spinel Former (B) Material

Following this success, additional lime mud cup testing was performed at ORNL to further assess the corrosion resistance of new spinel forming and magnesia-rich shotcrete formulations. Results of testing showed them to again perform very well, with no penetration of the lime mud into the refractory. Similar to what was previously seen, lime plugs were found to solidify and fall out of the cup with no adherence to the cup surface. Examples of the additional lime cup testing results are shown in Figure 54. Testing was also replicated at MINTEQ as shown in Figure 55. 

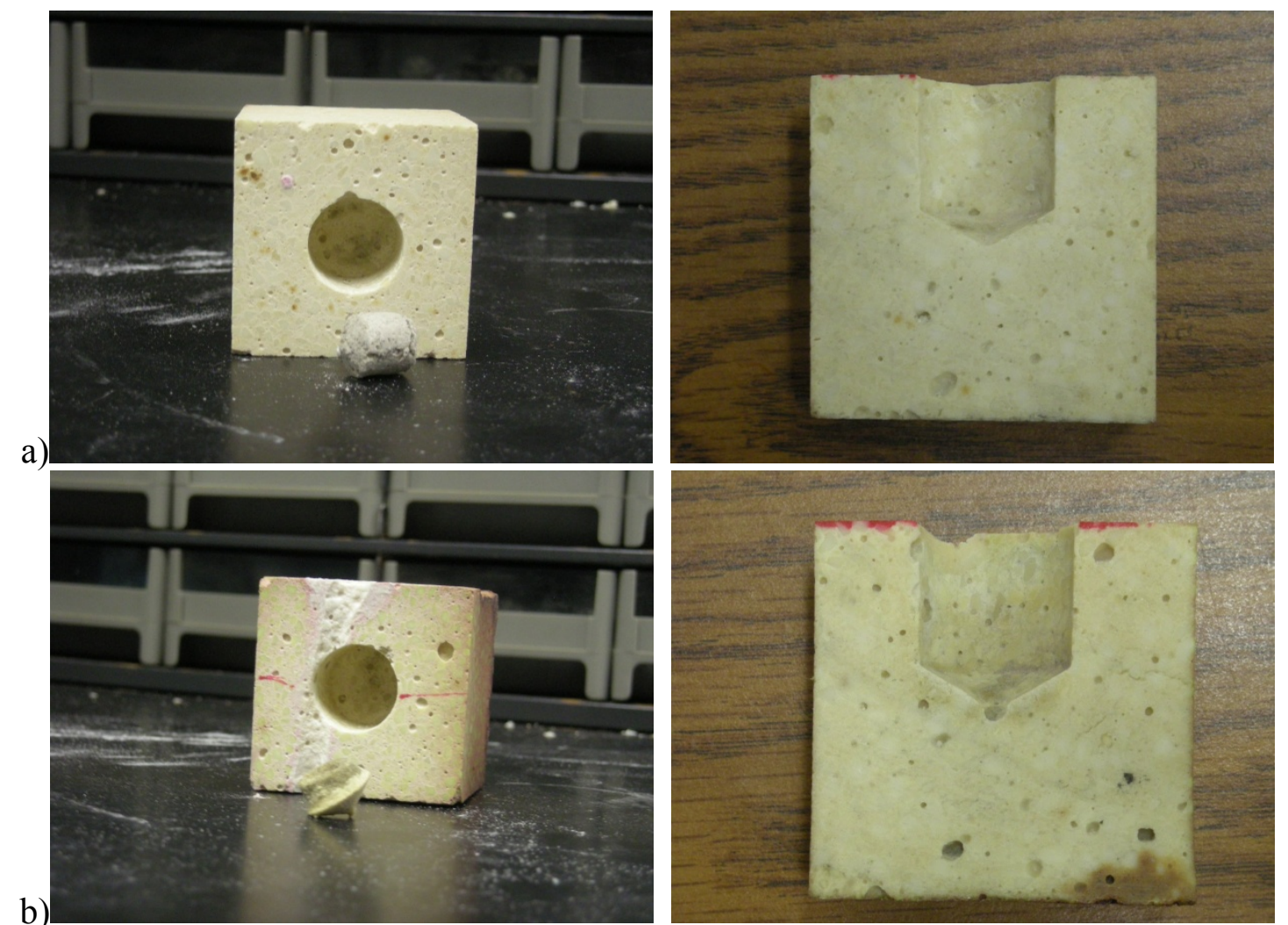

b)
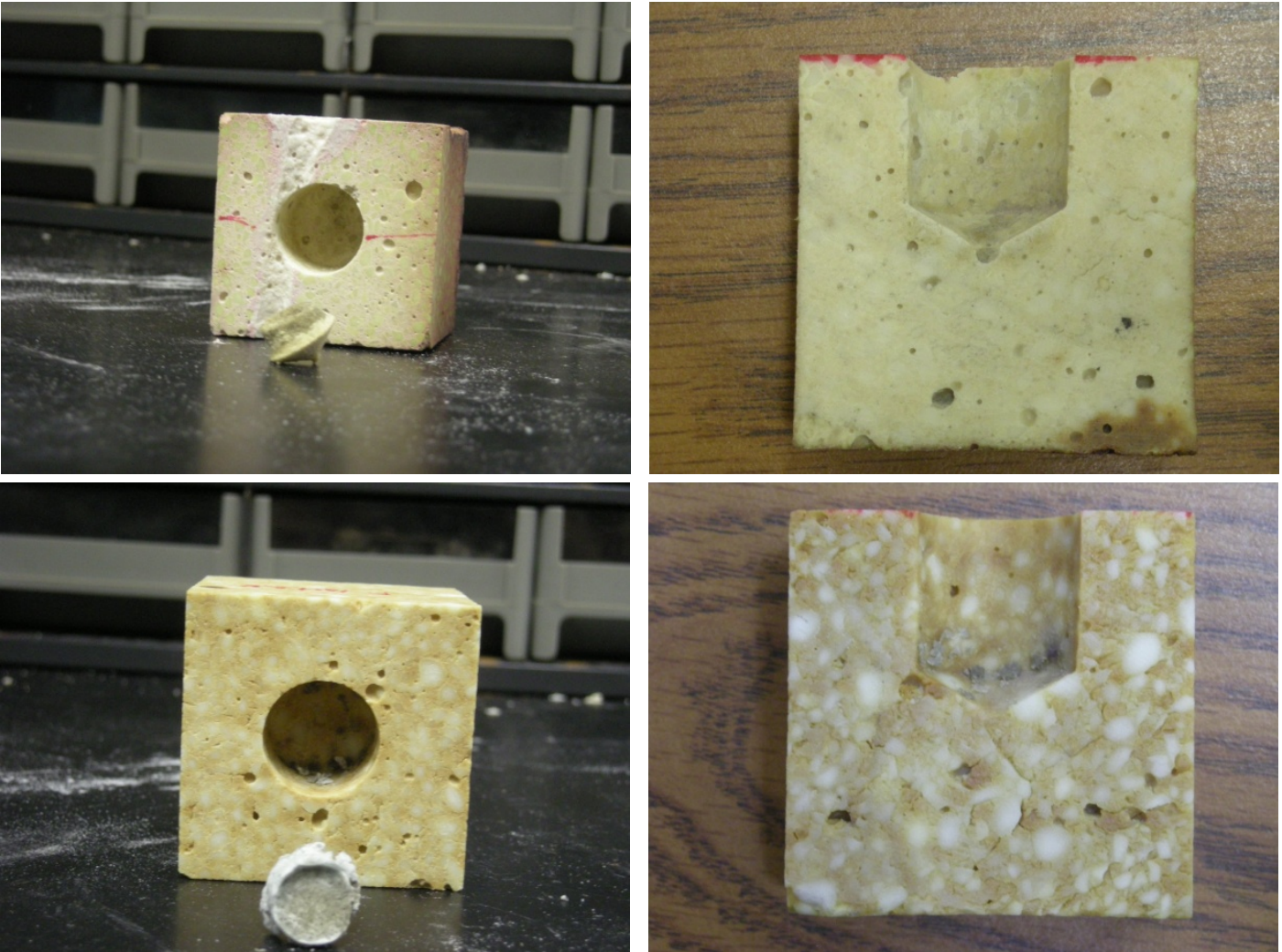

c)

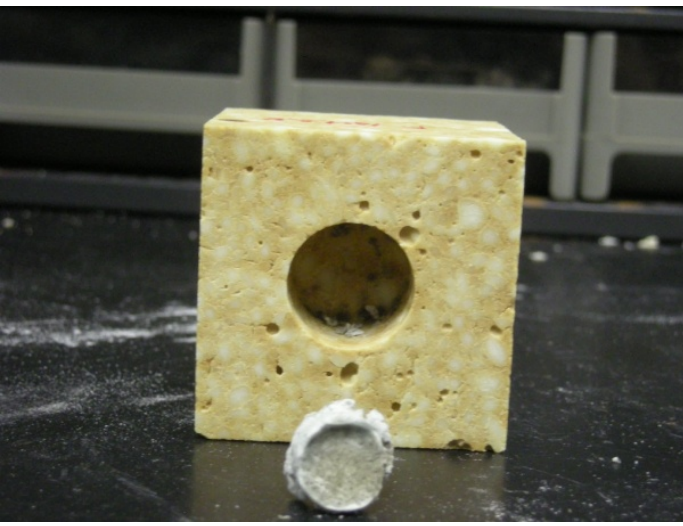

Figure 54. Examples of Lime Cup Testing Results for Spinel Forming and Magnesia-Rich

Shotcrete Formulations

( $\mathrm{a}$ - Spinel Former (B) Composition G, b - Spinel Former (B) Composition M, c Magnesia-Rich Shotcrete) 


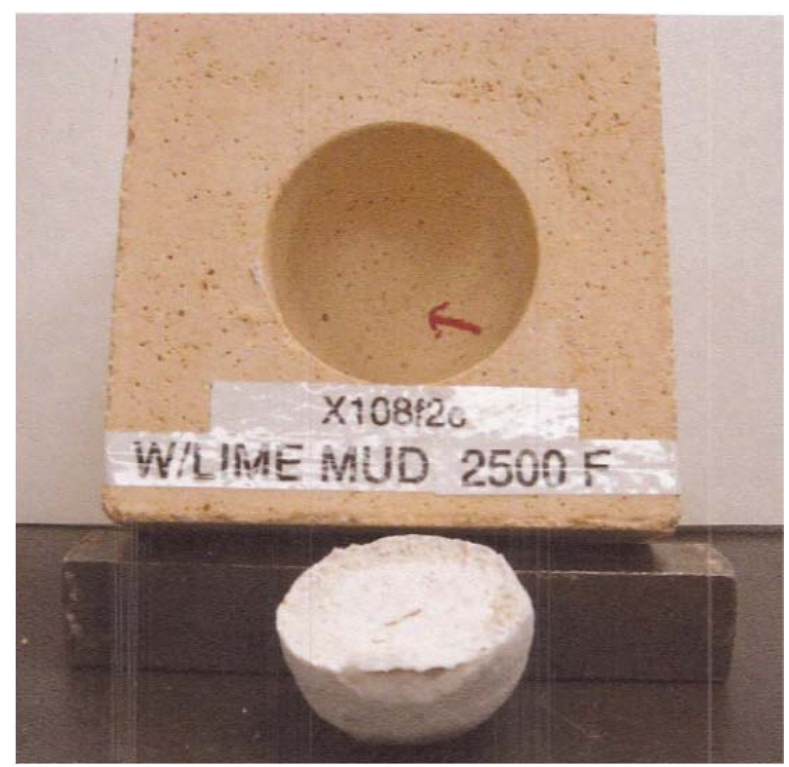

Figure 55. Example of Lime Smelt Cup Exposure Tests Performed at MINTEQ

Based on modifications made to spinel formulations being developed for use in gasification applications, a final spinel forming composition was developed for use in lime kiln applications and was tested at ORNL as shown in Figure 56.

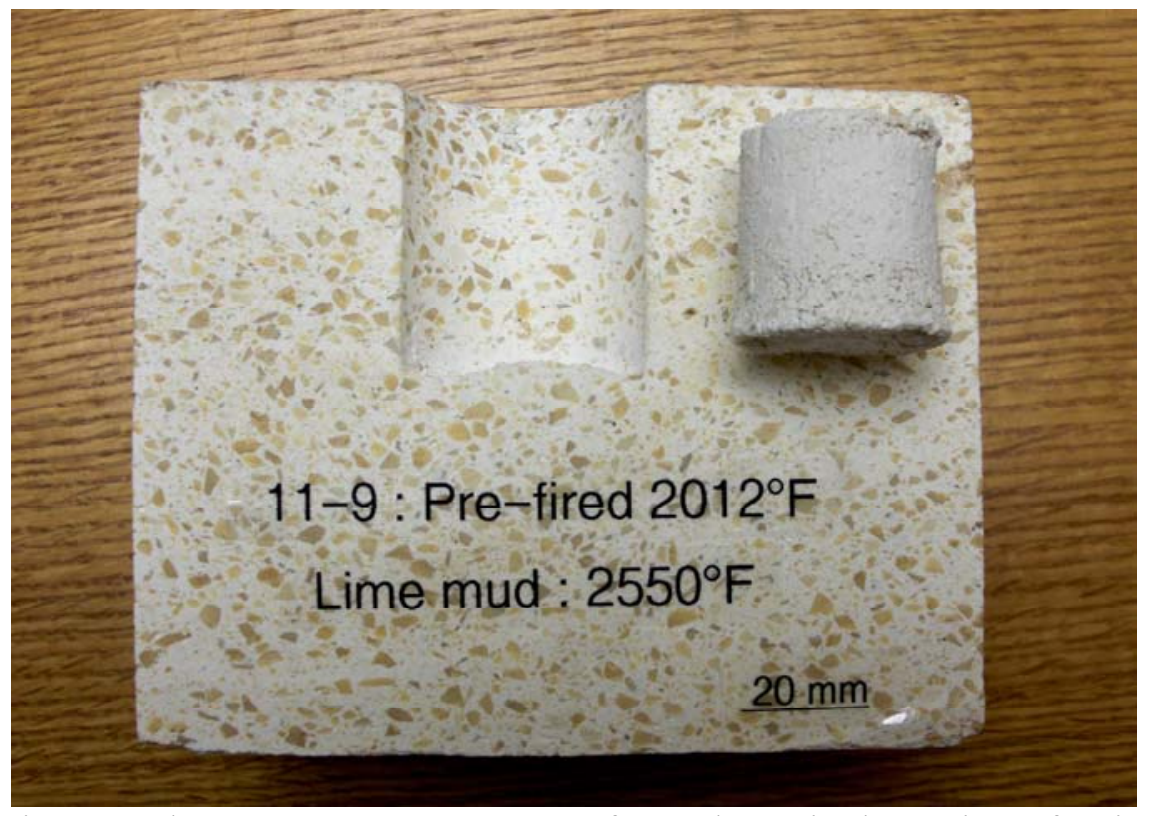

Figure 56. Lime Smelt Cup Exposure Tests Performed on Final Version of Spinel Forming Composition for Use in Lime Kilns

Refractory for Coal and Black Liquor Gasifiers

Initially, currently used and prospective candidate refractory materials were evaluated at ORNL in contact with coal slag supplied by industrial partner Eastman. It was also hoped that materials developed for coal gasification may be applicable for use in the Weyerhaeuser black liquor gasifier application in the developed or a slightly altered form. Initial results for MINTEQ developed refractories (spinel-based materials) designed for use in this application 
were favorable as shown in Figure 57. It was believed that materials based on this refractory family would be suitable to serve as candidates for both initial linings and repairs.

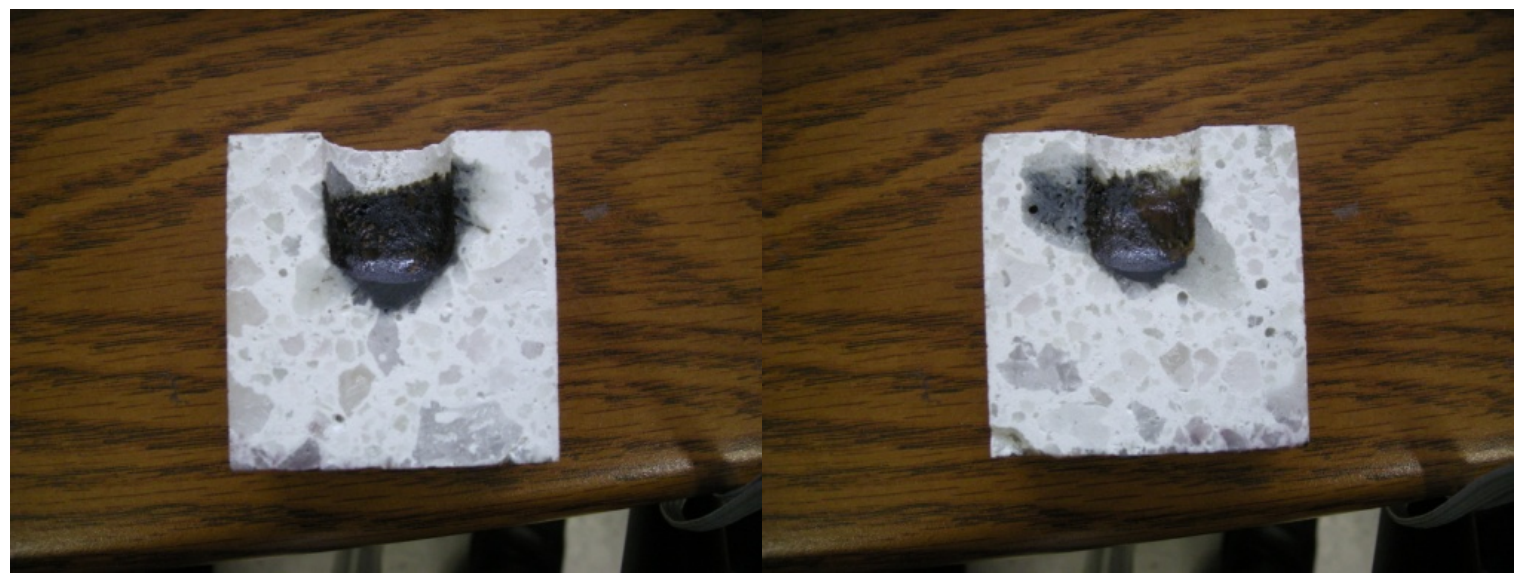

Figure 57. Coal Smelt Cup Test Samples of MINTEQ Developed Refractories for Coal Gasification

Post mortem studies of subsequent MINTEQ spinel based formulations (shown in Figure 58) determined that these products are very efficient at preventing penetration of $\mathrm{Fe}_{2} \mathrm{O}_{3}$ components which have been found to be key corrosion species in this environment through formation of spinel solid solutions. These materials were found to be somewhat less effective at stopping penetration of $\mathrm{K}_{2} \mathrm{O}$ and $\mathrm{SiO}_{2}$ components, although penetration was still found to be modest in scope.

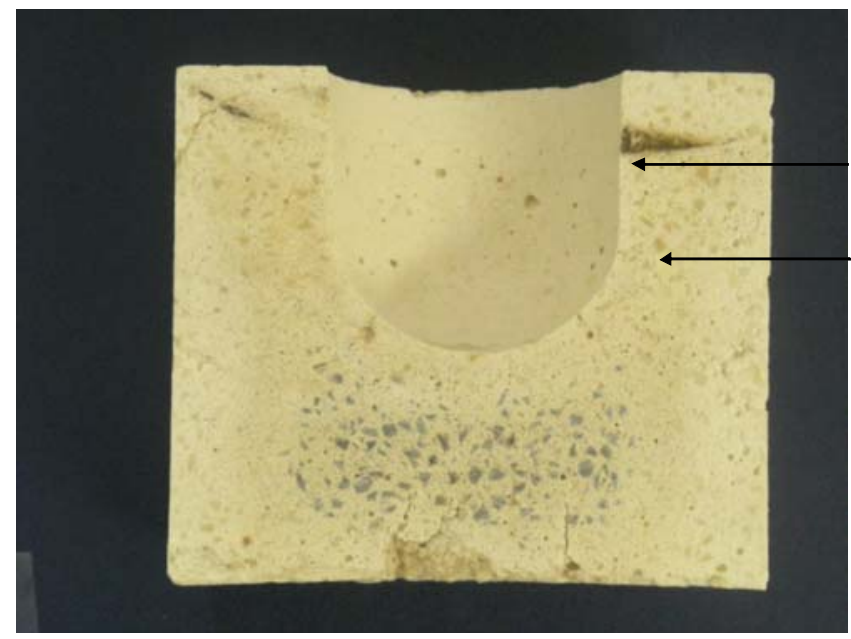

successful penetration prevention of $\mathrm{Fe}_{2} \mathrm{O}_{3}$ minor penetration by $\mathrm{K}_{2} \mathrm{O}$ and $\mathrm{SiO}_{2}$

Figure 58. Post Mortem Analysis of MINTEQ Spinel Based Formulation

Further analysis of spinel-based materials developed for coal gasifier applications was performed by XRD, optical microscopy, and FESEM. Formation of a penetrating aluminum-silicate phase was identified at the exposure surface which formed a continuous, low porosity vitrified layer of approximately $1 \mathrm{~cm}$ thickness. The structure of the spinel appeared to also change from the exposure surface to the unaffected region with a $\mathrm{Mg}$ deficient spinel being present at the exposure surface. 
Based on the positive results above, a slightly modified spinel-based refractory composition was also tested for use in black liquor gasification. Testing was performed using both straight alkali $\left(80 \% \mathrm{~K}_{2} \mathrm{C}_{3} / 20 \% \mathrm{Na}_{2} \mathrm{CO}_{3}\right)$ and in contact with actual black liquor gasifier smelt (provided by Weyerhaeuser) at $1100^{\circ} \mathrm{C}$. Considerable cracking was seen when this material was subjected to the alkali as shown in Figure 59. For the smelt exposure case, the reaction produced less cracking as shown in Figure 60. Subsequent work was performed to reduce the particle size of the raw materials in hopes of reducing structural damage (thought to lead to cracking) due to phase formation during reaction. Results for this refractory formulation were favorable as seen in Figure 61.

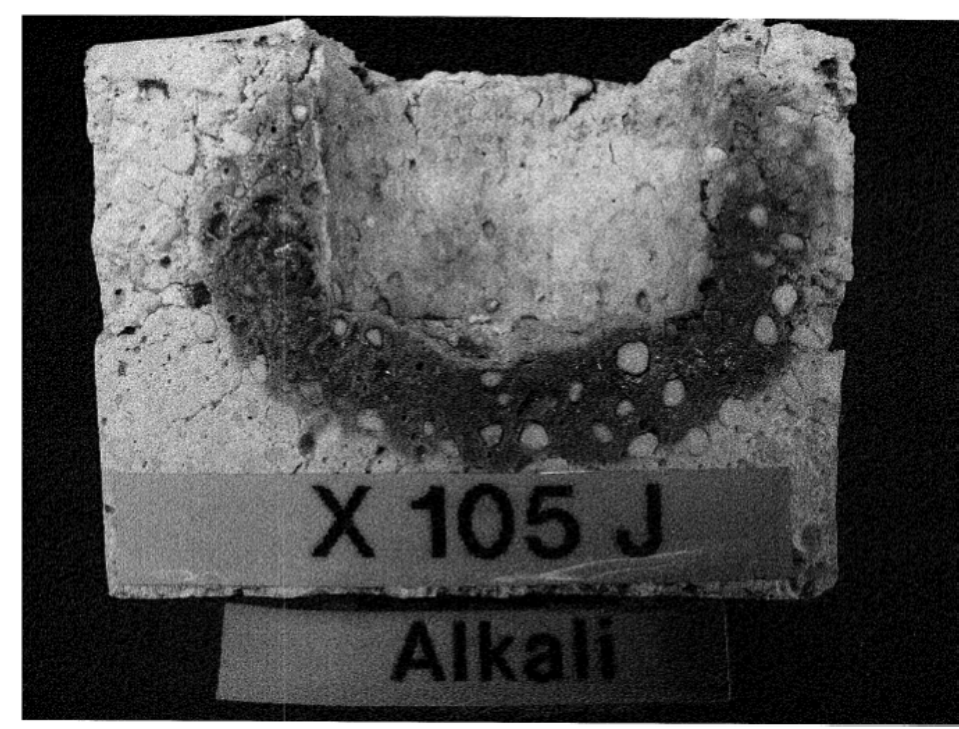

Figure 59. Alkali Testing of Experimental Refractory Spinel Former for Black Liquor Gasifier Application

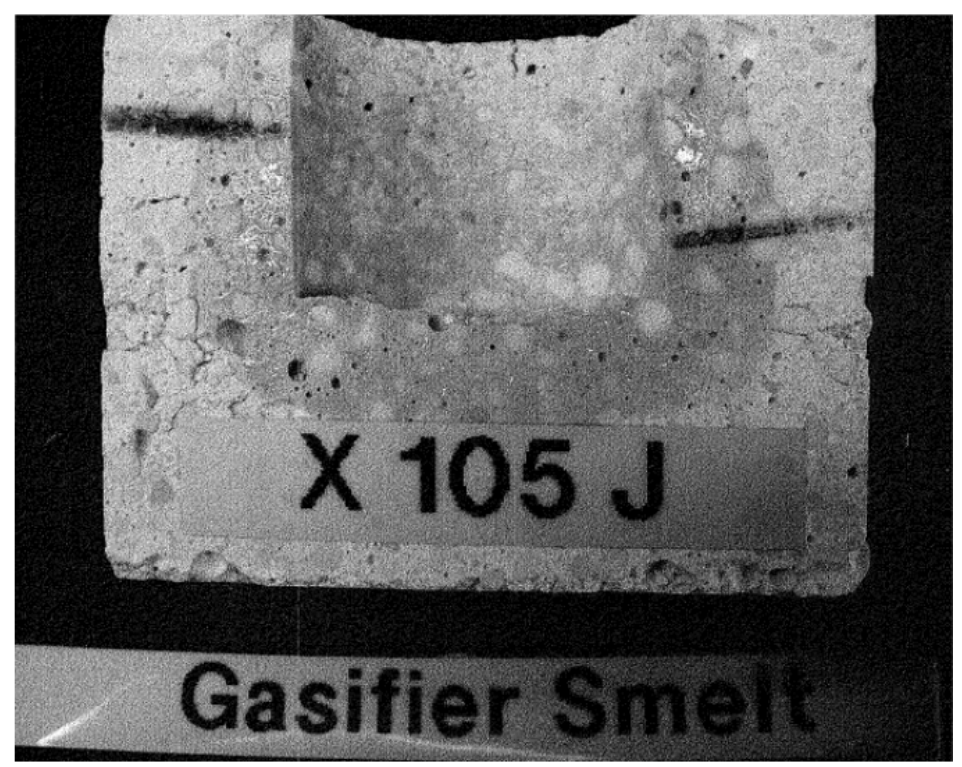

Figure 60. Smelt Testing of Experimental Refractory Spinel Former for Black Liquor Gasifier Application 


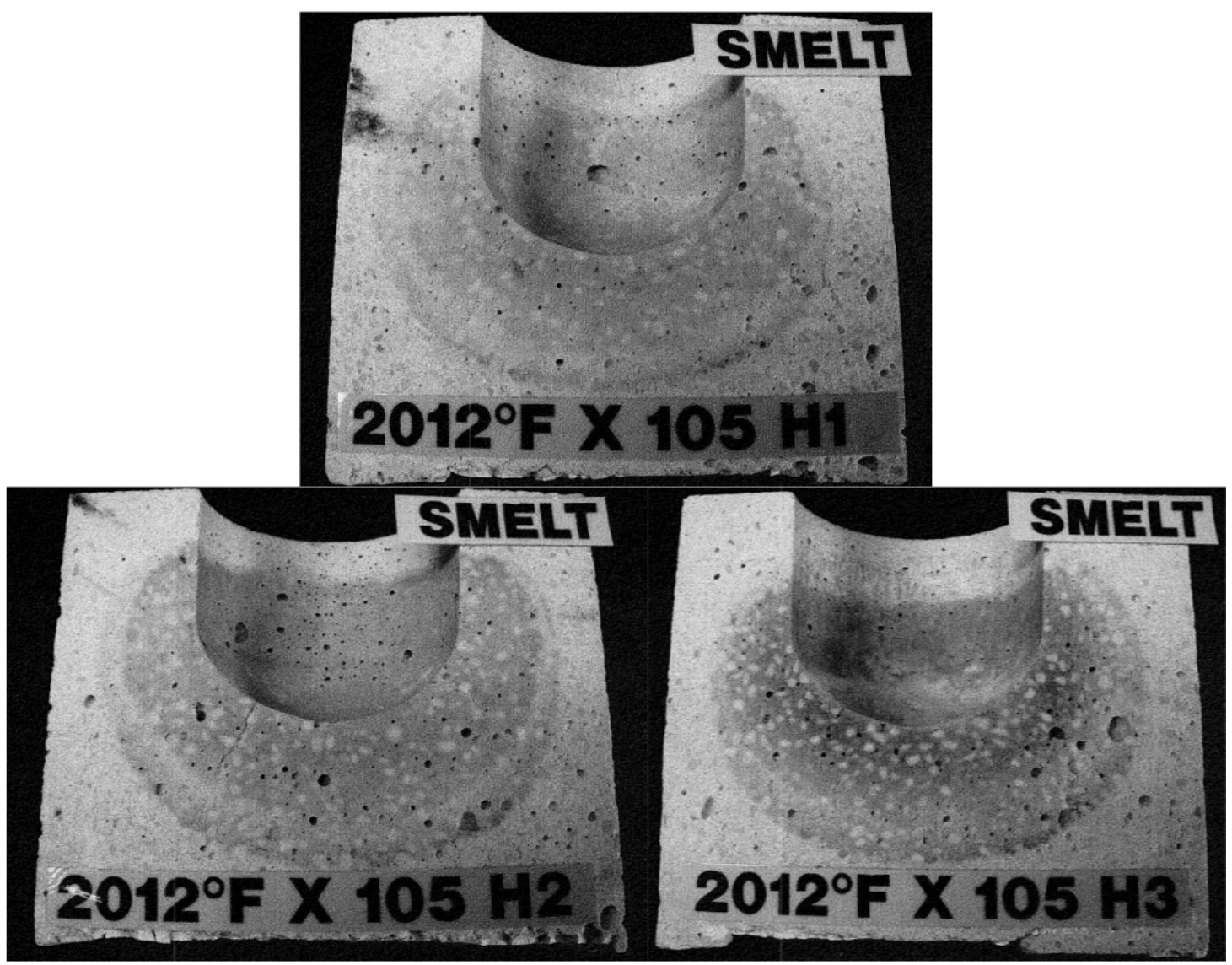

Figure 61. Smelt Testing of Experimental Refractory Spinel Former for Black Liquor Gasifier Application with Alternative Raw Materials

Supplemental black liquor smelt immersion testing of these spinel forming shotcrete formulations was performed at ORNL and resulted in favorable results as shown below in Figure 62. 

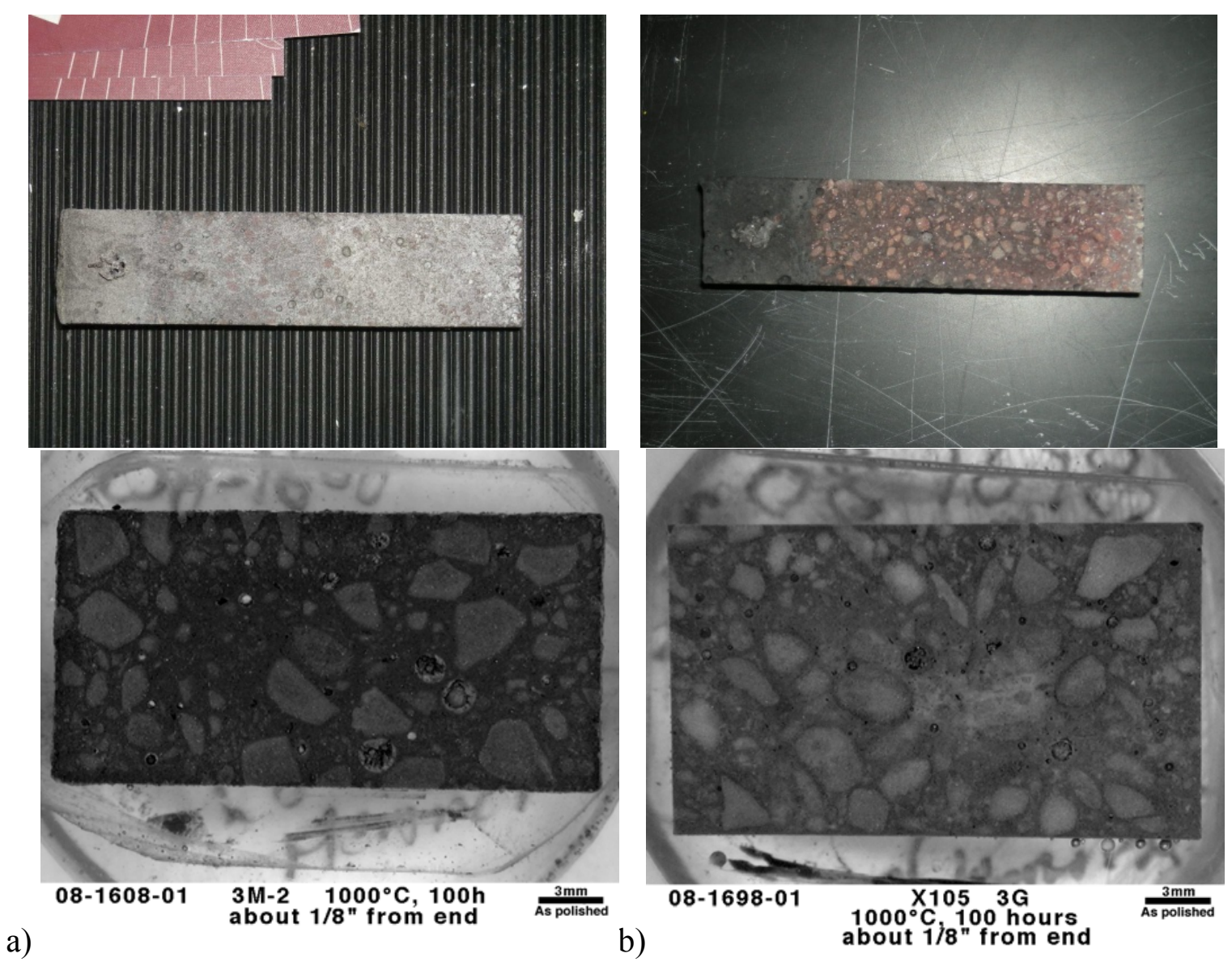

a) b)

Figure 62. Examples of Black Liquor Smelt Immersion Testing Results - Lab Samples (a - Spinel Former (B) Composition M, b - Spinel Former (B) Composition G)

Based on these favorable results, work was begun on evaluating samples prepared under actual industrial conditions (as opposed to laboratory prepared specimens). This involved firing samples to a higher temperature due to standard plant procedures. Samples of plant prepared samples were then evaluated at ORNL, but were found to be inferior to laboratory samples previously tested. Analysis of laboratory prepared smelt immersion samples was also undertaken at MINTEQ with to determine why the plant prepared samples did not perform as well as the laboratory prepared samples. It was found that due to the elimination of cracking in this material, smelt was unable to penetrate the sample. Corrosion resistance of the sample was also good due to spinel formation inhibiting the formation of sodium aluminates that result in expansion and spalling of refractory material.

Additional more in-depth analysis of these samples was undertaken at MINTEQ. Samples were examined by optical microscopy, FESEM, EDS, and XRD. Conclusions drawn from these analyses were (1) sodium aluminate $\left(\mathrm{NaAlO}_{2}\right)$ and sodium magnesium silicate $\left(\mathrm{Na}_{4} \mathrm{Mg}_{2} \mathrm{Si}_{3} \mathrm{O}_{10}\right)$ were forming in these materials due to interaction with the molten smelt, although the amount of these phases forming was not significant enough to lead to failure of the samples. (2) Forsterite $\left(\mathrm{Mg}_{2} \mathrm{SiO}_{4}\right)$ was reacting with sodium from the melt to form the magnesium silicate phase identified above. (3) Sodium penetration appeared greater at $1000^{\circ} \mathrm{C}$ than at $900^{\circ} \mathrm{C}$, as would be expected. Yet, the amount of penetration was still not significant enough though to lead to failure of the sample. 
Subsequent testing of additional samples prepared under actual industrial conditions (as opposed to laboratory prepared specimens) again found them to be inferior to the laboratory prepared samples as shown in Figure 63. Analysis of these samples led to the conclusion that this was due to larger grained spinel formation at the higher firing temperatures used in the industrial process which led to cracking in the samples and smelt infiltration sodium aluminate formation which led to spalling.

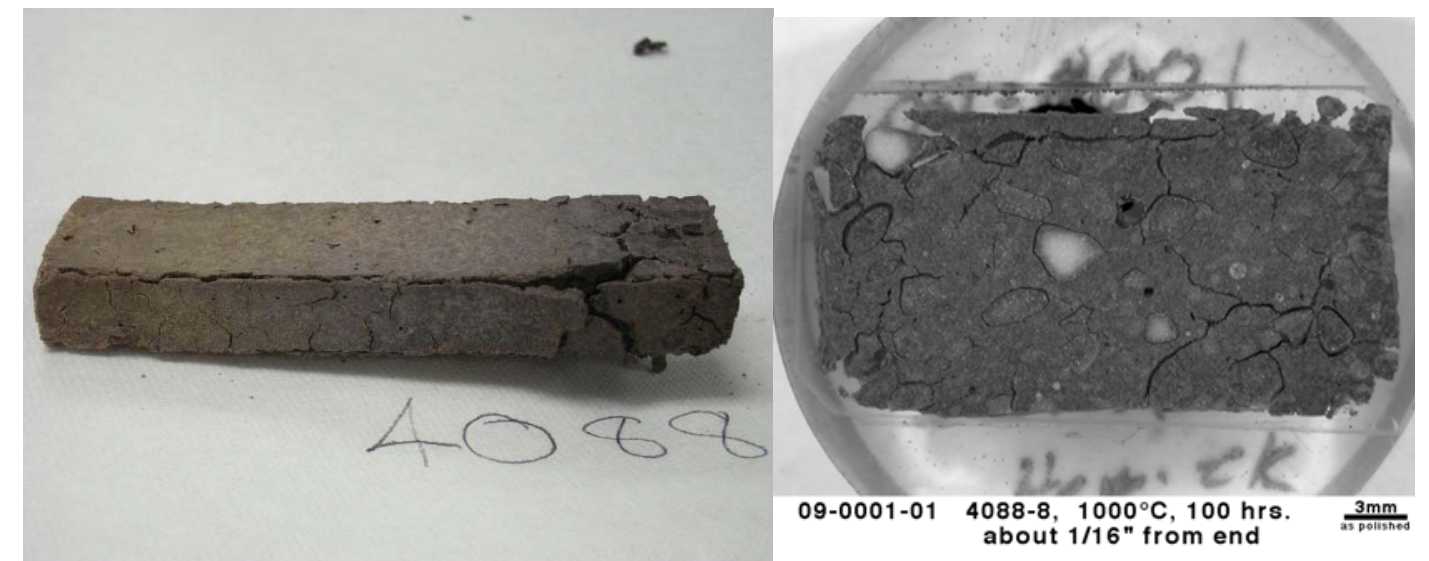

Figure 63. Examples of Black Liquor Smelt Immersion Testing Results for Industrial Samples

Additional work was performed at MINTEQ to further improve these materials based on what was learned from the above testing. Results for the modified spinel version produced by MINTEQ were greatly improved as shown in Figure 64 .

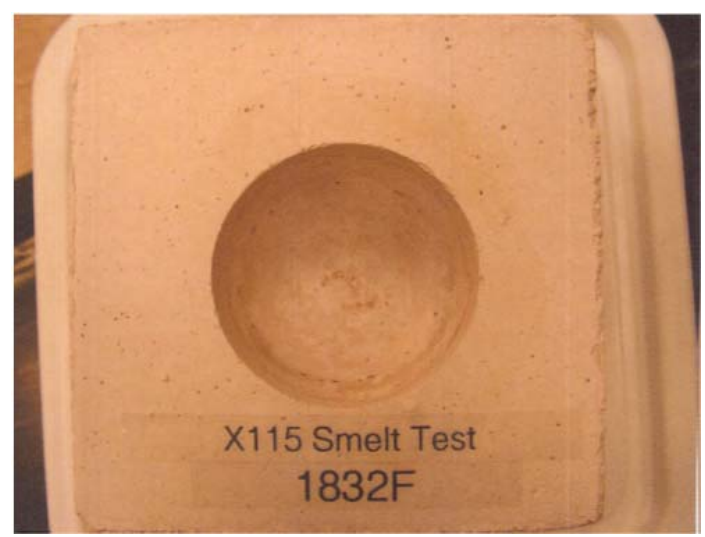

Figure 64. Example of Black Liquor Smelt Cup Exposure Tests Performed at ORNL on Improved Industrial Refractory Formulation

Additionally, black liquor smelt immersion testing was carried out on a magnesia-rich shotcrete material previously identified for use in black liquor gasification applications. This material was found to perform sufficiently, but not as well as spinel forming materials previously tested. Results are shown below in Figure 65. 

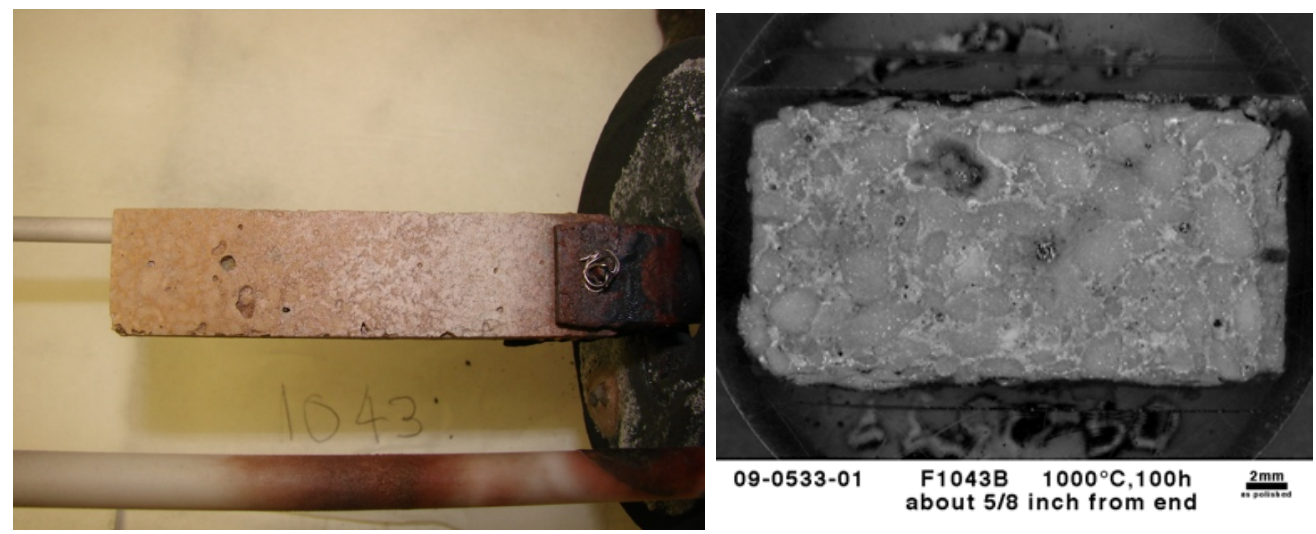

Figure 65. Black Liquor Smelt Immersion Testing Results for Magnesia-Rich Shotcrete Material

Based on the success in black liquor, crucibles of a modified magnesia-rich spinel formula were prepared by MINTEQ and sent to ORNL for exposure testing using coal smelt from industrial partner Eastman. Supplied materials were fired at either $1371^{\circ} \mathrm{C}$ or $1510^{\circ} \mathrm{C}$ $\left(2500^{\circ} \mathrm{F}\right.$ or $2750^{\circ} \mathrm{F}$ ) before being supplied to ORNL. Samples (shown in Figure 66) were filled with 35 grams of coal smelt and placed in a furnace where they were heated under Argon to $1600^{\circ} \mathrm{C}$ at $5^{\circ} \mathrm{C} / \mathrm{min}$. and held for four hours before being cooled naturally to room temperature.

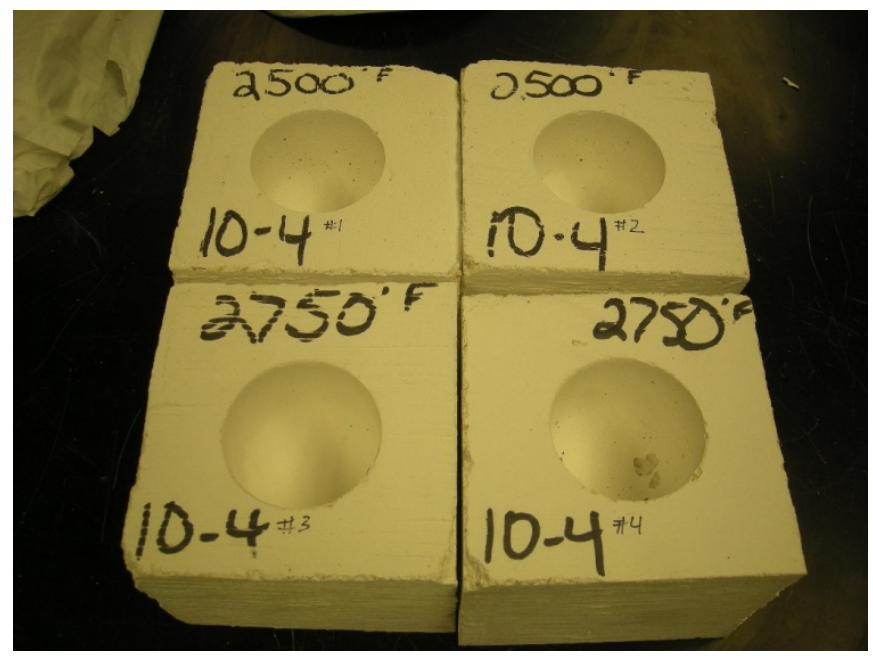

Figure 66. Magnesia-Rich Spinel Samples for Coal Smelt Exposure Testing

Pictures of samples after exposure are shown in Figure 67 and Figure 69 for materials fired at $1371^{\circ} \mathrm{C}$ or $1510^{\circ} \mathrm{C}\left(2500\right.$ and $\left.2750^{\circ} \mathrm{F}\right)$, respectively. Cracking (due to thermal exposure) and some chemical corrosion was seen for both materials as shown in Figure 68 and Figure 70. The material fired at $1510^{\circ} \mathrm{C}\left(2750^{\circ} \mathrm{F}\right)$ appeared to perform better than the material fired at $1371^{\circ} \mathrm{C}\left(2500^{\circ} \mathrm{F}\right)$. 

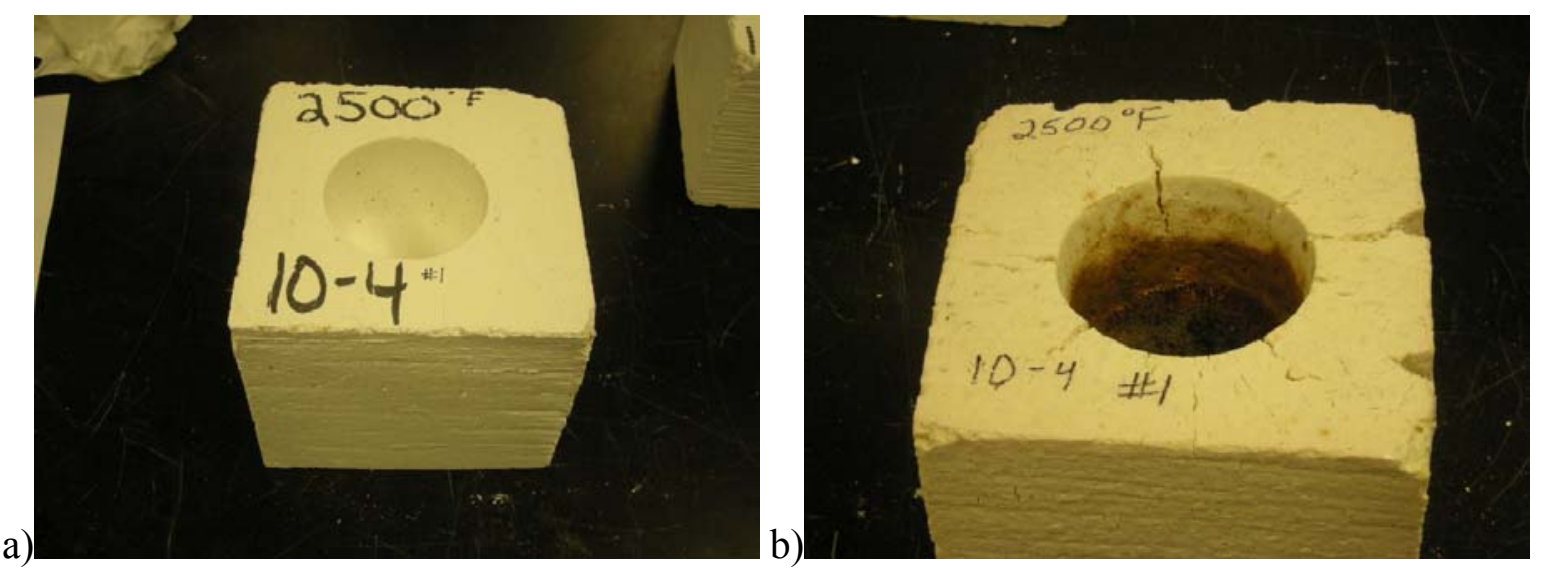

Figure 67. Magnesia-Rich Spinel Sample Fired at $1371^{\circ} \mathrm{C}\left(2500^{\circ} \mathrm{F}\right)$ Before (a) and After (b) Coal Smelt Exposure Testing

a)
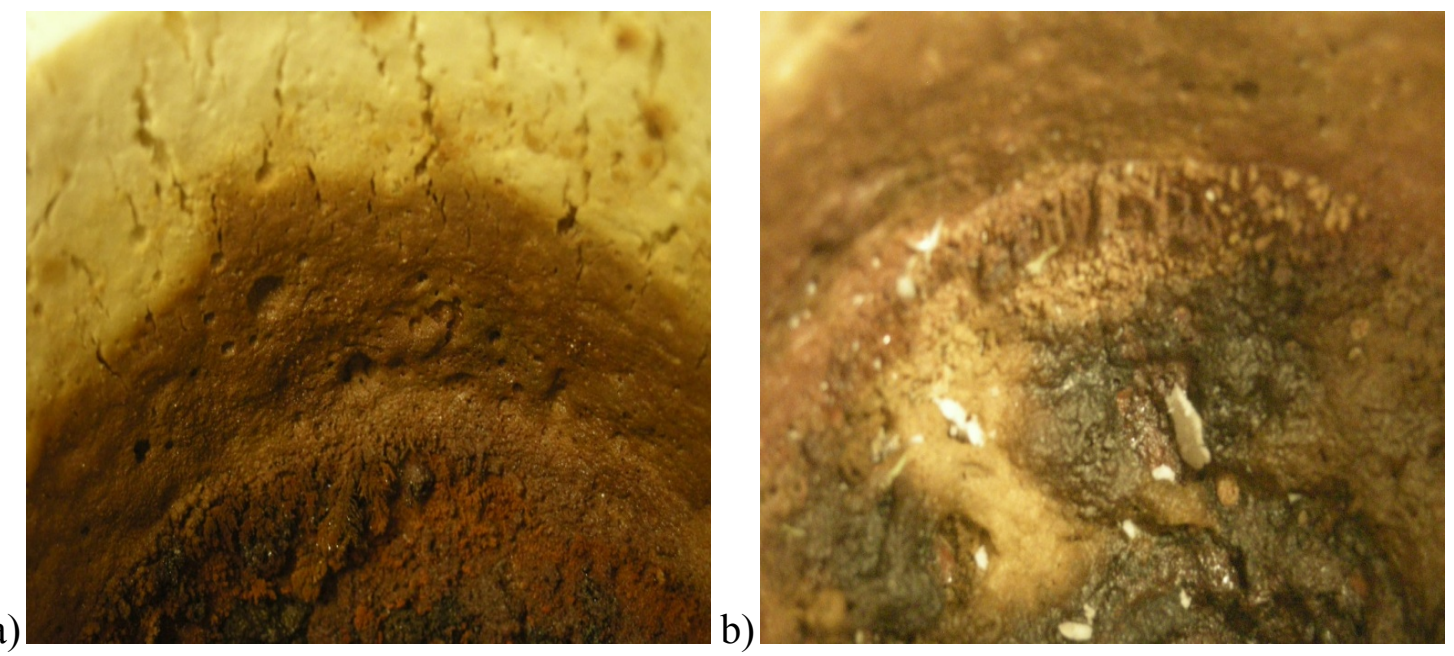

Figure 68. Coal Smelt Interaction with Magnesia-Rich Spinel Sample Fired at $1371^{\circ} \mathrm{C}$
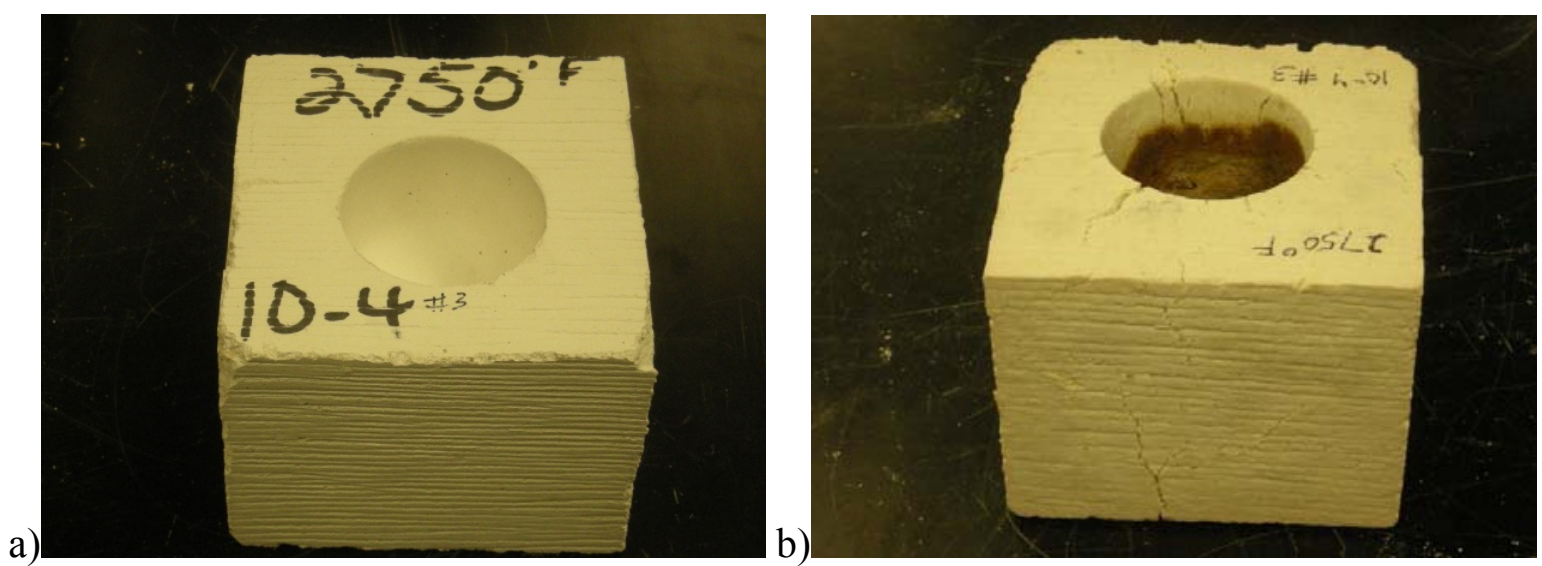

Figure 69. Magnesia-Rich Spinel Sample Fired at $1510^{\circ} \mathrm{C}\left(2750^{\circ} \mathrm{F}\right)$ Before (a) and After (b) Coal Smelt Exposure Testing 
a)

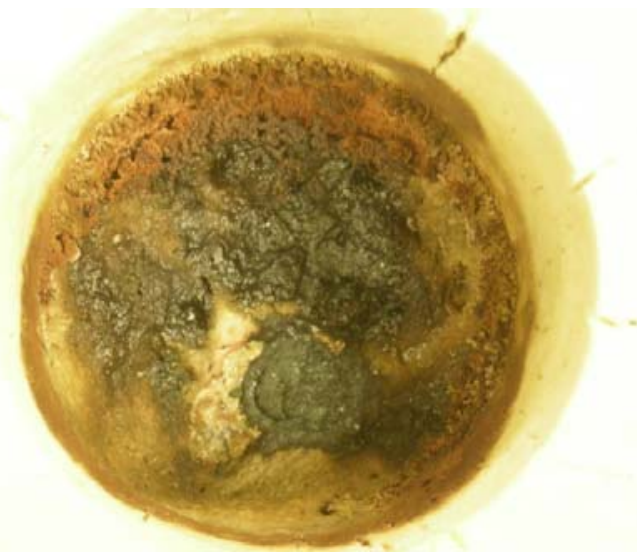

b)

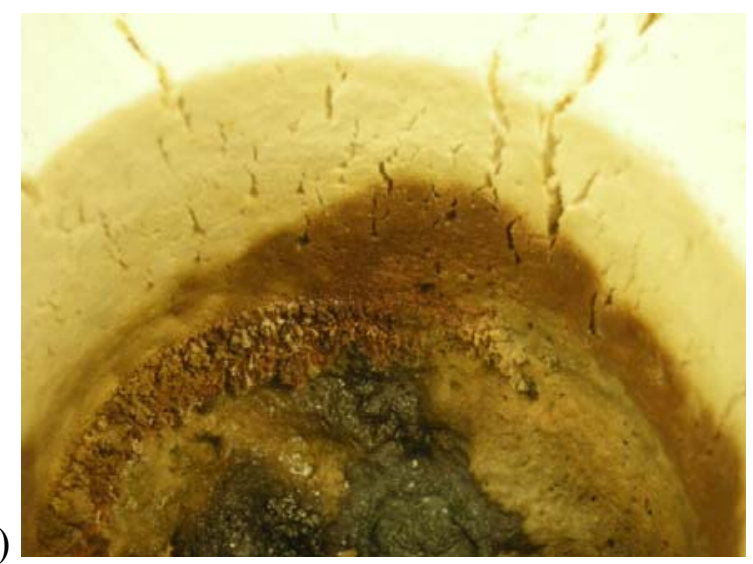

Figure 70. Coal Smelt Interaction with Magnesia-Rich Spinel Sample Fired at $1510^{\circ} \mathrm{C}$

Additionally, XRF and XRD testing were performed on samples of this material fired at various temperatures to characterize the spinel formation. Samples fired at $1650^{\circ} \mathrm{C}\left(3000^{\circ} \mathrm{F}\right)$ were found to exhibit spinel formation on the order of $23-24 \%$ with $63-68 \%$ residual periclase $(\mathrm{MgO})$ present as measured by XRD. XRF showed a composition of approximately $75 \% \mathrm{MgO}, 17.5 \% \mathrm{Al}_{2} \mathrm{O}_{3}$ and $2 \% \mathrm{CaO}$ for these samples. Samples fired at $1510^{\circ} \mathrm{C}\left(2750^{\circ} \mathrm{F}\right)$ were found to exhibit spinel formation on the order of $22-24 \%$ with $63-$ $68 \%$ residual periclase $(\mathrm{MgO})$ present as measured by XRD.

A study was also performed using XRD and Differential Thermal Analysis/Thermal Gravimetric Analysis (DTA/TGA) data to compare refractory samples prepared by shotcreting or casting and cured at $110^{\circ} \mathrm{C}\left(230^{\circ} \mathrm{F}\right)$ before being fired to elevated temperatures. Specifically, the onset and completion of spinel formation was characterized, along with the onset and completion of additional silicate formations. It was found that samples prepared by both methods exhibited similar intermediate and high temperature phase formations. Spinel formation was found to onset between $800-900^{\circ} \mathrm{C}$, with significant formation between $1100-1200^{\circ} \mathrm{C}$ and additional formation occurring up to and completed by $1400^{\circ} \mathrm{C}$. Silicate phases of Monticellite $\left(\mathrm{CaMgSiO}_{4}\right)$, Olivine $\left((\mathrm{Mg}, \mathrm{Fe})_{2} \mathrm{SiO}_{4}\right)$, and Forsterite $\left(\mathrm{Mg}_{2} \mathrm{SiO}_{4}\right)$ were found to form between $800-1000^{\circ} \mathrm{C}$ and up to $1300^{\circ} \mathrm{C}$. This change in composition (as measured by XRD) is shown in Table 16.

Table 16. XRD Analysis of Crystalline Phases (by \%) with Temperature

\begin{tabular}{|l|c|c|c|c|c|c|c|c|c|}
\hline & $\mathbf{1 1 0}^{\mathbf{}} \mathbf{C}$ & $\mathbf{6 0 0}^{\mathbf{}} \mathbf{C}$ & $\mathbf{8 0 0}^{\mathbf{}} \mathbf{C}$ & $\mathbf{9 0 0}^{\mathbf{}} \mathbf{C}$ & $\mathbf{1 0 0 0}^{\mathbf{C}} \mathbf{C}$ & $\mathbf{1 1 0 0}^{\mathbf{}} \mathbf{C}$ & $\mathbf{1 2 0 0}^{\mathbf{}} \mathbf{C}$ & $\mathbf{1 3 0 0}^{\mathbf{C}}$ & $\mathbf{1 4 0 0}^{\mathbf{}} \mathbf{C}$ \\
\hline MgO & $70-75$ & $70-75$ & $70-75$ & $70-75$ & $70-75$ & $70-75$ & $65-70$ & $65-70$ & $65-70$ \\
\hline Alumina & $10-12$ & $10-12$ & $10-12$ & $10-12$ & $10-12$ & $7-10$ & $2-4$ & $\leq 1$ & $\leq 0.5$ \\
\hline Spinel & $\leq 0.5$ & $\leq 0.5$ & $\leq 0.5$ & $\leq 1$ & $\leq 1$ & $2-4$ & $10-12$ & $15-20$ & $20-25$ \\
\hline Silicates & $1-2$ & $1-2$ & $1-2$ & $1-2$ & $1-2$ & $2-4$ & $3-6$ & $6-11$ & $6-11$ \\
\hline
\end{tabular}

The DTA/TGA data for a shot sample fired after curing is shown in Table 17 and Figure 71. Results for the cast sample were similar. 
Table 17. DTA/TGA Analysis of Shotcreted Refractory Sample Cured at $110^{\circ} \mathrm{C}\left(230^{\circ} \mathrm{F}\right)$

\begin{tabular}{|c|c|}
\hline \multicolumn{2}{|c|}{ TGA-DTA of SHOT, $230^{\circ} \mathrm{F}$ block-fired sample } \\
\hline & $\begin{array}{c}21073-00000 \\
\text { SHOT } \\
230^{\circ} \mathrm{F} \\
\left(110^{\circ} \mathrm{C}\right) \\
\text { Ground material from block fired }\end{array}$ \\
\hline$\%$ net LOl@ $1400^{\circ} \mathrm{C}$ & 2.31 \\
\hline$\% \mathrm{GOI}$ from $1145^{\circ}-1400^{\circ} \mathrm{C}$ & $\begin{array}{c}0.35 \\
\text { (Gain) }\end{array}$ \\
\hline$\%$ LOI@1145ㄷ & 2.66 \\
\hline $\begin{array}{l}\text { Room Temperature up to } 200^{\circ} \mathrm{C} \\
\text { Free } \mathrm{H}_{2} \mathrm{O} \text { type losses }\end{array}$ & 0.83 \\
\hline $\begin{array}{c}200^{\circ}-500^{\circ} \mathrm{C} \\
\text { Volatile losses-combination organic and inorganic }\end{array}$ & \\
\hline $\begin{array}{l}\text { Broad, poorly energetic-exothermic reaction } \\
\text { from } 255^{\circ}-400^{\circ} \mathrm{C}\end{array}$ & 1.55 \\
\hline $\begin{array}{c}500^{\circ}-600^{\circ} \mathrm{C} \\
\text { possible residual-organic volatile losses }\end{array}$ & 0.11 \\
\hline $\begin{array}{c}600^{\circ}-900^{\circ} \mathrm{C} \\
\text { possible } \mathrm{CO}_{2} \text { type losses }\end{array}$ & 0.16 \\
\hline $900^{\circ}-1145^{\circ} \mathrm{C}$ & 0.01 \\
\hline $\begin{array}{c}1145^{\circ}-1375^{\circ} \mathrm{C} \\
\text { Oxidation-weight gain from } \mathrm{SiC} \text { degradation } \\
\text { Broad, exothermic reaction } \\
\text { from } 1150^{\circ}-1375^{\circ} \mathrm{C} \\
\end{array}$ & $\begin{array}{l}0.35 \\
\text { (Gain) }\end{array}$ \\
\hline
\end{tabular}

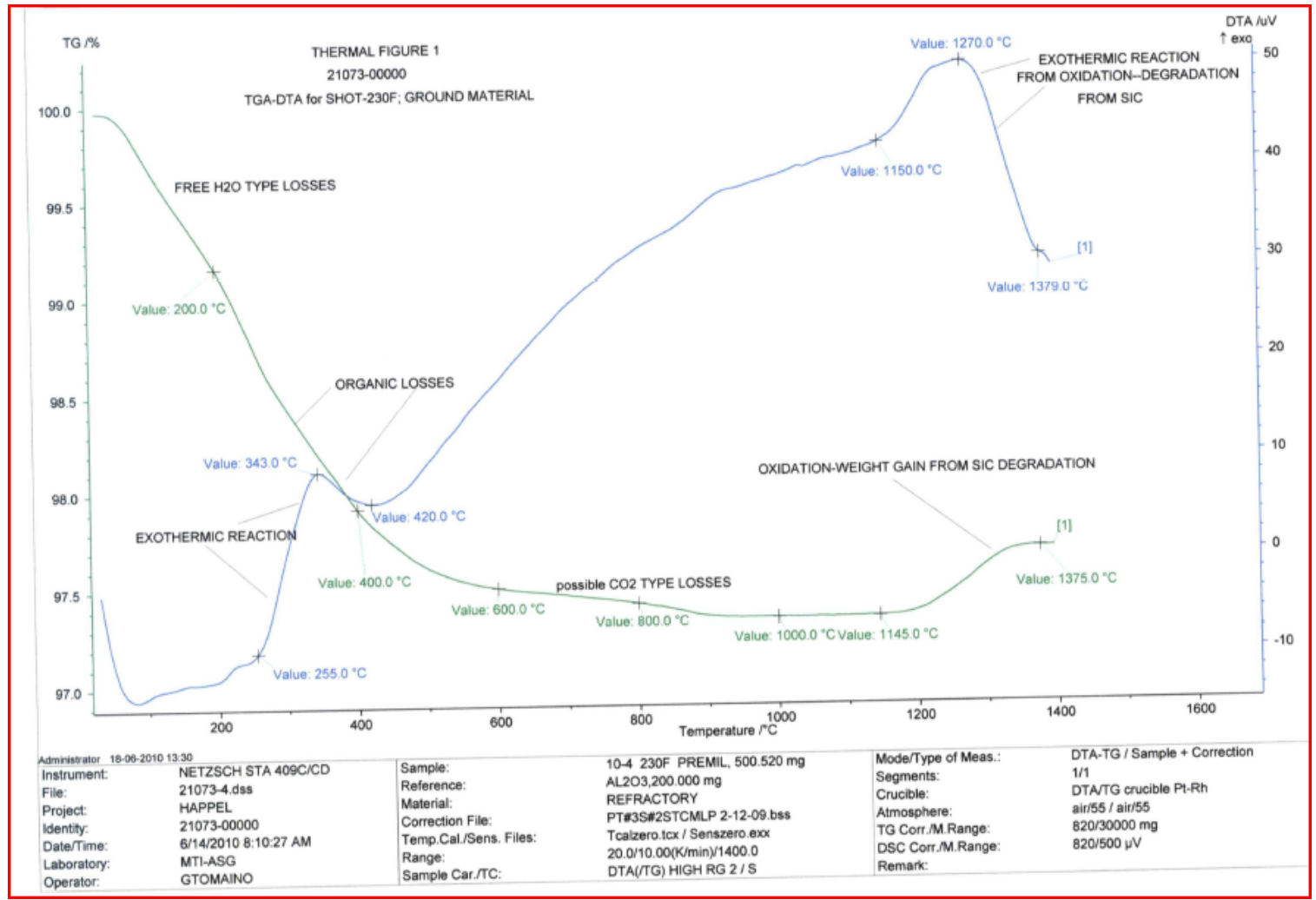

Figure 71 . DTA/TGA Analysis of Shotcreted Refractory Sample Cured at $110^{\circ} \mathrm{C}\left(230^{\circ} \mathrm{F}\right)$

Based on the above results and analysis, additional samples of modified magnesia-rich spinel formulation were prepared by MINTEQ and sent to ORNL for exposure testing using coal slag from industrial partner Eastman. Supplied materials were fired at $1510^{\circ} \mathrm{C}\left(2750^{\circ} \mathrm{F}\right)$ and then tested at ORNL. The test sample (shown in Figure 72) was filled with 3.5 grams of 
coal slag and placed in a furnace where it was heated under Argon to $1600^{\circ} \mathrm{C}$ at $5^{\circ} \mathrm{C} / \mathrm{min}$. and held for four hours before being cooled naturally to room temperature. Pictures of the sample after exposure are shown in Figure 73. Cracking (previously seen due to thermal exposure) was eliminated in these samples and corrosion due to interaction with the coal smelt appeared to be minimal. This was evident as there was a lack of smelt penetration and the sharp corners of the drilled cavity were preserved after testing.

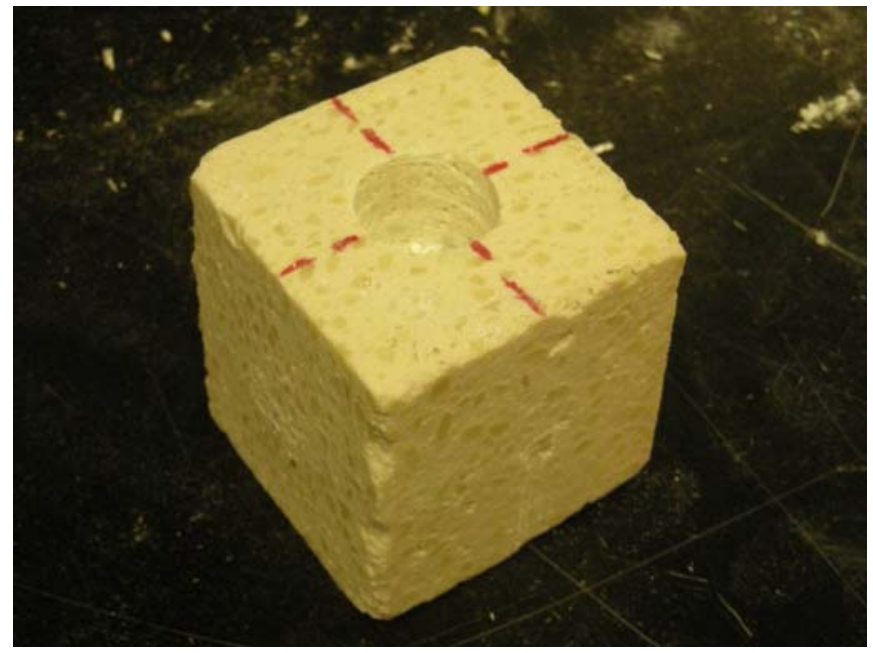

Figure 72. Magnesia-Rich Spinel Sample for Coal Smelt Exposure Testing

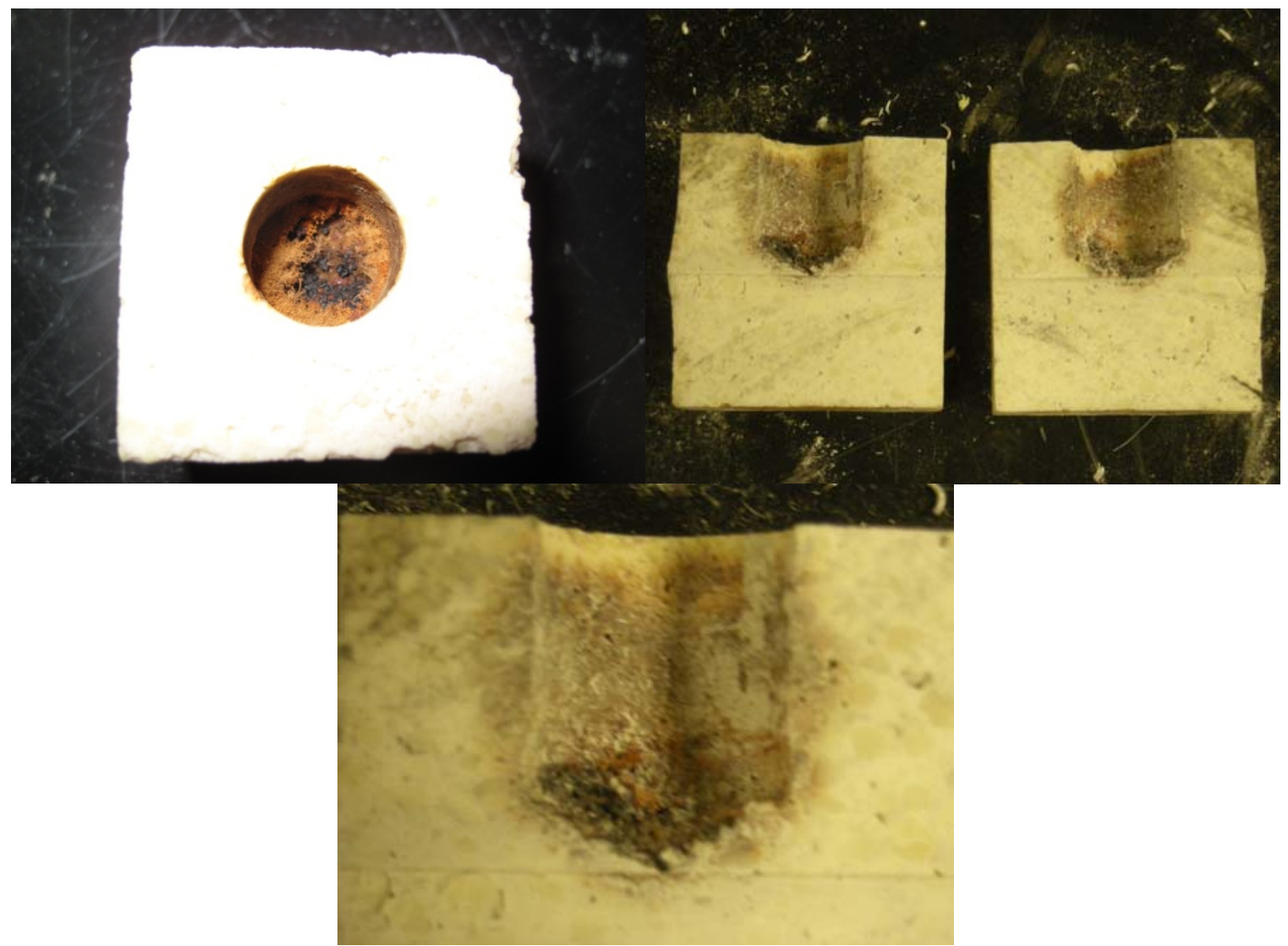

Figure 73. Magnesia-Rich Spinel Sample Fired at $1510^{\circ} \mathrm{C}\left(2750^{\circ} \mathrm{F}\right)$ after Coal Smelt Exposure Testing Showing Lack of Smelt Penetration and Corrosion 
The spinel formulation was further modified to improve its performance and additional cup testing was performed on the latest modifications in contact with black liquor and coal smelt. Pictures are shown in Figure 74. Results were found to be highly favorable.
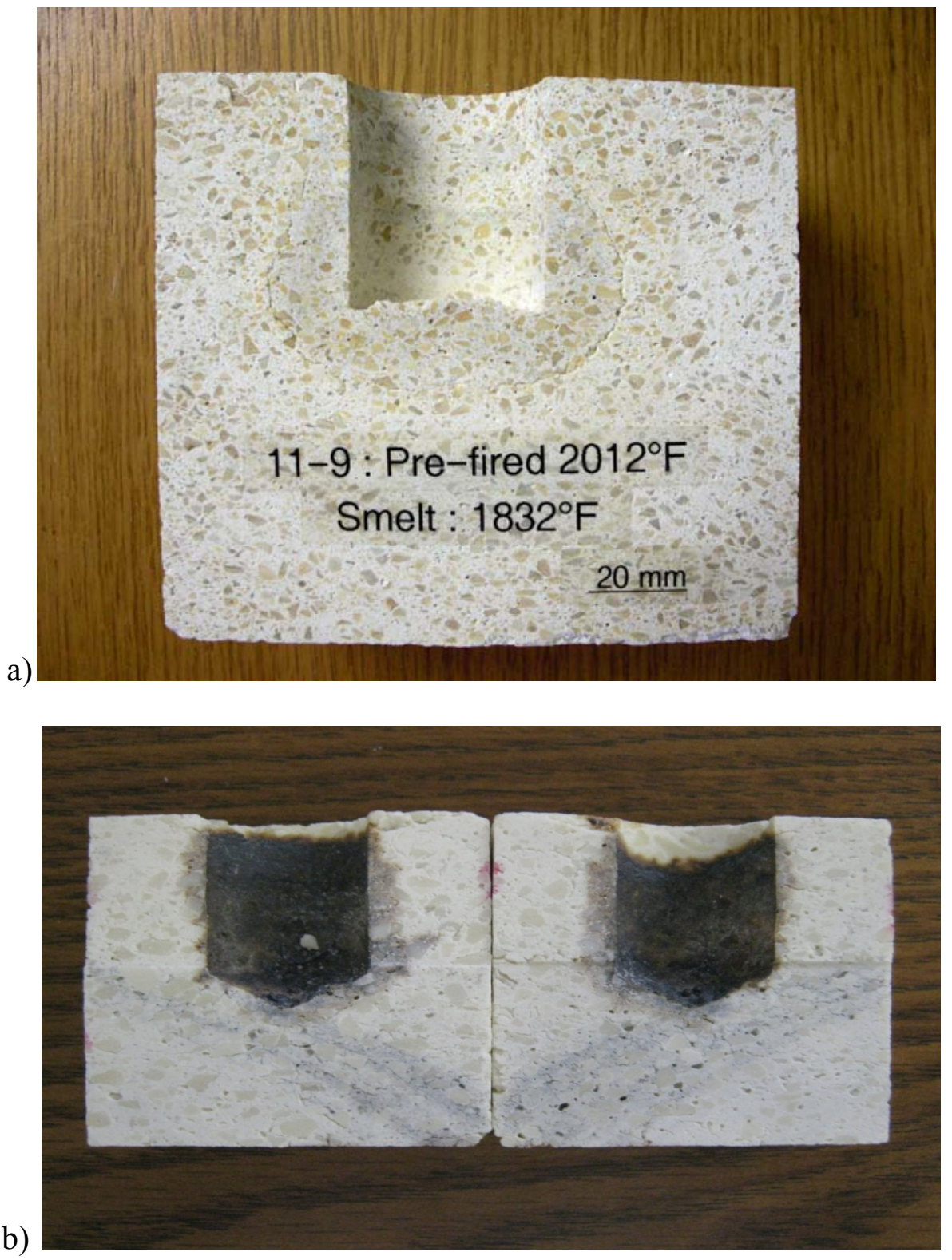

Figure 74. Examples from Cup Testing of Latest Spinel Formulations in Contact with (a) Black Liquor Smelt and (b) Coal Smelt

Using the modified spinel formulation tested above, refractory coatings to improve the lifetime of this material in contact with molten coal slag were pursued at ORNL. This work was based on previous efforts at ORNL to improve the lifetimes of refractory materials for coal gasification provided by Albany Research Center (Albany, OR) ${ }^{v}$. The approach involves creating a suspension of ground refractory material (the same base material as the

${ }^{v}$ K.S. Kwongm J.P. Bennett, R. Krabbe, H. Thomas, and C. Powell, "Engineered Refractories for Slagging Gasifiers," American Ceramic Society Bulletin, Vol. 85, No. 2, 17-20, February (2006). 
refractory that is being coated) and binder and then applying it through slurry based processing methods. A schematic of the process is shown in Figure 75 and a picture of a spinel refractory cube coated using this process is shown in Figure 76.
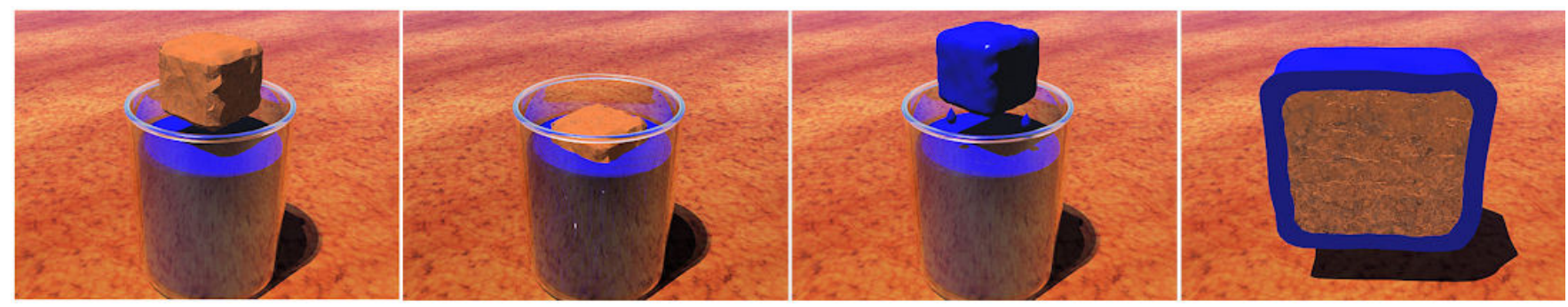

Figure 75. Schematic Representation of Slurry Based Coating Process

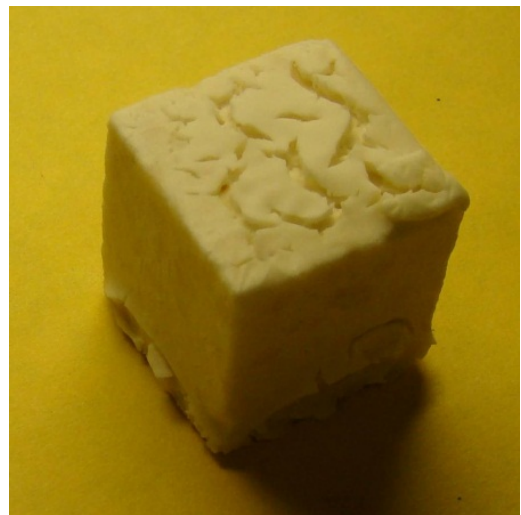

Figure 76. Coated Spinel Refractory Cube

Initial efforts resulted in cracked coatings due to difficulty with the heat treating of the coating to form a sintered outer layer (as evident in Figure 76 above). Yet, subsequent efforts resulted in higher quality continuous spinel composition coatings with good adherence to the refractory below as shown in Figure 77.

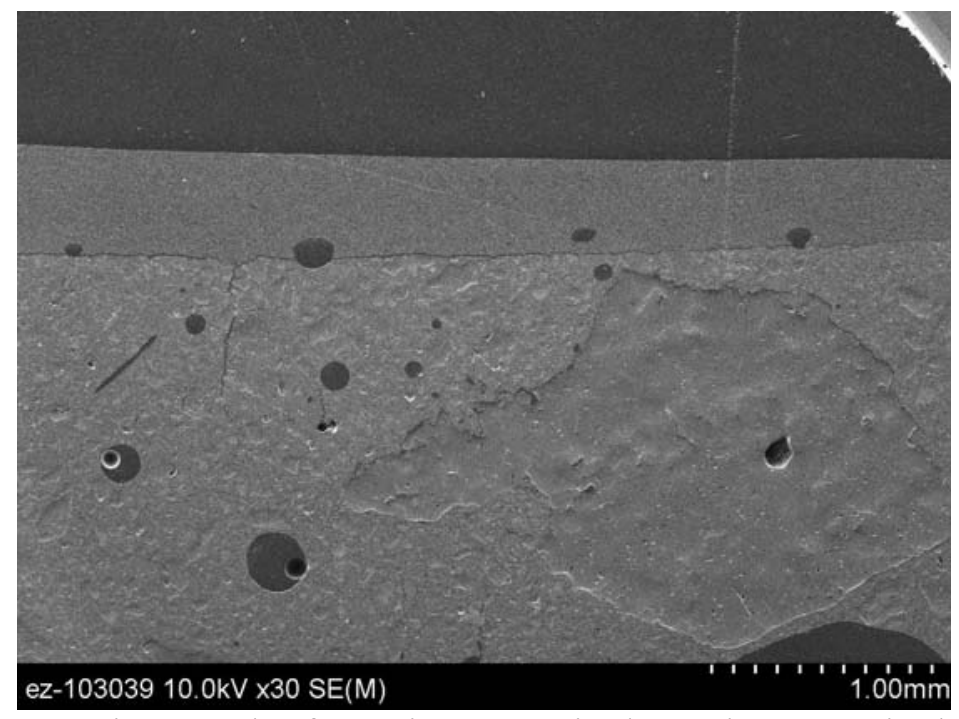

Figure 77. SEM Micrograph of Continuous Spinel Coating on Spinel Composition Refractory Cube Sample 
These coatings were shown through EDS to be transformed magnesium aluminum spinel with similar composition to the base spinel refractory material as shown in Figure 78.

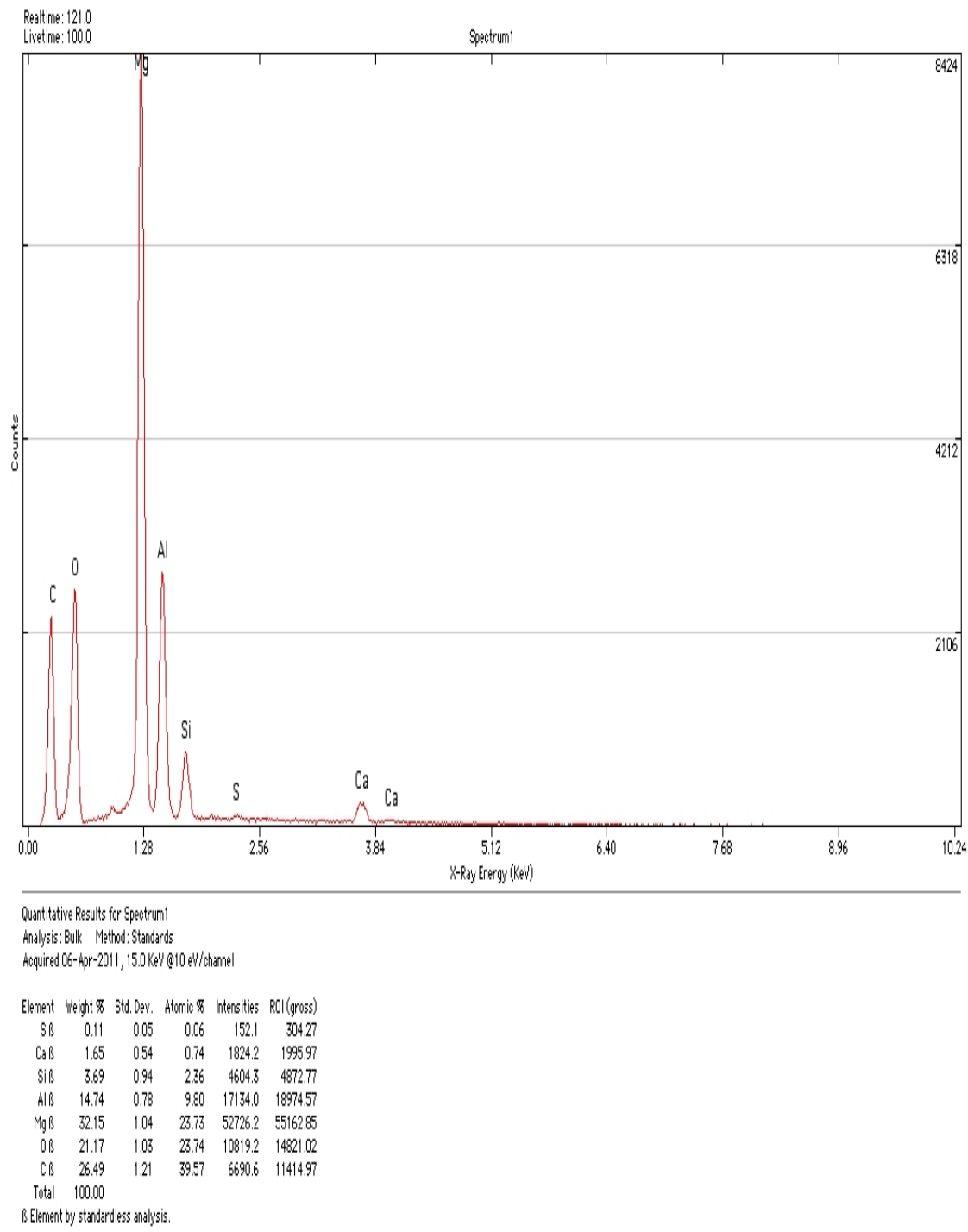

Figure 78. EDS Scan of Coating Applied on Spinel Composition Refractory Cube Sample As Shown in Figure 77

Subsequent work was then performed at ORNL to further develop these refractory coatings. Previously observed cracking in these coatings was thought to be due to difficulty with the heat treating of the coating to form a continuous sintered outer layer. Therefore, a study was performed over various temperatures to optimize the heat treating process and eliminate the cracking behavior as shown Figure 79. 


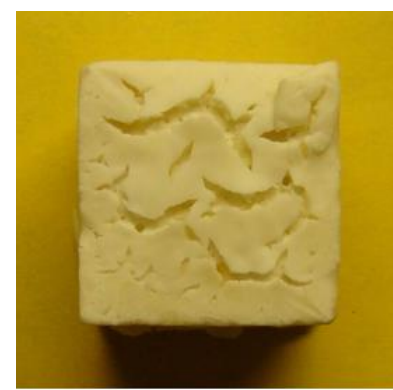

$1600^{\circ} \mathrm{C}$

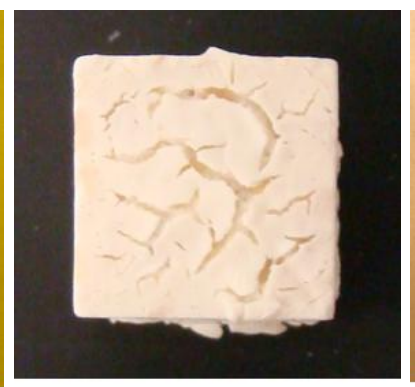

$1400^{\circ} \mathrm{C}$

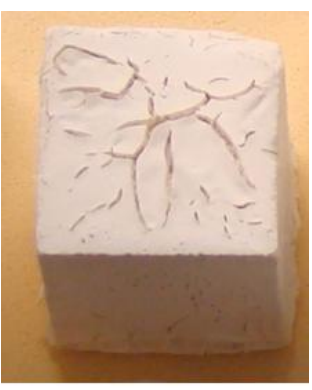

$1300^{\circ} \mathrm{C}$

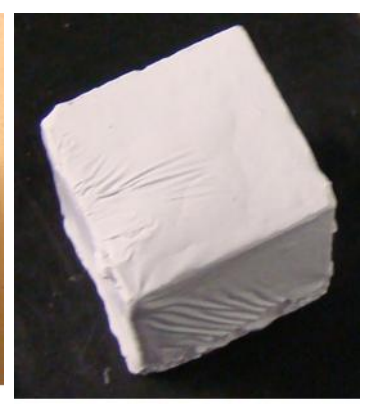

$1000^{\circ} \mathrm{C}$

Figure 79. Evaluation of Coating Quality at Various Heat Treat Temperatures

Using the optimized crack free coating based on results obtained with a $1000^{\circ} \mathrm{C}$ heat treat temperature, a refractory cup sample was coated and fired before being tested through exposure to molten slag using the standard refractory cup test. Results of testing are shown in Figure 80. Although the coating was crack free prior to testing, cracking was found in the coating following exposure to molten coal smelt at temperature. Beneath the cracking the refractory material was found to be relatively unaffected by the smelt, as limited interaction and lack of smelt penetration was noted.

a)

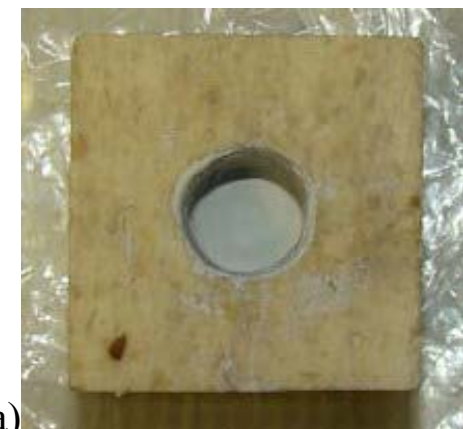

b)
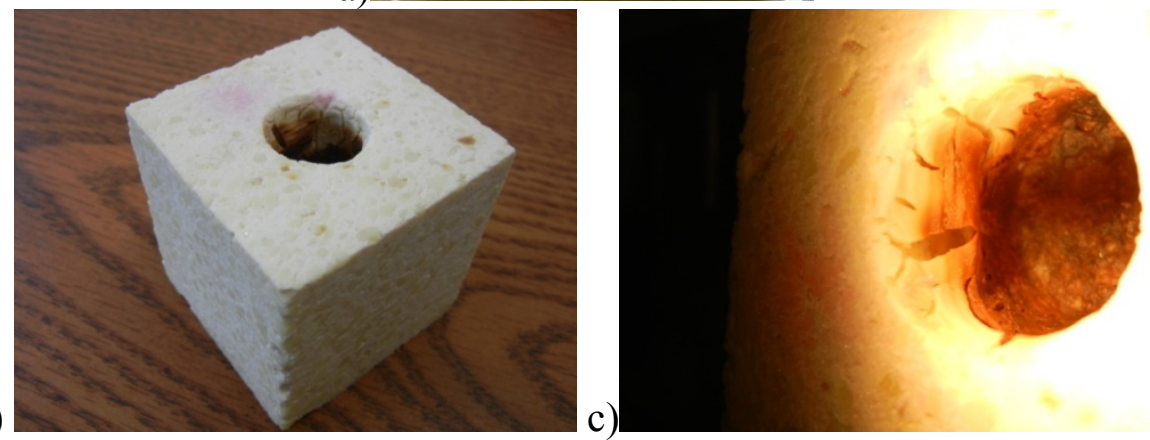

Figure 80. Refractory Cup Samples Before and After Exposure to Molten Coal Slag. Coated Modified Alumina-Rich Spinel Material Before (a) and After (b and c) Testing

Based on these positive results, work was then continued at ORNL on improving refractory coatings to extend the lifetime of the previously developed spinel materials in contact with molten coal slag. Cracking was eliminated in the fired coating surface through modification of the previous coating composition (see Figure 81). Additionally, previous coating compositions were analyzed in regard to solids loading and the effect of pre-wetting of the refractory cup surface with ethanol was investigated. Results, shown in Figure 82, indicated 
that higher solids loading was better than lower solids loadings and that pre-wetting had a mixed effect of reduced smelt penetration but higher reaction at the upper cavity wall.

a)
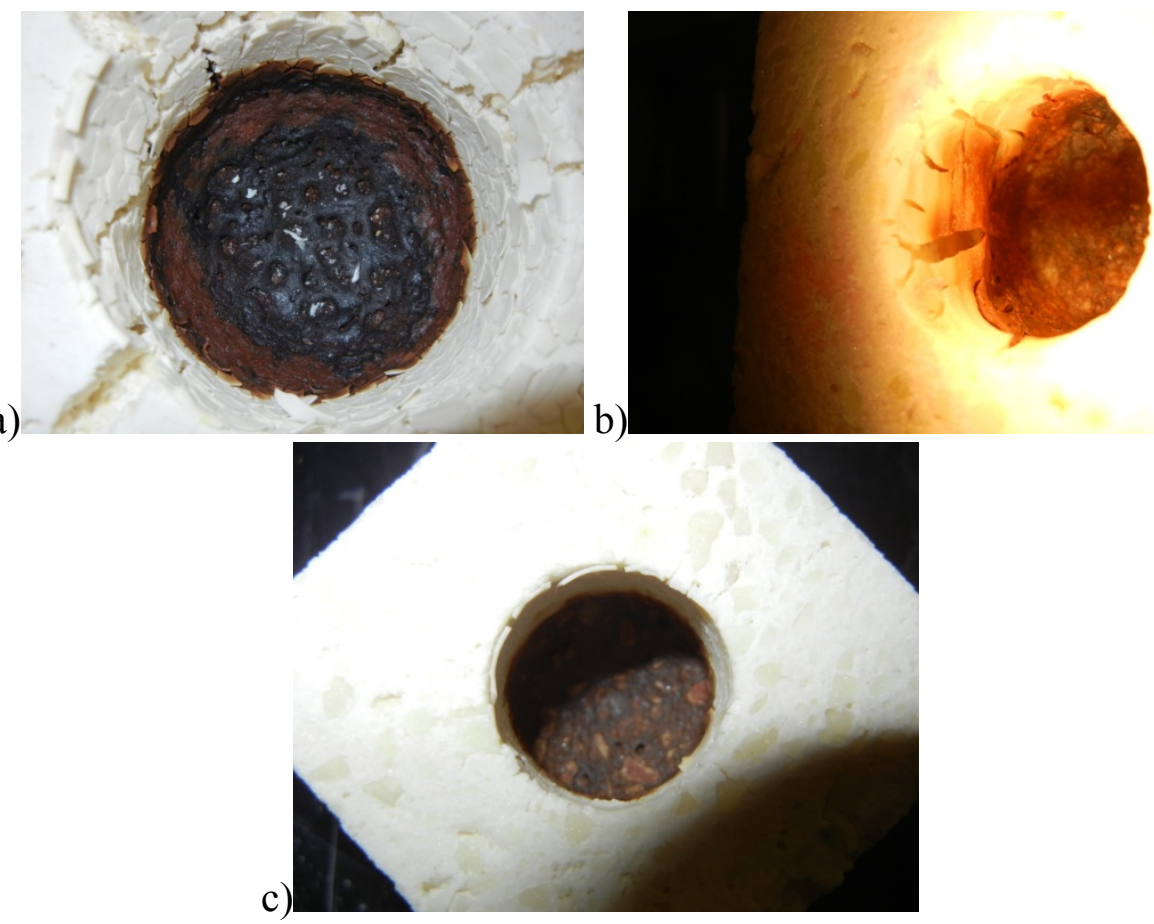

Figure 81. Coated Refractory Cup Testing Samples Following Exposure to Molten Coal Slag Representing (a) Sample From Previous First Round of Testing, (b) Sample From Previous Second Round of Testing, and (c) Sample From Current Round of Testing

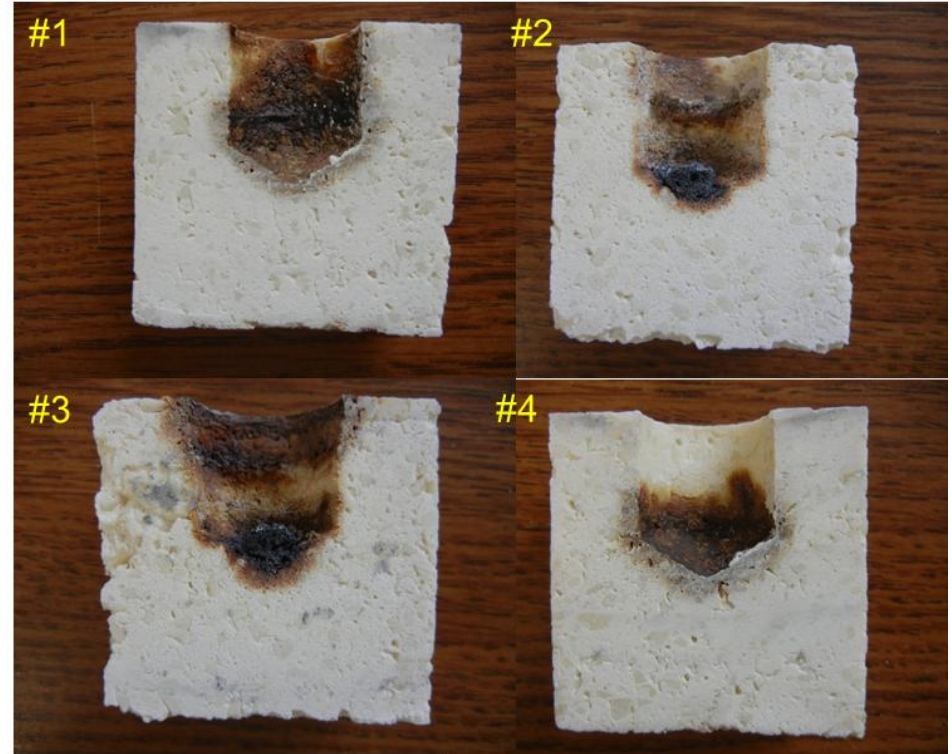

Figure 82. Coated Refractory Cup Testing Samples From Current Round of Testing Following Exposure to Molten Coal Slag Showing (1) Pre-wet Cavity and Coating with Original Solids Loading, (2) Pre-wet Cavity and Coating with Reduced Solids Loading (a), (3) Pre-wet Cavity and Coating with Solids Loading $(\mathrm{b}<\mathrm{a})$, and (4) Non Pre-wet Cavity and Coating with Original Solids Loading 
Thermal Analysis of Refractories

Refractory samples received from MS\&T were subjected to thermal diffusivity testing at ORNL using the laser flash technique over a temperature range of 25 to $1200^{\circ} \mathrm{C}$. Results shown in Figure 83 are calculated thermal conductivity values for $\mathrm{MgAl}_{2} \mathrm{O}_{4}$ with $0,1,2,4$, and $8 \mathrm{~mol} \% \mathrm{BaAl}_{2} \mathrm{O}_{4}$ calculated based on density and specific heat data measured elsewhere. These initial test results were used to show a decrease in thermal conductivity and diffusivity with increasing $\mathrm{BaAl}_{2} \mathrm{O}_{4}$ as well as with increasing temperature in support of the theoretical work being performed at MS\&T. As temperature increased past $700^{\circ} \mathrm{C}$ the effect of the increased amount of $\mathrm{BaAl}_{2} \mathrm{O}_{4}$ on thermal conductivity began to seem insignificant, as the standard deviation was found to be $\pm 0.414 \mathrm{~W} / \mathrm{mK}$ at $700^{\circ} \mathrm{C}$.

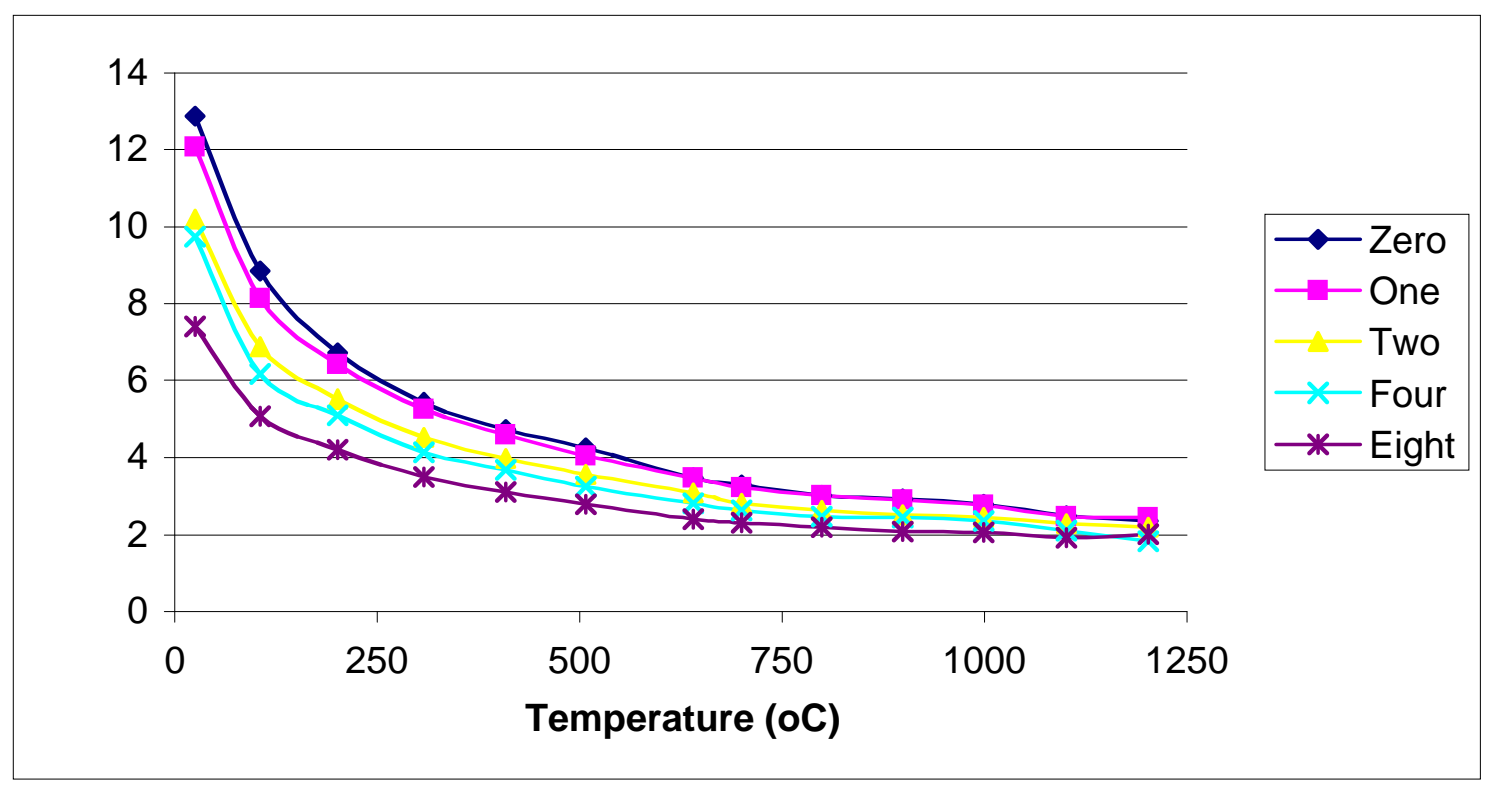

Figure 83. Calculated Thermal Conductivity vs. Temperature for $\mathrm{MgAl}_{2} \mathrm{O}_{4}$ with $0,1,2,4$, and $8 \mathrm{wt} \% \mathrm{BaAl}_{2} \mathrm{O}_{4}$ Based on Laser Flash thermal Diffusivity Measurements

Laser flash diffusivity measurements were also made at ORNL on $\mathrm{MgAl}_{2} \mathrm{O}_{4}-\mathrm{MgGa}_{2} \mathrm{O}_{4}$ samples from MS\&T in support of their theoretical work. Results are shown in Table 18 for the various compositions studied.

Table 18. Laser Flash Diffusivity Values for $\mathrm{MgAl}_{2} \mathrm{O}_{4}-\mathrm{MgGa} 2 \mathrm{O} 4$ Samples from MS\&T $\left(\mathrm{A}=\mathrm{MgAl}_{2} \mathrm{O}_{4}, \mathrm{~B}=\mathrm{MgGa}_{2} \mathrm{O}_{4}\right)$

\begin{tabular}{|r|r|r|r|r|r|r|}
\hline Temp & \multicolumn{1}{|c|}{$100 \% \mathrm{~A}$} & $95 \% \mathrm{~A}+5 \% \mathrm{~B}$ & $90 \% \mathrm{~A}+10 \% \mathrm{~B}$ & $50 / 50-1$ & $50 / 50-2$ & $100 \% \mathrm{~B}$ \\
\hline 103 & 0.0418 & 0.0322 & 0.0297 & 0.0267 & 0.0276 & 0.0261 \\
\hline 313 & 0.0247 & 0.0197 & 0.0188 & 0.0171 & 0.0178 & 0.0163 \\
\hline 501 & 0.0189 & 0.016 & 0.0155 & 0.0138 & 0.0143 & 0.0128 \\
\hline 697 & 0.0153 & 0.0133 & 0.0132 & 0.0118 & 0.0121 & 0.0105 \\
\hline 898 & 0.0128 & 0.0114 & 0.0113 & 0.0095 & 0.0103 & 0.0092 \\
\hline
\end{tabular}

Hot wire thermal conductivity testing (ASTM C-1113) was performed by an outside commercial testing laboratory on samples of the lightweight backup material (fired at $2500^{\circ} \mathrm{F}$ ) during development by MINTEQ as shown in Figure 84 . This testing showed $\mathrm{K}$ Factors of $\approx 0.36-0.63 \mathrm{~W} / \mathrm{mK}\left(\approx 2.5-4.4 \mathrm{BTU}\right.$ in $/ \mathrm{ft}^{20} \mathrm{~F} \mathrm{hr}$.) for mean temperatures from 18 - 
$1195^{\circ} \mathrm{C}\left(65-2183^{\circ} \mathrm{F}\right)$, respectively. These values were substantiated by testing at ORNL using their High Density Infra-Red (HDIR) diffusivity method ${ }^{\mathrm{vi}}$ as shown in Figure 85. Additional thermal conductivity testing of other materials developed under the project was also carried out using the HDIR test method developed at ORNL. Testing was carried out for two spinel forming refractories and the magnesia rich refractory material. Results of testing are shown in Figure 86 and Figure 87. As expected, the spinel forming refractories were found to possess a high conductivity on the order of 7.5-4.5 W/mK, which decreased with temperature. The magnesia rich refractory was found to have an extremely high thermal conductivity ranging from over $12 \mathrm{~W} / \mathrm{mK}$ and decreasing with temperature to around $6 \mathrm{~W} / \mathrm{mK}$.

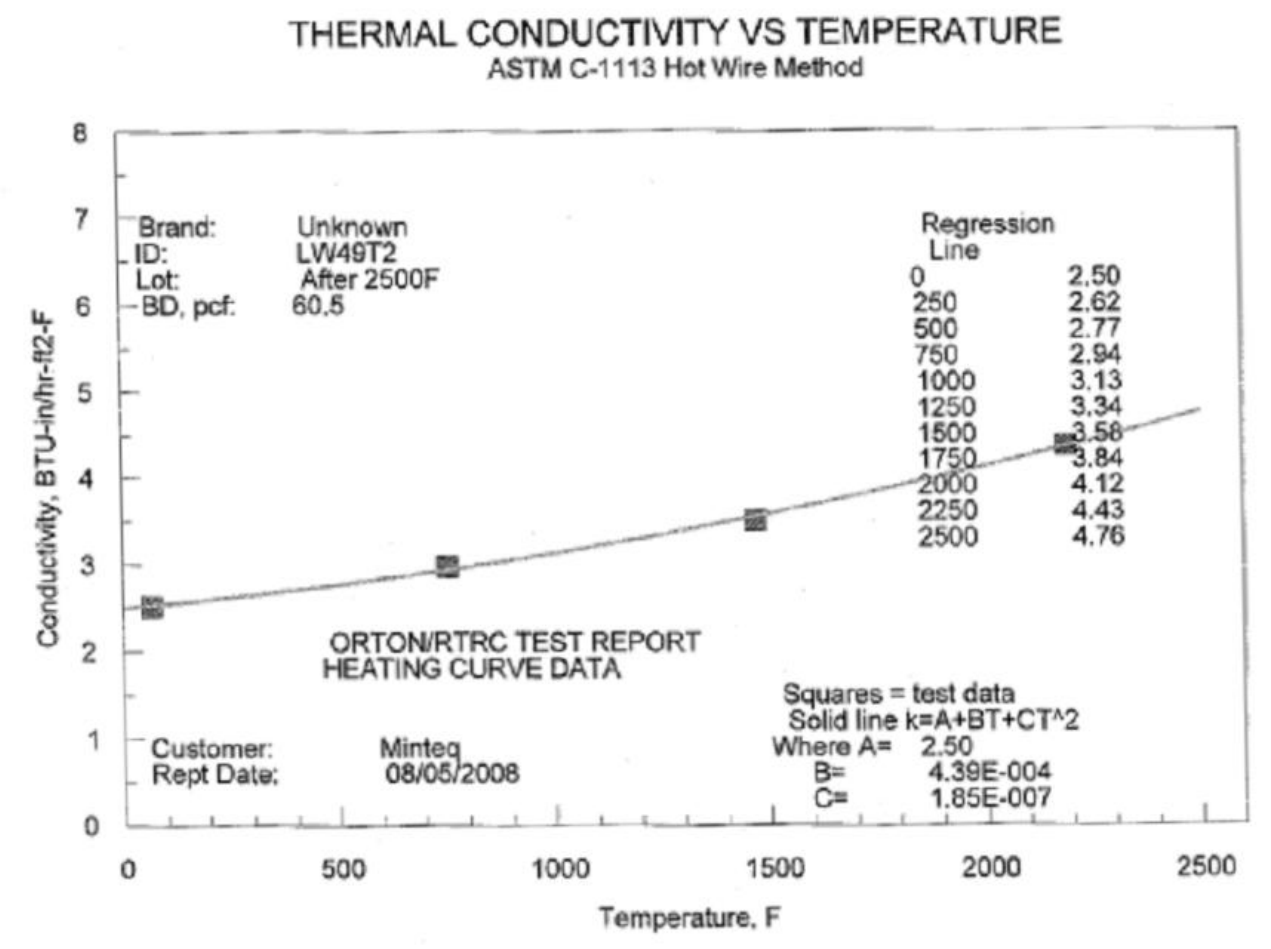

Figure 84. Hot Wire Thermal Conductivity Results for Back-up Lining Material (note: $1 \mathrm{BTU}-\mathrm{in} / \mathrm{hr}-\mathrm{ft}^{2}-{ }^{\circ} \mathrm{F}=0.144 \mathrm{~W} / \mathrm{mK}$ )

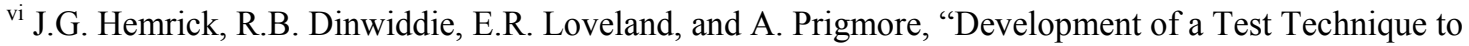
Determine the Thermal Diffusivity of Large Refractory Ceramic Test Specimens", International Journal of Applied Ceramic Technology, Vol. 9, Issue 1, January/February (2012). 
MinTeq Light Weight

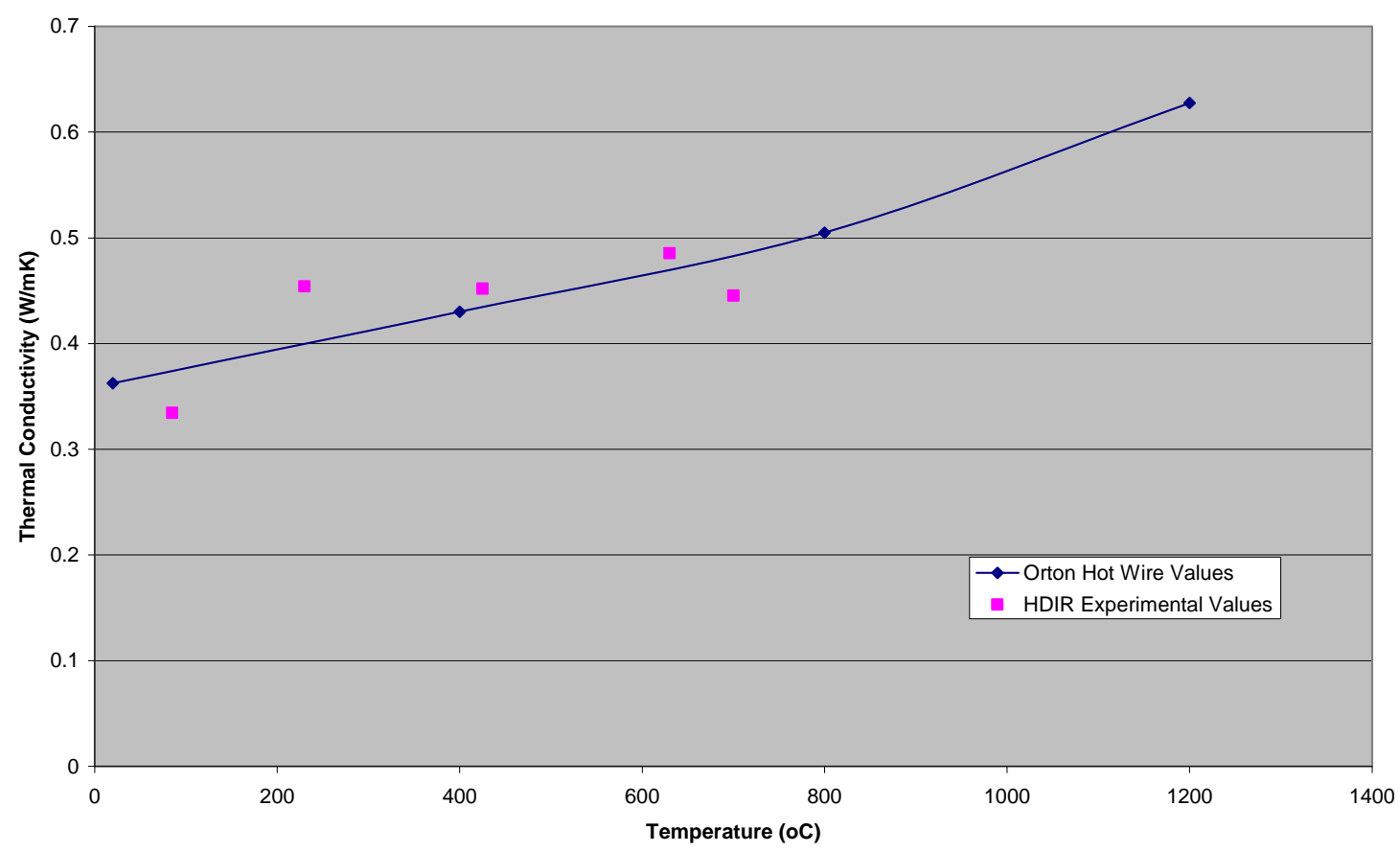

Figure 85. ORNL HDIR Thermal Conductivity Results for Back-up Lining Material

Spinel Forming Refractories

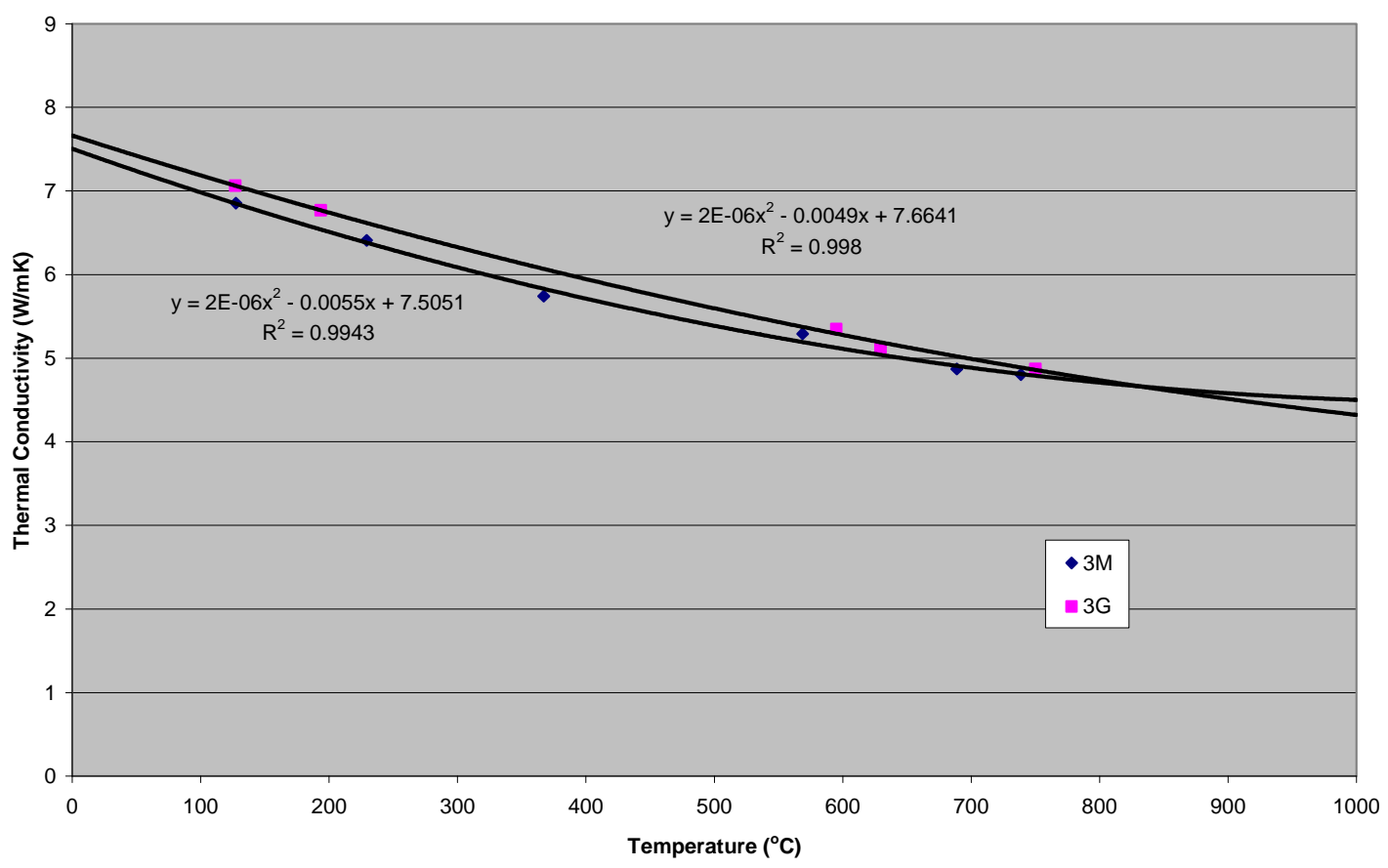

Figure 86. HDIR Thermal Conductivity Measurements for Spinel Forming Refractories 


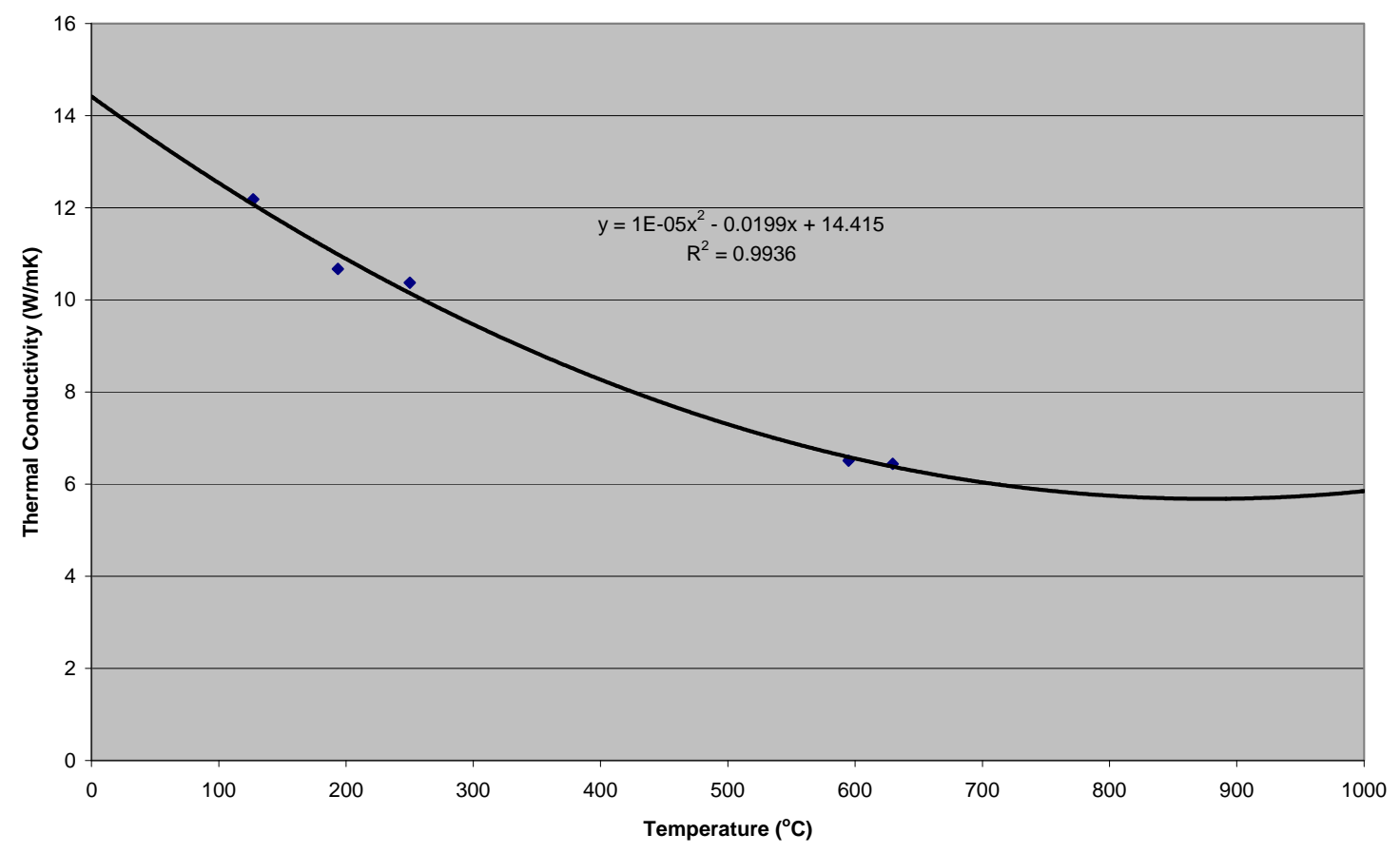

Figure 87. HDIR Thermal Conductivity Measurements for Magnesia Rich Refractory

Thermal diffusivity measurements were also conducted on experimental materials produced at MS\&T using the laser flash system at ORNL. Room temperature results are shown in Figure 88. As expected, thermal diffusivity of these materials decreased with increased solid solution formation.

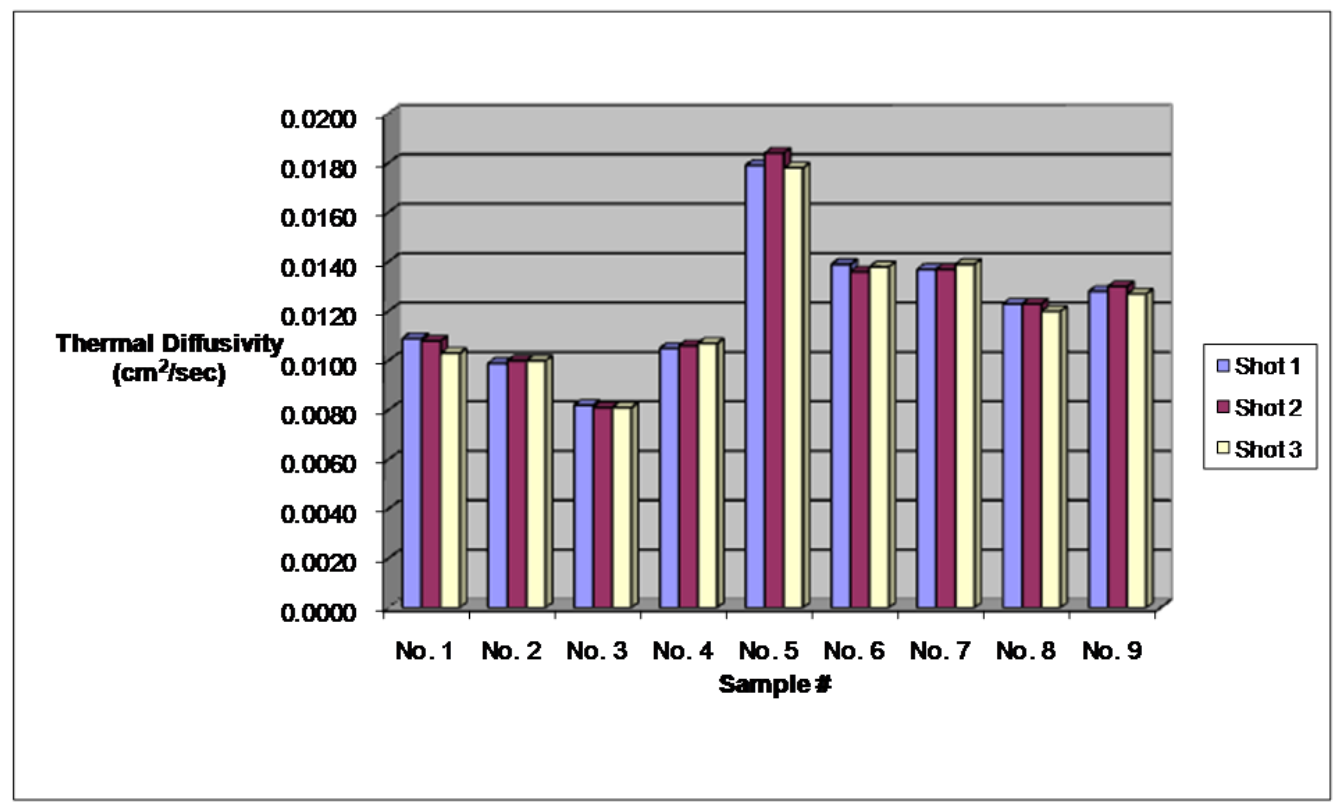

Figure 88. Room Temperature Thermal Diffusivity Results Obtained by Laser Flash Technique 
Thermal conductivity data for refractories developed for use in the aluminum industry was also measured by an outside commercial testing laboratory using the Hot Wire method (ASTM C1113) and are shown graphically in Figure 89. Values ranged from 2.5 to 3.5 $\mathrm{W} / \mathrm{mK}$.

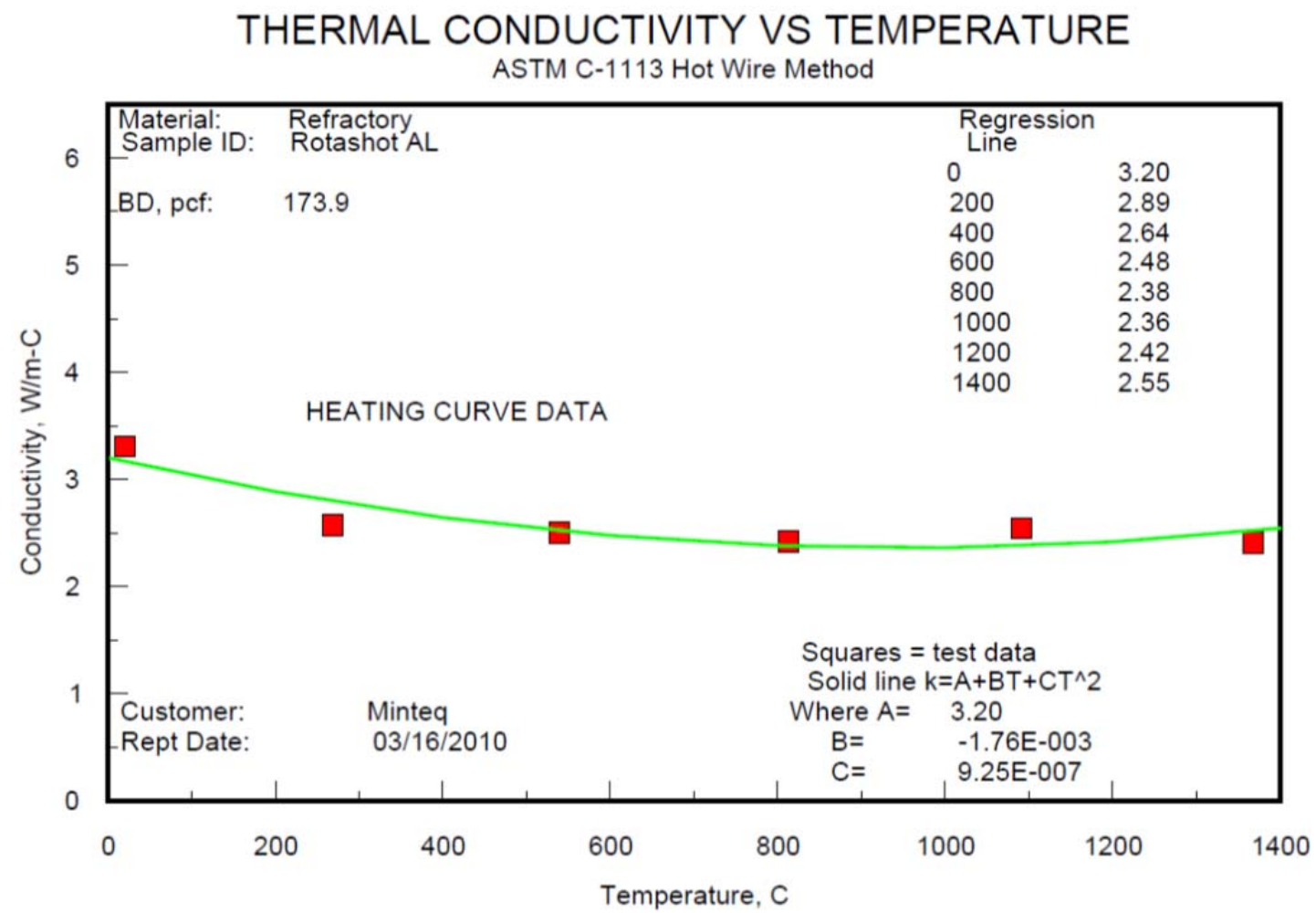

Figure 89. Thermal Conductivity of Experimental Aluminum Industry Shotcrete Material Developed Under This Project

Additionally, thermal expansion testing of new refractory materials being developed under this project was performed at MS\&T through dilatometery. Samples were heated at $3^{\circ} \mathrm{C} / \mathrm{min}$. to $1500^{\circ} \mathrm{C}$ with measurement of $\%$ linear change as a function of temperature recorded during heat-up and cool down. Coefficient of thermal expansion (CTE) was then calculated from the slope of the cool down curve. CTE values (shown in Table 19) ranged from 5.16 to $13.3 \times 10^{-6} /{ }^{\circ} \mathrm{C}$. These values were generally higher than that of the reference refractory material (Ufala brick $-\mathrm{CTE}=5.52 \times 10^{-6} /{ }^{\circ} \mathrm{C}$ ) which is used in many of the industrial applications of interest. Values for shot materials were found to be consistently higher than those for cast materials. Examples of results are shown below in Figure 90. 
Table 19. Summary of Refractory Thermal Expansion Results

\begin{tabular}{|c|c|}
\hline Material & Coefficient of Thermal Expansion $\left(\mathbf{x} \mathbf{1 0}^{-6} \boldsymbol{}^{\mathbf{0}} \mathbf{C}\right)$ \\
\hline MINTEQ 60C & 5.16 \\
MINTEQ 60S & 5.88 \\
\hline MINTEQ 70C & 6.19 \\
MINTEQ 70S & 6.37 \\
\hline MINTEQ 80C & 8.12 \\
MINTEQ 80S & 8.13 \\
\hline MINTEQ 635 & 8.86 \\
\hline MINTEQ 1090C & 8.68 \\
MINTEQ 1090S & 8.84 \\
\hline MINTEQ HSB & 13.3 \\
\hline UFALA & 5.52 \\
\hline
\end{tabular}

note: "C" signifies cast sample and "S" signifies shot sample
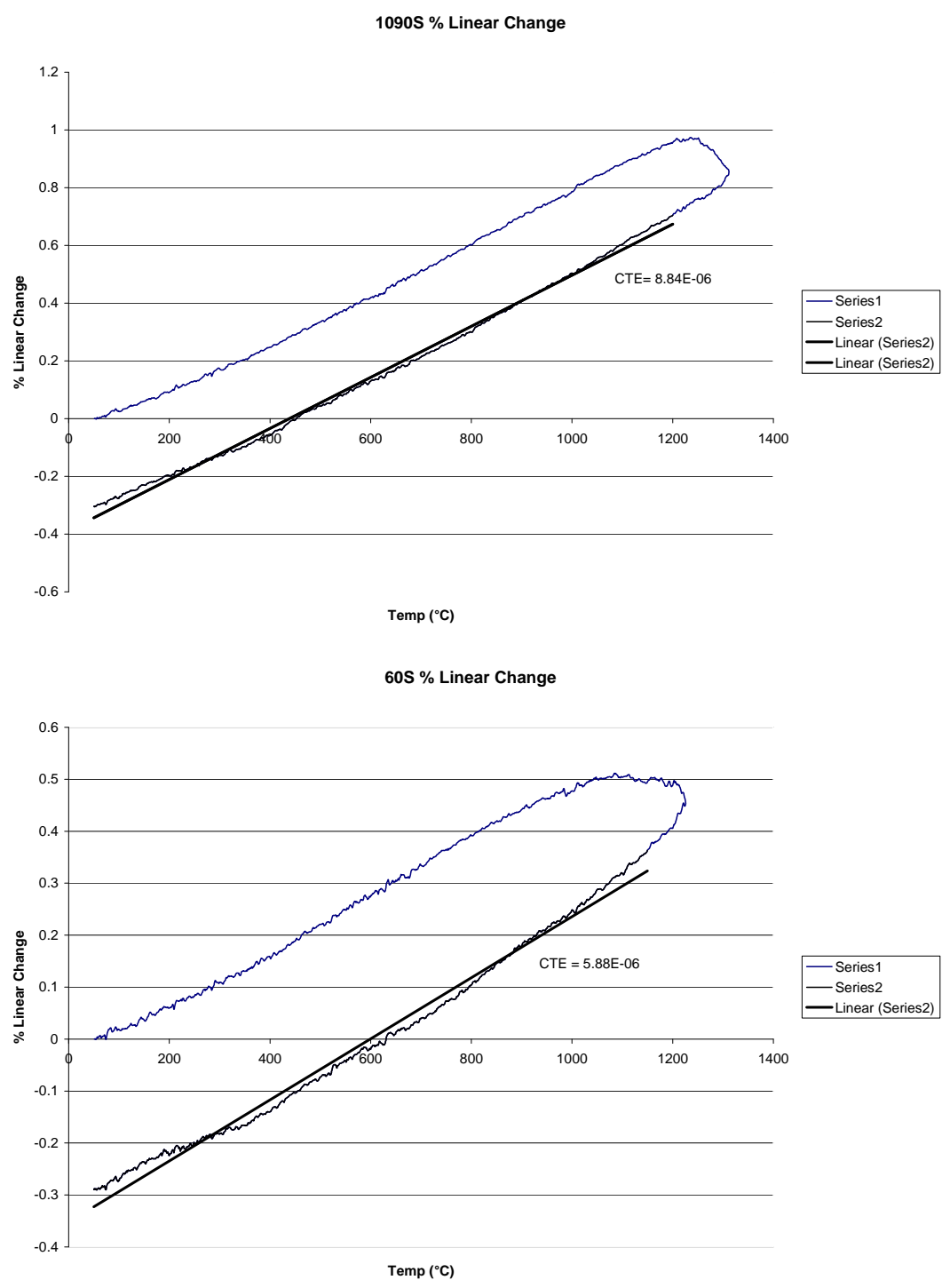

Figure 90. Examples of Dilatometer Thermal Expansion Results 
Thermal expansion testing was also performed by an outside commercial laboratory on the insulating shotcrete material and refractories for the aluminum industry developed under this project. Average thermal expansion coefficients on the order of $3 \times 10^{-6}{ }^{\circ} \mathrm{C}^{-1}$ and $3.5 \mathrm{x}$ $10^{-6}{ }^{\circ} \mathrm{C}^{-1}$ were measured for the insulating shotcrete and the shotcrete for use in the aluminum industry, respectively as shown in Figure 91 and Figure 92.

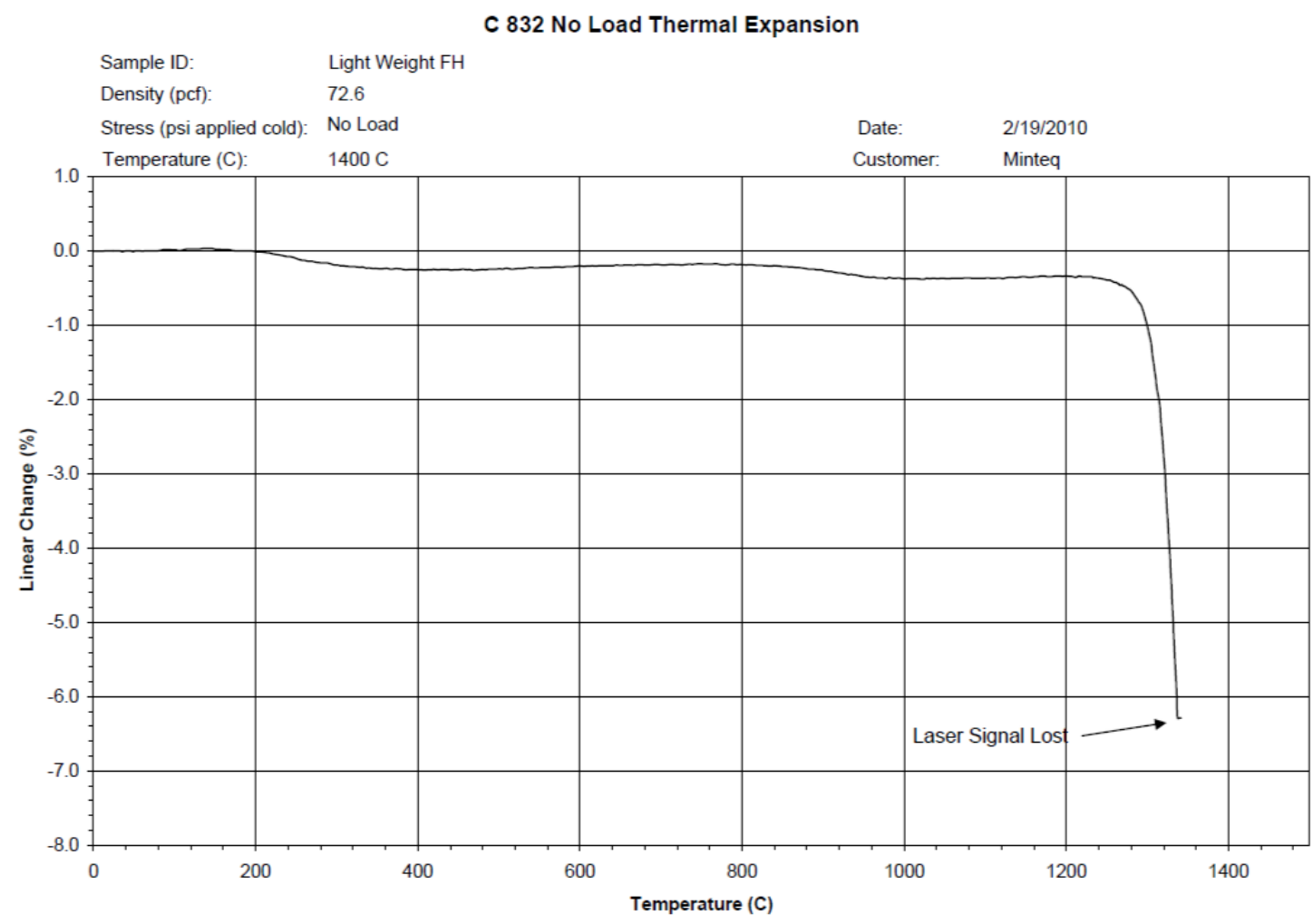

Figure 91. Thermal Expansion of Insulating Back-up Shotcrete Material 


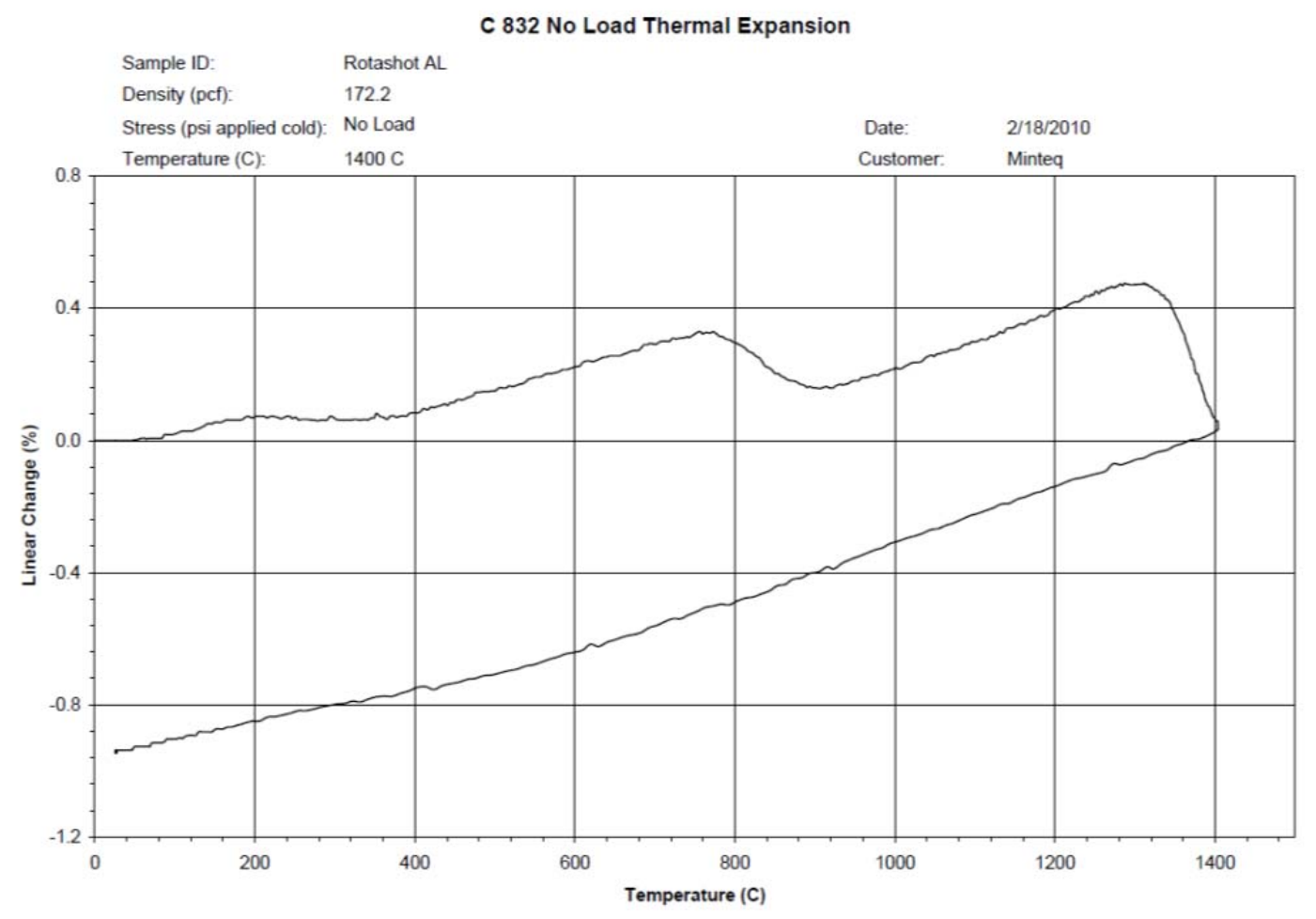

Figure 92. Thermal Expansion of Aluminum Industry Shotcrete Material

Thermal expansion testing was also run by the same outside commercial laboratory on both cast and shot samples of modified magnesia-rich spinel material for use in gasification applications as shown in Figure 93 and Figure 94, respectively.

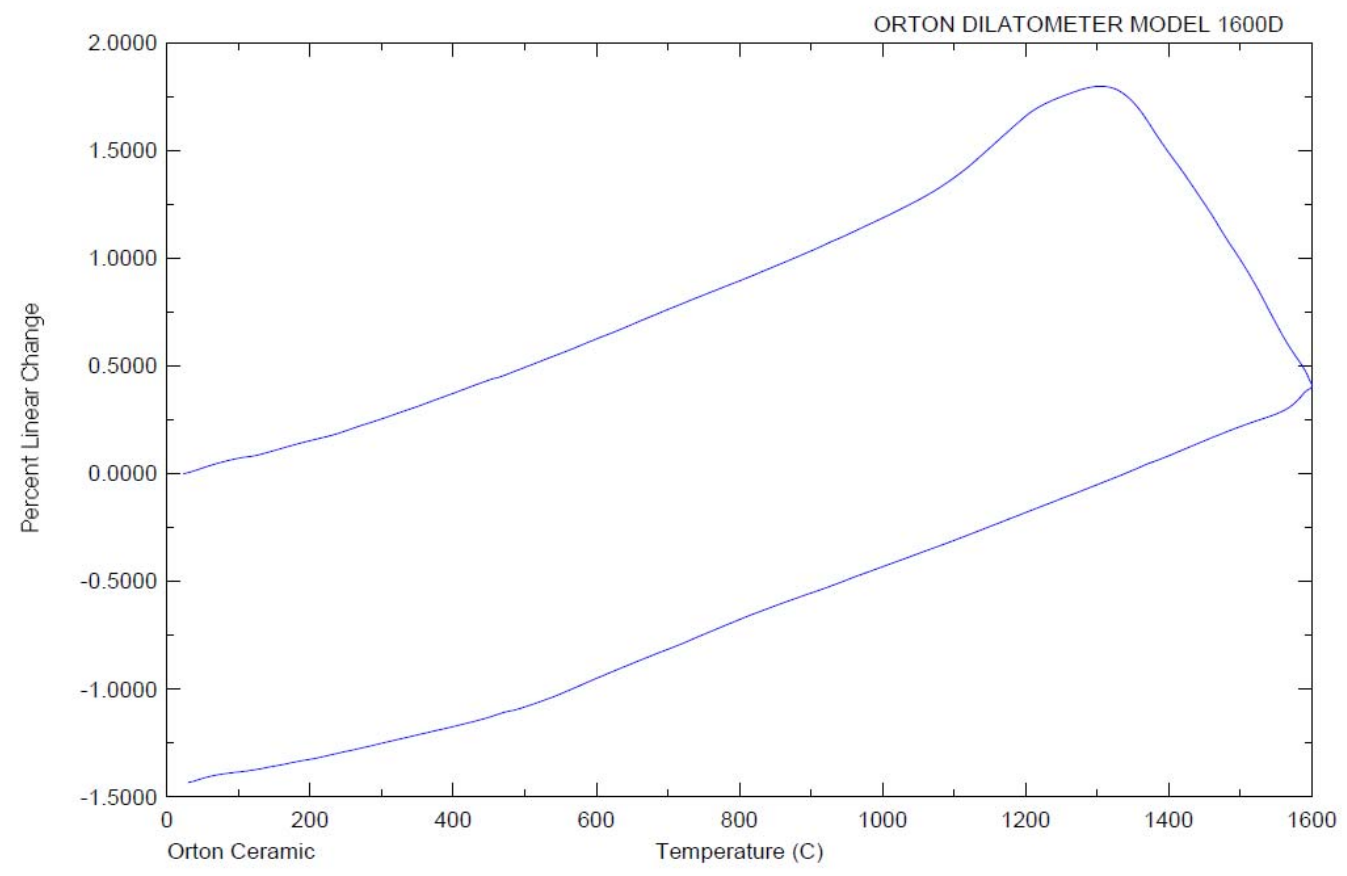

Figure 93. Thermal Expansion Curve for Cast Magnesia-Rich Spinel Material 


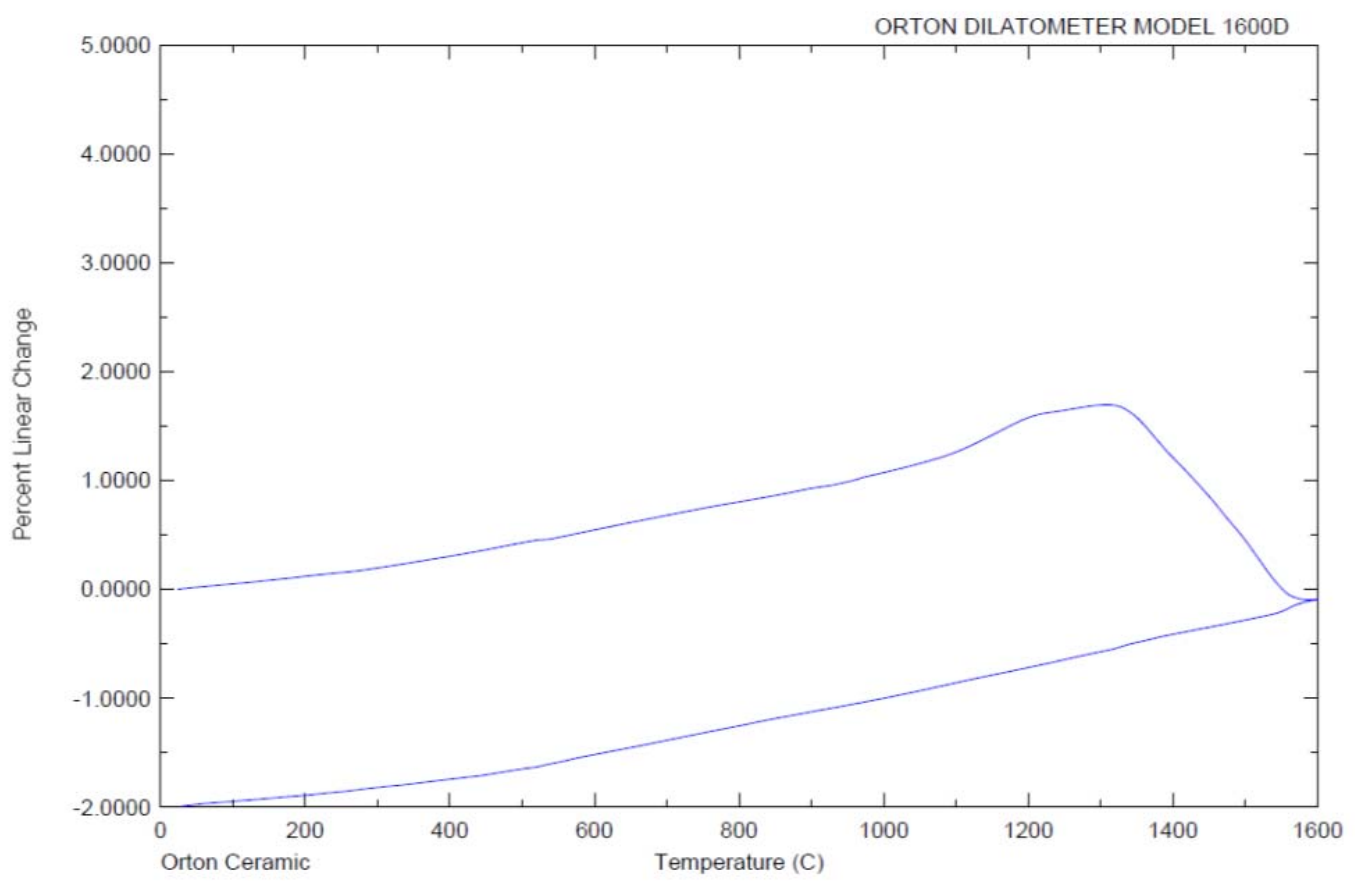

Figure 94. Thermal Expansion Curve for Shot Magnesia-Rich Spinel Material

Mechanical Analysis of Refractories

Compressive strength testing (carried out at room temperature and elevated temperature) and creep testing was performed at ORNL on materials currently used in the industrial processes of interest and on newly developed materials. Examples of test results from these tests are shown in Figure 95. 
Armor Flow 70AL Shot

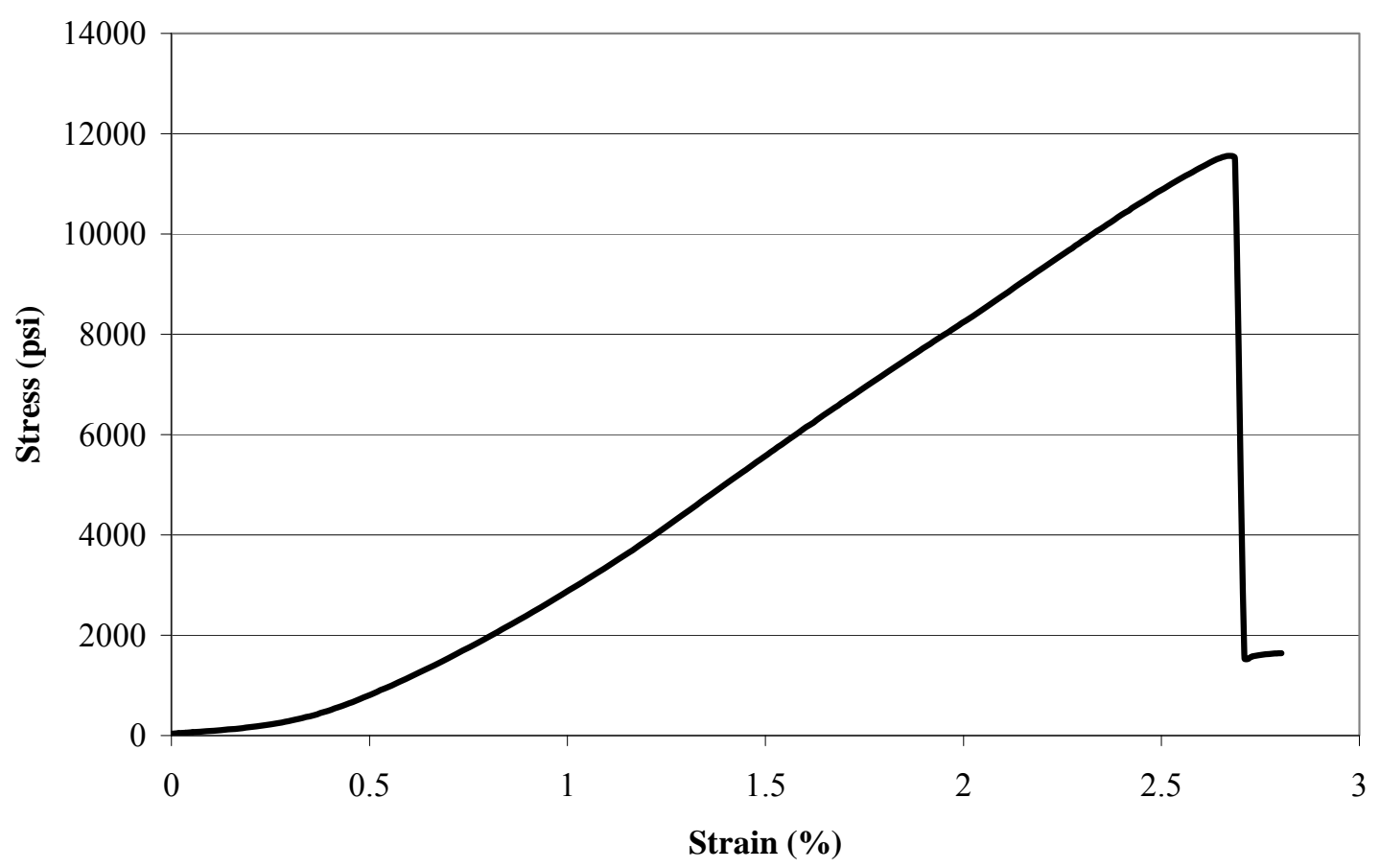

Ufala Compression Testing

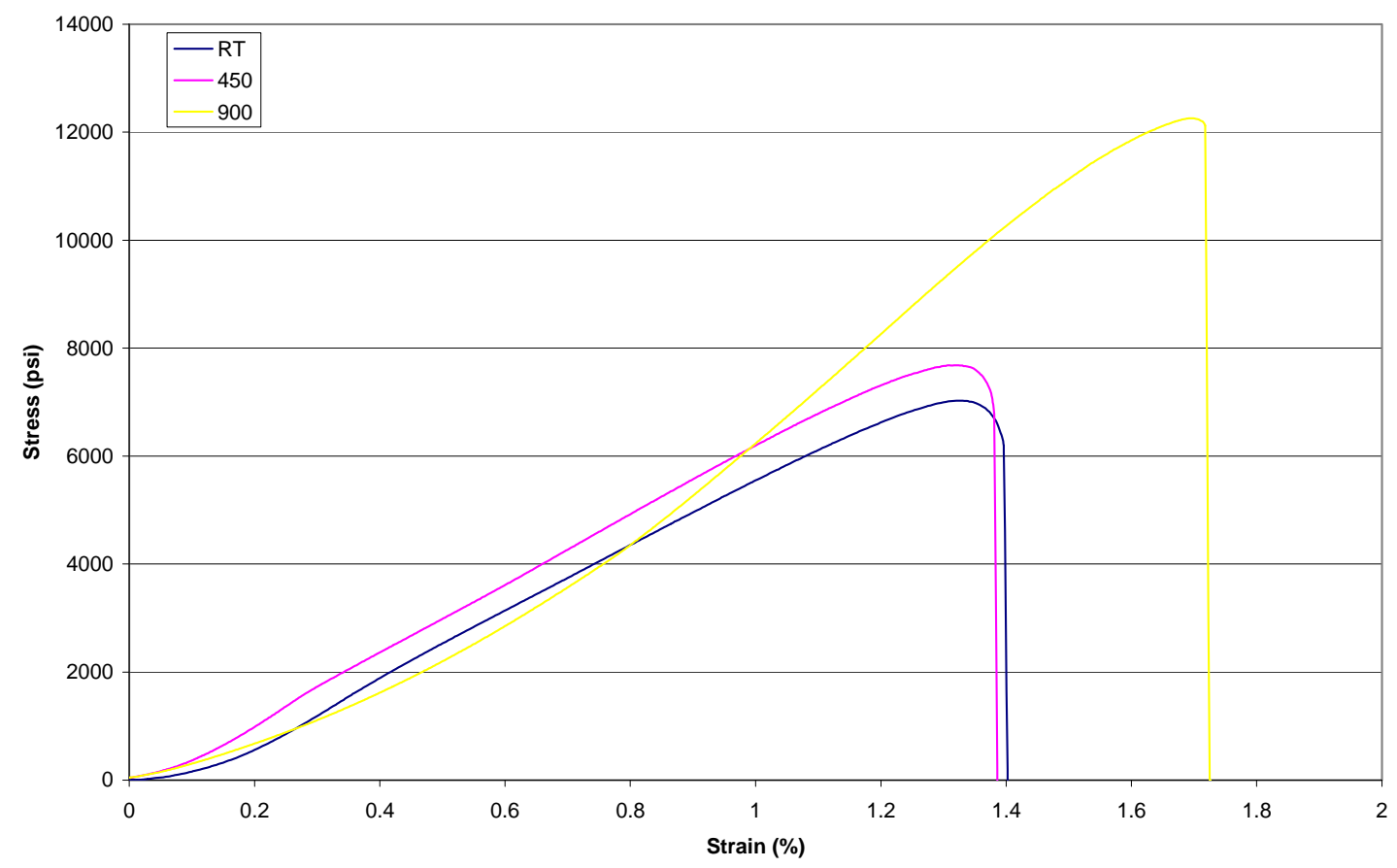

a) 


\section{Ufala Creep $\left(100^{\circ} \mathrm{C}, 1 \mathrm{MPa}\right)$}

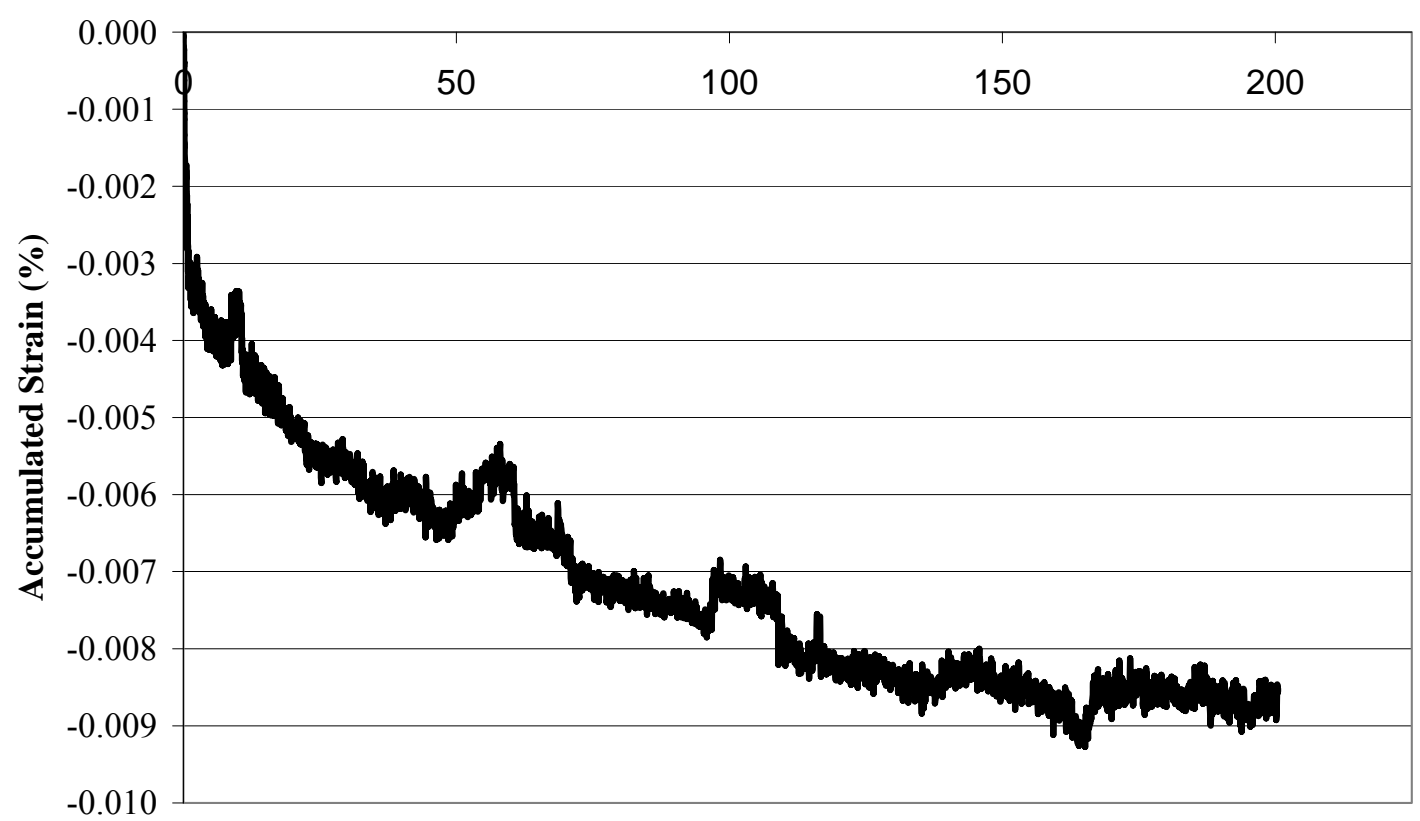

Time (hours)

Skamol Creep $\left(1000^{\circ} \mathrm{C}, 1 \mathrm{MPa}\right)$

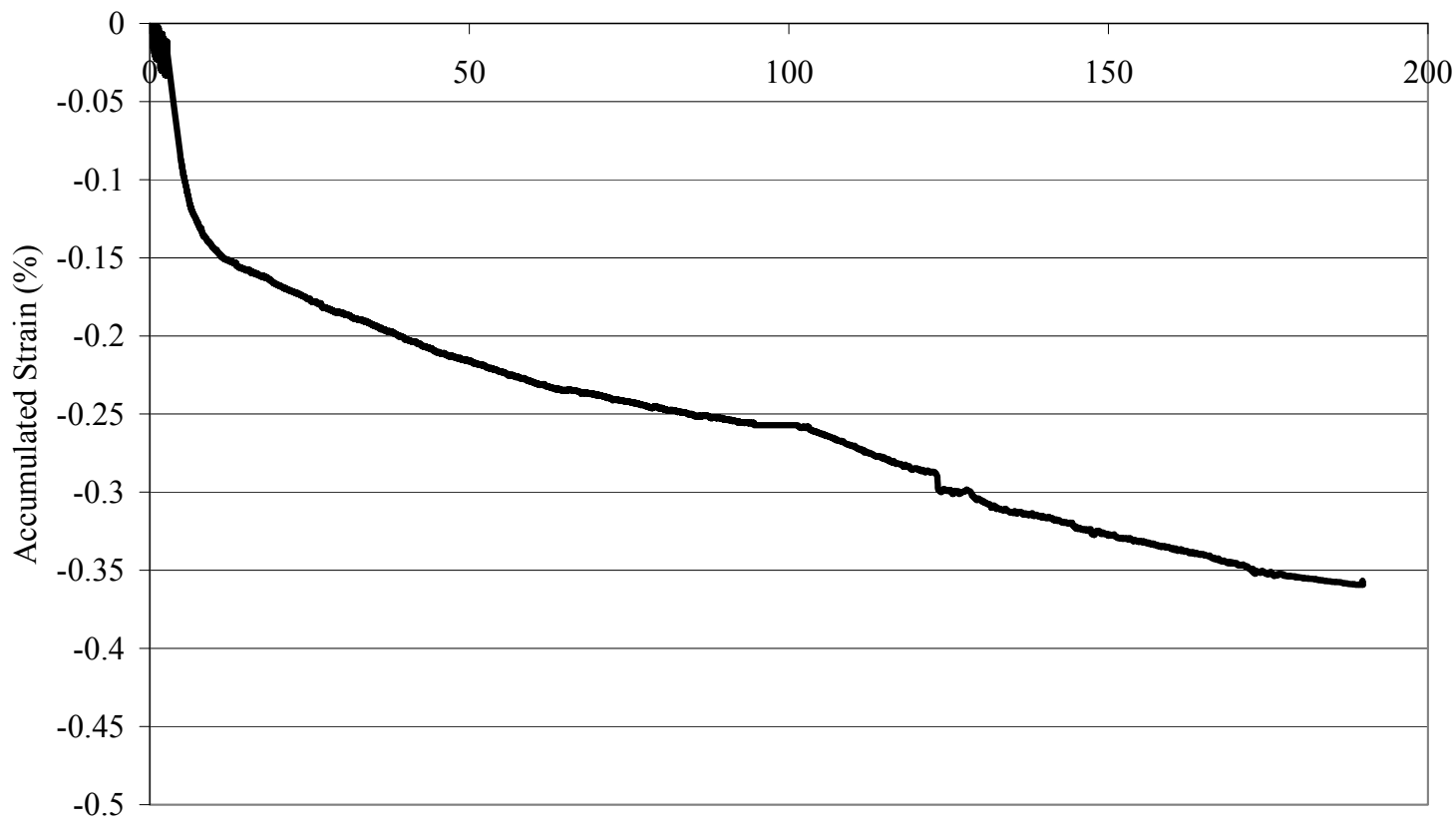

Time (hours)

b)

Figure 95. Examples of Mechanical Test Results ( $a$-Compressive Strength Testing, $b$ - Creep Testing) 
Creep testing was also performed on the insulating shotcrete and aluminum industry shotcrete materials developed under this project. A steady-state creep constant of $4 \times 10^{-5}$ was determined for the insulating shotcrete and a steady-state creep constant of $4 \times 10^{-2}$ was determined for the aluminum industry shotcrete as shown in Figure 96 and Figure 97, respectively.

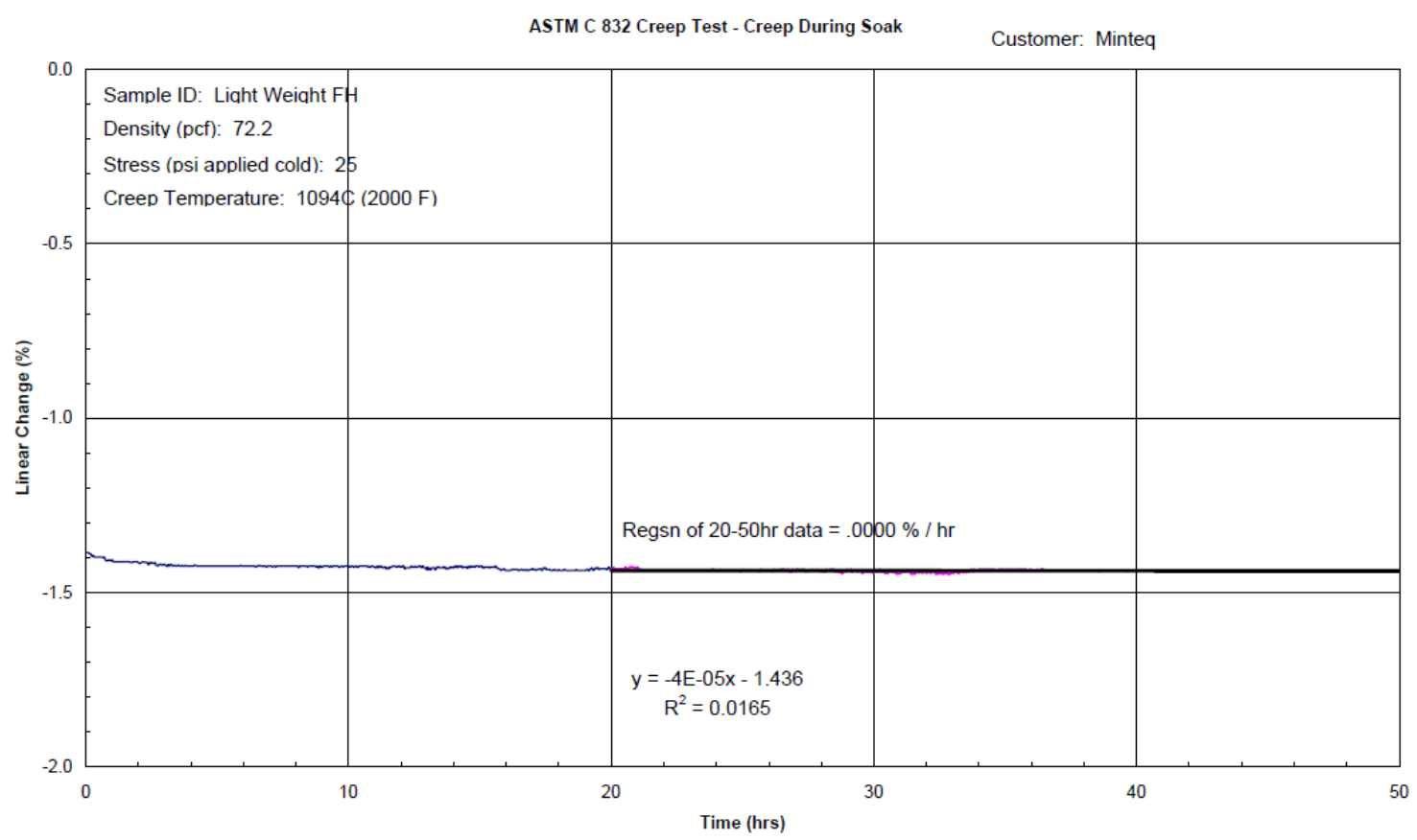

Figure 96. Creep Behavior of Insulating Back-up Shotcrete Material

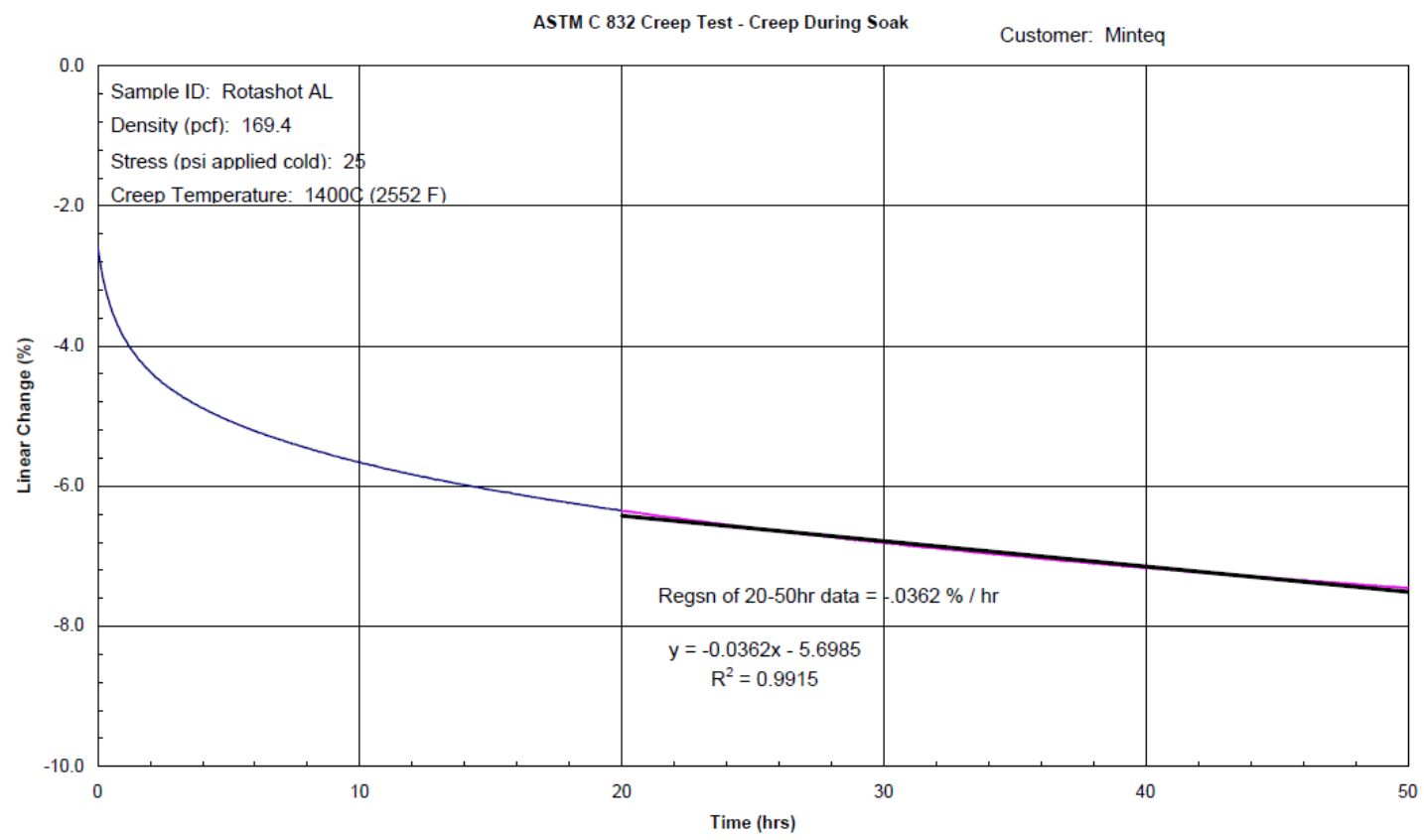

Figure 97. Creep Behavior of Aluminum Industry Shotcrete Material 
Abrasion testing (ASTM C-704) was also performed by an outside commercial laboratory on the aluminum industry shotcrete material. Results are shown in Figure 98 indicating a loss on the order of 6.5 to $7.5 \mathrm{~cm}^{3}$.

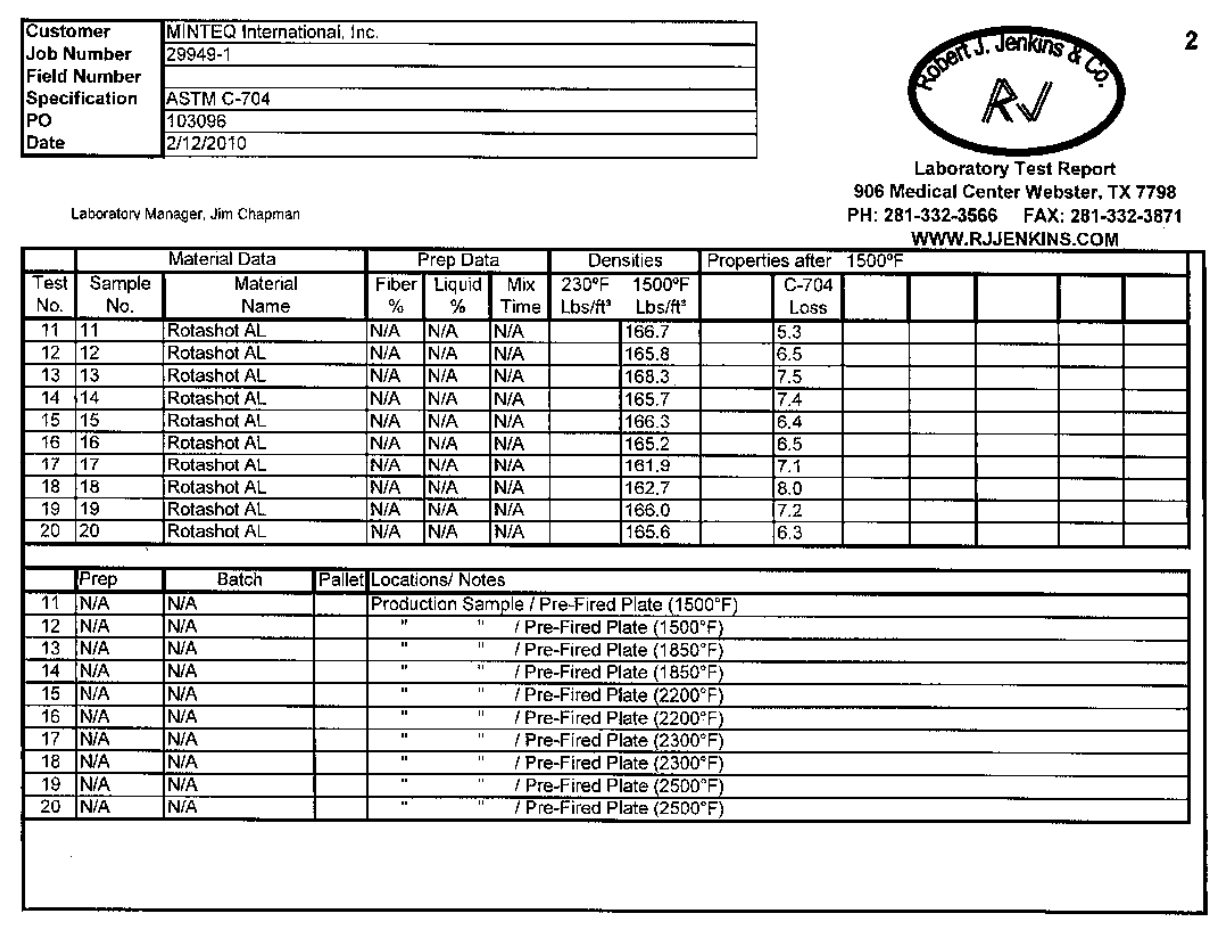

Figure 98. Abrasion Testing Results for Aluminum Industry Shotcrete Material

Physical characterization and abrasion testing was also performed on samples of modified magnesia-rich spinel material for use in gasification applications. Densities of shot samples ranged from 2.55 to $2.86 \mathrm{~g} / \mathrm{cm}^{3}$ ( 159.1 to $178.6 \mathrm{lbs} / \mathrm{ft}^{3}$ ). Abrasion testing of these samples showed losses of 4.9 to $12.7 \mathrm{~cm}^{3}$, with the variation found to be strongly dependent on sample density.

\section{Rotary Furnace Testing}

Additionally, a rotary furnace simulation test system was commissioned by MINTEQ for evaluation of material performance in the aluminum and lime kiln environments. The furnace was capable of being lined with test samples of both currently used and new materials developed under this project for a side by side comparison of materials on a scale between lab-scale and actual industrial implementation. A schematic and picture of the test furnace is shown in Figure 99. 

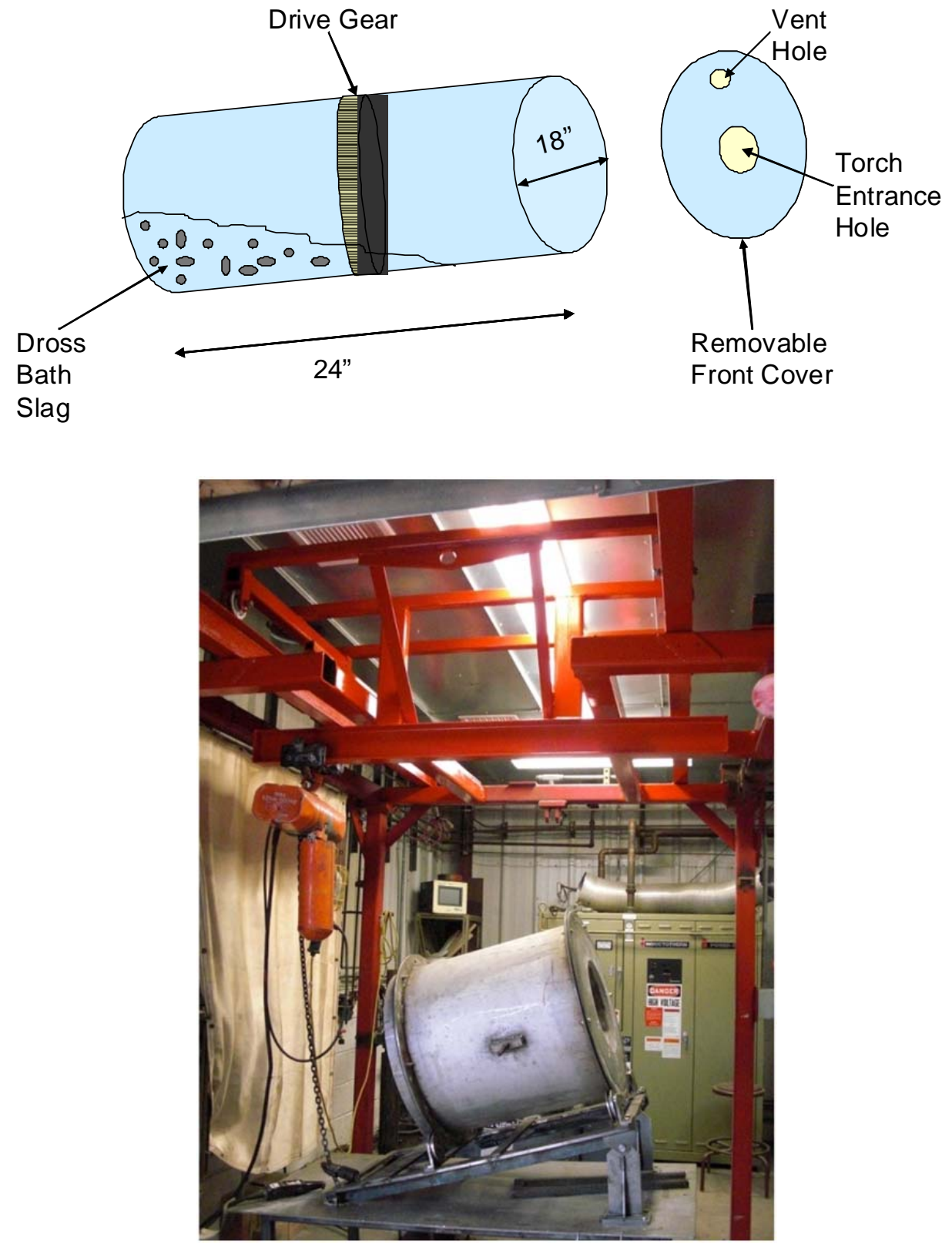

Figure 99. MINTEQ Rotary Furnace Simulation Test Schematic and Actual Picture of Completed System

The furnace was lined with test samples of both currently used (provided by industry) and new materials developed under this project (shotcreted by MINTEQ) for a side by side comparison of materials on a scale between lab-scale and actual industrial implementation. Pictures from a test to evaluate aluminum products developed under this project are shown in Figure 100. 

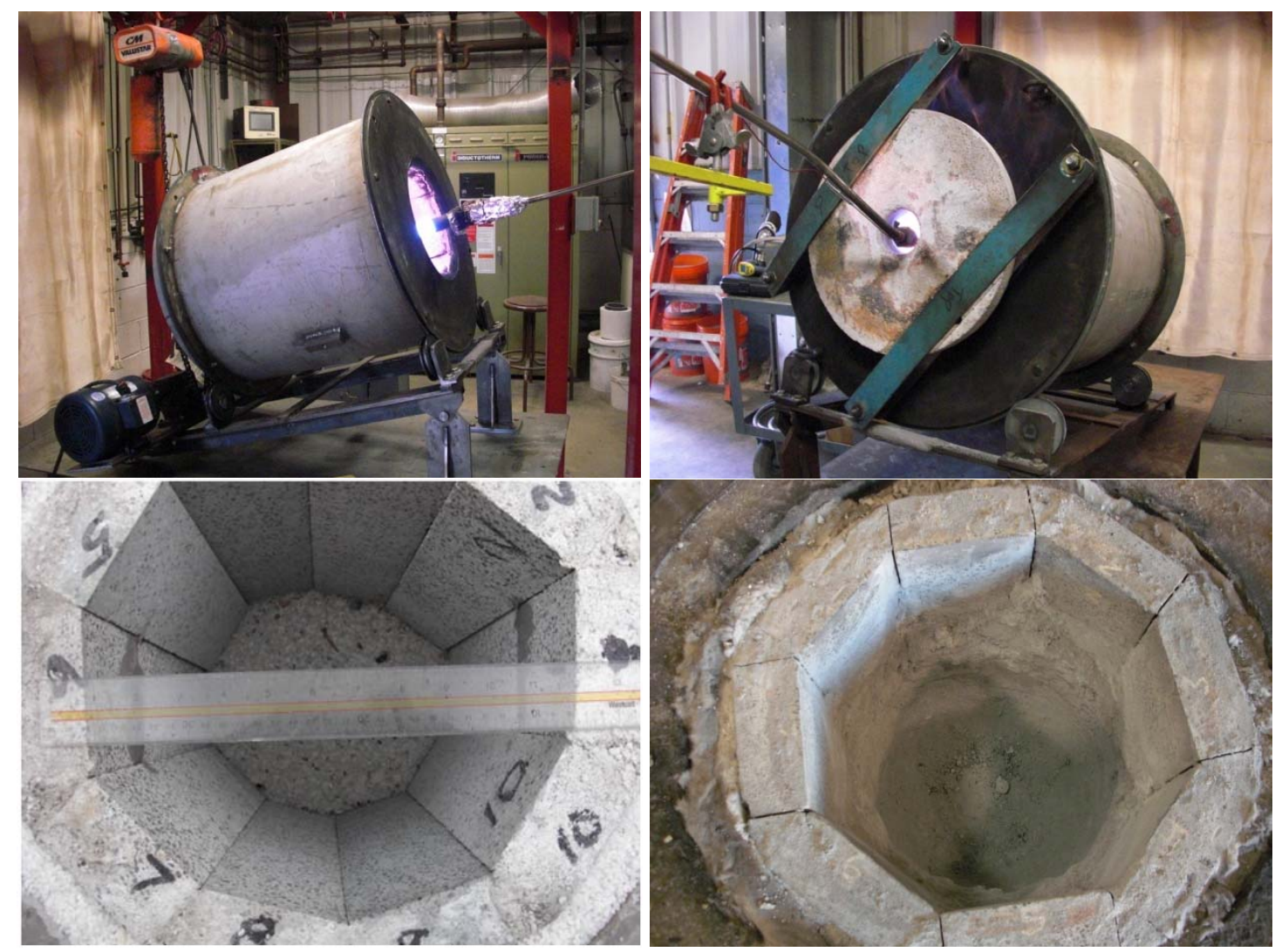

Figure 100. Rotary Furnace Simulation Test System During Testing and Pictures of Lining Before and After Aluminum Refractory Test

Four test runs were performed with molten aluminum to evaluate the performance of the new material developed under this project against currently and previously used materials. A total of five materials were evaluated (shotcrete material developed under this project, three shotcrete materials currently used by MINTEQ for aluminum applications, and one brick material used industrially for aluminum applications). No evident corrosion was observed after the four runs. Impregnation by the aluminum metal and reaction with the refractory (as indicated by observed dark areas on the refractories) were present in all samples. Based on the measured thickness of the dark areas, the performance of the tested refractories was split into three groups. The best performing group consisted of the experimental shotcrete material developed under the project, a $70 \%$ alumina-containing shotcrete material currently used by MINTEQ for aluminum applications, and a $60 \%$ alumina-containing shotcrete material currently used by MINTEQ for aluminum applications. All of these materials exhibited an $\approx 5 \mathrm{~mm}$ thick dark area of aluminum impregnation and reaction. The next best performance was shown by the $80 \%$ aluminacontaining refractory material currently used by MINTEQ for aluminum applications that exhibited a dark area $\approx 10 \mathrm{~mm}$ thick. The poorest performance was shown by the brick material that had a 15-20 mm thick dark area after only one run with molten aluminum (compared to four runs of exposure for the other materials). 
Energy Savings Estimates Based on Measured Refractory Properties

Energy savings estimates based on measured properties of the experimentally developed refractory systems from this project were made at MINTEQ to validate the energy savings estimates originally proposed for the project. One such analysis for lime kilns is shown below in Table 20. This analysis assumes a traditional lime kiln refractory lining consisting of $60 \%$ alumina brick backed by insulating refractory tiles as found in the current configuration used by industrial partner Weyerhaeuser. The performance of this lining system is compared to a refractory system composed of the experimental spinel forming refractory and back-up materials developed under this project. For identical service conditions (based on those observed at Weyerhaeuser) a reduction in shell temperature of $35^{\circ} \mathrm{C}\left(95^{\circ} \mathrm{F}\right)$ is realized using the new lining system which results in a reduction of estimated heat loss through the shell of $4,043 \mathrm{~kJ} / \mathrm{m}^{2}\left(356 \mathrm{Btu} / \mathrm{ft}^{2}\right)$ or 11.8 billion $\mathrm{kJ}$ (11.2 billion Btu) per kiln per year. At an estimated cost of $\$ 12 / \mathrm{MMBtu}$ for natural gas (average spot price), this results in an annual savings of $\$ 134,400 /$ year per kiln.

Table 20. Lime Kiln Energy Analysis

\begin{tabular}{|l|c|c|}
\hline $\begin{array}{l}\text { Refractory } \\
\text { Configuration }\end{array}$ & $\begin{array}{l}\text { 60\% Al2O3 Brick } \\
\text { Insulating Tiles }\end{array}$ & $\begin{array}{l}\text { Experimental Spinel Material } \\
\text { Lightweight Insulation }\end{array}$ \\
\hline $\begin{array}{l}\text { Estimated Shell Temp } \\
\left({ }^{\circ} \mathrm{C}\right)\end{array}$ & 230 & 195 \\
\hline $\begin{array}{l}\text { Estimated Heat Loss } \\
\left(\mathrm{kJ} / \mathrm{m}^{2}\right)\end{array}$ & 15,649 & 11,606 \\
\hline $\begin{array}{l}\text { Estimated Heat Loss per } \\
\text { kiln per year }(\mathrm{B} \mathrm{kJ})\end{array}$ & 46.0 & 34.2 \\
\hline
\end{tabular}

Property information generated through the testing above was used to validate that the newly developed materials would lead to improved life span and thermal efficiency. This was accomplished through analyzing how the refractory materials which were developed under this project will either lead to the possibility of operating processes at higher temperatures (original project goal of $100-200^{\circ} \mathrm{C}$ increase in operating temperatures), increased refractory life (original project goal of two times the original life or an incremental step in lifetime to the next process determined service increment), or increased heat kept in the process. A summary of how materials developed under this project were found to contribute to these goals is discussed below based on the testing described above.

Materials for the aluminum industry were targeted for use in reverberatory melting furnaces and rotary scrap processing furnaces. The developed refractories are alumino-silicate primary lining and repair materials and alumina-rich spinel forming repair materials. These materials showed reduced corrosion in contact with molten aluminum through refractory cup testing. Amounts of recession could be calculated based on measurement of penetration of the molten aluminum into the refractory cup per unit time. Through testing it was shown that the materials developed under this project showed half as much or less penetration compared to current industrially used materials tested under identical conditions leading to the expectation that these materials would provide twice the service life of currently used materials. Other properties such as strength, creep resistance, and thermal conductivity were also tested to ensure that these properties were not degraded by gains made in corrosion resistance. Additionally, these materials were evaluated for use at operating temperatures of 
$1260-1315^{\circ} \mathrm{C}$ (typical aluminum processing temperatures on the order of $700-900^{\circ} \mathrm{C}$ ). Finally, since these materials are shotcretes as opposed to brick technology, they should be easier to install and make possible hot repair of aluminum furnace linings not currently possible.

Materials for black liquor gasification were targeted for repair applications. The materials developed under this project are magnesia-rich spinel forming and phosphate bonded materials which show equivalent corrosion resistance to currently used fusion cast spinel materials, but offer lower cost and easier installation. Other properties such as strength, creep resistance, and thermal conductivity were also tested to ensure that these properties were not degraded compared to currently used materials. Additionally, these materials make hot repair a possibility. These materials not only offer economic benefits, but increased energy efficiency through the elimination of the need to cool the gasifier for refractory repairs. Additionally, through the use of the light-weight insulating back-up lining that has been developed under this project for use behind the spinel forming primary lining, increased heat can be kept in the process.

Materials for coal gasification have also been targeted for repair applications. These materials are alumina-rich spinel materials that show increased corrosion resistance in the acidic slag environment. Other properties such as strength, creep resistance, and thermal conductivity were also tested to ensure that these properties were not degraded compared to currently used materials. Additionally, since these materials are shotcretes as opposed to brick technology, they should be easier to install and make possible hot repair of gasifier linings with the advantages identified above. Again, the use of the light-weight insulating back-up lining developed for use behind the spinel forming primary lining is possible here as well, leading to increased heat maintained in the process.

Finally, materials for lime kilns were targeted for primary furnace linings. These materials were designed for increased resistance to cracking (increased strength) and reduced corrosion. These properties were validated compared to currently used materials through cup testing and mechanical testing. Newly developed materials were also evaluated for higher temperature use (targeting the $100-200^{\circ} \mathrm{C}$ increase in operating temperature goal). Other properties such as strength, creep resistance, and thermal conductivity were also tested to ensure that these properties were not degraded by gains made in corrosion resistance.

Although this is only a qualitative analysis and validation that the new materials developed under this project will lead to improved life span and thermal efficiency, such expectations were quantitatively validated through the industrial trials scheduled in the last years of the project under Task 8.

\section{Task 5 Development of new refractory application techniques}

Work on this task was completed during year two of the project (meeting Milestone \#4). Initial property evaluation of installed materials was also completed in year two, with wear testing and microstructural evaluation being competed in the first part of year three. 
Work concentrated on fine-tuning techniques for the installation of spinel forming shotcrete materials. Such considerations as adequate pumpability, ease of installation, along with the stability and accelerator response of the mix had to be determined. To aid in this, MinTeq developed a system for laboratory evaluation shotcrete materials.

\section{Task 6 Development of on-line inspection and hot-repair techniques}

This task was completed during year three of the project. Efforts were completed to evaluate current methods, along with applicable new systems and techniques for targeted applications. Additionally, discussions were held with various partners about interest in online inspection and hot-repair techniques being developed with MinTeq and their possible participation in the final year of the project as an industrial test site.

It was determined that although repair materials have been developed for aluminum, black liquor, and coal gasification systems which enable hot repair, there is only minor interest from the industrial partners in implanting these materials. The best opportunities for hot repair were felt to exist in the aluminum industry (as shown in Figure 101) and discussions were continued throughout the life of the project with industrial aluminum partners. Discussions were also held with the developers of black liquor gasification systems (Chemrec AB of Sweden who oversaw the New Bern Weyerhaeuser gasifier) about implementation of materials in a repair capacity in their high pressure unit located in Europe.

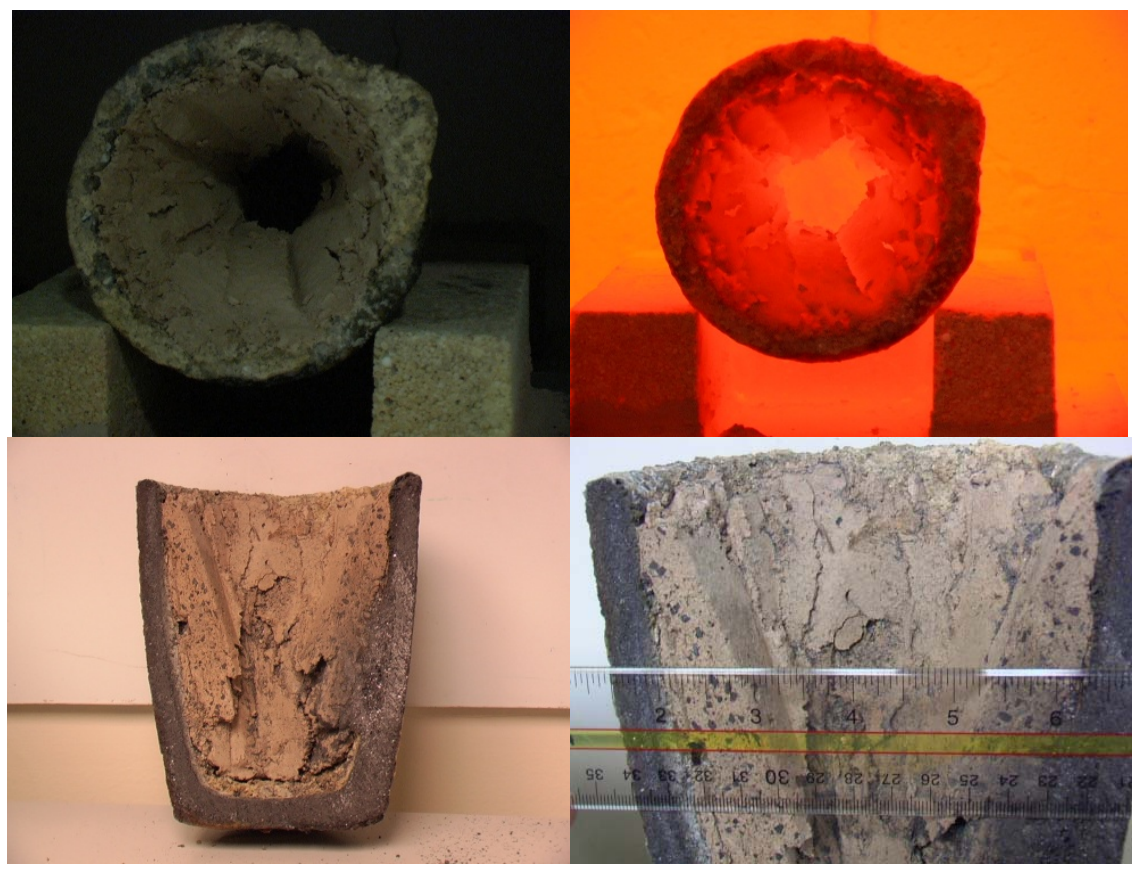

Figure 101. Spent Refractory Crucible Repair Material/Technique Adhesion Study Results for Aluminum Industry Applications

Regarding on-line inspection, laser-based on-line inspection techniques were identified which are currently used in the steel industry, but implantation of these techniques in applications such as black liquor and coal gasification where higher temperatures and tighter 
access clearances exist proved difficult due to cost considerations. Therefore, on-line inspection was not further pursued under this project.

Milestone 5 was completed in the third quarter of year three with the completion of the development of hot repair materials for aluminum, black liquor, and coal gasification systems and the determination of on-line inspection techniques being cost prohibitive for implementation.

\section{Task 7 Formation of database}

This task was scheduled to be completed during year four of the project based on data collected in Task 5. Actual completion of this task took place in 12/10 during a no-cost extension of the project. Information was entered from data collected during this and previous DOE projects. Over twenty five separate materials were initially included in the database at a publically available site (http://extwebapps.ornl.gov/crpd/Default.aspx). Sample screen shots of the database site are shown in Figure 102. A list of materials currently contained in the database is given in Appendix 4.

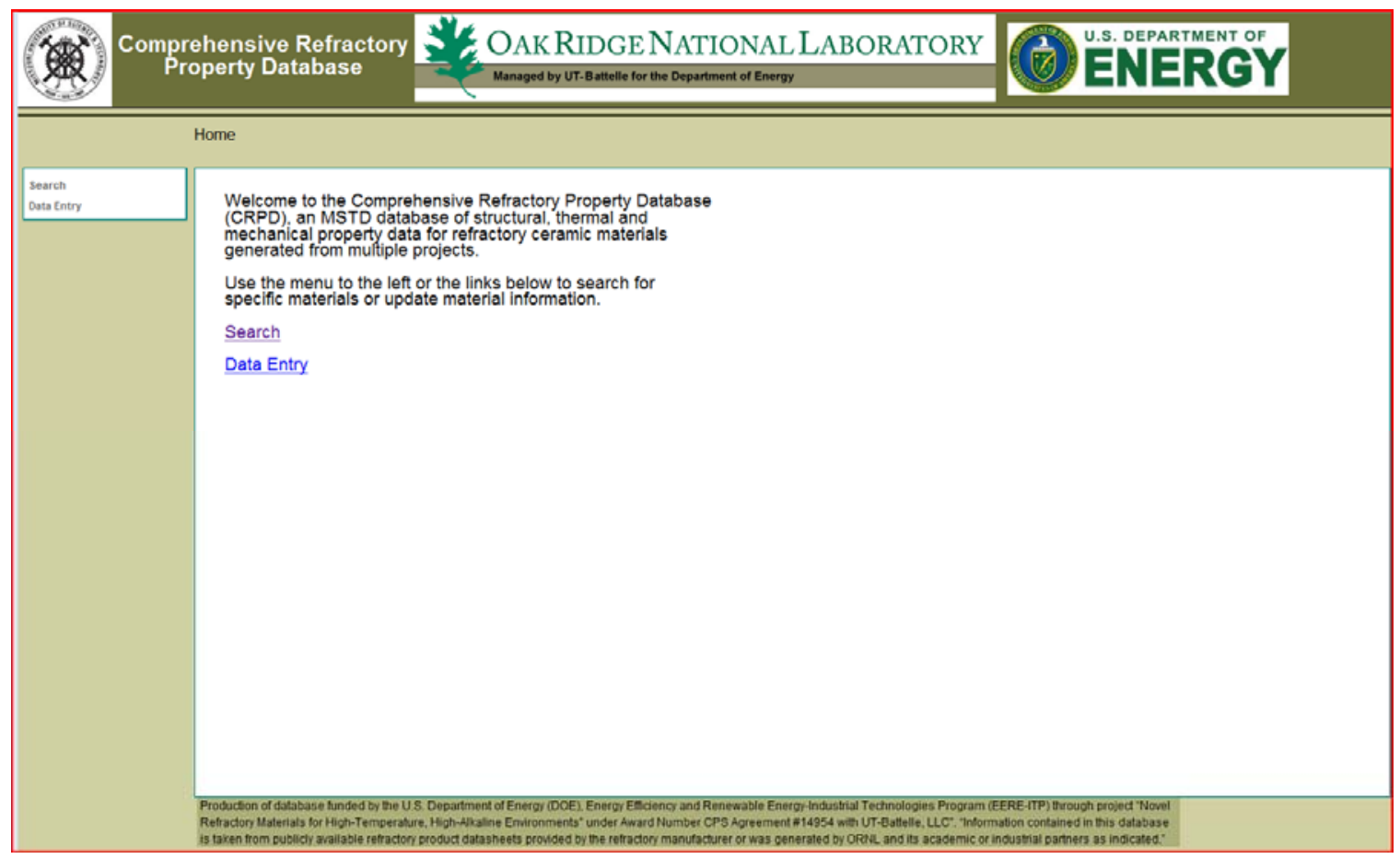



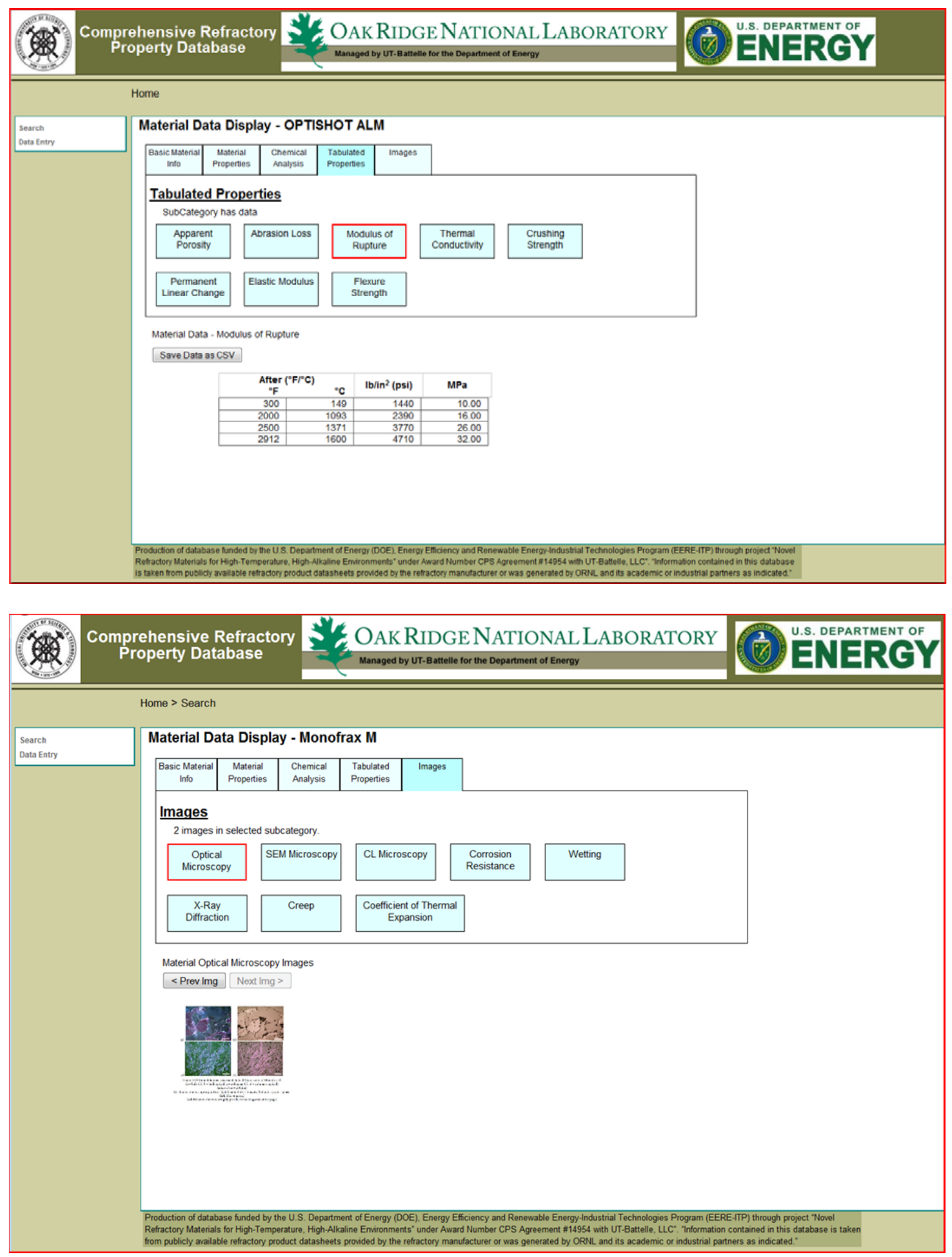

Figure 102. Examples of Pages from Comprehensive Refractory Property Database Constructed and Hosted at ORNL 


\section{Task 8 In-plant trials and commercialization}

Work on this task was planned to take place during the final planned year of the project (Year 4), but was continued during a no cost extension of the project through 3/12. The focus of the work was identifying and securing industrial trial sites for validation of the materials developed during the first three years of the project. Industrial trials were monitored through the end of the project, and will be continued by the respective industrial trial sites as long as materials remain viable or until the associated processes where the materials are being tested are brought down for normal maintenance outages. In total, over one hundred and sixty tons of refractory for use in aluminum furnaces and sixty tons of the lightweight back-up refractory material were installed in commercial furnaces to validate the materials developed under this project and in all cases the materials exceeded the customer's expectations.

A plant trial of the insulating shotcrete product developed under this project was first conducted at a MinTeq plant in Portage, IN to demonstrate industrial scale production of this material. An industrial scale shotcrete demonstration of the insulating shotcrete product was also conducted at a MinTeq facility in Steubenville, OH. Pictures from the shotcrete demonstration are shown in Figure 103.

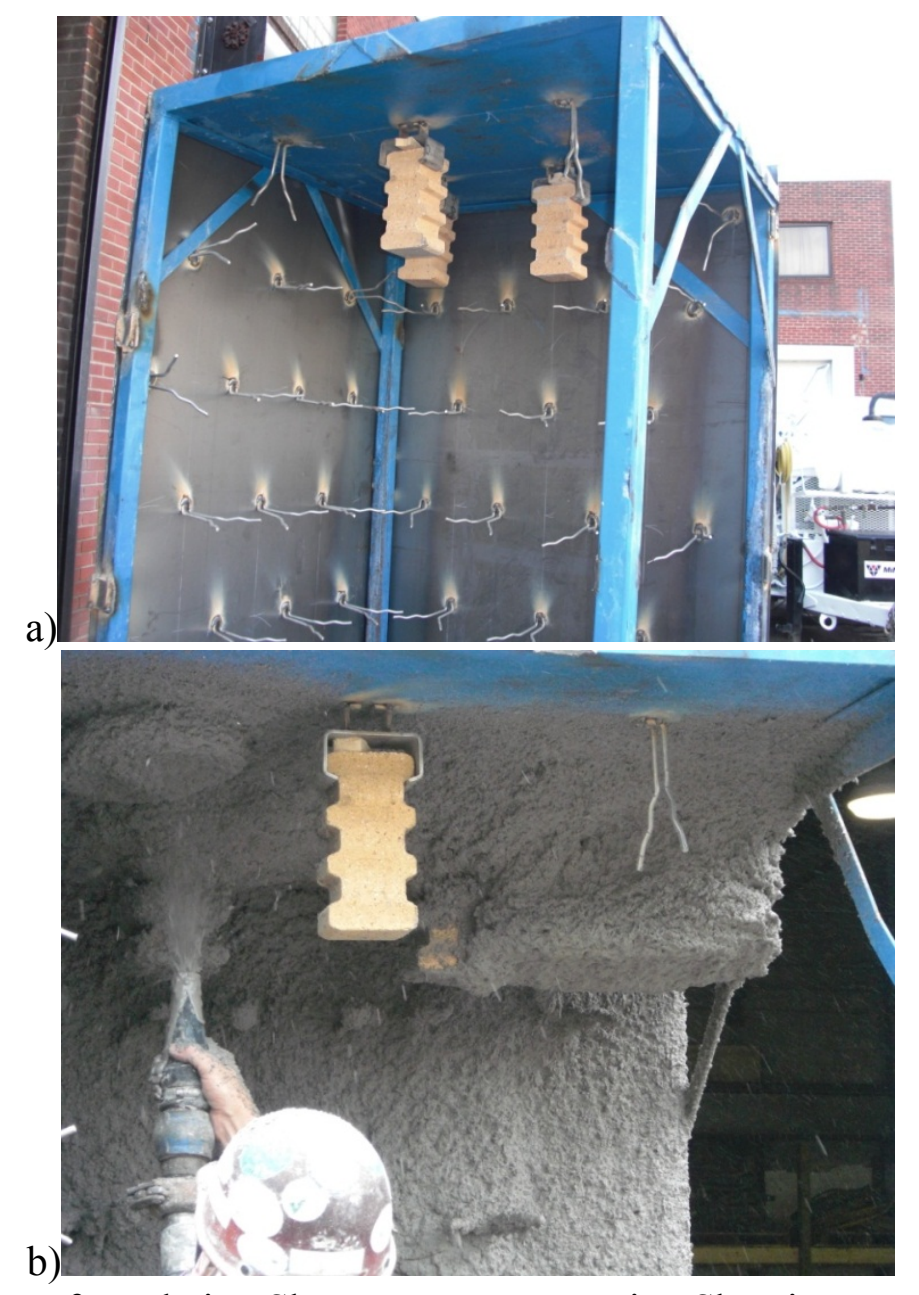

Figure 103. Pictures of Insulating Shotcrete Demonstration Showing Form Before Shooting

(a) and Form During Shooting (b) 
The first full scale industrial trial was held at Newco Metals (Bedford, IN) through a field installation of 14 tons of material developed for aluminum rotary dross furnace applications as shown in Figure 104. The same customer placed a second order of 14 tons of additional refractory based on the easy/rapid installation of this product during the initial installation. It was noted by the customer during the second order that the durability of the product from the first installation had already met the customer's expectation and that life times on the order of six months were typical for previous linings in these furnaces. These trials (shown in Figure 105) were monitored in excess of six months (linings actually monitored in excess of fifteen months and still installed at the time of the writing of this report, far exceeding material life time expectations) meeting Milestone Go/No Go Decision Point \#6. These linings were still installed at the completion of the project.

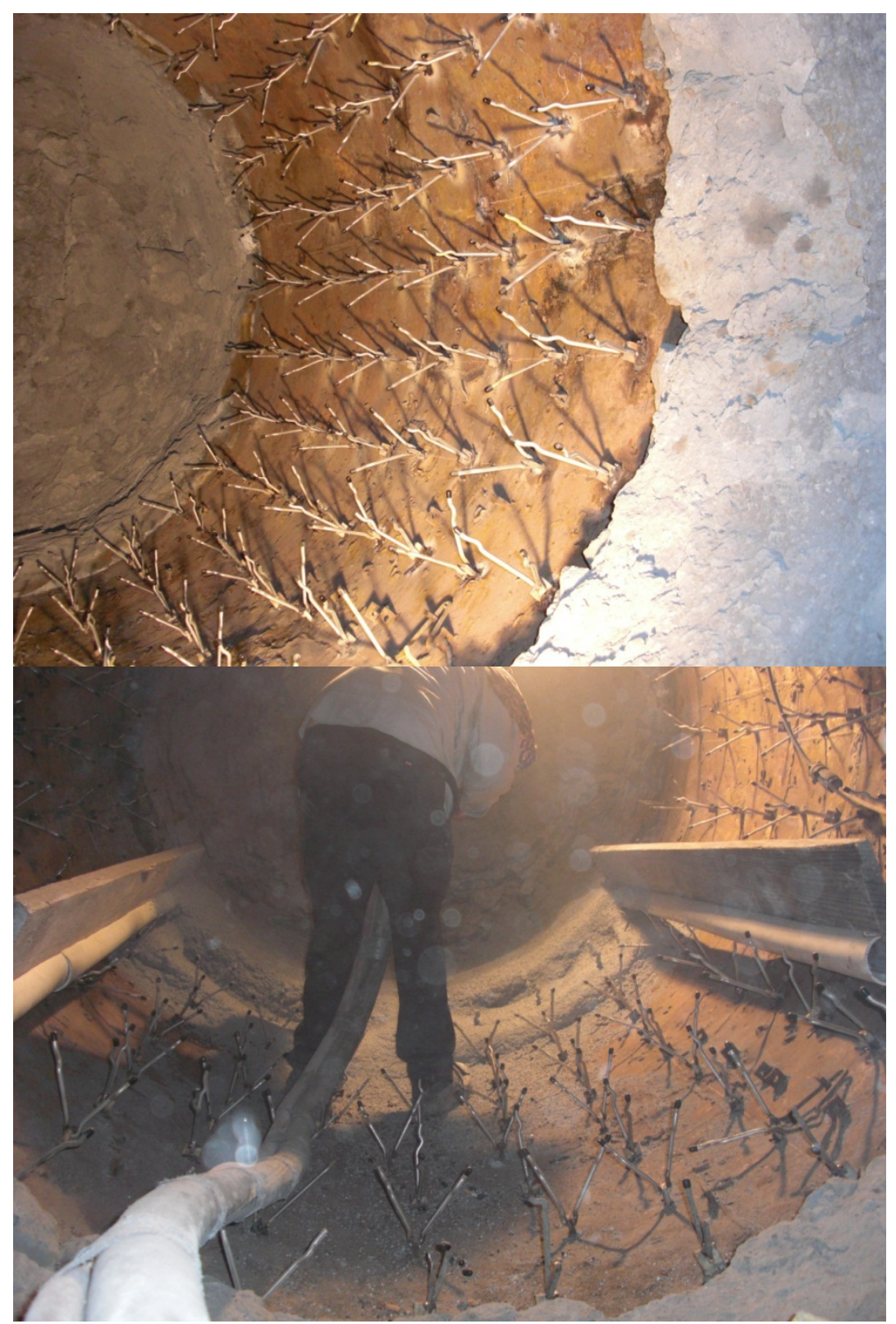

Figure 104. Aluminum Rotary Dross Furnace at Newco Metals (Bedford, IN) Before and During Installation of Developed Aluminum Furnace Refractory 


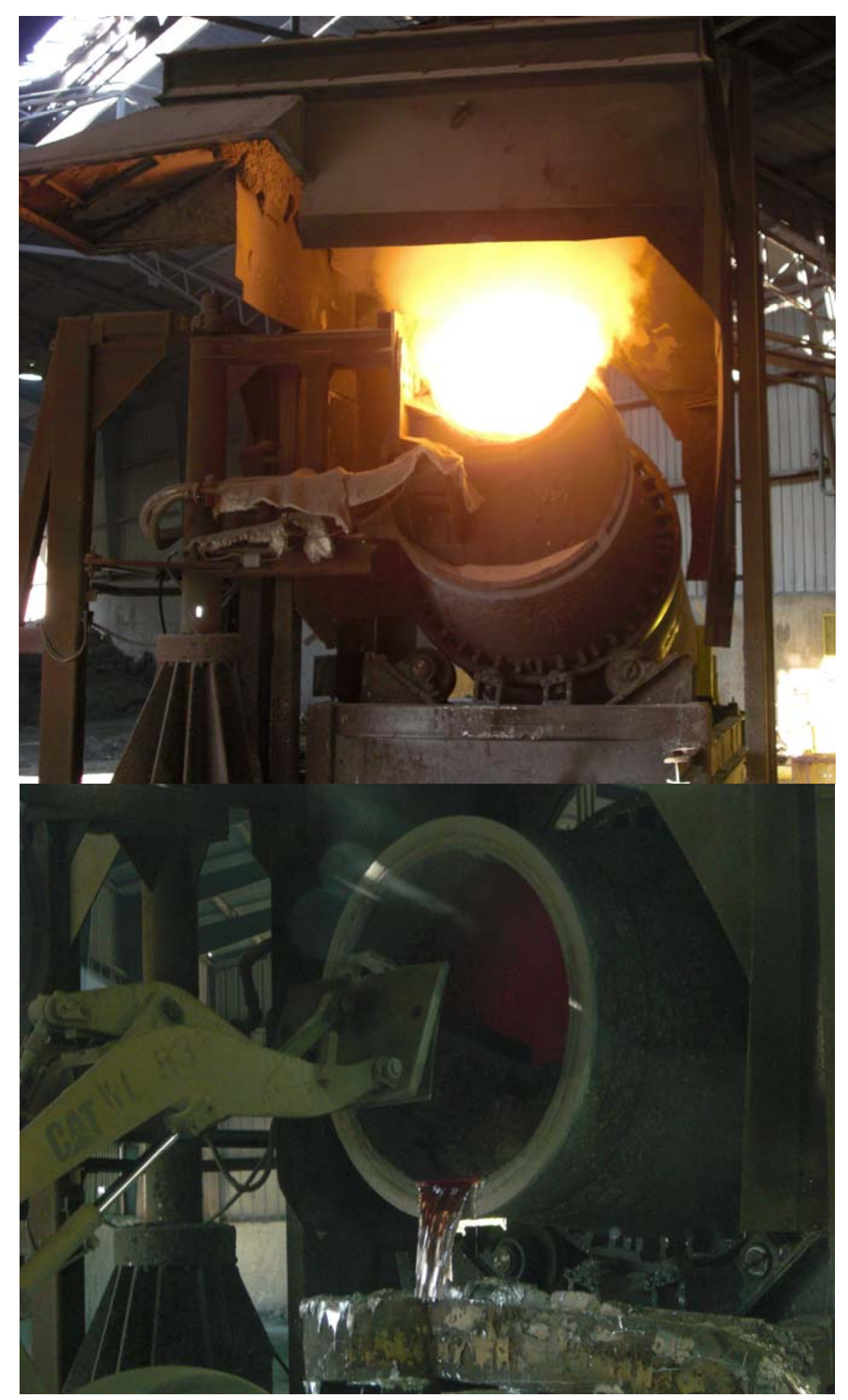

Figure 105. Aluminum Rotary Dross Furnace at Newco Metals (Bedford, IN) in Operation

A field installation of three tons of light weight insulating back-up material developed under this project was next carried out at Tate \& Lyle in Lafayette, IN. This material was used behind their normal hot face lining to improve the thermal efficiency of the combustion 
chamber for a drying system. A picture of the commercially released refractory is shown in Figure 106. A picture of the dryer unit is shown in Figure 107.

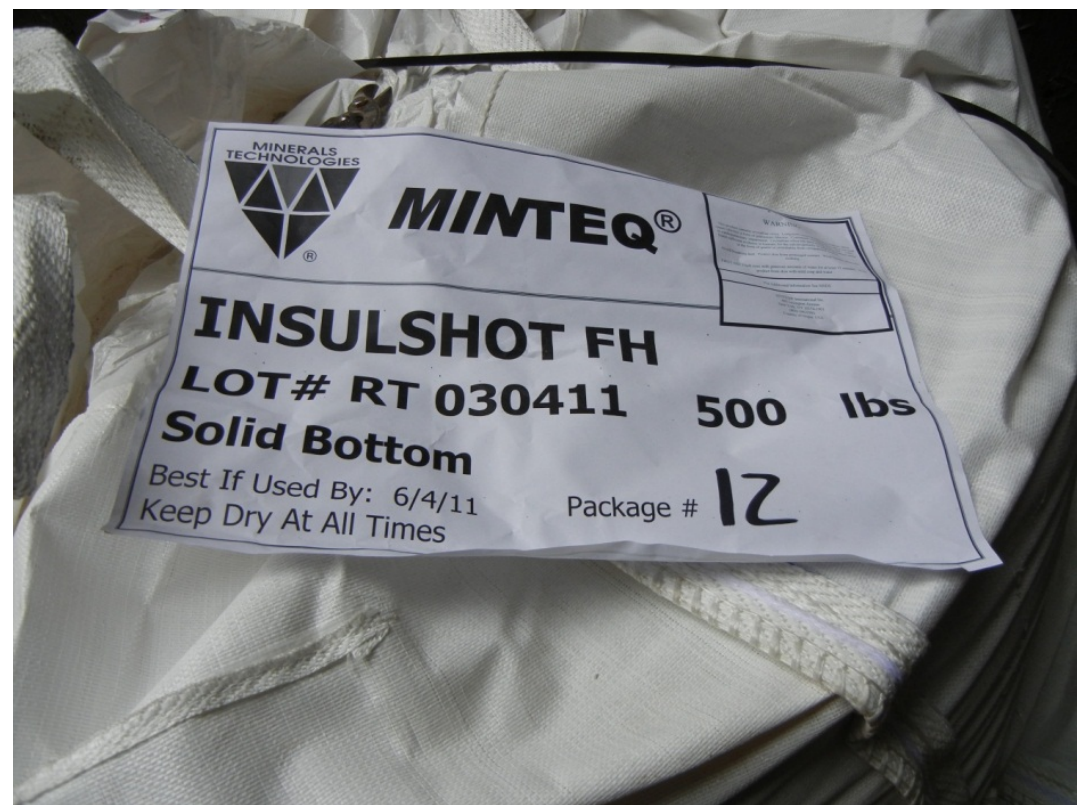

Figure 106. Super Sack of Commercially Released Light Weight Refractory Material Developed Under This Project

Refractory was installed in the combustion zone located on the right end of this vessel (Figure 107-a). Prior to refractory installation metallic anchors were installed (Figure 107-b) to facilitate installation of the gunnable refractory. 


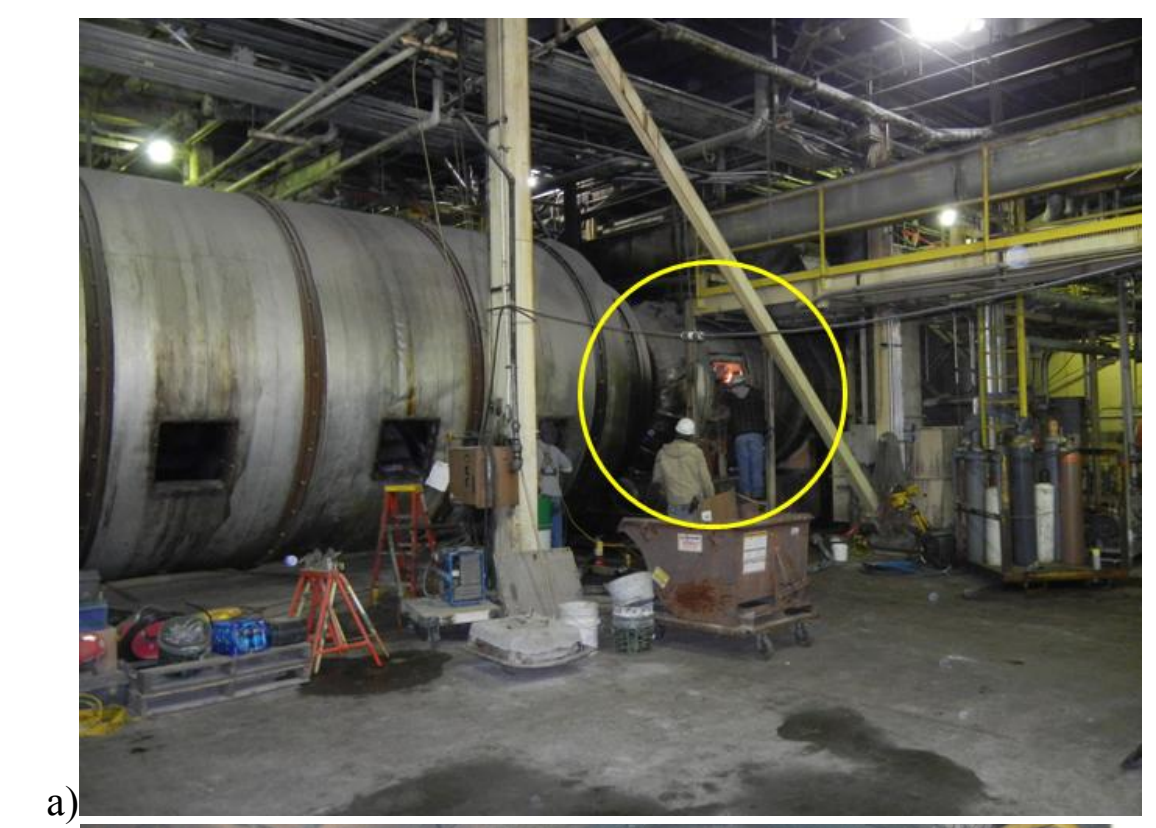

a)

b)

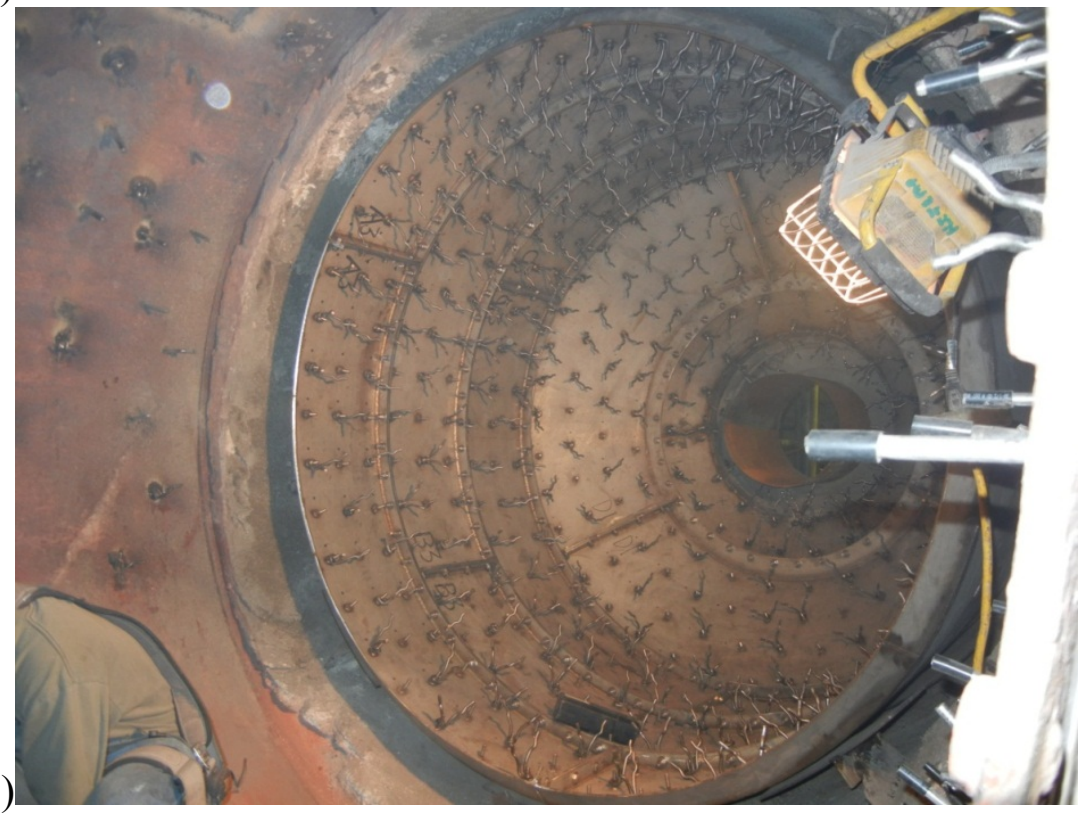

Figure 107. Picture of Dryer Vessel (a) and Combustion Zone (b) Where Light Weight Refractory Was Installed

Actual installation of the refractory is shown in Figure 108. Pictures of the installed backup refractory lining are shown in Figure 109. Anchor hooks visible in Figure 109 were installed to facilitate the installation of the hot face lining (a separate material not associated with this project). This installation was monitored for the remainder of the project and had been operating successfully for over twelve months when the project was completed. This lining was still installed at the completion of the project. 


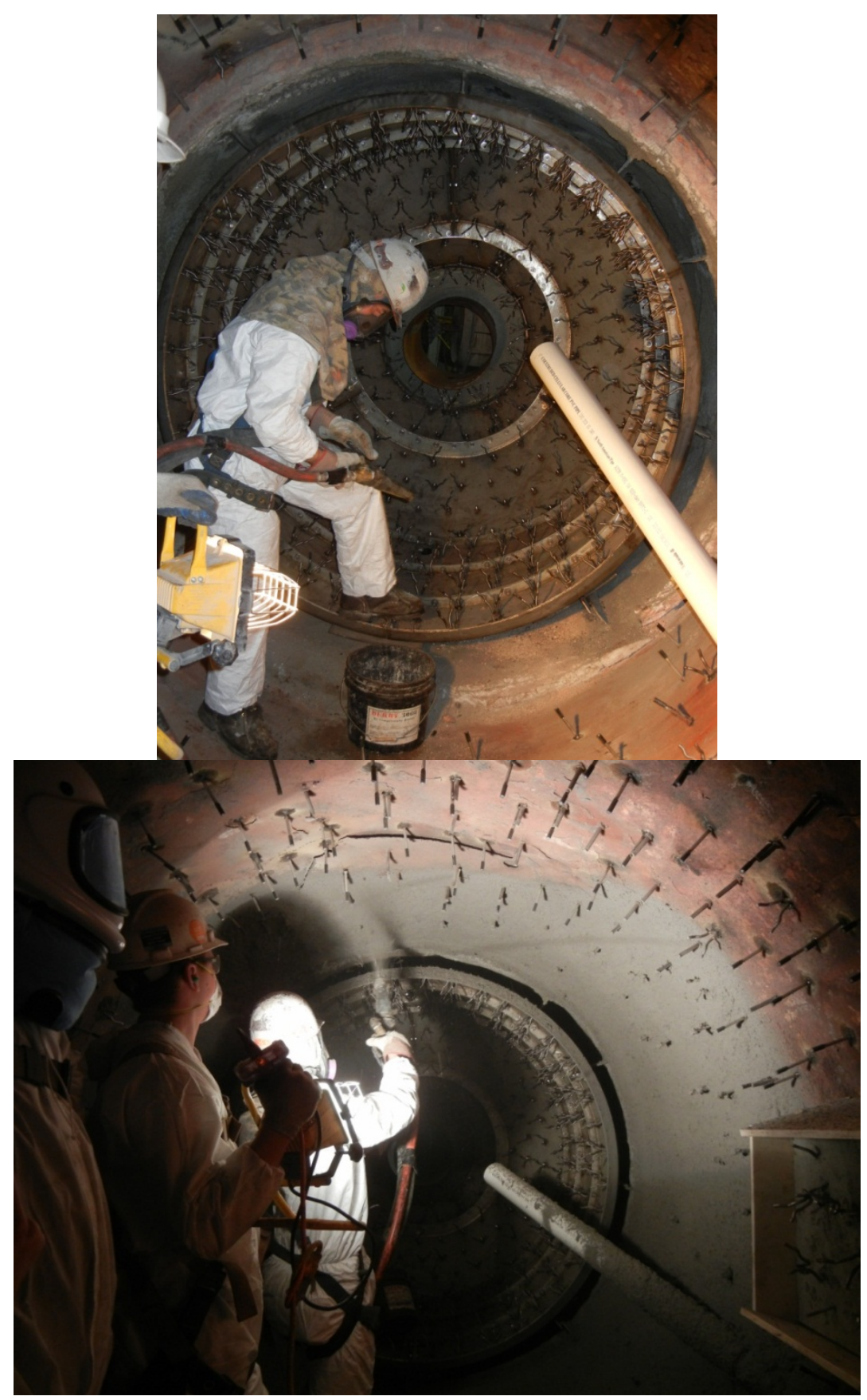

Figure 108. Installation of Light Weight Refractory in Combustion Zone of Dryer 


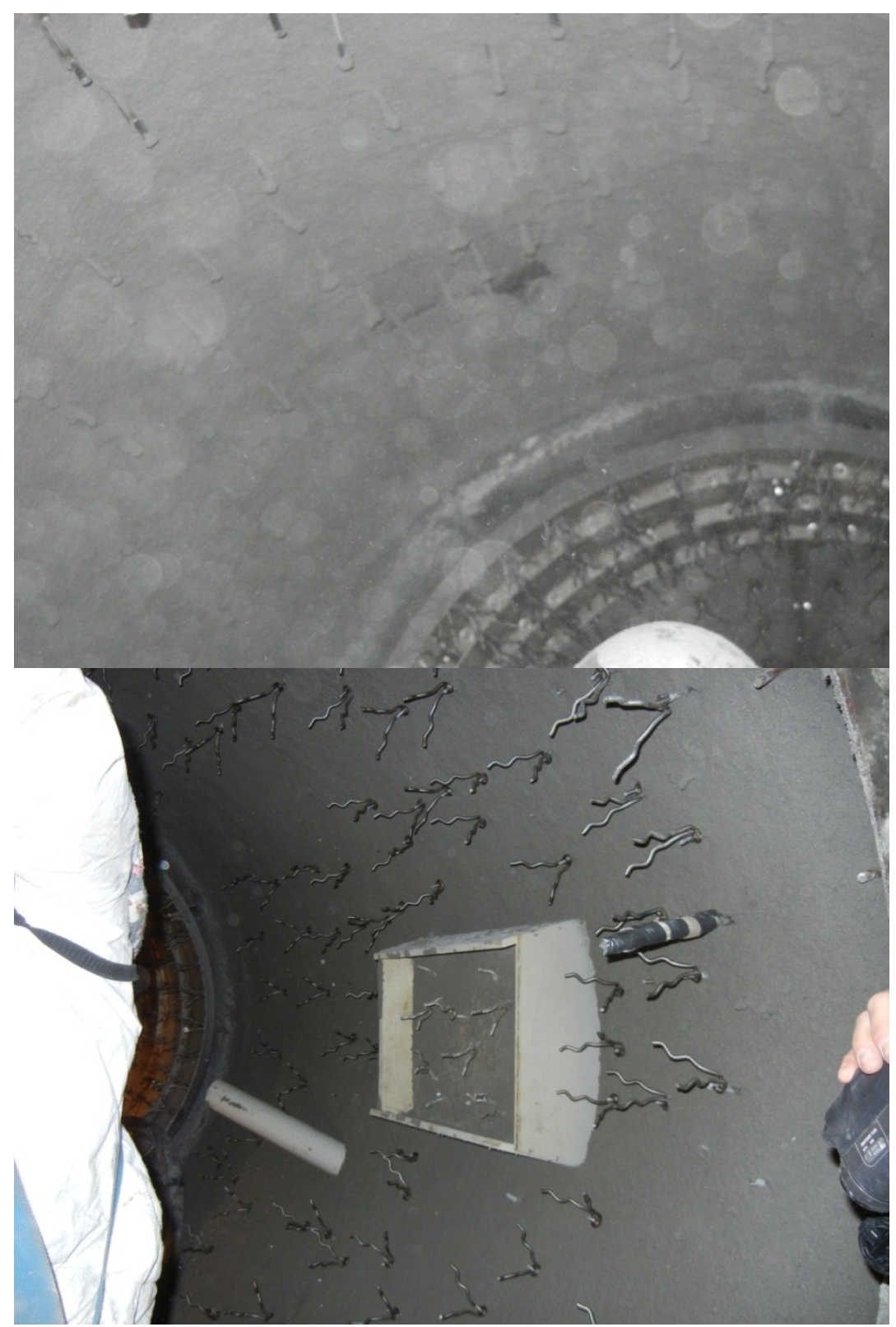

Figure 109. Installed Insulshot Lightweight Back-up Refractory at Tate \& Lyle (Lafayette, $\mathrm{IN})$

As a second industrial trial of materials developed under this project for use in the aluminum industry, a field installation of 70 tons of material developed for aluminum dross furnace applications (Rotoshot AL) was performed in collaboration with Refractory Engineers Inc./Ceramic Technology Inc. and MINTEQ at Alcoa Warrick Operations (Evansville, IN). This installation was monitored by Alcoa through thermal imaging for the remainder of the project and had been operating successfully for over seven months when the project was completed, far exceeding the customer's expectations of three to five months. This lining was still installed at the completion of the project and based on current performance was scheduled to be run twelve to eighteen months before being evaluated for repair or replacement. 
A third rotary dross furnace refractory installation was performed at an Al-Rec, LLC plant in Milwood, WV. This installation was again performed by Refractory Engineers Inc./Ceramic Technology Inc. and used 46 tons of Rotoshot AL backed by 5 tons of Insulshot FH. This installation represented the first time the Rotoshot was used in conjunction with the light weight insulating back-up material. At the completion of the project, this material had successfully performed for over three months meeting the customer's expectations. This lining was still installed at the completion of the project.

Additionally, 18 tons of Rotoshot AL was subsidized by this project for installation by MINTEQ at two additional industrial aluminum producer sites in Indiana and 52 tons of insulating back-up material was shipped to Christy Company (44 tons) and Thorpe Canada ( 8 tons) for installations not subsidized by this project.

Discussions during the project with Houghton Cascade Holdings, LLC (formerly employees of original industrial partner Weyerhaeuser) about possible trial sites for the lime kiln materials developed under this project resulted in determination that many lime kiln operators are hesitant to install shotcrete materials and multi-layer linings in their kilns. Single component, traditional brick linings were found to be preferred, as opposed to multicomponent systems consisting of a corrosion resistant hot-face material backed by a more insulating material, as was pursued under this project. Therefore, it was decided that a different approach would have to be taken to implement materials from this project in this application.

Discussions were held during the final year of the project with CALPORTLAND and CEMEX regarding the utilization of materials developed under this project for use in lime kilns in cement kiln applications. Although no industrial trials resulted from these discussions, a proposal supported by CALPORTLAND to develop materials specifically for the cement industry based on spinel materials from this project was submitted to the DOE/EERE Innovative Manufacturing Initiative Call (12/11). Additionally, a collaboration with the local Knoxville CEMEX plant has formed due to these discussions.

Original discussions were held with Eastman regarding industrial trials of materials developed for coal gasification, but an actual trial could never be agreed upon. Subsequent discussions were held with the Energy and Power Research Institute (EPRI) regarding possible coal gasification test sites and materials developed under this project. Additionally, the University of Utah Gasification Test Facility ${ }^{\text {vii }}$ and sites at ConocoPhillips and Shell were identified as possible future places for implementation of the technology developed under this project.

Discussions were held with Chemrec $\mathrm{AB}$, the company who designed and aided in the operation of the black liquor gasifier at the Weyerhaeuser New Bern, NC facility, concerning the installation of trial refractories at the Chemrec experimental high pressure unit running in Europe or in other units being constructed by Chemrec. No trials resulted from these discussions, but information on the developed materials and test results were provided to Chemrec at their request.

vii (http://www.eng.utah.edu/ whitty/utah_blg/gasification_research_system.shtml) 
Planning and implementation of commercialization for materials developed under this project were carried out by MINTEQ. As a result of this project three new commercial products were developed and are being sold commercially. Data sheets for these products are included in Appendix 5-7. 


\section{PUBLICATIONS, AND PRESENTATIONS RESULTING FROM THIS PROJECT}

A description of this project was presented as part of an invited paper entitled "DOE-EERE Industrial Technologies Program (ITP) and Refractory Related Efforts" presented by James Hemrick on behalf of Sara Dillich at the Forty-third Symposium on Refractories sponsored by The St. Louis Section and Refractory Ceramics Division of The American Ceramic Society in St. Louis, MO March 28-29, (2007).

A presentation was given to the Chattanooga Tennessee Engineers Club (January 2009) entitled "Refractory Ceramics, An Opportunity for Improved Energy Efficiency" which contained information from this project.

A presentation was given and a proceedings paper was published - J.G Hemrick, K.M. Peters, and J. Damiano, "Energy Saving Strategies for the Use of Refractory Materials in Molten Material Contact", Energy Technology Perspectives: Conservation, Carbon Dioxide Reduction and Production from Alternative Sources, TMS, (February 2009).

A poster was prepared at ORNL describing work from this project for display at the 2009 Global Venture Challenge Meeting, Oak Ridge, TN, (March 2009).

Two presentations with accompanying proceedings papers (one by ORNL entitled "Novel Spinel-Family Refractories for High-Temperature, High-Alkaline Environments" and one by MS\&T entitled "Solid Solution Effects on the $\mathrm{MgAl}_{2} \mathrm{O}_{4}$ System") were presented at the Unified International Technical Conference on Refractories (UNITECR 2009) meeting in Salvador Brazil (October 2009).

A poster was prepared by SULI summer student Kyle Anderson from Missouri University of Science and Technology regarding the analysis of salvaged aluminum metal contact refractories from the first year of this project. This poster was displayed at a student poster competition for the SULI participants where their research work was showcased and at a SERCH poster competition for outstanding work from the previous competition (November 2009).

A presentation was given at the University of Tennessee entitled "Refractory Ceramics: An Opportunity for Improved Energy Efficiency" which contained information from this project (March 2010).

A presentation regarding this project entitled "Solid Solution Effects on the $\mathrm{MgAl}_{2} \mathrm{O}_{4}$ System" with accompanying proceedings paper was presented by Kelley O'Hara (MS\&T) at the Forty-sixth Symposium on Refractories sponsored by The Saint Louis Section and Refractory Ceramics Division of the American Society in Saint Louis, MO (March 2010).

A presentation was given at the Oak Ridge Chapter of ASM International May Technical Meeting and Awards Night entitled "Refractory Ceramics, An Opportunity for Improved Energy Efficiency" which discussed concepts and materials from this project, Knoxville, TN, May 20, 2010.

A presentation entitled "Novel Spinel-Family Refractories for High-Temperature, HighAlkaline Environments" with associated proceedings paper was given at the 2010 Advances in Refractories V, $5^{\text {th }}$ International Symposium, The Michel Rigaud Symposium, Vancouver, British Columbia, Canada, October (2010).

A presentation entitled "IMPROVED FURNACE EFFICIENCY THROUGH THE USE OF REFRACTORY MATERIALS" with associated proceedings paper was given at the TMS 2011 Meeting in San Diego, CA, February (2011). 
An R\&D 100 Award application was completed and submitted by MinTeq regarding the refractory materials for aluminum applications developed under this project (2011).

A presentation entitled "Development of Novel Spinel Refractories For Use in Coal Gasification Environments" with associated proceedings paper was prepared by James Hemrick (ORNL) for the $28^{\text {th }}$ Annual International Pittsburgh Coal Conference, Pittsburgh, Pennsylvania, September (2011).

An ORNL CRADA report "CRADA Final Report for CRADA Number NFE-07-00093" was written and submitted (9/11) marking the completion of the CRADA with MinTeq undertaken under this project.

A presentation entitled "Solid Solution Effects on the $\mathrm{MgAl}_{2} \mathrm{O}_{4}-\mathrm{MgGa}_{2} \mathrm{O}_{4}$ System" with associated proceedings paper was prepared by Kelley O'Hara (MS\&T) for the UNITECR 2011 Meeting in Kyoto, Japan, October (2011).

A paper entitled "Development of a Test Technique to Determine the Thermal Diffusivity of Large Refractory Ceramic Test Specimens," was published by James Hemrick (ORNL) in International Journal of Applied Ceramic Technology, Vol. 9, Issue 1, January/February (2012).

A presentation regarding this project entitled "Novel Spinel-Family Refractories for High Temperature, High-Alkaline Environments" with accompanying proceedings paper was presented by James Hemrick (ORNL) at the Forty-eighth Symposium on Refractories sponsored by The Saint Louis Section and Refractory Ceramics Division of the American Society in Saint Louis, MO (March 2012).

A paper regarding this project entitled "Solid Solution Effects on the Thermal Properties in the $\mathrm{MgAl}_{2} \mathrm{O}_{4}-\mathrm{MgGa}_{2} \mathrm{O}_{4}$ System" was submitted by Kelley O'Hara (MS\&T) to the Journal of the American Ceramic Society (March 2012). 


\section{CONCLUSIONS}

- Seven new materials were developed under this project for both primary and repair applications in aluminum, black liquor, coal gasification, and lime kiln environments. Developed materials were based on alumino-silicate, magnesia, and spinel forming systems. One of the developed materials was an insulating shotcrete to be used behind the high conductivity spinel linings developed under this project. Shotcreting was selected as the preferred application method for materials developed under this project.

- Fundamental research work was continued at MS\&T throughout the life of the project to provide support for the development and production of the experimental refractory materials being developed. Work was focused on extending the fundamental understanding of the spinel microstructure and of spinel formation, along with the effects of microstructure and degree of formation on properties such as thermal expansion and refractoriness, density/porosity, thermal conductivity, and penetration/corrosion resistance. This work directly fed into the spinel forming refractory development which was on-going though out the duration of the project at MINTEQ.

- Energy savings estimates based on measured properties of the experimentally developed refractory systems from this project were made at MINTEQ to validate the energy savings estimates originally proposed for the project.

- It was determined that although repair materials were developed under this project for aluminum, black liquor, and coal gasification systems which enable hot repair, there is only minor interest from industry in implementing these materials. On-line inspection techniques were also identified under this project, which are currently used in the steel industry, but implementation of these techniques in applications such as black liquor and coal gasification where higher temperatures and tighter access clearances exist proved difficult due to cost considerations. Therefore, on-line inspection was not further pursued under this project.

- Information from data collected during this and previous DOE projects was inputted into a refractory database housed at a publically available site (http://extwebapps.ornl.gov/crpd/Default.aspx). Over twenty five separate materials have been initially included in the database.

- Industrial trials of the insulating shotcrete (INSULSHOT ${ }^{\mathrm{TM}} \mathrm{FH}$ ) and the material for use in aluminum rotary furnaces (ROTOSHOT ${ }^{\mathrm{TM}} \mathrm{AL}$ ) developed under this project were performed validating the commercial potential of these materials. Additionally, the magnesia-rich spinel formulation (FAST FIRE ${ }^{\circledR}$ MG-SP SHOT) for use in black liquor and lime kiln/cement applications was commercially released by MINTEQ.

- Fourteen presentations were given, twelve papers were published, and two posters and one R\&D 100 Award application were composed regarding this project. 
APPENDICES 
Appendix 1: Results from FEA modeling of refractory lining (taken from summary report document)

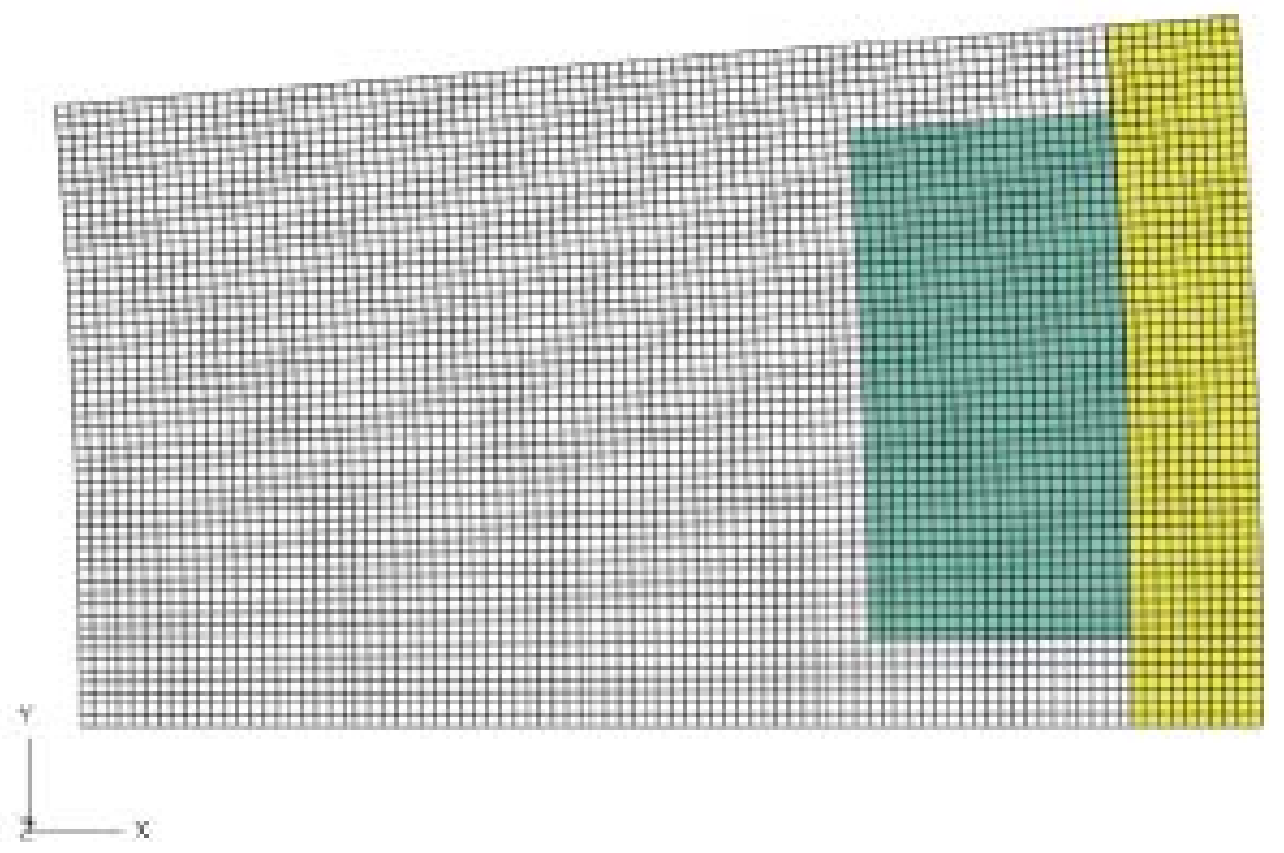

Figure 5: Schematic and mesh for the case with the backup lining anranged as 84 equally spaced squares.
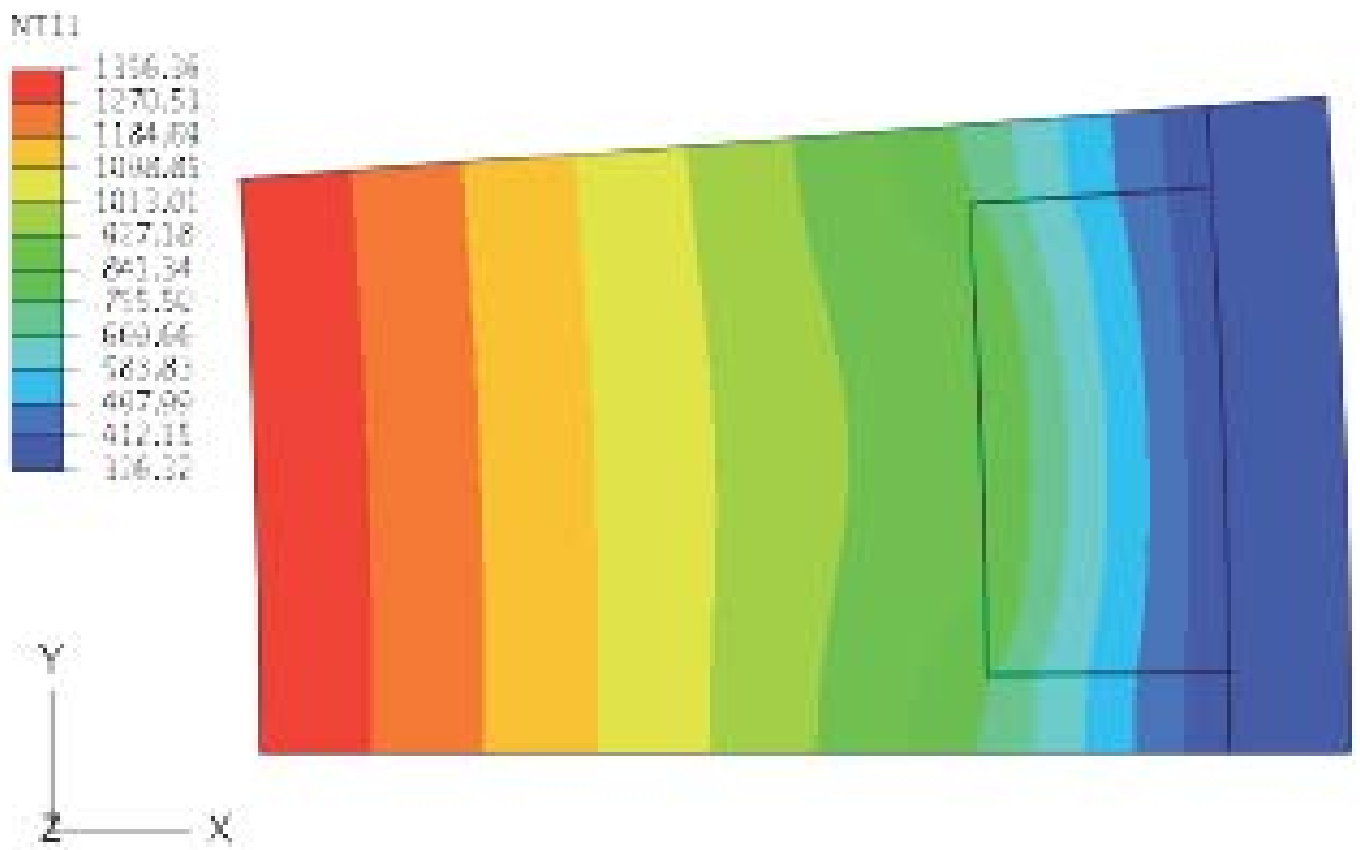

Figure 6: Distribution of temperature $\left[{ }^{\circ} \mathrm{C}\right]$ under operating conditions for the case with the backup lining arranged as 84 equally spaced squares. 


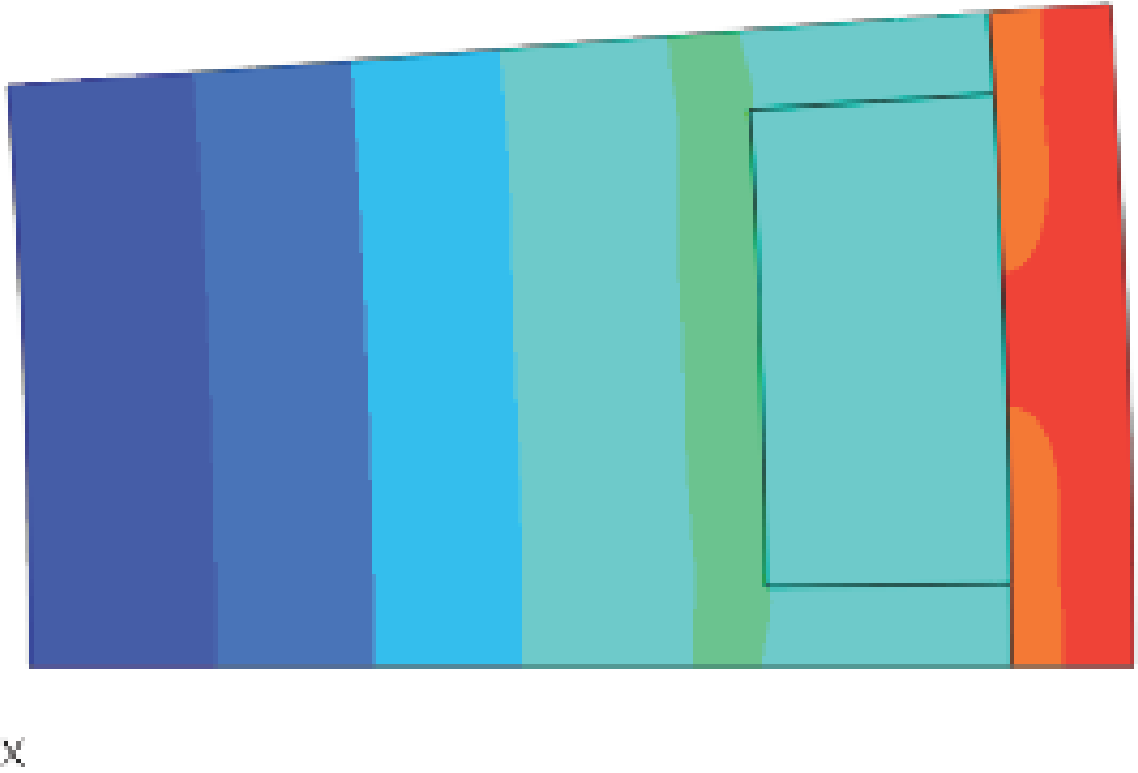

Figure 7: Distribution of hoop stress [MPa] under operating conditions for the case with the backup lining anranged as 84 equally spaced squares.

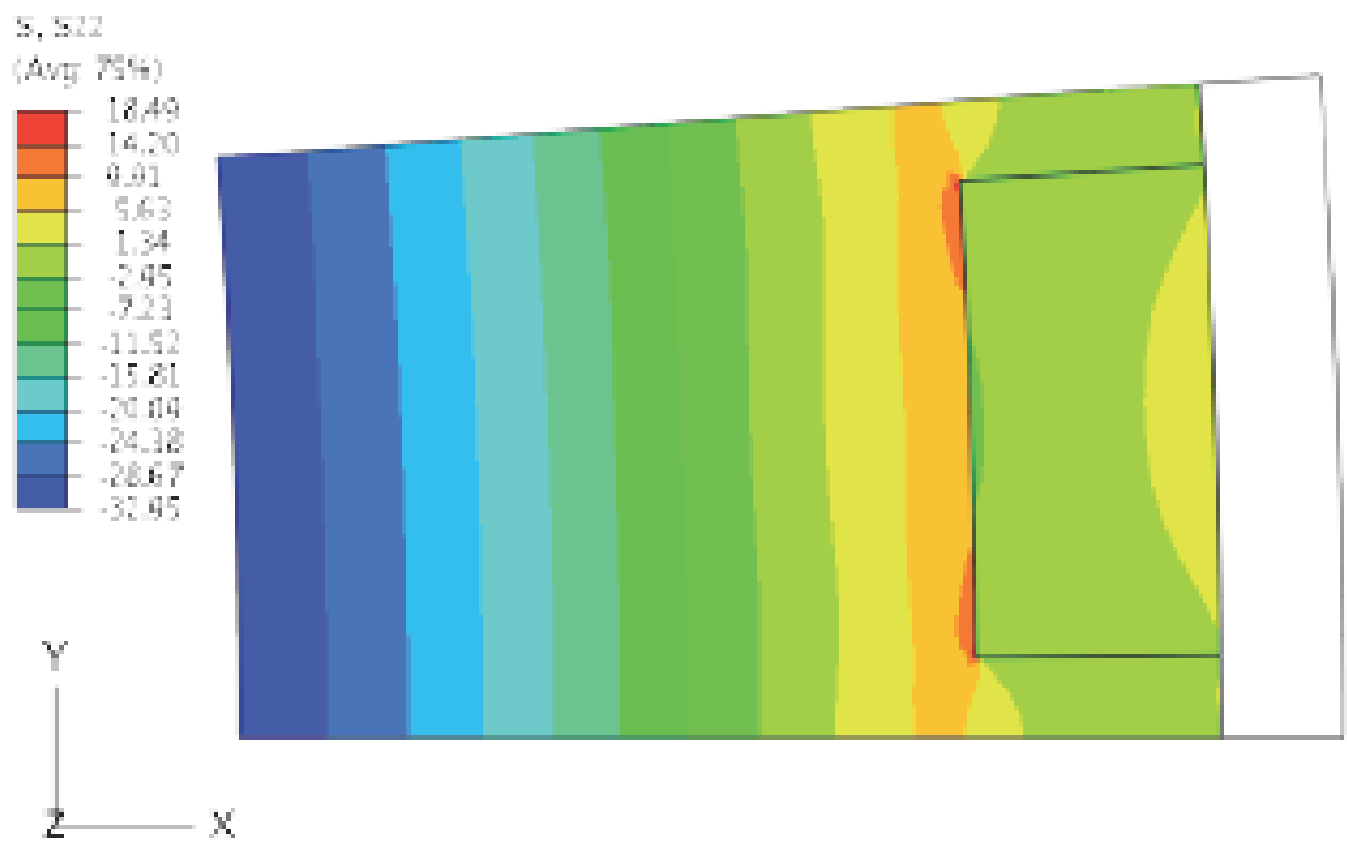

Figure 8: Distribution of hoop stress. [MPa] in the refiactory material only under operating conditions for the case with the backup lining arranged as 84 equally spaced squares. 


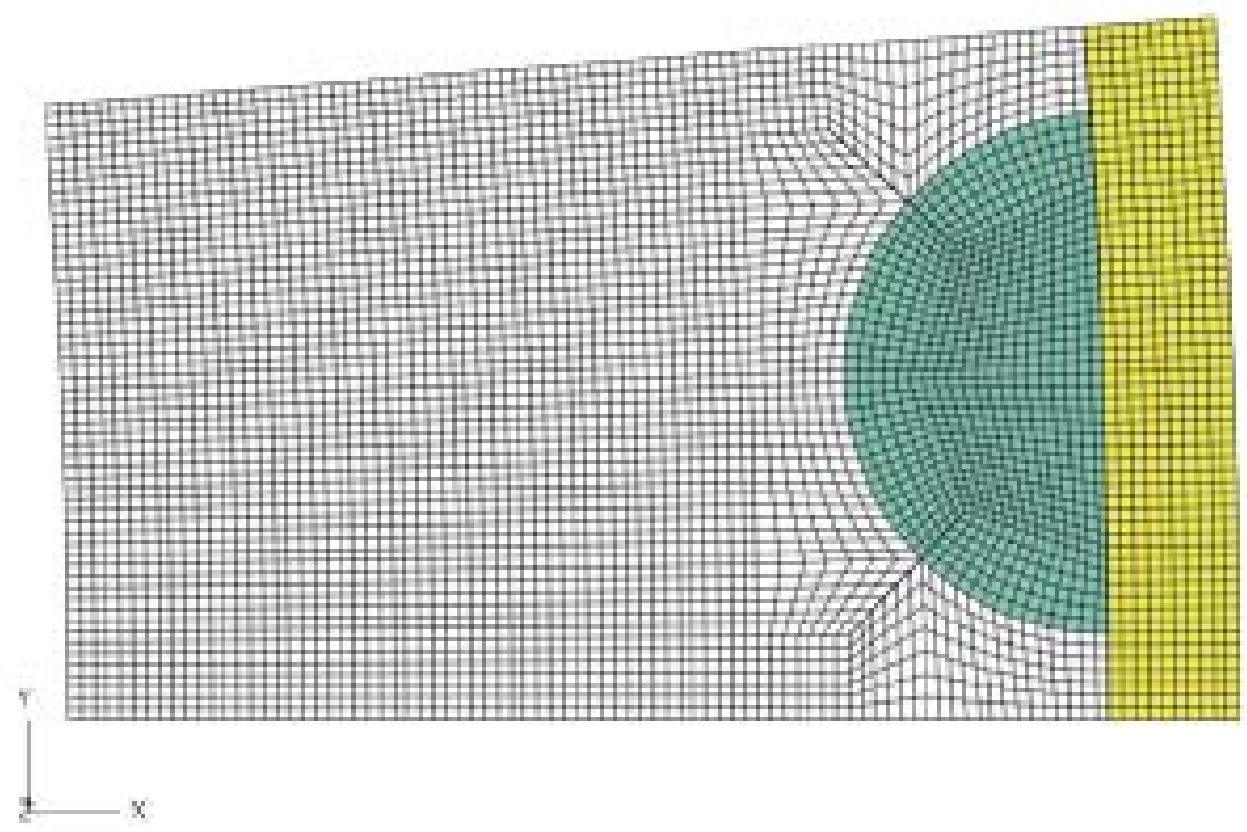

Figure 9: Schematic and mesh for the case with the backup liming arniged as 84 equally spaced round arches:

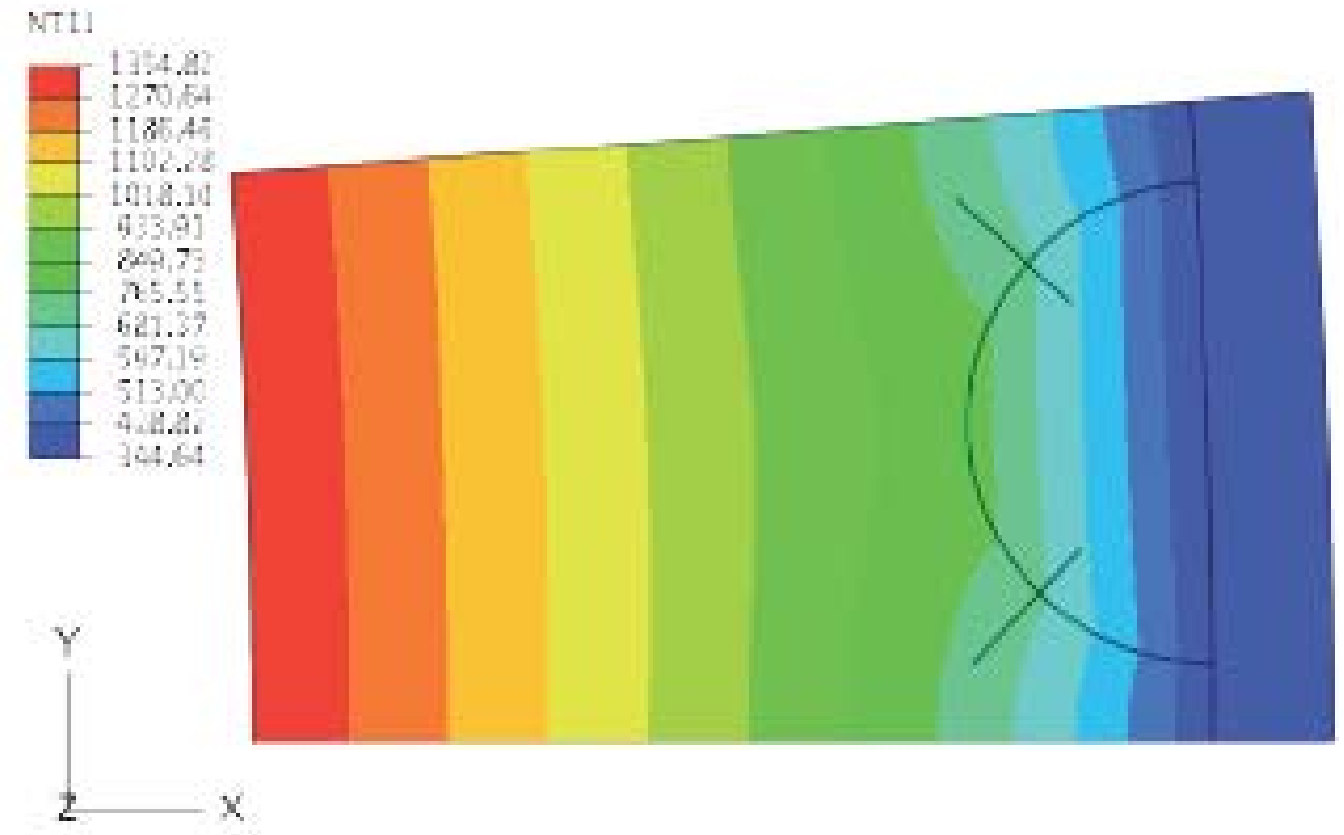

Figure 10: Distribution of temperature [ $\left.{ }^{\circ} \mathrm{C}\right]$ under operating conditions for the case with the backup lining arranged as 84 equally spaced round arches. 


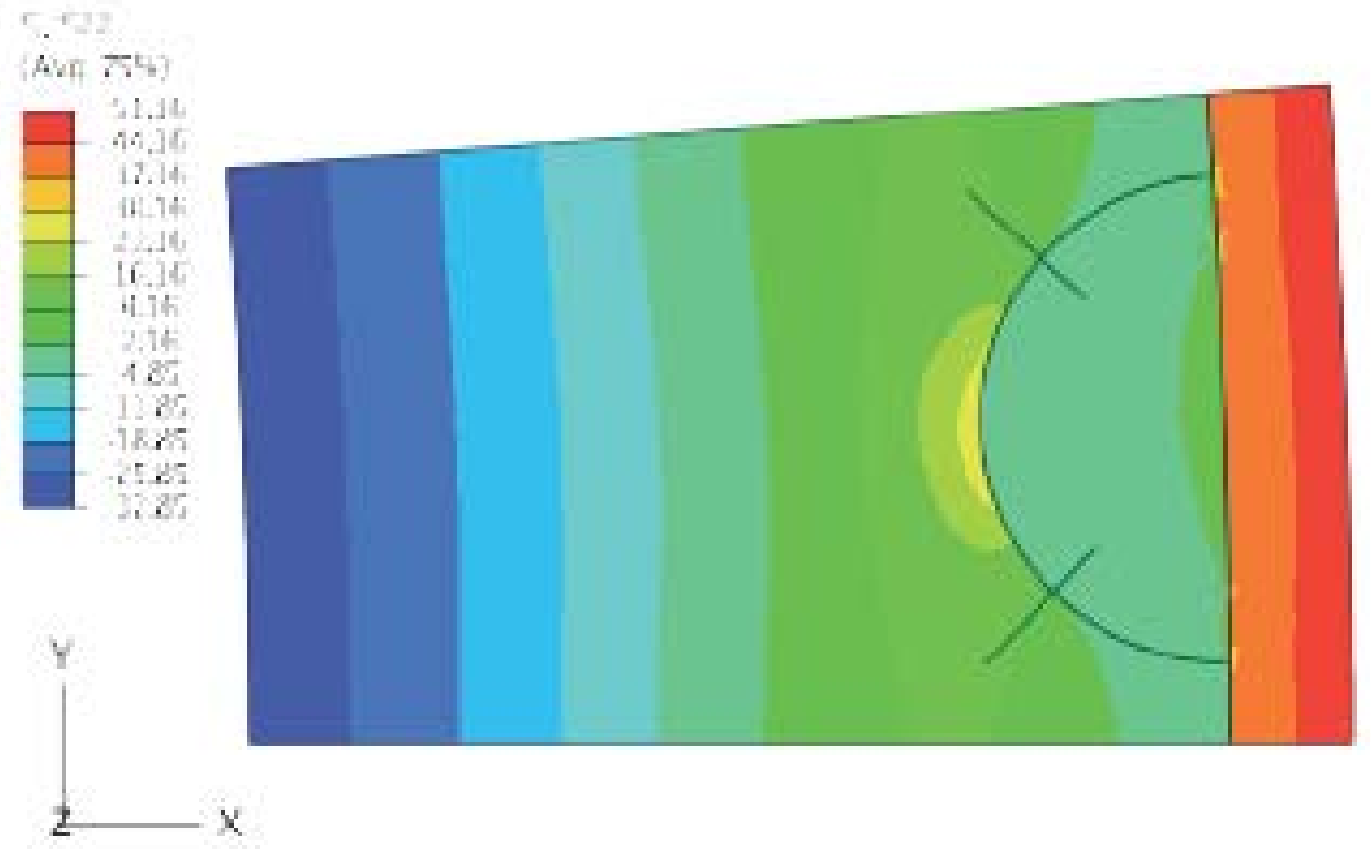

Figure 11: Distribution of hoop stress [MPa] under operating conditions for the case with the backup lining ananged as 84 equally spaced round arches.

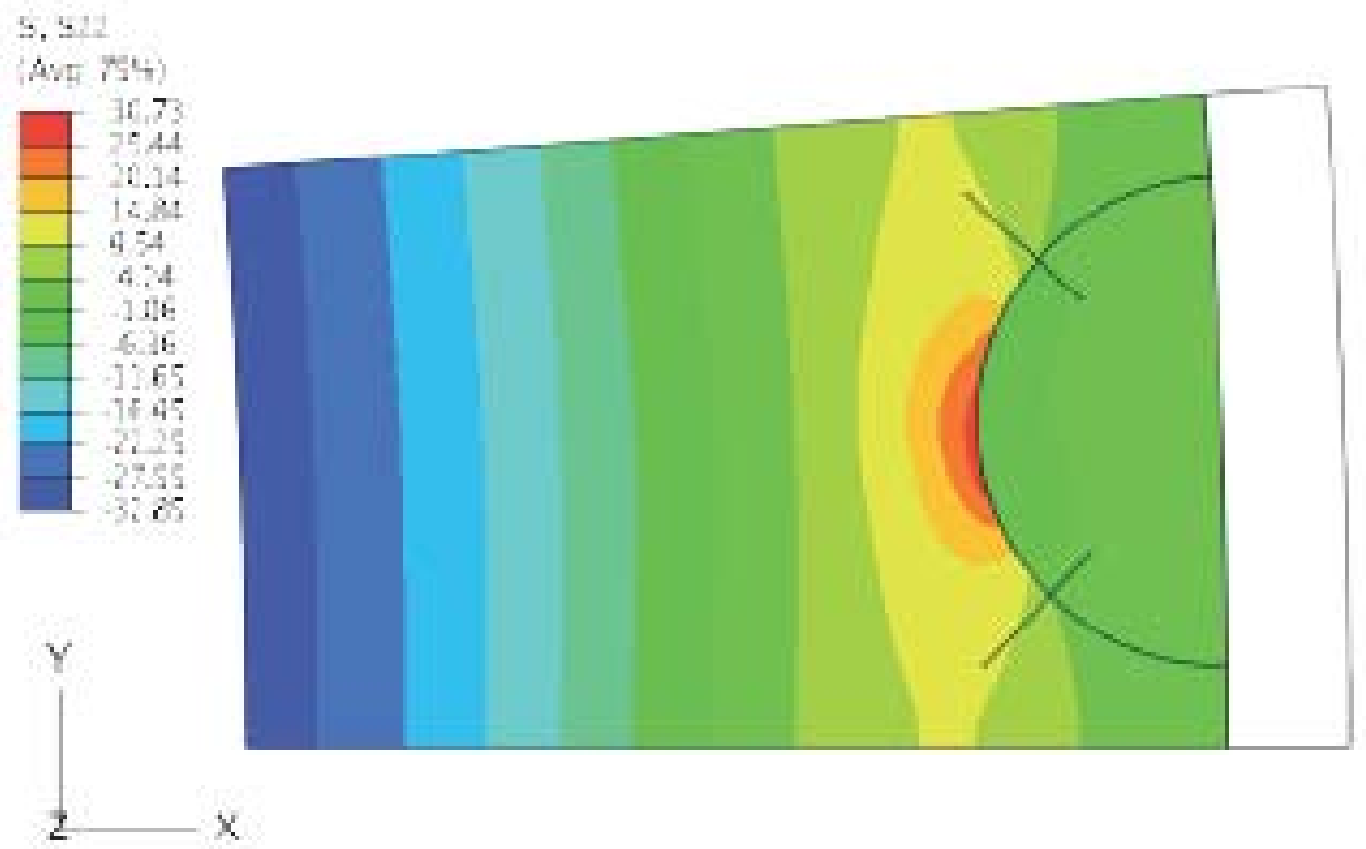

Figure 12: Distribution of hoop stress [MPa] in the refractory material only under operating conditions for the case with the bachup lining arranged as 84 equally spaced round arches. 


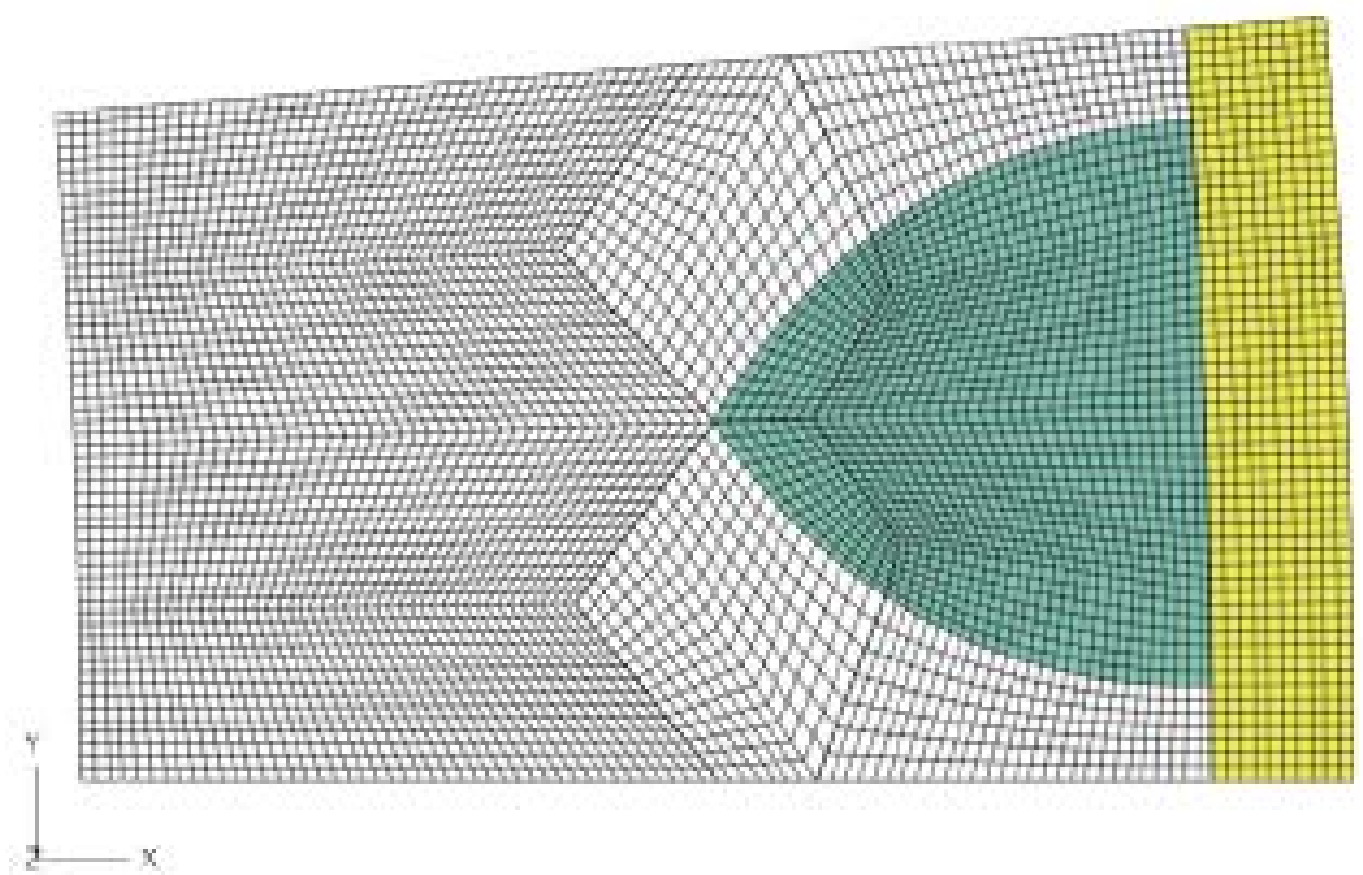

Figure 13: Schematic and mesh for the case with the backup lining anranged as 84 equally spaced gothic arches.

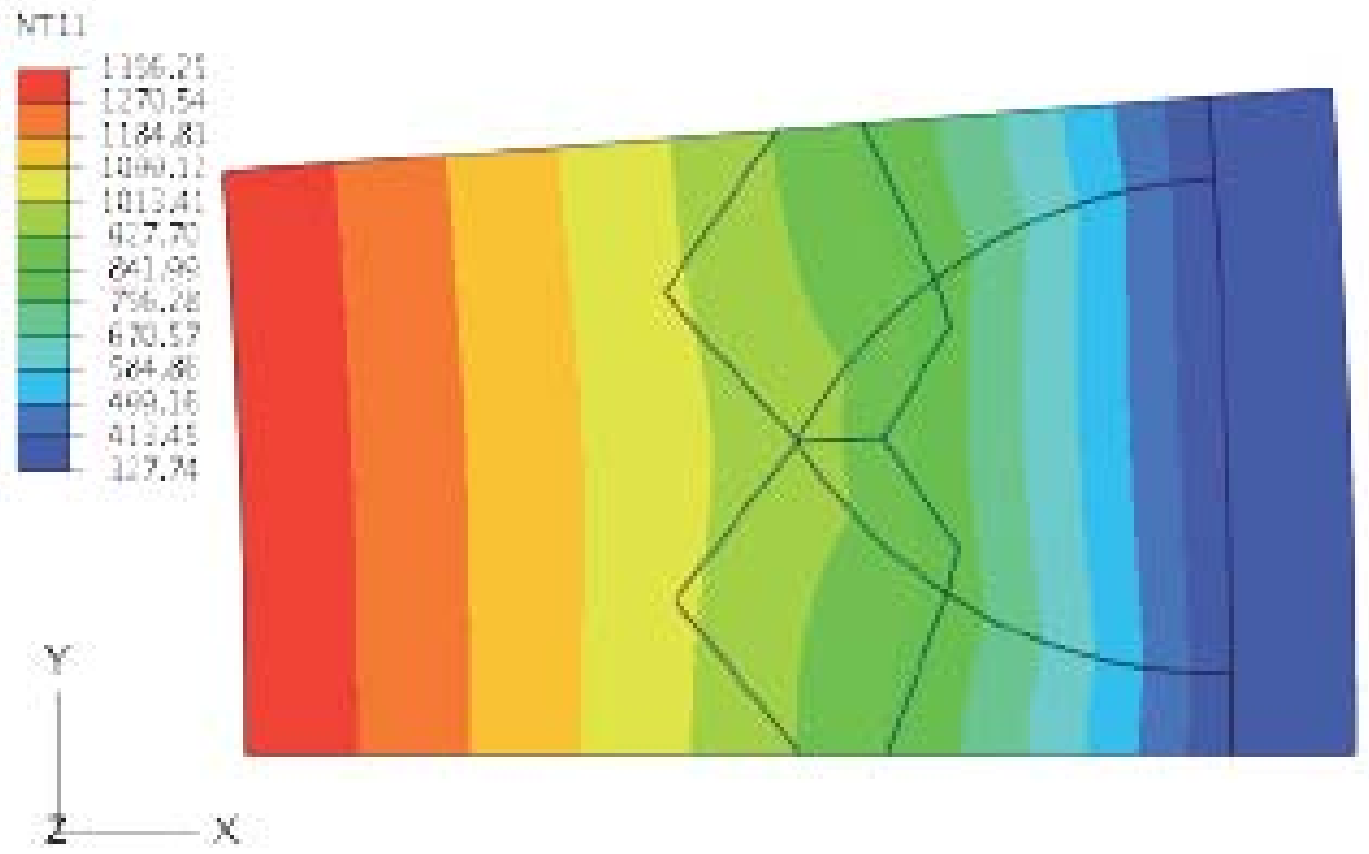

Figure 14: Distribution of temperatume $\left[^{\circ} \mathrm{C}\right]$ under operating conditions for the case with the backup lining anranged as 84 equally spaced gothic arches. 


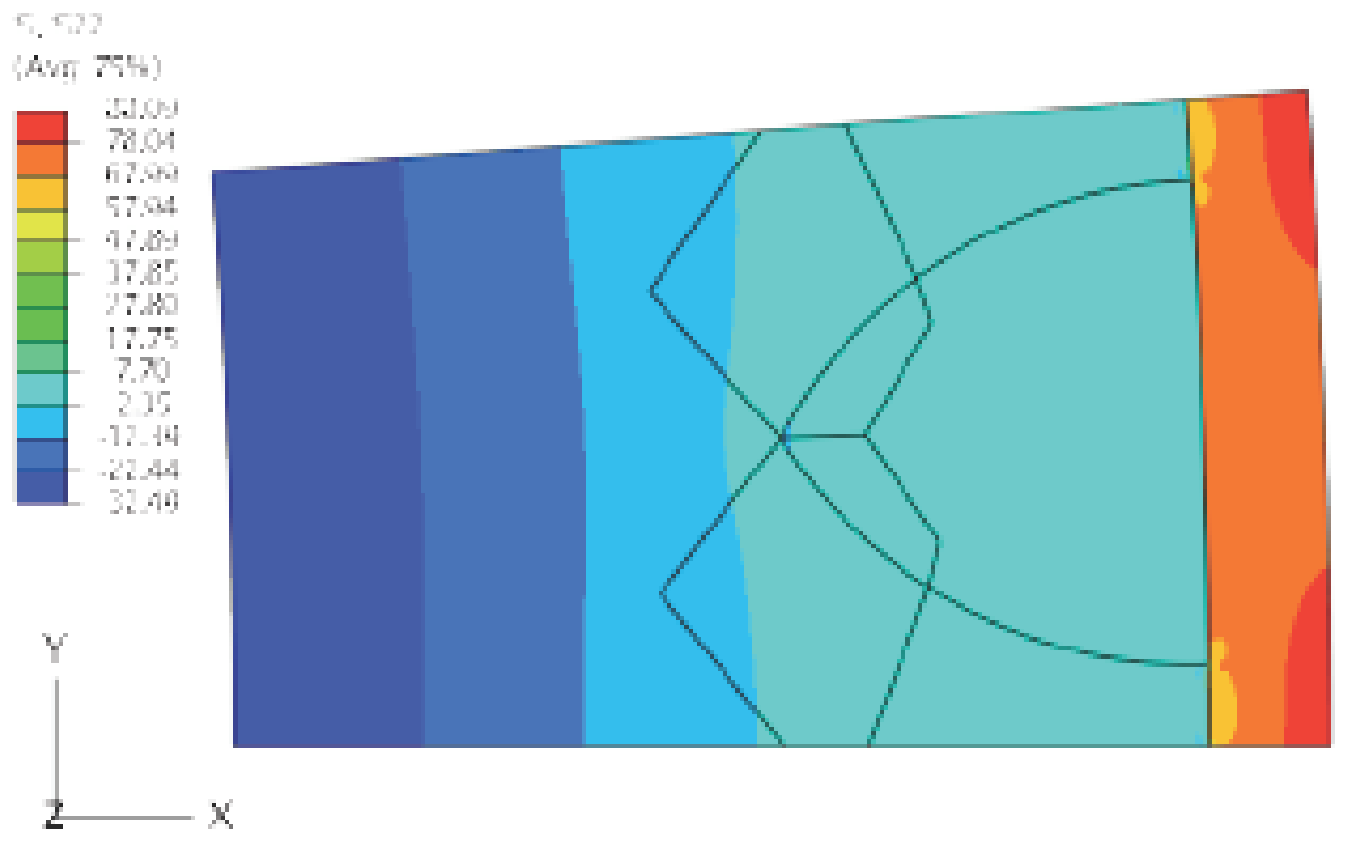

Figure 15: Distribution of hoop stress [MPa] under operating conditions for the case with the backup lining ananged as 84 equally spaced gothic arches.

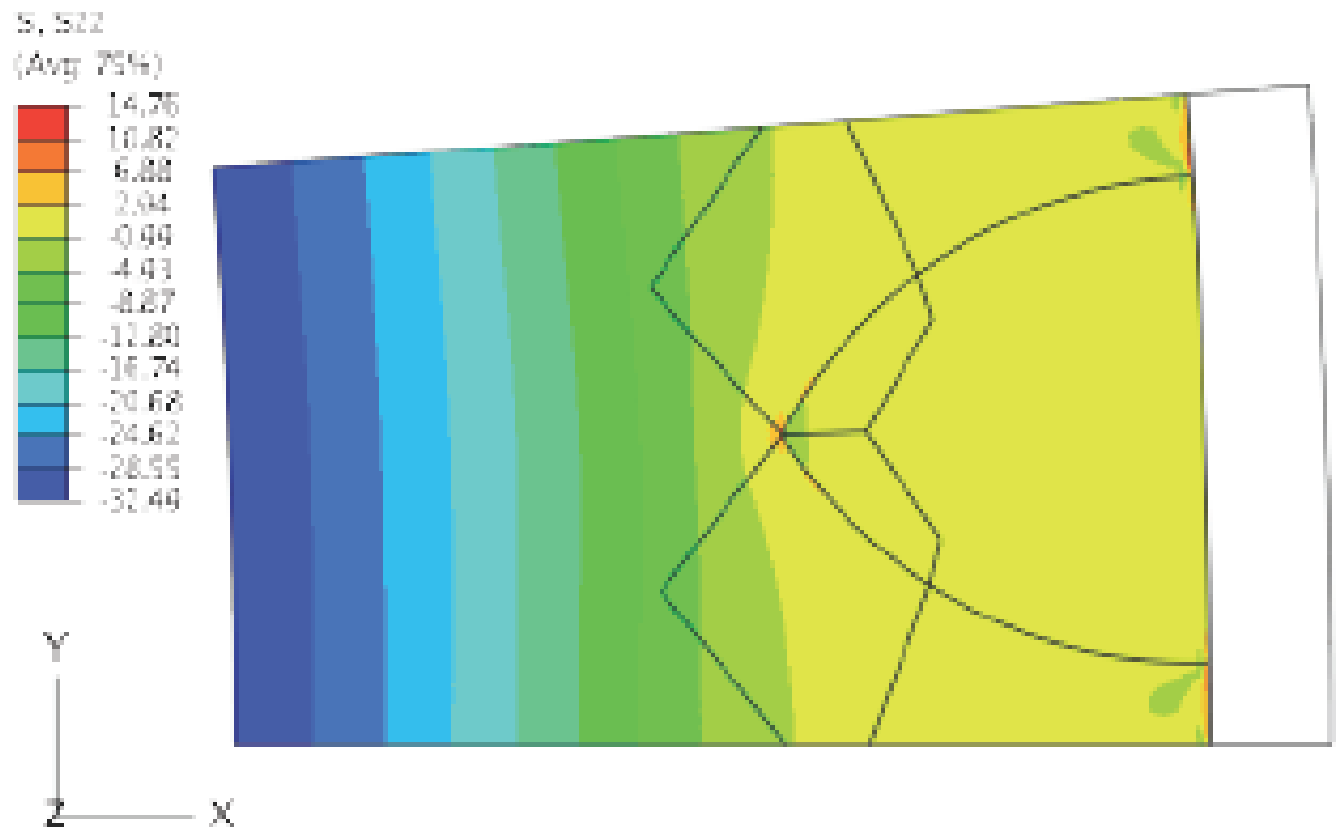

Figure 16: Distribution of hoop stress [MPa] in the refiactory material only under operating conditions for the case with the backup liming arranged as 84 equally spaced gothic anches. 
Appendix 2: Property Testing Standardization

(1) Glass Industry Partner - PPG

A. Chemical Analysis - Induction Coupled Plasma (lithium metaborate fusion)

B. Room Temperature Values for:

1. ASTM C-20/C-830 Porosity, Bulk Density, and Specific Gravity

2. ASTM C-133 Modulus of Rupture and Compressive Strength

3. ASTM C-704 Abrasion Resistance

4. ASTM C-577 Permeability

5. ASTM C-885/C-1419 Young's modulus - Sonic velocity

C. Thermal Properties and/or Properties at Temperature, such as:

1. Linear Thermal Expansion ${ }^{1}$

2. Thermal Conductivity ${ }^{2}$

3. ASTM C-1171 Thermal Cycling/Thermal Shock Resistance

4. ASTM C-583 Hot Modulus of Rupture

5. ASTM C-832 Thermal Expansion and Creep of Refractoriness Under Load

6. ASTM C-987 Vapor Corrosion Test

7. Hot Abrasion ${ }^{3}$

8. HMOR with flux penetration ${ }^{3}$

9. Patch Bonding ${ }^{4}$

10. Hot Rebound Minimization ${ }^{5}$

11. Dynamic Glass Contact Corrosion ${ }^{6}$

Sample Preparation: Samples cut from gunned or shotcreted shapes.

Industry Operating Temperature / Atmosphere: $1200-1400^{\circ} \mathrm{C} /$ Air

(2) Aluminum Industry Partner - Aleris

A. Chemical Analysis - Induction Coupled Plasma (lithium metaborate fusion)

B. Room Temperature Values for:

1. ASTM C-20/C-830 Porosity, Bulk Density, and Specific Gravity

2. ASTM C-133 Modulus of Rupture and Compressive Strength

3. ASTM C-704 Abrasion Resistance

4. ASTM C-577 Permeability

5. ASTM C-885/C-1419 Young's modulus - Sonic velocity

C. Thermal Properties and/or Properties at Temperature, such as:

1. Linear Thermal Expansion ${ }^{1}$

2. Thermal Conductivity ${ }^{2}$ 
3. ASTM C-1171 Thermal Cycling/Thermal Shock Resistance

4. ASTM C-583 Hot Modulus of Rupture

5. ASTM C-832 Thermal Expansion and Creep of Refractoriness Under Load

6. ASTM C-987 Vapor Corrosion Test

7. Hot Abrasion ${ }^{3}$

8. DOE Steam Corrosion Test ${ }^{7}$

Sample Preparation: Samples cut from preformed cast, shot or pressed shapes.

Industry Operating Temperature / Atmosphere: $600-750^{\circ} \mathrm{C} /$ Air

\section{(3) Gasifier Industry Partner - Eastman Chemical}

A. Chemical Analysis - Induction Coupled Plasma (lithium metaborate fusion)

B. Room Temperature Values for:

1. ASTM C-20/C-830 Porosity, Bulk Density, and Specific Gravity

2. ASTM C-133 Modulus of Rupture and Compressive Strength

3. ASTM C-704 Abrasion Resistance

4. ASTM C-577 Permeability

5. ASTM C-885/C-1419 Young's modulus - Sonic velocity

C. Thermal Properties and/or Properties at Temperature, such as:

1. Linear Thermal Expansion ${ }^{1}$

2. Thermal Conductivity ${ }^{2}$

3. ASTM C-1171 Thermal Cycling/Thermal Shock Resistance

4. ASTM C-583 Hot Modulus of Rupture

5. ASTM C-832 Thermal Expansion and Creep of Refractoriness Under Load

6. ASTM C-987 Vapor Corrosion Test

7. Slag Corrosion Test $^{8}$

Sample Preparation: Samples cut from gunned, cast or pressed shapes.

Industry Operating Temperature / Atmosphere: $1400-1500^{\circ} \mathrm{C} /$ Reducing

\section{(4) Lime Kiln Industry Partner - Weyerhaeuser}

A. Chemical Analysis - Induction Coupled Plasma (lithium metaborate fusion)

B. Room Temperature Values for:

1. ASTM C-20/C-830 Porosity, Bulk Density, and Specific Gravity 
2. ASTM C-133 Modulus of Rupture and Compressive Strength

3. ASTM C-704 Abrasion Resistance

4. ASTM C-577 Permeability

5. ASTM C-885/C-1419 Young's modulus - Sonic velocity

\title{
C. Thermal Properties and/or Properties at Temperature, such as:
}

1. Linear Thermal Expansion ${ }^{1}$

2. Thermal Conductivity ${ }^{2}$

3. ASTM C-1171 Thermal Cycling/Thermal Shock Resistance

4. ASTM C-583 Hot Modulus of Rupture

5. ASTM C-832 Thermal Expansion and Creep of Refractoriness Under

Load

6. ASTM C-987 Vapor Corrosion Test

7. Slag Corrosion Test ${ }^{9}$

Sample Preparation: Samples cut from gunned, cast or pressed shapes.

Industry Operating Temperature / Atmosphere: $1350-1500^{\circ} \mathrm{C} / \mathrm{Air}$

\author{
$\underline{\text { References }}$ \\ ${ }^{1}$ Utilizing Orton Dilatometer, heating rate $3^{\circ} \mathrm{C} /$ minute to $1500^{\circ} \mathrm{C}$, or the softening \\ temperature whichever is lower. \\ ${ }^{2}$ As determined by Oak Ridge National Laboratories \\ ${ }^{3}$ By a currently undetermined method \\ ${ }^{4}$ Developing a test similar to the ASTM C-198 Standard Test Method for Cold Bonding \\ Strength of Refractory Mortar \\ ${ }^{5}$ See ASTM C-903 Standard Practice for Preparing Refractory Castable Specimens by Cold \\ Gunning for how to measure rebound \\ ${ }^{6}$ Comparison test of up to 3 samples, cored into "fingers", rotating in a crucible 2 \\ revolutions per minute for 6 hours at furnace operating temperature \\ ${ }^{7}$ Test type: Static Cup Test,Test parameters: Duration: 240 hours (10 days) at $1000^{\circ} \mathrm{C}$, Pre- \\ oxidized to $1200^{\circ} \mathrm{C}$ for 5 hours, Steam atmosphere maintained during test \\ ${ }^{8}$ Static cup test, requires controlled atmosphere, by capping the cups or artificial atmosphere \\ of argon, slags from partners will be tested, at industry operating temperature $1450^{\circ} \mathrm{C}$ \\ ${ }^{9}$ Static cup test, using lime sludge $\left(93.9 \% \mathrm{Ca}(\mathrm{OH})_{2}, 2.5 \% \mathrm{Mg}(\mathrm{OH})_{2}, 1.3 \% \mathrm{NaOH}, 2.1 \%\right.$ \\ $\mathrm{P}_{2} \mathrm{O}_{5}, 0.3 \% \mathrm{SiO}_{2}$ ) at standard industry operating temperature, 140
}


Appendix 3: Characterization Matrix for Refractory Materials

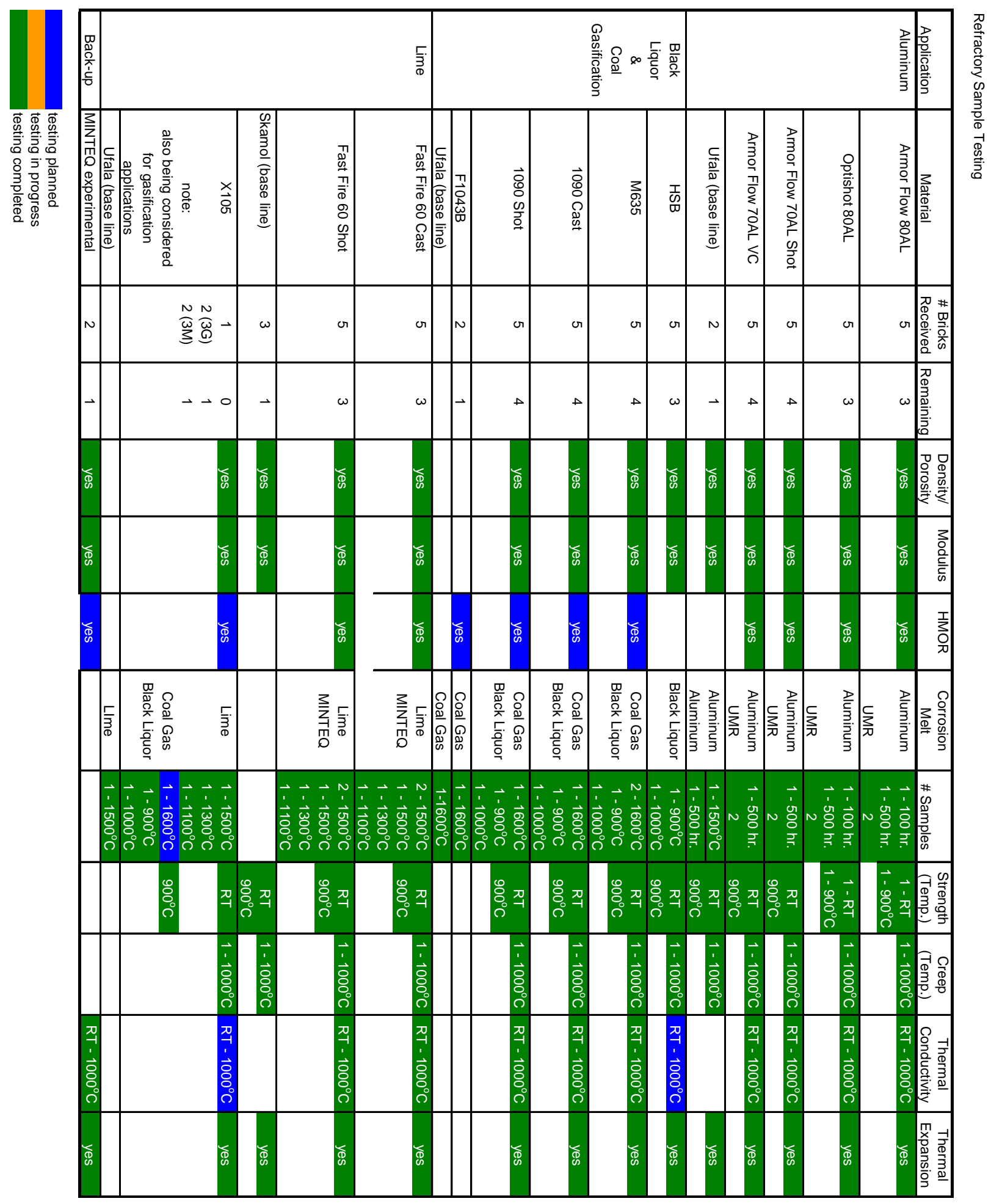


Appendix 4. Materials Included in Comprehensive Refractory Property Database Created Under This Project

1. ArmorKast $65 \mathrm{AL}^{\mathrm{a}}$ (ANH Refractories)

2. Aurex 90 (ANH Refractories)

3. Clipper $\mathrm{DP}^{\mathrm{a}}$ (Harbison Walker)

4. F-4054 (MINTEQ)

5. FASTFIRE MG-SP SHOT ${ }^{\mathrm{b}}$ (MINTEQ)

6. Frimax $7^{\mathrm{a}}$ (DSF Refractories \& Minerals)

7. Frimul $\mathrm{F}^{\mathrm{a}}$ (DSF Refractories \& Minerals)

8. $\mathrm{HF} 7^{\mathrm{a}}$ (DSF Refractories \& Minerals)

9. INSULSHOT FH ${ }^{\mathrm{b}, \mathrm{c}}$ (MINTEQ)

10. Jargal $M^{\mathrm{a}}$ (SEPR)

11. Metcast MS LB (Magneco/Metrel)

12. Metcast MSC (Magneco/Metrel)

13. Metcast MSD (Magneco/Metrel)

14. Metgun M (Magneco/Metrel)

15. M-Extra $\mathrm{E}^{\mathrm{b}}$ (Skamol A/S)

16. Microtherm Super $G^{\text {a }}$ (Microtherm Thermal Insulation Solutions)

17. Min-K TE $1400^{\mathrm{a}}$ (Thermal Ceramics)

18. Monofrax L $L^{\text {a }}$ (Monofrax)

19. Monofras $M^{\mathrm{a}}$ (Monofrax)

20. MORCAST AZ-10a (Missouri Refractories Co., Inc.)

21. OPTISHOT ALM (MINTEQ)

22. ROTOSHOT $\mathrm{AL}^{\mathrm{b}, \mathrm{c}}$ (MINTEQ)

23. Ruby Mortar (ANH Refractories)

24. Tuffline Mortar (ANH Refractories)

25. UFALA ${ }^{\mathrm{a}, \mathrm{b}}$ (Harbison Walker)

26. UFALA UCR ${ }^{\mathrm{a}}$ (Harbison Walker)

27. ZED FM ${ }^{\mathrm{a}}$ (MINTEQ)

28. ZED FMC ${ }^{\text {a }}$ (MINTEQ)

$\underline{\text { Notes }}$

(a) Data included from characterization under a previous DOE funded project

(b) Data included from characterization under a the current DOE funded project

(c) Material developed under the current DOE funded project

Manufacturer Given in () 
Appendix 5. INSULSHOT ${ }^{\mathrm{TM}}$ FH Technical Data Sheet

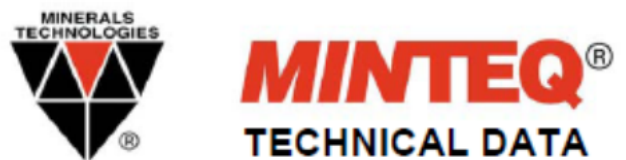

INSULSHOT ${ }^{\mathrm{TM}} \mathrm{FH}$

Shotcrete Material

Ref: F-1376

Issued: 26-Mar-10

DESCRIPTION: INSULSHOT ${ }^{\mathrm{TM}}$ FH refractory material is a $2300^{\circ} \mathrm{F}$ INSULATING SHOTCRETE castable that exhibits low densities, low thermal conductivity, excellent strengths, and energy saving characteristics. INSULSHOT FH refractory material is ideal for use as a working and/or back up lining. Applications include: Fireproofing, Coking Systems, Catalytic Cracking Systems and back up linings for industrial furnaces and process vessels.

Packaging:

$500 \mathrm{lb}$. bags

2 or 3 per pallet

CHEMICAL

COMPOSITION

Typical

(lgnited Basis)

$\mathrm{Al}_{2} \mathrm{O}_{3}$

$\mathrm{SiO}_{2}$

$\mathrm{CaO}-4.5$

$\mathrm{Fe}_{2} \mathrm{O}_{3}$

$\mathrm{TiO}_{2} \quad 0.9$

Others 1.4

PHYSICAL Typical, as determined on shotcreted specimens, ASTM firing and methods where PROPERTIES: applicable.

Fired to ${ }^{\circ} \mathrm{F} \quad$ Bulk $\quad$ Linear $\quad$ Modulus Cold $\quad$ Apparent

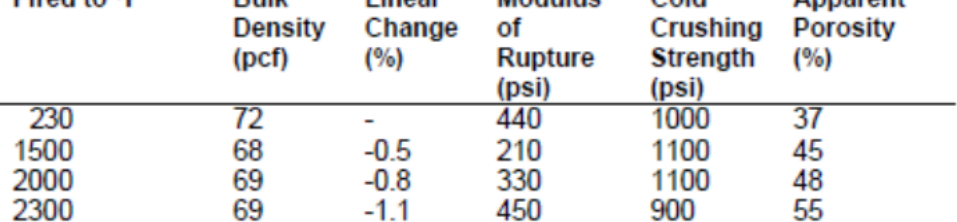

Thermal Conductivity: $\quad$ Typical

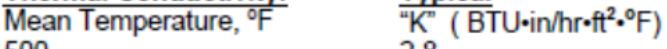

500

2.8

1000

2.8

SERVICE

1500

3.2

\section{LIMIT:}

$2300^{\circ} \mathrm{F}$

MINTEQ is a registered trademark of Minerals Technologies Inc. or its subsidiaries

INSULSHOT ${ }^{\mathrm{N}}$ is a trademark of Minerals Technologies Inc. or its subsidiaries.

MINTEQ INTERNATIONAL INC.35 Highland Avenue, Bethlehem, PA 18017

Copyright $\odot 2010$ MINTEQ International Inc. All rights reserved.

For more information please call the Customer Service Department at 1-900-390-9393.

MINTEQ MAKES NO EXPRESS OR IMPLIED WARRANTIES, NO WARRANTY OF MERCHANTABILTY OR FTINESS FOR ANY PARTICULAR PURPOSE

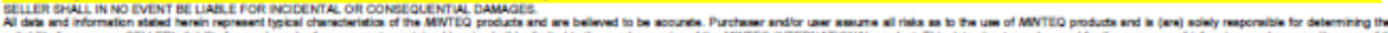

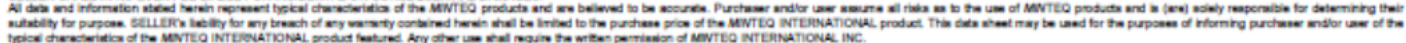

APPLICATION METHOD:
The recommended water addition to an intensive concrete mixer is $34-38 \%$ by weight to achieve $20-40 \%$ static flow (cone test). The typical air pressure requirement for INSULSHOT ${ }^{\mathrm{TM}} \mathrm{FH}$ installations is $12-15$ psi at the nozzle. A hose lubricant is not necessary during pumping for hose length shorter than $75 \mathrm{ft}$. INSULSHOT ${ }^{\mathrm{TM}} \mathrm{FH}$ requires its unique accelerator. Dry out schedule is dependent upon its application. Consult your MINTEQ representative for selecting the accelerator and the dry out schedule. 
Appendix 6. ROTOSHOT ${ }^{\mathrm{TM}}$ AL Technical Data Sheet

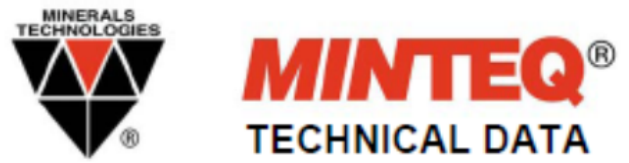

\section{ROTOSHOT ${ }^{\text {TM }}$ AL \\ Shotcrete Material \\ Ref: F-1377 \\ Issued: 05-Mar-10}

DESCRIPTION: ROTOSHOT" AL refractory material is a low cement, abrasion resistant, shotcrete material designed for molten aluminum contact. The hot strengths and non-wetting characteristics provide exceptional performance when exposed to temperatures up to $2300{ }^{\circ} \mathrm{F}$. Typical applications include working linings for aluminum rotary dross furnaces and high wear of aluminum reverb furnaces.

Packaging:

$2000 \mathrm{lb}$. bulk bags

CHEMICAL

COMPOSITION:

\section{Shelf Life:}

2 bags/ pallet

6 months

\section{Typical}

(Ignited Basis)

$\mathrm{Al}_{2} \mathrm{O}_{3}$

$\mathrm{SiO}_{2}$

$73.4 \%$

19.6

1.5

1.5

0.4

$\mathrm{Fe}_{2} \mathrm{O}_{3}$

Others

PHYSICAL PROPERTIES:

Typical, as determined on shotcreted specimens, ASTM methods where applicable.

\begin{tabular}{rlllllll}
$\begin{array}{l}\text { Fired } \\
\text { to }\end{array}$ & $\begin{array}{l}\text { Bulk } \\
\text { Density } \\
\text { (lbs/ft') }\end{array}$ & $\begin{array}{l}\text { Linear } \\
\text { Change } \\
(\%)\end{array}$ & $\begin{array}{l}\text { Modulus } \\
\text { of } \\
\text { Rupture } \\
\text { (psi) }\end{array}$ & $\begin{array}{l}\text { Hot } \\
\text { Modulus } \\
\text { of Rupture } \\
\text { (psi) }\end{array}$ & $\begin{array}{l}\text { Cold } \\
\text { Crushing } \\
\text { Strength } \\
\text { (psi) }\end{array}$ & $\begin{array}{l}\text { Apparent } \\
\text { Porosity } \\
(\%)\end{array}$ & $\begin{array}{l}\text { Abrasion } \\
\text { Volume } \\
\text { Loss } \\
\text { (cc) }\end{array}$ \\
\hline 230 & 172 & - & 2150 & - & 7100 & 11.7 & - \\
1500 & 173 & -0.3 & 1600 & 3000 & 11100 & 18.9 & 5.9 \\
1850 & 170 & -0.3 & 1650 & 3500 & 15000 & 19.5 & 7.5 \\
2200 & 167 & -0.4 & 2000 & 2500 & 11150 & 20.5 & 6.5 \\
2300 & 169 & -0.4 & 1900 & 1650 & 13550 & 20.4 & 7.6 \\
2500 & 171 & -0.6 & 2150 & & 16500 & 18.9 & 6.8 \\
\hline
\end{tabular}

ALCOA Aluminum cup penetration (72 hr. @ $\left.1500^{\circ} \mathrm{F}\right)$

\begin{tabular}{llll}
\multicolumn{2}{r}{ After firing @ $\mathbf{1 6 0 0}{ }^{\circ} \mathrm{F}$ for $\mathbf{1 0}$ hrs. } & After firing @ $\mathbf{2 3 0 0}{ }^{\circ} \mathrm{F}$ for $\mathbf{1 0}$ hrs. & ALCOA standard \\
\hline Si pick up $(\%)$ & 0.21 & 0.24 & $0.5 \max$ \\
Fe pick up $(\%)$ & 0.03 & 0.03 & 0.1 max \\
Rated & Excellent * & Excellent * & \\
\hline
\end{tabular}

"No visual reaction, discoloration or metal penetration as rated by an independent lab.

SERVICE LIMIT: $\quad 2300^{\circ} \mathrm{F}$ for aluminum contact and $2800^{\circ} \mathrm{F}$ for non-aluminum contact

MINTEQ* is a reglatered trademark of Minerals Technologles inc. or its subsidlaries.

ROTOSHOT ${ }^{*}$ is a trademark of Minerala Technologles inc, or Its aubsidlarles.

MINTEQ INTERNATIONAL INC., 405 Lexington Avenue, New York, NY 10174-1901

Copyright $\odot 2010$ MINTEQ International Inc. All rights reserved.

For more information please cal the Customer Service Department at 1-800-390-9393.

MINTEQ MAKES NO EXPRESS OR IMPLIED WARRANTIES, NO WARRANTY OF MERCHANTABILTY OR FITNESS FOR ANY PARTICULAR PURPOSE,

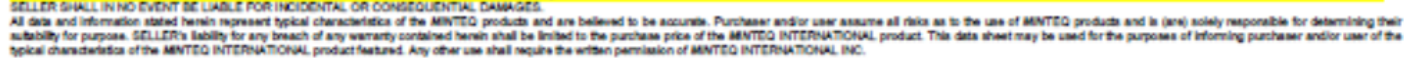

APPLICATION METHOD:
The recommended water addition to an intensive concrete mixer is $5.4-6.2 \%$ by weight to achieve $40-60 \%$ static flow (cone test). The material must be applied through a highpressure concrete pump. OPTISHOT ${ }^{*}$ Installation Procedures (MII-INST-021) should be followed when mixing, placing, using and storing this product. 
Appendix 7. FASTFIRE ${ }^{\circledR}$ MG-SP SHOT Technical Data Sheet

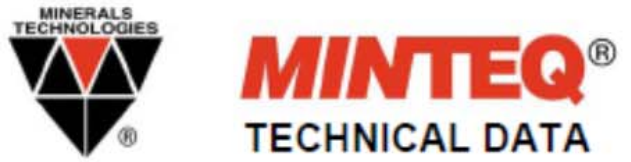

\section{FASTFIRE ${ }^{\circledR}$ MG-SP SHOT \\ Shotcrete Material \\ Ref: F-1382 \\ Issued: 04-Jan-11}

DESCRIPTION:

ASTFIRE@ MG-SP SHOT refractory material is a magnesia-rich spinel forming, shotcrete castable. It provides all of the physical properties and performance of a traditional cast in place refractory lining with the added benefit of reduced installation time and reduced heat-up time required during initial start-up of the unit. Typical applications for FASTFIRE@ MG-SP SHOT refractory material include refractory working linings in lime kilns, cement kilns, and other metallurgical processing vessels.

\section{Packaging:}

CHEMICAL

COMPOSITION:

\begin{tabular}{l}
2 per pallet \\
Typical \\
\hline (Ignited Basis) \\
$79.8 \%$ \\
14.3 \\
3.2 \\
1.7 \\
1.0
\end{tabular}

PHYSICAL

PROPERTIES: $\quad$ Typical, as determined on shotcreted specimens, including specimens fast fired at $2000^{\circ} \mathrm{F}\left({ }^{*}\right)$. ASTM methods where applicable.

\begin{tabular}{llllllll}
$\begin{array}{l}\text { Fired to } \\
{ }^{\circ} \mathrm{F}\end{array}$ & $\begin{array}{l}\text { Bulk } \\
\text { Density } \\
\text { (lbs/ft') }\end{array}$ & $\begin{array}{l}\text { Linear } \\
\text { Change } \\
\text { (\%) }\end{array}$ & $\begin{array}{l}\text { Modulus } \\
\text { of } \\
\text { Rupture } \\
\text { (psi) }\end{array}$ & $\begin{array}{l}\text { Hot } \\
\text { Modulus } \\
\text { of Rupture } \\
\text { (psi) }\end{array}$ & $\begin{array}{l}\text { Cold } \\
\text { Crushing } \\
\text { Strength } \\
\text { (psi) }\end{array}$ & $\begin{array}{l}\text { Apparent } \\
\text { Porosity } \\
\text { (\%) }\end{array}$ & $\begin{array}{l}\text { Abrasion } \\
\text { Volume } \\
\text { Lost } \\
\text { (cc) }\end{array}$ \\
\hline 230 & 171 & - & 1020 & & 6800 & 16 & 9.8 \\
1500 & 167 & -0.1 & 1320 & & 7500 & 21 & 11.3 \\
2000 & 164 & 0.5 & 720 & 1000 & 6500 & 22 & 13.6 \\
FF2000(*) & 168 & 0.4 & 710 & & 7300 & 22 & 12.8 \\
2500 & 172 & -0.3 & 1300 & 860 & 8400 & 20 & 10.2 \\
2750 & 176 & -0.9 & 1500 & & 8500 & 18 & 9.9 \\
2850 & 178 & -1.3 & 1300 & & 9000 & 17 & 9.6 \\
\hline
\end{tabular}

Material Required to install one cubic foot (without waste): (lbs)

171

SERVICE LIMIT:

$3000^{\circ} \mathrm{F}$

APPLICATION METHOD:

The recommended water addition to an intensive concrete mixer is $5.0-6.0 \%$ by weight to achieve $40-60 \%$ static flow (cone test). The material must be applied through a high-pressure concrete pump. OPTISHOT Refractory Installation Procedures (MII-INST-021) should be followed when mixing, placing, using and storing this product. Dry Out Schedule for FASTFIRE@ Refractory Procedure (MII-INST-039) or for OPTISHOT ${ }^{\circ}$ Products (MII-INST-046) could be followed when drying this product.

The MTI LOgO, MINTEQ $Q^{\circ}$. FASTFIRE" and OPTISHOT' are reglatered trademarks of Minerale Technologles inc. or ite subsidlarles. MiNTEQ INTERNATIONAL INC., 35 Highland Avenue, Bethighem, PA 18017

Copyright 02010 MINTEQ international inc.

For more intormation please cal the Customer Service Department at 1-800-390-9393. All rights reserved.

MINTEQ MAKES NO EXPRESS OR MPUIED WARRANTIES, NO WARRANTY OF MERCHANTAGIUTY OR FITNESS FOR ANY PARTICULAR PURPOSE

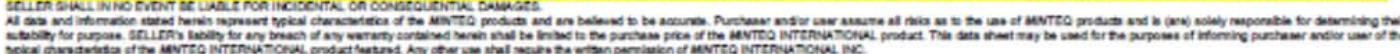




\section{DISTRIBUTION}

\section{INTERNAL DISTRIBUTION}

1. ORNL ITP Program Office (Missy Shanken)

2. Craig Blue

3. Hiram Rogers

4. James Hemrick

5. Jy-An Wang

6. ORNL Laboratory Records_-OST

\section{EXTERNAL DISTRIBUTION}

7-9. MINTEQ International, Inc.

Richard Griffin

Dom Calovito

Angela Rodrigues-Shroer

10-11. Missouri University of Science and Technology

Jeffrey Smith

Kelley O’Hara

12-14. Funding Sponsor, DOE/EERE Industrial Technologies Program

Steve Sikirica

Chad Sapp

Mahesh Jha 